US Army Corps

of Engineers ${ }_{\circledast}$

Engineer Research and

Development Center

Dredging Operations and Environmental Research Program

\title{
Erosion Thresholds and Rates for Sand-Mud Mixtures
}

David W. Perkey, S. Jarrell Smith, and Anthony M. Priestas

July 2020
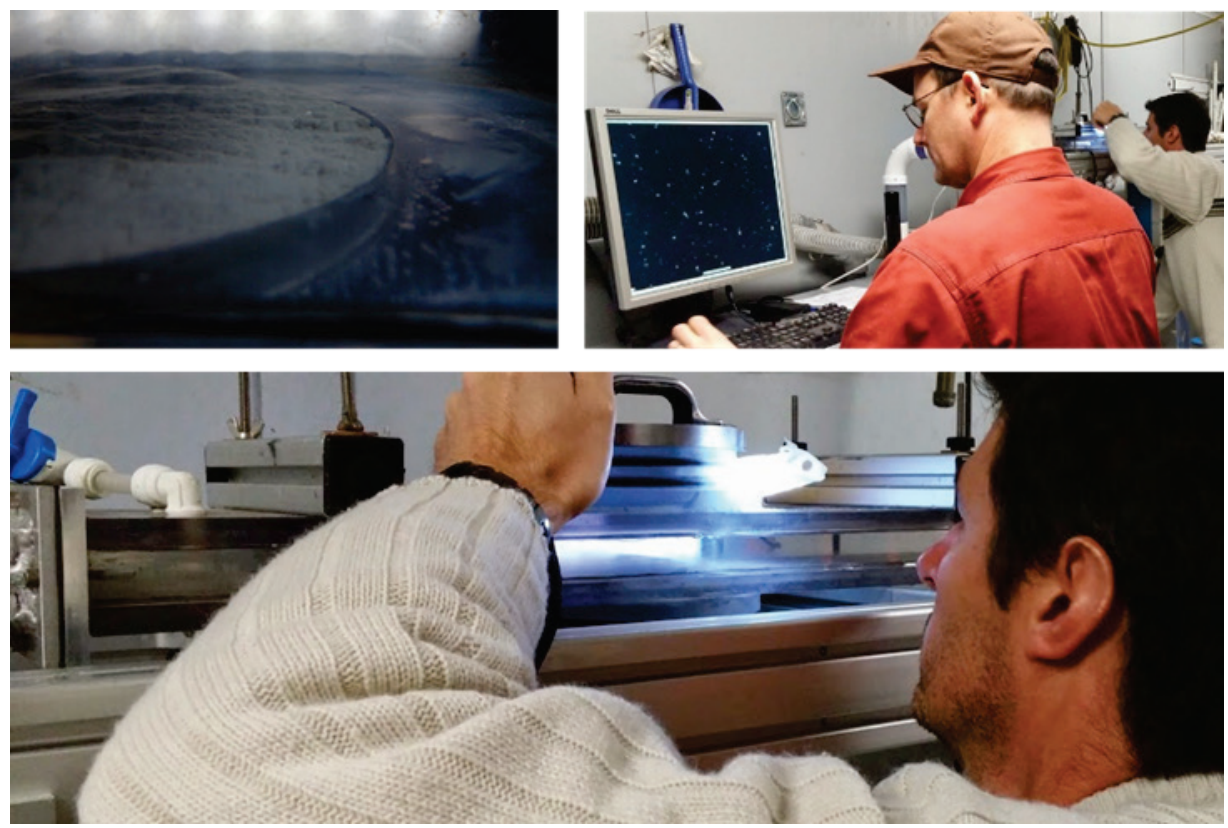
The U.S. Army Engineer Research and Development Center (ERDC) solves the nation's toughest engineering and environmental challenges. ERDC develops innovative solutions in civil and military engineering, geospatial sciences, water resources, and environmental sciences for the Army, the Department of Defense, civilian agencies, and our nation's public good. Find out more at www.erdc.usace.army.mil.

To search for other technical reports published by ERDC, visit the ERDC online library at https://erdclibrary.on.worldcat.org/discovery. 


\section{Erosion Thresholds and Rates for Sand-Mud Mixtures}

David W. Perkey, S. Jarrell Smith, and Anthony M. Priestas

Coastal and Hydraulics Laboratory

U.S. Army Engineer Research and Development Center

3909 Halls Ferry Road

Vicksburg, MS 39180-6199

Final report

Approved for public release; distribution is unlimited

Prepared for Dredging Operations and Environmental Research Program

Vicksburg, MS 39180

Under Project No. 485304, "Cost Effective Stabilization of Dredged Sediment for Capping and Nearshore Placement" 


\section{Abstract}

Differences in erosion behavior of non-cohesive and cohesive sediments are widely recognized. In many natural environments, sand and mud are not completely separated and occur as mixtures. Significantly less research has been conducted on the erosion behavior of sand-mud mixtures compared to the separate treatment of sand and mud erosion. Sedflume erosion experiments were conducted on sand-mud mixtures with varying mud content to define the relationships between mud content, critical stress for erosion $\left(\tau_{c}\right)$, and erosion rate. Sand-mud mixtures were prepared with three mud sources: (1) non-swelling clay (kaolinite), (2) swelling clay (kaolinite/bentonite), and (3) a swelling, natural mud from the Mississippi River.

Test results showed that critical shear stresses of the mixed sediments departed from that of pure sand with mud fractions on the order of $2 \%$ to $10 \%$. Peak $\tau_{c}$ was observed between $30 \%$ to $40 \%$ mud content, with swelling muds achieving a ten-fold increase in $\tau_{c}$ while a five-fold increase in $\tau_{c}$ was measured for kaolinite. Additionally, this study demonstrated that the introduction of small amounts $(\leq 5 \%)$ of mud to sand reduced erosion rates by a factor of 10 to 100 . This observed abatement of erosion rate has implications for the use of dredged materials in civil and environmental engineering projects.

DISCLAIMER: The contents of this report are not to be used for advertising, publication, or promotional purposes. Citation of trade names does not constitute an official endorsement or approval of the use of such commercial products. All product names and trademarks cited are the property of their respective owners. The findings of this report are not to be construed as an official Department of the Army position unless so designated by other authorized documents. 


\section{Contents}

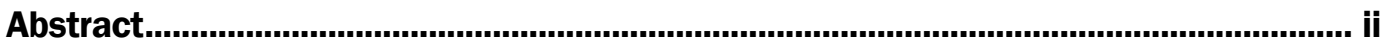

Figures and Tables............................................................................................................. iv

Preface

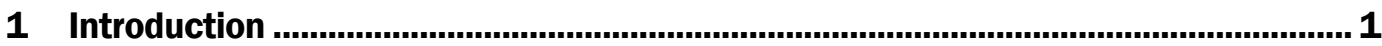

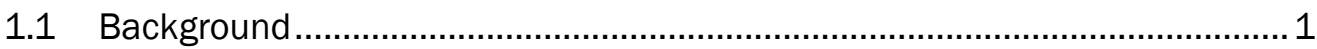

1.2 Objective(s) .................................................................................. 1

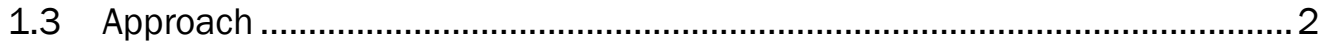

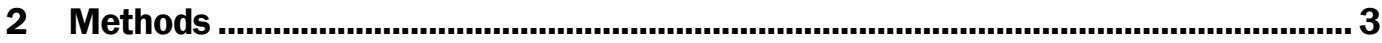

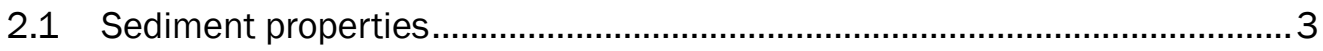

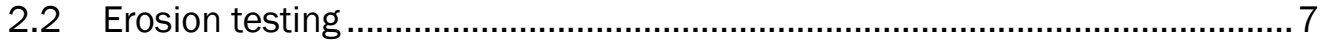

2.2.1 Sediment Erosion with Depth flume (Sedflume) .................................................. 7

2.2.2 Slurry preparation ........................................................................................... 9

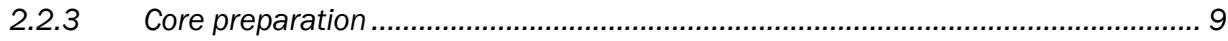

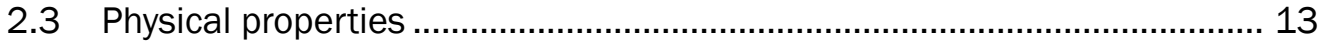

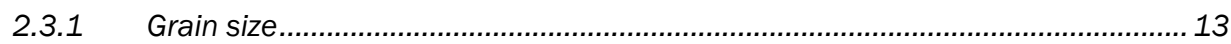

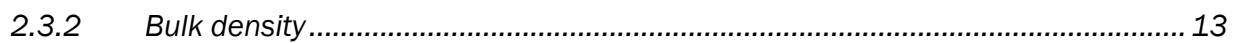

2.3.3 Atterberg limits......................................................................................... 14

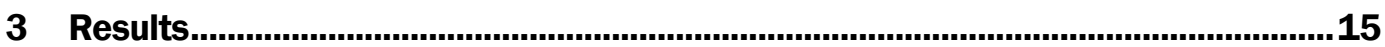

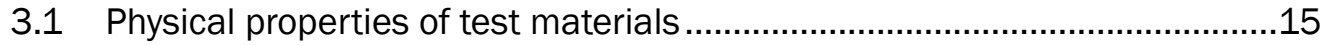

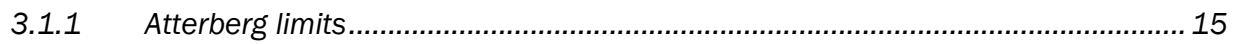

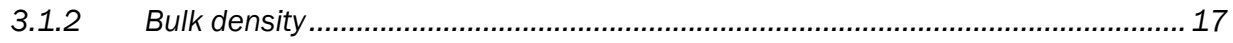

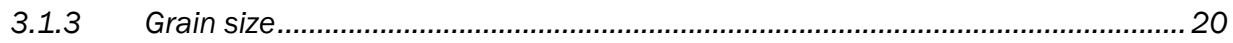

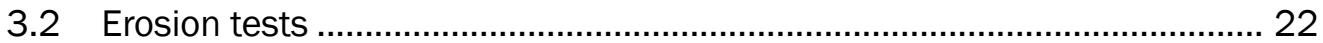

3.2.1 Erosion parameterization ..................................................................................... 22

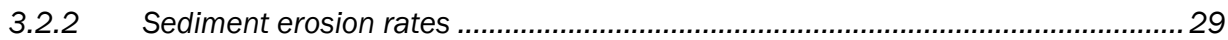

4 Summary and Conclusions …...............................................................................32

5 Future Work

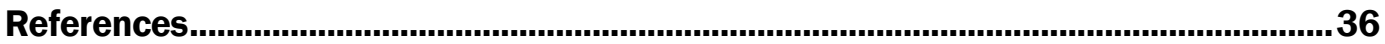

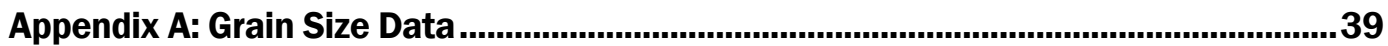

Appendix B: X-Ray Attenuation Bulk Density Plots ......................................................52

Appendix C: Erosion Data .................................................................................................... 57

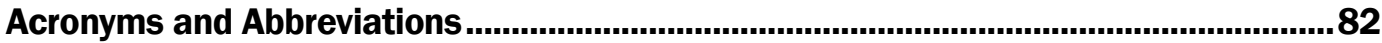

\section{Report Documentation Page}




\section{Figures and Tables}

\section{Figures}

Figure 1. X-ray diffractograms of kaolin material. Strong peaks at 12.5 and $252 \theta$ indicate kaolinite as the predominant mineral in the material.

Figure 2. X-ray diffractograms of CSP Forestry sodium bentonite material. The shifting in position and intensity of peaks in the 3-7 $2 \theta$ range after exposure to magnesium (Mg) indicates the presence of smectite mineralogy.....

Figure 3. X-ray diffractograms of sediments collected from the MR. Quartz and illite appear to dominate the mineralogy with smaller amount of kaolinite. The collapse of the broad peak below $9^{\circ} 2 \theta$ in the heating treatments also suggests the presence of a smectite clay.

Figure 4. Images of the Sedflume (upper left), erosion surface (lower left), and operator (lower center), along with operational test range of the flume (right).

Figure 5. Diagram of sediment core erosion process. The brown arrow indicates advancement of sediment into the flume with erosion. The blue arrow indicates flow direction of water. An example erosion sequence is provided in the table to the right of the sediment core.

Figure 6. Photos depicting the mixing of sand and mud are presented in A - C. Photos demonstrating the methods utilized to place material in core tubes are presented in D - G.

Figure 7. PI plotted against mud content for materials with kaolinite $(K)$, kaolinite-bentonite (KB), and MR muds.

Figure 8. Bulk densities obtained through $\mathrm{x}$-ray attenuation are shown for kaolinbentonite cores with mud contents ranging from 1\% to 5\% (KB001 - KB005). A surface transition zone was commonly observed at the water-sediment interface down to a depth of $\sim 30 \mathrm{~mm}$. Note that the " $5 \mathrm{R}$ " in KB005R refers to an independent, duplicate measurement of a $5 \%$ kaolin-bentonite core.

Figure 9. Plots showing bulk density versus mud content for each core. Blue, red, and black lines indicate cores made with kaolinite $(\mathrm{K})$, kaolinite-bentonite $(\mathrm{KB})$, and MR muds, respectively. Curves with solid lines depict density values calculated by wet-dry analysis. Curves with dashed lines represent density values obtained from XRA.

Figure 10. Plot of mean mud content measured by laser diffraction against mud content by mass of each test core. Dashed blue line indicates least squares regression while the solid black line shows 1:1 correlation.

Figure 11. Plot of mean erosion rate against shear stress for cores composed of $21 \%$ kaolinite-bentonite mud. Regression lines fit to the data were used to determine $T_{c}$ at an erosion rate of $1.0 \mathrm{E}-04 \mathrm{~cm} / \mathrm{s}$.

Figure 12. Critical shear stress $\left(T_{c}\right)$ plotted against mud content. Blue, red, and black lines indicate cores made with kaolinite $(K)$, kaolinite-bentonite $(K B)$, and MR muds, respectively. Dashed lines represent the 95\% confidence interval of $T_{c}$. The $T_{c}$ obtained from replicate cores are plotted with triangles with error bars indicating the $95 \%$ confidence. 
Figure 13. Erosion rate plotted against kaolinite mud content. The colored solid lines depict the calculated erosion rates at various shear stresses, with dashed lines indicating 95\% confidence. Mean erosion rate data are plotted with circles. Triangles represent replicate mean erosion rates with error bars indicating the $95 \%$ confidence.

Figure 14. Erosion rate plotted against kaolinite-bentonite mud content. The colored solid lines depict the calculated erosion rates at various shear stresses, with dashed lines indicating 95\% confidence. Mean erosion rate data are plotted with circles. Triangles represent replicate mean erosion rates with error bars indicating the 95\% confidence.

Figure 15. Erosion rate plotted against MR mud content. The colored solid lines depict the calculated erosion rates at various shear stresses, with dashed lines indicating 95\% confidence. Mean erosion rate data are plotted with circles. Triangles represent replicate mean erosion rates with error bars indicating the 95\% confidence.

Figure A-1. Cumulative grain size distributions for sand. ..................................................39

Figure A-2. Grain size distributions for sand.

Figure A-3. Cumulative grain size distributions for kaolinite cores with mud contents ranging from $1 \%$ to $5 \%$.

Figure A-4. Cumulative grain size distributions for kaolinite cores with mud contents ranging from $8 \%$ to $21 \%$.

Figure A-5. Cumulative grain size distributions for kaolinite cores with mud contents ranging from $29 \%$ to $100 \%$.

Figure A-6. Grain size distributions for kaolinite cores with mud contents ranging from $1 \%$ to $5 \%$.

Figure A-7. Grain size distributions for kaolinite cores with mud contents ranging from $8 \%$ to $21 \%$.

Figure A-8. Grain size distributions for kaolinite cores with mud contents ranging from $29 \%$ to $100 \%$.

Figure A-9. Cumulative grain size distributions for kaolinite-bentonite cores with mud contents ranging from $1 \%$ to $5 \%$.

Figure A-10. Cumulative grain size distributions for kaolinite-bentonite cores with mud contents ranging from $8 \%$ to $21 \%$.

Figure A-11. Cumulative grain size distributions for kaolinite-bentonite cores with mud contents ranging from $29 \%$ to $100 \%$.

Figure A-12. Grain size distributions for kaolinite-bentonite cores with mud contents ranging from $1 \%$ to $5 \%$.

Figure A-13. Grain size distributions for kaolinite-bentonite cores with mud contents ranging from $8 \%$ to $21 \%$.

Figure A-14. Grain size distributions for kaolinite-bentonite cores with mud contents ranging from $29 \%$ to $100 \%$.

Figure A-15. Cumulative grain size distributions for MR cores with mud contents ranging from $1 \%$ to $5 \%$.

Figure A-16. Cumulative grain size distributions for MR cores with mud contents ranging from $8 \%$ to $21 \%$. 
Figure A-17. Cumulative grain size distributions for MR cores with mud contents ranging from $29 \%$ to $100 \%$.

Figure A-18. Grain size distributions for MR cores with mud contents ranging from $1 \%$ to $5 \%$.

Figure A-19. Grain size distributions for MR cores with mud contents ranging from $8 \%$ to $21 \%$.

Figure A-20. Grain size distributions for MR cores with mud contents ranging from $29 \%$ to $100 \%$.

Figure B-1. Bulk densities obtained through x-ray attenuation are shown for sand cores.

Figure B-2. Bulk densities obtained through x-ray attenuation are shown for kaolinite cores with mud contents ranging from $1 \%$ to $5 \%$.

Figure B-3. Bulk densities obtained through x-ray attenuation are shown for kaolinite cores with mud contents ranging from $8 \%$ to $21 \%$.

Figure B-4. Bulk densities obtained through x-ray attenuation are shown for kaolinite cores with mud contents ranging from $29 \%$ to $100 \%$.

Figure B-5. Bulk densities obtained through x-ray attenuation are shown for kaolinite-bentonite cores with mud contents ranging from $1 \%$ to $5 \%$

Figure B-6. Bulk densities obtained through x-ray attenuation are shown for kaolinite-bentonite cores with mud contents ranging from $8 \%$ to $21 \%$.

Figure B-7. Bulk densities obtained through x-ray attenuation are shown for kaolinite-bentonite cores with mud contents ranging from $29 \%$ to $100 \%$.

Figure B-8. Bulk densities obtained through x-ray attenuation are shown for MR cores with mud contents ranging from $1 \%$ to $5 \%$.

Figure B-9. Bulk densities obtained through x-ray attenuation are shown for MR cores with mud contents ranging from $8 \%$ to $21 \%$.

Figure B-10. Bulk densities obtained through x-ray attenuation are shown for MR cores with mud contents ranging from $29 \%$ to $100 \%$

Figure C-1. Plot of mean erosion rate data against shear stress for cores composed of $100 \%$ sand. Regression lines fit to the data were used to determine TC at an erosion rate of $1.0 \mathrm{E}-04$.

Figure $\mathrm{C}$-2. Plot of mean erosion rate data against shear stress for cores composed of $1 \%$ kaolinite mud. Regression lines fit to the data were used to determine Tc at an erosion rate of 1.0E-04.

Figure C-3. Plot of mean erosion rate data against shear stress for cores composed of $2 \%$ kaolinite mud. Regression lines fit to the data were used to determine Tc at an erosion rate of 1.0E-04.

Figure C-4. Plot of mean erosion rate data against shear stress for cores composed of $3 \%$ kaolinite mud. Regression lines fit to the data were used to determine Tc at an erosion rate of 1.0E-04.

Figure $\mathrm{C}-5$. Plot of mean erosion rate data against shear stress for cores composed of $4 \%$ kaolinite mud. Regression lines fit to the data were used to determine Tc at an erosion rate of 1.0E-04.

Figure C-6. Plot of mean erosion rate data against shear stress for cores composed of $5 \%$ kaolinite mud. Regression lines fit to the data were used to determine $T_{c}$ at an erosion rate of 1.0E-04. 
Figure C-7. Plot of mean erosion rate data against shear stress for cores composed of $8 \%$ kaolinite mud. Regression lines fit to the data were used to determine $T_{c}$ at an erosion rate of 1.0E-04

Figure C-8. Plot of mean erosion rate data against shear stress for cores composed of $11 \%$ kaolinite mud. Regression lines fit to the data were used to determine $T_{c}$ at an erosion rate of 1.0E-04

Figure C-9. Plot of mean erosion rate data against shear stress for cores composed of $15 \%$ kaolinite mud. Regression lines fit to the data were used to determine $T_{c}$ at an erosion rate of 1.0E-04.

Figure C-10. Plot of mean erosion rate data against shear stress for cores composed of $21 \%$ kaolinite mud. Regression lines fit to the data were used to determine $T_{c}$ at an erosion rate of 1.0E-04.

Figure C-11. Plot of mean erosion rate data against shear stress for cores composed of $29 \%$ kaolinite mud. Regression lines fit to the data were used to determine $T_{c}$ at an erosion rate of 1.0E-04.

Figure C-12. Plot of mean erosion rate data against shear stress for cores composed of $40 \%$ kaolinite mud. Regression lines fit to the data were used to determine $T_{c}$ at an erosion rate of 1.0E-04.

Figure C-13. Plot of mean erosion rate data against shear stress for cores composed of $60 \%$ kaolinite mud. Regression lines fit to the data were used to determine $T_{c}$ at an erosion rate of 1.0E-04.

Figure C-14. Plot of mean erosion rate data against shear stress for cores composed of $80 \%$ kaolinite mud. Regression lines fit to the data were used to determine $T_{c}$ at an erosion rate of 1.0E-04.

Figure C-15. Plot of mean erosion rate data against shear stress for cores composed of $100 \%$ kaolinite mud. Regression lines fit to the data were used to determine $T_{c}$ at an erosion rate of 1.0E-04

Figure C-16. Plot of mean erosion rate data against shear stress for cores composed of $1 \%$ kaolinite-bentonite mud. Regression lines fit to the data were used to determine $T_{c}$ at an erosion rate of 1.0E-04.

Figure C-17. Plot of mean erosion rate data against shear stress for cores composed of $2 \%$ kaolinite-bentonite mud. Regression lines fit to the data were used to determine $T_{c}$ at an erosion rate of 1.0E-04.

Figure C-18. Plot of mean erosion rate data against shear stress for cores composed of 3\% kaolinite-bentonite mud. Regression lines fit to the data were used to determine $T_{c}$ at an erosion rate of 1.0E-04.

Figure C-19. Plot of mean erosion rate data against shear stress for cores composed of $4 \%$ kaolinite-bentonite mud. Regression lines fit to the data were used to determine $T_{c}$ at an erosion rate of 1.0E-04.

Figure C-20. Plot of mean erosion rate data against shear stress for cores composed of $5 \%$ kaolinite-bentonite mud. Regression lines fit to the data were used to determine $T_{c}$ at an erosion rate of 1.0E-04.

Figure C-21. Plot of mean erosion rate data against shear stress for cores composed of $8 \%$ kaolinite-bentonite mud. Regression lines fit to the data were used to determine $T_{c}$ at an erosion rate of 1.0E-04. 
Figure C-22. Plot of mean erosion rate data against shear stress for cores composed of $11 \%$ kaolinite-bentonite mud. Regression lines fit to the data were used to determine $T_{c}$ at an erosion rate of 1.0E-04.

Figure C-23. Plot of mean erosion rate data against shear stress for cores composed of $15 \%$ kaolinite-bentonite mud. Regression lines fit to the data were used to determine $T_{c}$ at an erosion rate of 1.0E-04.

Figure C-24. Plot of mean erosion rate data against shear stress for cores composed of $21 \%$ kaolinite-bentonite mud. Regression lines fit to the data were used to determine $T_{c}$ at an erosion rate of 1.0E-04.

Figure C-25. Plot of mean erosion rate data against shear stress for cores composed of $29 \%$ kaolinite-bentonite mud. Regression lines fit to the data were used to determine $T_{c}$ at an erosion rate of 1.0E-04.

Figure C-26. Plot of mean erosion rate data against shear stress for cores composed of $40 \%$ kaolinite-bentonite mud. Regression lines fit to the data were used to determine $T_{c}$ at an erosion rate of 1.0E-04.

Figure C-27. Plot of mean erosion rate data against shear stress for cores composed of $60 \%$ kaolinite-bentonite mud. Regression lines fit to the data were used to determine $T_{c}$ at an erosion rate of 1.0E-04.

Figure C-28. Plot of mean erosion rate data against shear stress for cores composed of $80 \%$ kaolinite-bentonite mud. Regression lines fit to the data were used to determine $T_{c}$ at an erosion rate of 1.0E-04.

Figure C-29. Plot of mean erosion rate data against shear stress for cores composed of $100 \%$ kaolinite-bentonite mud. Regression lines fit to the data were used to determine $T_{c}$ at an erosion rate of 1.0E-04.

Figure C-30. Plot of mean erosion rate data against shear stress for cores composed of $1 \%$ MR mud. Regression lines fit to the data were used to determine $T_{c}$ at an erosion rate of 1.0E-04.

Figure C-31. Plot of mean erosion rate data against shear stress for cores composed of $2 \%$ MR mud. Regression lines fit to the data were used to determine $T_{c}$ at an erosion rate of 1.0E-04.

Figure C-32. Plot of mean erosion rate data against shear stress for cores composed of 3\% MR mud. Regression lines fit to the data were used to determine $T_{c}$ at an erosion rate of 1.0E-04.

Figure 33. Plot of mean erosion rate data against shear stress for cores composed of $4 \%$ MR mud. Regression lines fit to the data were used to determine $T_{c}$ at an erosion rate of 1.0E-04.

Figure C-34. Plot of mean erosion rate data against shear stress for cores composed of $5 \%$ MR mud. Regression lines fit to the data were used to determine $T_{c}$ at an erosion rate of 1.0E-04.

Figure C-35. Plot of mean erosion rate data against shear stress for cores composed of $8 \%$ MR mud. Regression lines fit to the data were used to determine $T_{c}$ at an erosion rate of 1.0E-04.

Figure C-36. Plot of mean erosion rate data against shear stress for cores composed of $11 \%$ MR mud. Regression lines fit to the data were used to determine $T_{c}$ at an erosion rate of 1.0E-04. 
Figure C-37. Plot of mean erosion rate data against shear stress for cores composed of 15\% MR mud. Regression lines fit to the data were used to determine $T_{c}$ at an erosion rate of 1.0E-04

Figure C-38. Plot of mean erosion rate data against shear stress for cores composed of $21 \%$ MR mud. Regression lines fit to the data were used to determine $T_{c}$ at an erosion rate of 1.0E-04.

Figure C-39. Plot of mean erosion rate data against shear stress for cores composed of $29 \%$ MR mud. Regression lines fit to the data were used to determine $T_{c}$ at an erosion rate of 1.0E-04.

Figure C-40. Plot of mean erosion rate data against shear stress for cores composed of $40 \%$ MR mud. Regression lines fit to the data were used to determine $T_{c}$ at an erosion rate of 1.0E-04.

Figure C-41. Plot of mean erosion rate data against shear stress for cores composed of $60 \%$ MR mud. Regression lines fit to the data were used to determine $T_{c}$ at an erosion rate of 1.0E-04.

Figure C-42. Plot of mean erosion rate data against shear stress for cores composed of $80 \%$ MR mud. Regression lines fit to the data were used to determine $T_{c}$ at an erosion rate of 1.0E-04.

Figure C-43. Plot of mean erosion rate data against shear stress for cores composed of $100 \%$ MR mud. Regression lines fit to the data were used to determine $T_{c}$ at an erosion rate of 1.0E-04.

\section{Tables}

Table 1. Wentworth classification and median grain size $\left(D_{50}\right)$ of test materials.

Table 2. Masses of sand, slurry and water utilized in core preparation. The "R" indicates replicate cores.

Table 3. Atterberg limit results for cores with mud content $>20 \%$.

Table 4. Average bulk densities of cores obtained from both XRA and wet-dry methods.

Table 5. Kaolinite-bentonite mud laser diffraction data.

Table 6. Erosion parameters for sand cores.

Table 7. Erosion parameters for kaolinite mud cores. ......................................................... 24

Table 8. Erosion parameters for kaolinite-bentonite mud cores..........................................25

Table 9. Erosion parameters for MR mud cores................................................................... 26

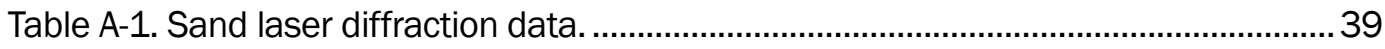

Table A-2. Kaolinite mud laser diffraction data. ............................................................... 40

Table A-3. Kaolinite-bentonite mud laser diffraction data................................................. 44

Table A-4. MR mud laser diffraction data. .................................................................. 48

Table C-1. Sand erosion parameters...................................................................... 57

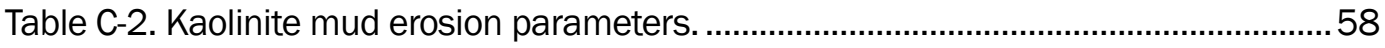

Table C-3. Kaolinite-bentonite mud erosion parameters.....................................................66

Table C-4. MR mud erosion parameters. …………........................................................... 74 


\section{Preface}

This study was conducted for the Dredging Operations and Environmental Research (DOER) Program under Project No. 485304, "Cost Effective Stabilization of Dredged Sediment for Capping and Nearshore Placement" The Program Manager was Dr. Todd Bridges.

The work was performed by the Field Data Collection and Analysis Branch of the Navigation Division, U.S. Army Engineer Research and Development Center, Coastal and Hydraulics Laboratory (ERDC-CHL). At the time of publication of this report, Mr. William Butler was Chief, Field Data Collection and Analysis Branch; Dr. Jacqueline Pettway was Chief, Navigation Division; and Mr. Charles E. Wiggins, was the Technical Director for Navigation. The Deputy Director of ERDC-CHL was Mr. Jeffrey R. Eckstein, and the Director was Dr. Ty V. Wamsley.

The Commander of ERDC was COL Teresa A. Schlosser, and the Director was Dr. David W. Pittman. 


\section{Introduction}

\subsection{Background}

The differences in erosion behavior of non-cohesive (sand, gravel) and cohesive sediments (mud) are widely recognized. Erosion of non-cohesive sediments such as sand is dependent primarily upon the balance of weight, buoyancy, drag, and lift forces on the sediment, which is related to the size, density, and shape of the non-cohesive particles (Graf 1984; Garcia 2008). Erosion of cohesive sediments is largely influenced by electrochemical bonding between sediment particles, which is influenced by clay mineralogy, pore water chemistry, organic content, biological cementation, and bed density (among others) (e.g., Mehta et al. 1989; Mehta and McAnally 2008; Mehta 2013). In many natural environments, sand and mud are not completely separated but instead occur as mixtures. Much less research has been conducted on the erosion behavior of sandmud mixtures compared to the separate treatment of sand erosion and mud erosion. Erosion and transport processes of these heterogeneous sediments are more complex than that of pure sand as they vary with factors such as mud content, particle packing efficiency, and clay type (e.g., Mehta et al, 1989; Mitchner and Torfs 1996; van Ledden et al. 2004; Barry et al. 2006; Dickhudt et al. 2011; Jacobs et al. 2011; Wu et al. 2018). These previous studies have shown that as little as 3\% to $15 \%$ mud added to sand can change erosion behavior from non-cohesive to cohesive; however, their focus was largely placed on the influence that mud fraction had on the critical shear stress for initiation of erosion. Less attention has been placed on the effect of mud fraction on erosion rates of mixed sediments. A notable exception is the work by Gailani et al. (2001), which investigated the effect of bentonite clay on the erosion rates of sand-mud mixtures. Their results showed that erosion rates decreased 2 orders of magnitude with $2 \%$ added bentonite, though they noted that other clay types should also be investigated; the present work was pursued to help fill this knowledge gap.

\subsection{Objective(s)}

The objective of this research is to conduct erosion experiments on sandmud mixtures to define the relationships between mud content, critical stress for erosion, and erosion rate for muds of differing mineralogy. The 
primary aim of the work is to increase the predictive capability of erosion resistance and sediment transport by experimentally determining the relationship between sand-mud mixtures and erosion rates to improve the planning and design of civil and environmental engineering projects (e.g., estuarine sediment modeling, environmental capping design, and management of dredged materials).

\subsection{Approach}

A series of laboratory experiments were conducted to quantify changes in critical shear stress and erosion rate of sand-mud mixtures as a function of mud content (by mass percent) and clay mineralogy. An experimental set consisted of 15 artificially created cores prepared from a known mass of fine to medium sand mixed with a mud slurry of known mass and density. The mud content for each core varied between $0 \%$ to $100 \%$. Erosion rates were measured as a function of flow rate (and thus applied shear stress) in the U.S. Army Corps of Engineers (USACE)-developed Sedflume (Sediment Erosion with Depth) erosion device.

This report presents the methodologies utilized and results from laboratory erosion experiments conducted on several sand-mud mixtures. Impacts of mud content on both critical shear stress and erosion rate will be discussed. In addition, this report will also describe how variations in mineral composition and the physical properties of mud also impact the critical shear stress and erosion rate of the test beds. 


\section{Methods}

\subsection{Sediment properties}

Three groups of sand-mud mixtures were prepared for the erosion experiments. The sand source, a natural grain silica sand obtained through U.S. Silica, was constant for all three mixtures. Mud fractions among the three groups varied the following way: (1) a 100\% Edgar Plastic Kaolin (EPK), hereafter referred to as kaolin, (2) a mud mixture composed of $80 \%$ kaolin with $20 \%$ sodium bentonite, and (3) a natural mud collected from the lower Mississippi River (MR). Both the kaolin and sodium bentonite clays were purchased through commercial vendors, Edgar Minerals and CSP Forestry, respectively. The natural sediment was collected from the bottom of a perched boat basin off the MR near Grand Gulf, MS. MR sediment was obtained with a $14 \mathrm{~cm}^{*}$ diameter stainless steel bottom drag sampler. Multiple sampling passes ( $150 \mathrm{~m}$ in length) were made across the boat basin until the appropriate volume of sediment $\left(\sim 20\right.$ gallons $\left.^{\dagger}\right)$ had been collected.

Grain size analysis was performed on all four components of the mixtures via laser diffraction methods (described later in this section). Table 1 presents the Wentworth classification and $\mathrm{D}_{50}$ results of these analyses for the silica sand, kaolin, bentonite, and MR sediment. Size distribution and additional grain size data for these materials are presented in Tables A-1 through A-4 and Figures A-1 through A-20 in Appendix A. Results showed that the U.S. Silica sediment was $100 \%$ sand $(>63 \mu \mathrm{m})$ and was primarily composed of fine sand grains $(125-250 \mu \mathrm{m})$. Both the kaolin and bentonite clays, along with the MR sediment, were classified primarily as silt $(4 \mu \mathrm{m}<\mathrm{x}<63 \mu \mathrm{m})$. Grain size data provided by Edgar Minerals reported the kaolin to be $>98 \%$ clay $(<4 \mu \mathrm{m})$. These results were obtained through settling techniques utilizing a sedigraph (Goossens 2008) and not via laser diffraction. The bentonite obtained from CSP Forestry was in

\footnotetext{
* For a full list of the spelled-out forms of the units of measure used in this document, please refer to US Government Publishing Office Style Manual, 31st ed. (Washington, DC: US Government Publishing Office 2016), 248-52, https://www.govinfo.gov/content/pkg/GPO-STYLEMANUAL-2016/pdf/GPOSTYLEMANUAL-2016.pdf.

† For a full list of the unit conversions used in this document, please refer to US Government Publishing Office Style Manual, 31st ed. (Washington, DC: US Government Publishing Office 2016), 345-7, https://www.govinfo.gov/content/pkg/GPO-STYLEMANUAL-2016/pdf/GPO-STYLEMANUAL-2016.pdf.
} 
pellet form (500-2000 $\mu \mathrm{m})$, and therefore a report describing clay size content was not available.

Table 1. Wentworth classification and median grain size ( $\left.D_{50}\right)$ of test materials.

\begin{tabular}{|c|c|c|c|c|}
\hline Sample & \%Sand & \%Silt & \%Clay & $\begin{array}{c}\text { D50 } \\
(\mu \mathrm{m})\end{array}$ \\
\hline Silica Sand & 100 & 0.0 & 0.0 & 159 \\
\hline Kaolin & 5.8 & 72.8 & 21.4 & 10 \\
\hline Bentonite & 5.1 & 65.4 & 29.5 & 7.1 \\
\hline MR & 2.7 & 81.8 & 15.5 & 11 \\
\hline
\end{tabular}

While grain size results from laser diffraction indicated predominantly silt-sized particles in the kaolin, bentonite, and MR sediment material, disparities in clay/silt content between laser diffraction and traditional settling techniques have been well documented in previous studies (e.g., Konert and Vandenberghe 1997; Buurman et al. 2001; Eshel et al. 2004). These studies have indicated that biases associated with both laser diffraction and settling methods commonly produce results that indicate lower clay content of material analyzed by laser diffraction when compared to settling methods.

To further evaluate the properties of the clay sources utilized in this study, powder X-ray diffraction analysis was performed on the kaolin, bentonite, and MR clays. Standard methods that included exposure of the clays to different heating treatments, solutions of potassium and magnesium, and exposure to glycol were utilized to elucidate the clay mineralogies present in each material (Moore and Reynolds 1989; Jackson and Barak 2005) Figures 1, 2, and 3 display the diffractogram patterns that resulted from these analyses.

Kaolinite peaks located at 12.5 and 25 2-theta ( $2 \theta)$ dominate the diffractograms of the kaolin material, indicating kaolinite to be the primary mineral in the sample (Figure 1). The shifting of position and intensity of the peaks located in the 3-7 $2 \theta$ range in the various treatments of the bentonite samples indicates a strong presence of smectite interstratified with mica (Figure 2). The term smectite refers to a group of 
monoclinic minerals, of which bentonite is a member. The exact variety of smectite present could not be determined by the X-ray diffraction analysis, but the analysis did confirm a large presence of smectite minerals in the sodium bentonite material.

Quartz and mica peaks were more pronounced in the MR diffractograms (Figure 3) when compared to those of kaolin and bentonite, suggesting a higher concentration of these minerals in the MR clays. The stability in location of the $10 \AA$ peak at $9^{\circ} 2 \theta$ during the magnesium and glycol treatments suggests that the mica present in the MR clay is from the illite group (Gaudette et al. 1966). Illites are members of the phyllosilicate mineral group and are commonly formed from the weathering of argillaceous rocks and sediments. However, the broad features below the $10 \AA \AA$ peak in the potassium treatment do collapse down to $9^{\circ} 2 \theta$ after heating, which still indicates the presence of some form of smectite mineralogy. Additionally, the kaolinite peaks of 12.5 and $252 \theta$ are both still present, but far less pronounced in comparison to the kaolin diffractograms. These findings suggest that the MR material is composed predominantly of illite group clays with a significant amount of fine grained quartz. Kaolinite and some form of smectite clays are also present but likely in lower abundance.

Figure 1. X-ray diffractograms of kaolin material. Strong peaks at 12.5 and $252 \theta$ indicate kaolinite as the predominant mineral in the material.

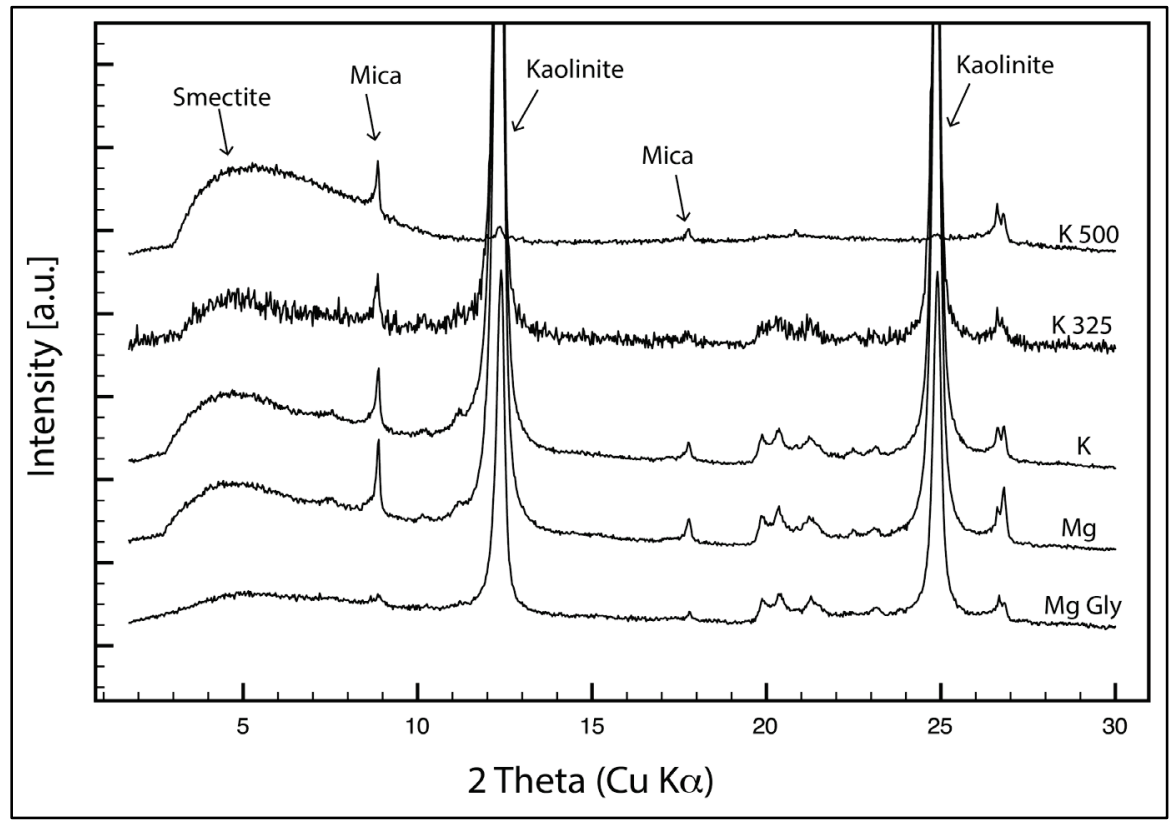


Figure 2. X-ray diffractograms of CSP Forestry sodium bentonite material. The shifting in position and intensity of peaks in the 3-7 $2 \theta$ range after exposure to magnesium

$(\mathrm{Mg})$ indicates the presence of smectite mineralogy.

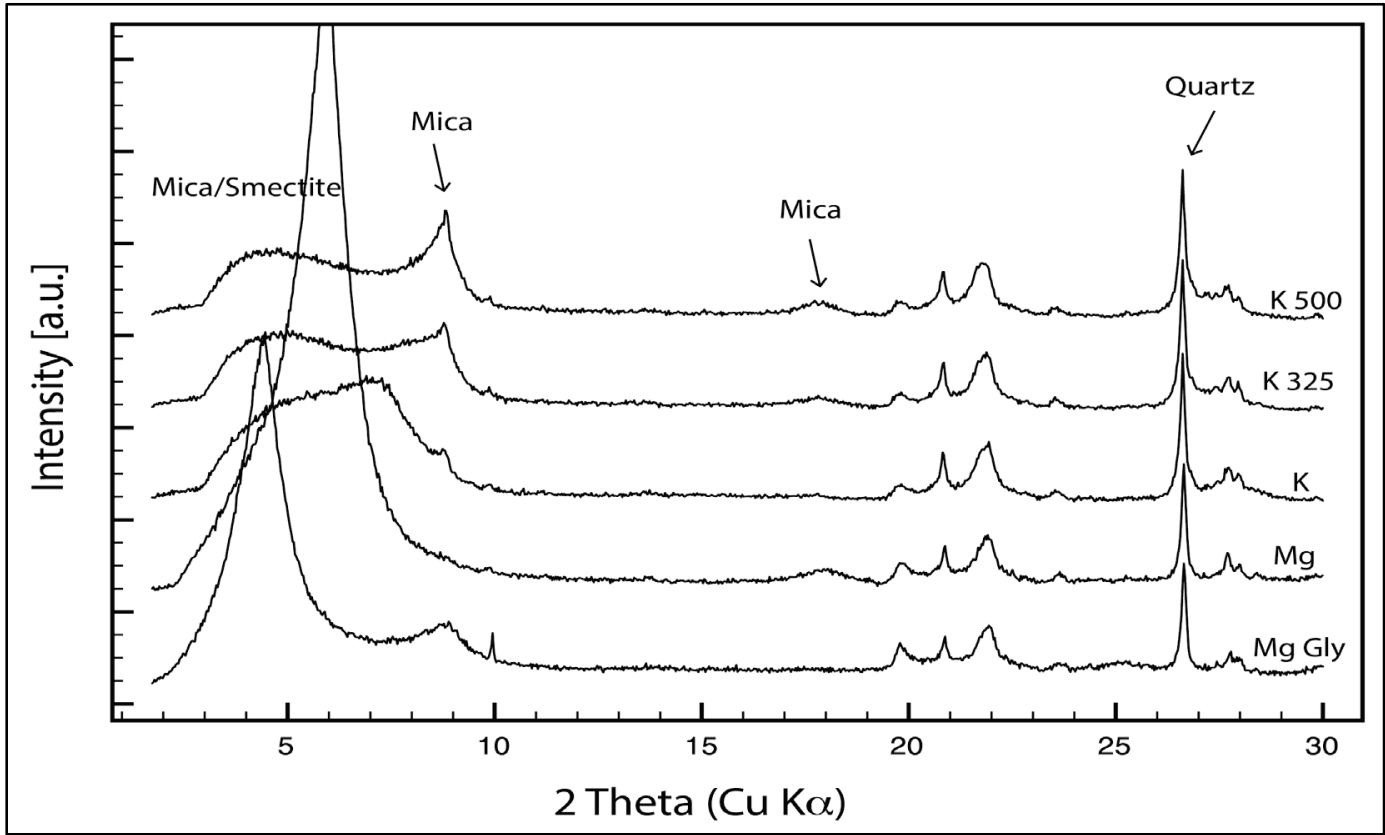

Figure 3. X-ray diffractograms of sediments collected from the MR. Quartz and illite appear to dominate the mineralogy with smaller amount of kaolinite. The collapse of the broad peak below $9^{\circ} 2 \theta$ in the heating treatments also suggests the presence of a smectite clay.

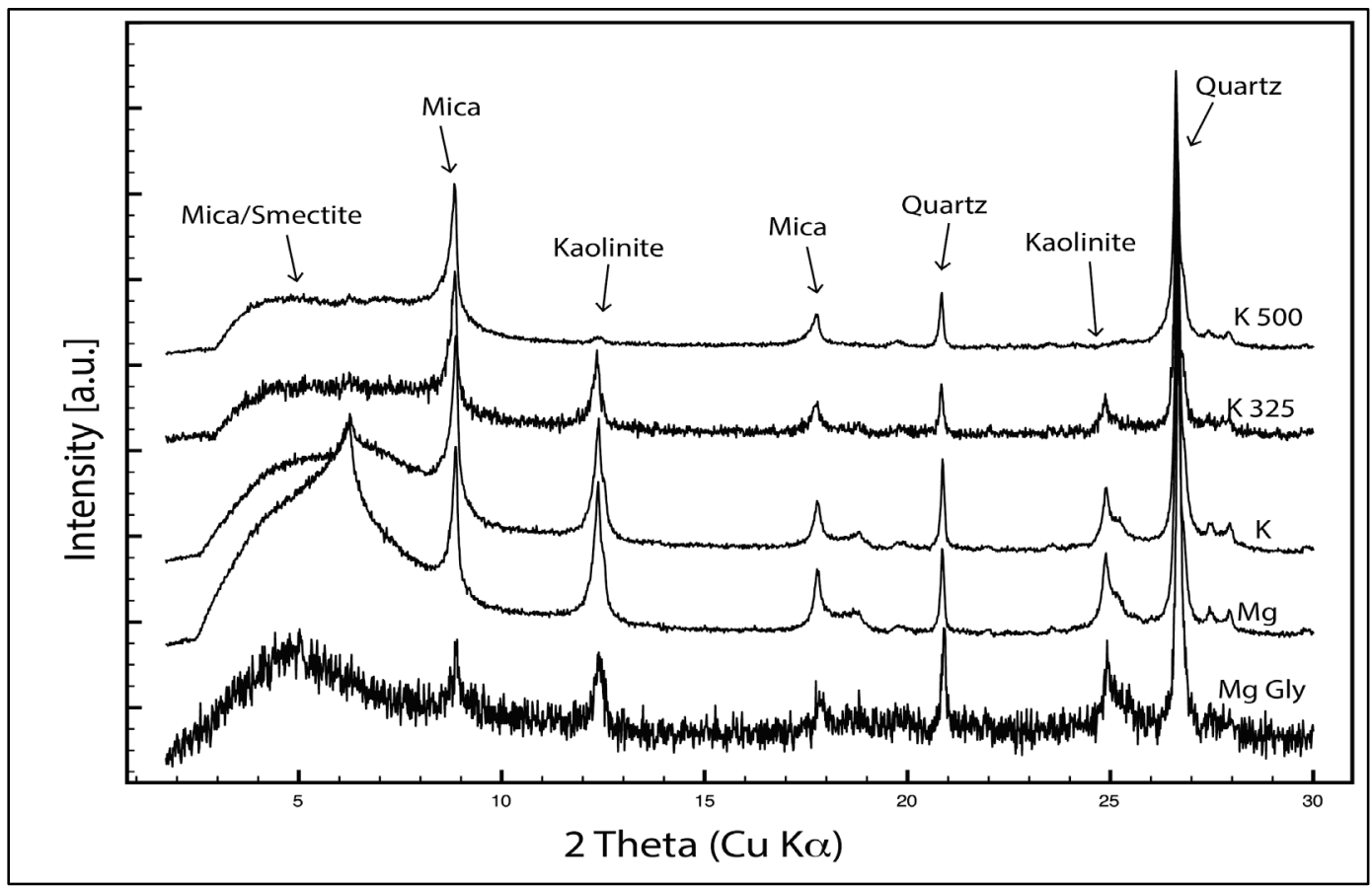




\subsection{Erosion testing}

\subsubsection{Sediment Erosion with Depth flume (Sedflume)}

Sedflume is a field- or laboratory-deployable flume for quantifying cohesive sediment erosion. The USACE-developed Sedflume is a derivative of the flume developed by researchers at the University of California at Santa Barbara (McNeil et al. 1996). The flume includes an $80 \mathrm{~cm}$ long inlet section (Figure 4) with cross-sectional area of $2 \times 10 \mathrm{~cm}$ for uniform, fully developed, smooth-turbulent flow. The inlet section is followed by a test section with a $10 \mathrm{~cm}$ diameter open bottom. Coring tubes and flume test section, inlet section, and exit sections are constructed of clear polycarbonate materials to permit observation of sediment-water interactions during the course of erosion experiments. The flume includes a port over the test section to provide access to the core surface for physical sampling. The flume accepts sediment cores up to $80 \mathrm{~cm}$ in length.

Figure 4. Images of the Sedflume (upper left), erosion surface (lower left), and operator (lower center), along with operational test range of the flume (right).

\begin{tabular}{|l|c|c|}
\hline Shear Stress & $\begin{array}{c}\text { Flow Rate } \\
\text { (Pa) }\end{array}$ & \begin{tabular}{c} 
(GPM) \\
\hline 0.1
\end{tabular} \\
\hline 0.2 & 7.2 \\
\hline 0.4 & 11.5 \\
\hline 0.8 & 17.8 \\
\hline 1.5 & 25.8 \\
\hline Screw Jack & 1.0 & 20.3 \\
\hline Bed Surface During Erosion Test & 25.8 \\
\hline
\end{tabular}

Prior to conducting an erosion experiment, descriptions of the core are recorded, including length, condition of the core, and any visual evidence of layering. Cores are inserted into the testing section of Sedflume, and a 
screw jack is used to advance the plunger such that the core surface becomes flush with the bottom wall of the flume. Flow is directed over the sample by diverting water from a $5.5 \mathrm{hp}$ trash pump, through a $5 \mathrm{~cm}$ inner diameter hose, into the flume. The flow through the flume produces a shear stress on the surface of the core. Numerical, experimental, and analytical analyses have been performed to relate flow rate to bottom shear stress (Figure 4). As sediment is eroded from the core surface, the operator advances the screw jack to maintain the sediment surface flush with the bottom wall of the erosion flume. Erosion experiments were performed by repeating a sequence of five increasing shear stresses. Initial erosion testing is conducted in the surface region (upper $1-3 \mathrm{~cm}$ ) of each core to identify shear stresses that produced erosion velocities within the bounds of typical operation $\left(1.7 \times 10^{-4} \mathrm{~cm} / \mathrm{s}-1.7 \times 10^{-2} \mathrm{~cm} / \mathrm{s}\right)$.

Approximately $1-5 \mathrm{~mm}$ of sediment is eroded at each specified shear stress; thus, the duration of each test is dependent on the rate of erosion. These shear stresses were utilized to create the erosion sequence, which was typically repeated five times for each core. An average erosion rate was then calculated for each shear stress. A diagram depicting this erosion test process along with an example erosion sequence is shown in Figure 5.

Figure 5. Diagram of sediment core erosion process. The brown arrow indicates advancement of sediment into the flume with erosion. The blue arrow indicates flow direction of water. An example erosion sequence is provided in the table to the right of the sediment core.

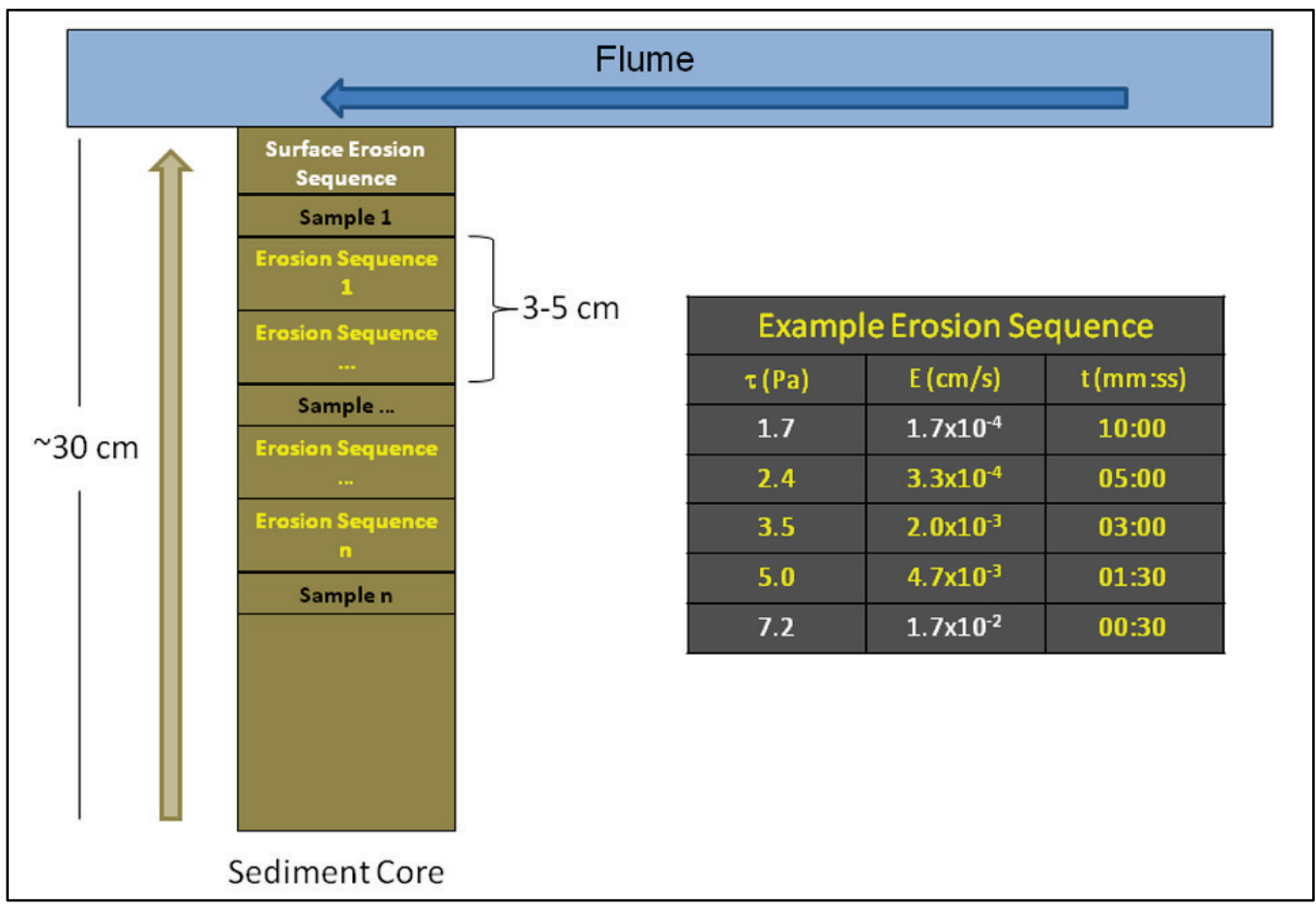


Physical samples for bulk sediment property measurements were taken at approximately $3-5 \mathrm{~cm}$ intervals during erosion experiments, generally at the end of a shear stress cycle. Physical samples were collected by draining the flume channel, opening the port over the test section, and extracting a sample from the sediment bed. These samples were then measured for bulk density and grain-size distribution. These properties can strongly influence erosion; therefore, documenting any variation with depth is important in interpreting the erosion data. Core material remaining after completion of the erosion test was retained for Atterberg limit testing.

\subsubsection{Slurry preparation}

The commercial clays were allowed a wetting period of at least 72 hours using fresh tap water, and each slurry was mixed in a rotary drum for several hours to disaggregate clumps and ensure uniform mixing. Slurry water contents were tested periodically to ensure a constant density of approximately $1.4 \mathrm{~g} / \mathrm{cm}^{3}$, which offered sufficient viscosity to prevent sand particles from settling at high mud contents. A full description of the bulk density measurements is provided in section 2.3.2.

\subsubsection{Core preparation}

The general guidelines for preparing sediment mixtures follows that of Jacobs et al. (2011) whereby sand and mud fractions are sufficiently homogenized and the pore volume of the mixture is fully saturated with water. The goal is to minimize downcore variability of sediment properties that would otherwise affect erosion rates.

First, an appropriate mass of mud slurry was added to a prescribed mass of sand to achieve the targeted mud mass fraction (Table 2; Figure 6A). For mud contents of $11 \%$ or less, a prescribed mass of water was also added to saturate the mixture assuming a sand porosity of 0.35 and slurry density of $1.4 \mathrm{~g} / \mathrm{cm}^{3}$. The sample was then hand mixed for 3-10 min until the mud and sand were evenly distributed throughout the sample (Figure 5B). For mud contents less than $21 \%$, this involved folding and shearing the sample; shearing helps to minimize the formation of mud balls and distributes the mud as evenly as possible (Figure 6C). The sample was then prepared into $10 \mathrm{~cm}$ diameter cores by one of two methods. For fluid mixtures, the sample was extruded from a bag into the bottom of a core to minimize gas entrapment (Figure 6D). For highly viscous and granular 
mixtures that could not easily be extruded, water was added to the sample to achieve saturation, and the samples were tamped into the core tube in approximately 0.5 to $1 \mathrm{~cm}$ lifts (Figures 6E-G). The prepared sediment cores were allowed to consolidate in a $4^{\circ} \mathrm{C}$ cooler for approximately 30 days prior to erosion.

Replicate cores were prepared utilizing the same methodology previously described. A total of 16 replicate cores were prepared. For each clay type, five mud contents were randomly selected for replication. Additionally, a replicate core of the $100 \%$ sand core was also prepared.

Table 2. Masses of sand, slurry and water utilized in core preparation. The "R" indicates replicate cores.

\begin{tabular}{|c|c|c|c|c|c|c|c|c|c|}
\hline & \multicolumn{3}{|c|}{$\begin{array}{c}\text { Non-Swelling Clay } \\
\text { (100\% kaolin) }\end{array}$} & \multicolumn{3}{|c|}{$\begin{array}{l}\text { Swelling Clay } \\
\text { ( } 80 \% \text { kaolin, } \\
20 \% \text { bentonite) }\end{array}$} & \multicolumn{3}{|c|}{$\begin{array}{c}\text { Natural } \\
\text { (MR) }\end{array}$} \\
\hline $\begin{array}{c}\text { Mud } \\
\text { (mass \%) }\end{array}$ & $\begin{array}{l}\text { Sand } \\
\text { Mass } \\
\text { (g) }\end{array}$ & $\begin{array}{c}\text { Slurry } \\
\text { Mass } \\
\text { (g) }\end{array}$ & $\begin{array}{c}\text { Water } \\
\text { Mass } \\
\text { (g) }\end{array}$ & $\begin{array}{c}\text { Sand } \\
\text { Mass } \\
\text { (g) }\end{array}$ & $\begin{array}{c}\text { Slurry } \\
\text { Mass } \\
\text { (g) }\end{array}$ & $\begin{array}{c}\text { Water } \\
\text { Mass } \\
\text { (g) }\end{array}$ & $\begin{array}{c}\text { Sand } \\
\text { Mass } \\
(\mathrm{g})\end{array}$ & $\begin{array}{l}\text { Slurry } \\
\text { Mass } \\
\text { (g) }\end{array}$ & $\begin{array}{c}\text { Water } \\
\text { Mass } \\
\text { (g) }\end{array}$ \\
\hline 0 & 3657 & - & 760 & - & - & - & - & - & - \\
\hline OR & 3657 & - & 760 & - & - & - & - & - & - \\
\hline 1 & 3657 & 81 & 702 & 3566 & 79 & 684 & 3688 & 79 & 710 \\
\hline $1 R$ & 3693 & 81 & 709 & - & - & - & - & - & - \\
\hline 2 & 3657 & 163 & 644 & 3664 & 164 & 643 & 3664 & 157 & 650 \\
\hline 3 & 3657 & 247 & 584 & 3631 & 247 & 578 & 3755 & 247 & 606 \\
\hline $3 R$ & 3657 & 247 & 584 & - & - & - & 3636 & 247 & 578 \\
\hline 4 & 3657 & 333 & 523 & 3637 & 333 & 517 & 3761 & 333 & 546 \\
\hline 5 & 3657 & 420 & 461 & 3658 & 423 & 457 & 3782 & 423 & 487 \\
\hline $5 R$ & 3657 & 420 & 461 & 3698 & 419 & 471 & - & - & - \\
\hline 8 & 3657 & 694 & 265 & 3656 & 698 & 259 & 3781 & 698 & 292 \\
\hline $8 \mathrm{R}$ & - & - & - & 3683 & 689 & 275 & - & - & - \\
\hline
\end{tabular}




\begin{tabular}{|c|c|c|c|c|c|c|c|c|c|}
\hline & \multicolumn{3}{|c|}{$\begin{array}{l}\text { Non-Swelling Clay } \\
\text { (100\% kaolin) }\end{array}$} & \multicolumn{3}{|c|}{$\begin{array}{l}\text { Swelling Clay } \\
\text { (80\% kaolin, } \\
20 \% \text { bentonite) }\end{array}$} & \multicolumn{3}{|c|}{$\begin{array}{c}\text { Natural } \\
\text { (MR) }\end{array}$} \\
\hline $\begin{array}{c}\text { Mud } \\
\text { (mass \%) }\end{array}$ & $\begin{array}{l}\text { Sand } \\
\text { Mass } \\
\text { (g) }\end{array}$ & $\begin{array}{c}\text { Slurry } \\
\text { Mass } \\
\text { (g) }\end{array}$ & $\begin{array}{c}\text { Water } \\
\text { Mass } \\
\text { (g) }\end{array}$ & $\begin{array}{c}\text { Sand } \\
\text { Mass } \\
\text { (g) }\end{array}$ & $\begin{array}{c}\text { Slurry } \\
\text { Mass } \\
\text { (g) }\end{array}$ & $\begin{array}{l}\text { Water } \\
\text { Mass } \\
\text { (g) }\end{array}$ & $\begin{array}{c}\text { Sand } \\
\text { Mass } \\
(\mathrm{g})\end{array}$ & $\begin{array}{l}\text { Slurry } \\
\text { Mass } \\
\text { (g) }\end{array}$ & $\begin{array}{c}\text { Water } \\
\text { Mass } \\
\text { (g) }\end{array}$ \\
\hline 11 & 3657 & 986 & 57 & 3644 & 989 & 48 & 3768 & 989 & 84 \\
\hline $11 R$ & - & - & - & 3661 & 973 & 69 & 3646 & 991 & 47 \\
\hline 15 & 4199 & 1617 & - & 3524 & 1365 & - & 3644 & 1365 & - \\
\hline $15 R$ & 4199 & 1617 & - & - & - & - & - & - & - \\
\hline 21 & 3312 & 1921 & - & 2902 & 1694 & - & 3001 & 1694 & - \\
\hline $21 R$ & 2901 & 1683 & - & 2902 & 1659 & - & 2921 & 1708 & - \\
\hline 29 & 2274 & 2027 & - & 2902 & 2603 & - & 3001 & 2603 & - \\
\hline $29 R$ & - & - & - & - & - & - & 2905 & 2609 & - \\
\hline 40 & 1620 & 2356 & - & 1621 & 2373 & - & 1676 & 2373 & - \\
\hline 60 & 845 & 2766 & - & 845 & 2783 & - & 874 & 2783 & - \\
\hline 80 & 348 & 3034 & - & 347 & 3048 & - & 359 & 3048 & - \\
\hline $80 R$ & - & - & - & 347 & 2988 & - & - & - & - \\
\hline 100 & - & 3212 & - & - & 3210 & - & - & 3254 & - \\
\hline 100R & - & - & - & - & - & - & - & 3208 & - \\
\hline
\end{tabular}


Figure 6. Photos depicting the mixing of sand and mud are presented in A - C. Photos demonstrating the methods utilized to place material in core tubes are presented in $\mathrm{D}-\mathrm{G}$.
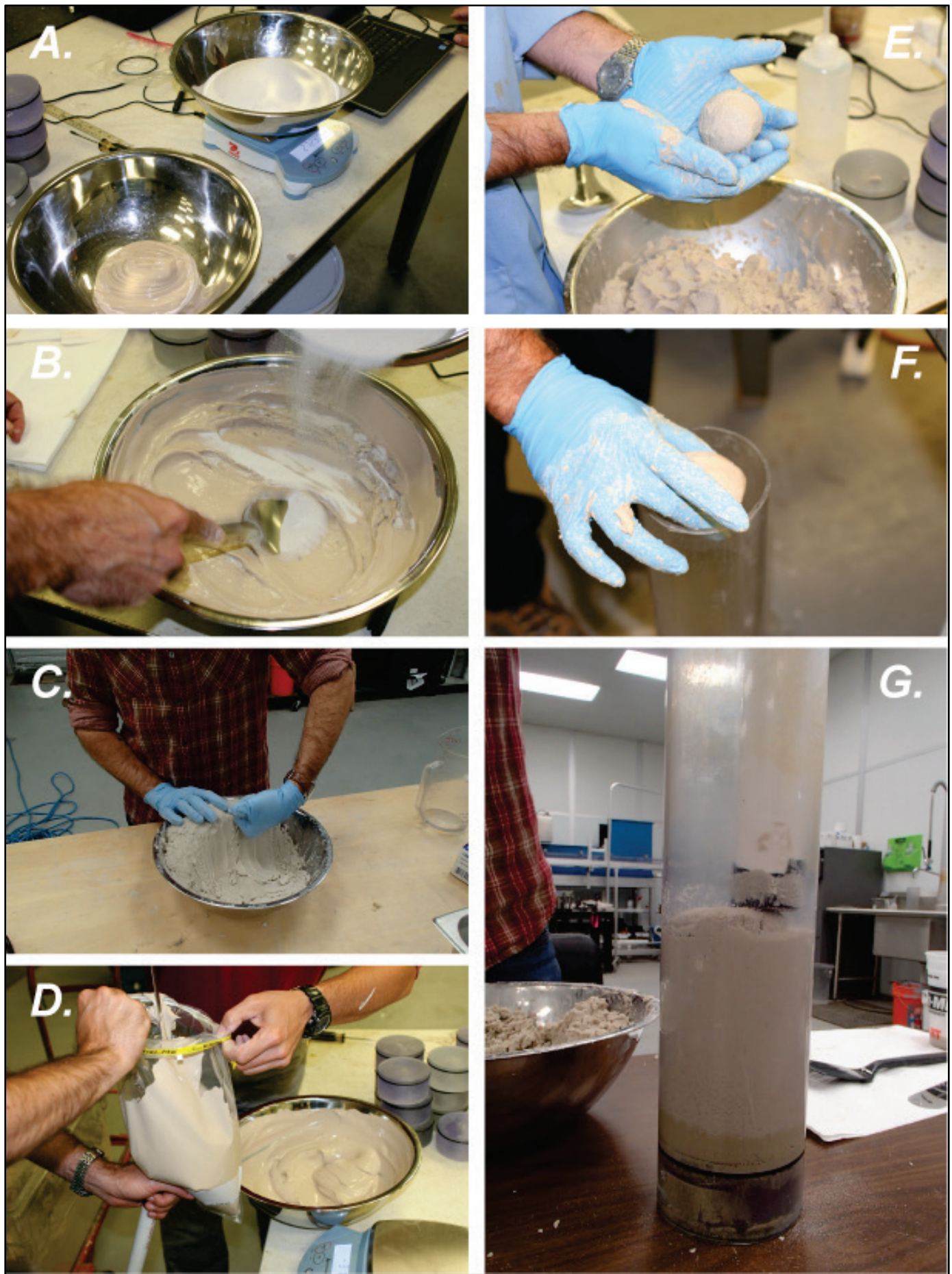


\subsection{Physical properties}

Sub-samples of each sediment type were set aside for the purpose of Atterberg Limit testing before the preparation of sediment cores. Additional physical samples for bulk sediment property measurements were taken at periodic intervals during Sedflume testing, generally at the end of an erosion cycle (Figure 5). These samples were collected by draining the flume channel, opening the port over the test section, and extracting a sample from the sediment bed. Samples collected in this manner were used to characterize the bulk density and grain-size distribution of the test bed. The methods used to determine these properties are presented in this section.

\subsubsection{Grain size}

Grain size distributions and characterizations were obtained through Laser Diffraction Particle Size Analysis (LDPSA) with a Malvern Mastersizer 2000, which measures particle sizes in the range of 0.02 to $2000 \mu \mathrm{m}$. Sediments were homogenized and disaggregated overnight in a solution of sodium metaphosphate $(40 \mathrm{~g} / \mathrm{L})$. To remove any macro organic material, samples were passed through a $1000 \mu \mathrm{m}$ sieve into the instrument's reservoir and sonicated for $60 \mathrm{~s}$ prior to analysis. The Wentworth scale (1929) was used for the classification of sand ( $>63 \mu \mathrm{m})$, silt $(63-4 \mu \mathrm{m})$ and clay $(<4 \mu \mathrm{m})$ sized particles.

\subsubsection{Bulk density}

Bulk sediment density of the mud slurries was determined by two methods: X-ray attenuation and a wet-dry weight analysis.

\subsubsection{X-Ray Attenuation (XRA)}

Considerable variation in bed density is often found within the upper portion of the sediment bed, associated with expulsion of pore water from fine sediments through the process of self-weight consolidation (Winterwerp and van Kesteren 2004). Additionally, cohesive sediment erosion has been shown to typically decrease with increasing bed density, owing to the associated increased particle-particle contact and cohesion (Jepsen et al. 1997). Consequently, high-resolution, non-destructive methods to estimate bed density are desired in order to relate erosion to bed density. The U.S. Army Engineer Research and Development Center XRA device was applied to provide high-resolution, density profiles. 
The cores were scanned with varying vertical resolution to allow high resolution of the sediment-water interface and bulk density variation near the water surface. The typical scanning scheme was to sample for $10 \mathrm{~cm}$ with $1 \mathrm{~mm}$ resolution starting approximately $5 \mathrm{~mm}$ above the sedimentwater interface. The next $10 \mathrm{~cm}$ were then scanned in a $10 \mathrm{~cm}$ long segment at $2 \mathrm{~mm}$ resolution, followed by another segment to the bottom of the core (typically less than $10 \mathrm{~cm}$ ) at $3 \mathrm{~mm}$ resolution. The reference material for these scans was water, and the reference material and all specimen scans were conducted with a $40 \mathrm{~s}$ dwell time.

\subsubsection{Wet-dry weight analysis}

Water content $(w)$ of each sample was measured through wet-dry weight analysis following ASTM D2216-19 (2019) in which $w$ is given by

$$
w=\left(\frac{m_{w}-m_{d}}{m_{d}}\right)
$$

where $m_{w}$ and $m_{d}$ are the wet and dry weights, respectively. The total volume of sample was assumed to consist of both solid particles and water, with assumed densities of $2.65 \mathrm{~g} / \mathrm{cm}^{3}$ and $1.0 \mathrm{~g} / \mathrm{cm}^{3}$, respectively. The bulk density as a function of $w$ and the densities of the sediment particles $\left(\rho_{s}\right)$ and water $\left(\rho_{\mathrm{w}}\right)$ were calculated with Equation 2, derived from Jepsen et al. (2010):

$$
\rho=\rho_{s}+\frac{w \rho_{s}\left(\rho_{w}-\rho_{s}\right)}{\rho_{w}+w \rho_{s}}
$$

\subsubsection{Atterberg limits}

After completion of erosion testing, the remaining material in each core was retained for the purpose of obtaining the Atterberg limits of the mixture. The Atterberg limits are composed of the liquid limit (LL), plastic limit (PL), and plasticity index (PI) of a material. Standard methods, described in ASTM D4318-5, were utilized to measure and calculate each parameter. To obtain the LL, the multipoint method was utilized with a motorized liquid limit device to maintain a constant drop rate. PL testing was conducted on a polished granite counter top using the hand method. The difference between LL and PL yielded the PI for each mixture. 


\section{Results}

\subsection{Physical properties of test materials}

The results of the physical parameters measured for each test material are presented in this section.

\subsubsection{Atterberg limits}

Upon the completion of erosion testing, sediment remaining within the core tube was retained and utilized to determine the Atterberg limits (LL, PL, and PI) of each mixture. It was found that mixtures with mud contents less than $20 \%$ by mass did not display plastic behavior for any of the mud types. Therefore, no results for those materials are reported. Plastic behavior was observed in the kaolin-bentonite cores starting at a mud content of $21 \%$ while both the kaolin and MR mud mixtures did not display plastic behavior until mud contents reached $29 \%$ by mass (Table 3 ).

Results showed that the LL, PL, and PI of each material increased with mud content. Seed et al. (1964) documented similar trends in their study where they likewise mixed different amounts of kaolin and bentonite with fine sand and evaluated the Atterberg limits of those mixtures. Reported values of LL and PI for similar mixtures showed substantial variability between the two studies. Seed et al. (1964) reported 100\% kaolin to have values of 45.0, 34.8, and 10.2 for the LL, PL, and PI, respectively. By comparison, this study reported $100 \%$ kaolin to have values of $65.5,33.9$, and 31.6 for the LL, PL, and PI, respectively. While the PLs of the kaolin in the two studies are within close agreement, the LLs show a difference of nearly 20 . This variability may largely be due to the variety of kaolin that was utilized. The LL of various types of kaolin have been reported to range from 34.98 to 72.0 (White 1949; Lemos and Vaughan 2000; Sasanian et al. 2014). This study utilized EPK kaolin, which had a similarly reported LL of 61.o by Sasanian and Newson (2014). Seed et al. (1964) did not identify the variety of kaolin that was utilized, but it is possible that they utilized a material that had similar properties to those reported by White (1949), $34.98-58.35$. Regardless of these differences, both studies showed that the PI of the mixtures of materials increased with increasing clay content. 
Table 3. Atterberg limit results for cores with mud content $>\mathbf{2 0} \%$.

\begin{tabular}{|c|c|c|c|c|c|c|c|c|c|}
\hline & \multicolumn{2}{|c|}{$\begin{array}{c}\text { Non-Swelling Clay } \\
(100 \% \text { kaolin) }\end{array}$} & \multicolumn{2}{c|}{$\begin{array}{c}\text { Swelling Clay } \\
\text { (80\% kaolin, }\end{array}$} & \multicolumn{3}{c|}{$\begin{array}{c}\text { Natural } \\
\text { (MR) }\end{array}$} \\
\hline $\begin{array}{c}\text { Mud } \\
\text { (mass \%) }\end{array}$ & LL & PL & PI & LL & PL & PI & LL & PL & PI \\
\hline 21 & - & - & - & 18.4 & 14.7 & 3.8 & - & - & - \\
\hline 29 & 18.3 & 14.9 & 3.4 & 22.1 & 13.5 & 8.6 & 24.3 & 16.0 & 8.3 \\
\hline 40 & 25.3 & 14.6 & 10.7 & 28.4 & 14.2 & 14.2 & 32.3 & 15.0 & 17.3 \\
\hline 60 & 37.7 & 21.8 & 15.9 & 41.9 & 18.7 & 23.2 & 44.7 & 20.1 & 24.6 \\
\hline 80 & 51.0 & 27.7 & 23.3 & 54.7 & 24.4 & 30.4 & 60.6 & 23.7 & 36.9 \\
\hline 100 & 65.5 & 33.9 & 31.6 & 68.9 & 30.1 & 38.8 & 76.0 & 27.4 & 48.6 \\
\hline
\end{tabular}

The PI of the materials tested in this study are plotted against the mass percent mud content in Figure 7. Since PI is the difference between the LL and PL, it can be thought of as the range of water content over which a soil or sediment will behave plastically. Therefore, larger PI values indicate larger ranges in plasticity for the corresponding material. While the kaolin-bentonite mixtures displayed plasticity behavior at the lowest mud content, the MR cores tended to have higher PI values, indicating that they had a wider range of plasticity at a given mud content (Figure 7).

Figure 7. PI plotted against mud content for materials with kaolinite $(\mathrm{K})$, kaolinite-bentonite (KB), and MR muds.

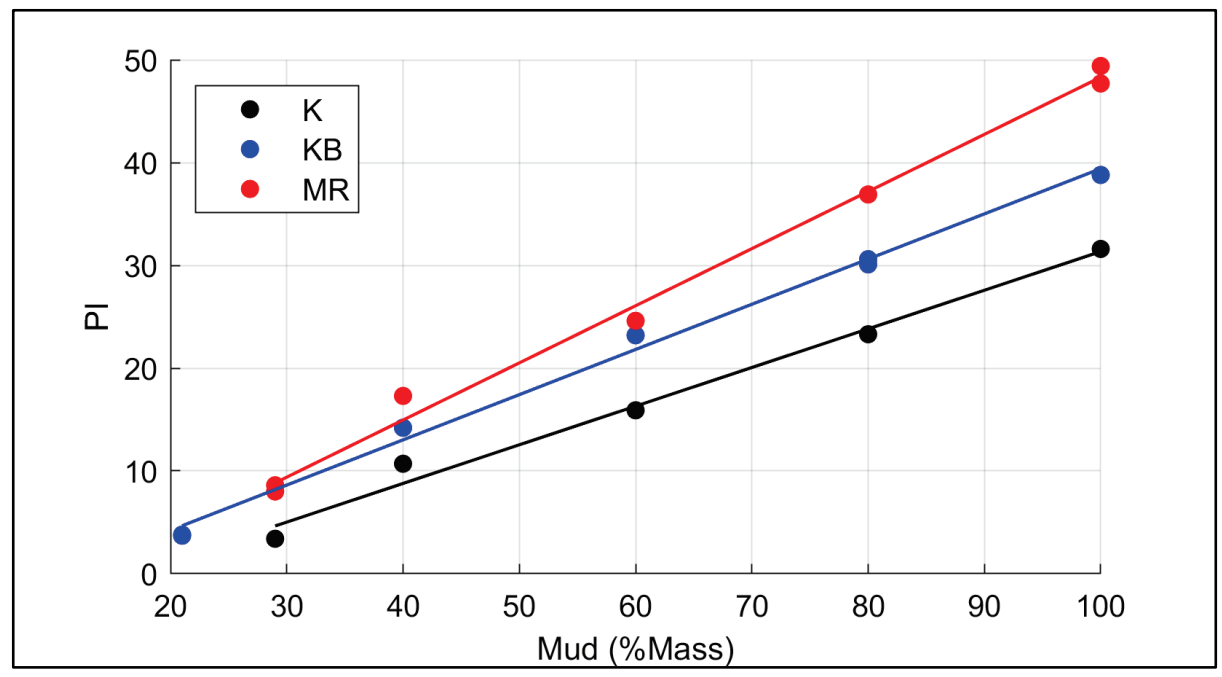




\subsubsection{Bulk density}

\subsubsection{XRA}

After a 30-day consolidation period, the length of each sediment core was scanned with a collimated x-ray beam to determine the bulk sediment density of the core prior to erosion analysis. In general, the density scans showed a density transition zone between overlaying water and the sediment for the upper few centimeters of each core. As seen in Figure 8, below a depth of $\sim 3 \mathrm{~cm}$, densities typically remained constant. Density values below this transition zone were averaged to produce a mean density for each core (Table 4). Plots showing the density profiles of each core can be found in Figures B-1 through B-10 in Appendix B.

Figure 8. Bulk densities obtained through $\mathrm{x}$-ray attenuation are shown for kaolinbentonite cores with mud contents ranging from 1\% to 5\% (KB001 - KB005). A surface transition zone was commonly observed at the water-sediment interface down to a depth of $\sim 30 \mathrm{~mm}$. Note that the " $5 \mathrm{R}$ " in KB005R refers to an independent, duplicate measurement of a $5 \%$ kaolin-bentonite core.

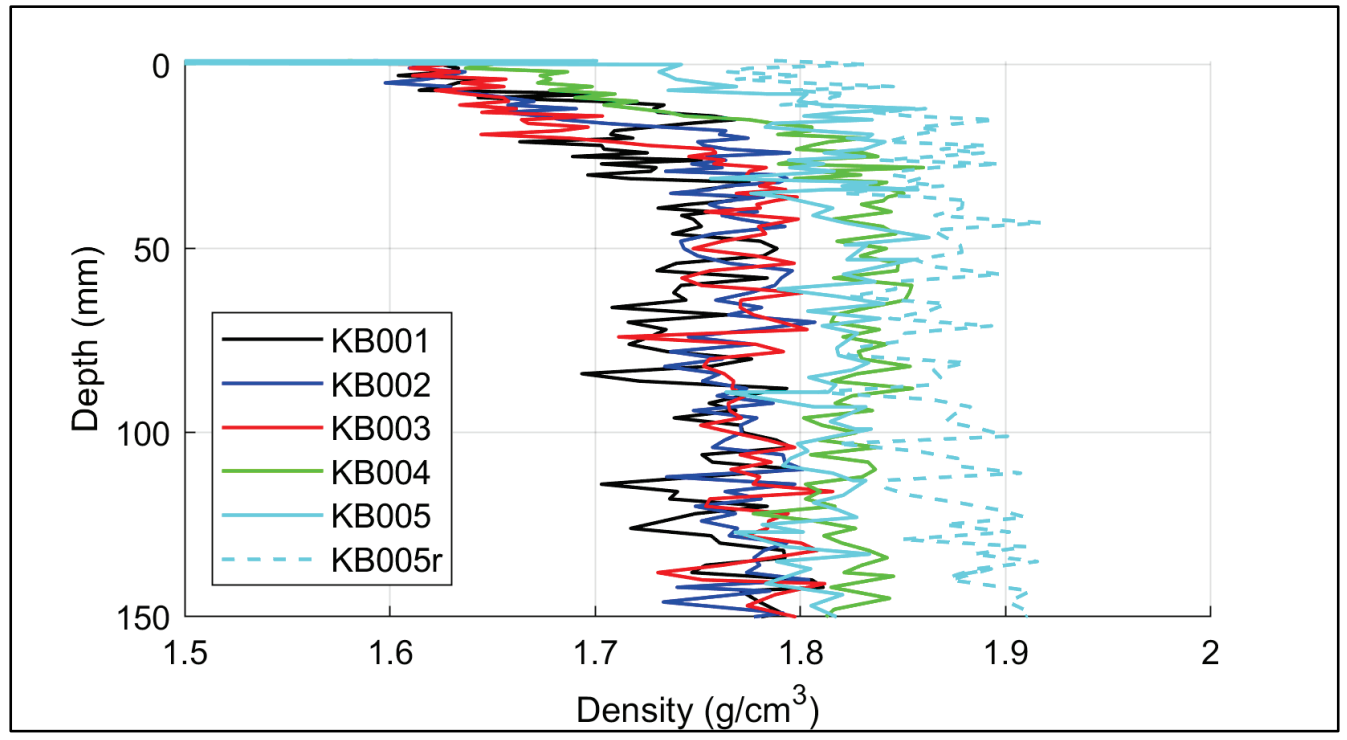

\subsubsection{Wet-dry weight analysis}

Through the process of wet-dry analysis, bulk density measurements were also performed on the physical samples collected during erosion testing. Bulk density measurements of the physical samples from each core were averaged to produce a mean bulk density. These values are reported in Table 3. Note that mean bulk density values obtained through wet-dry analysis were consistently higher than x-ray attenuation density values. The discrepancies between the two measurements were also found to be 
greatest for cores in which mud contents ranged between $1 \%$ to $21 \%$ (Table 4; Figure 9). One possible explanation for this disparity in bulk density would be the presence of air in the void space of the cores.

Table 4. Average bulk densities of cores obtained from both XRA and wet-dry methods.

\begin{tabular}{|c|c|c|c|c|c|c|}
\hline & \multicolumn{3}{|c|}{$\begin{array}{l}\text { Wet-Dry Analysis } \\
\qquad\left(\mathrm{g} / \mathrm{cm}^{3}\right)\end{array}$} & \multicolumn{3}{|c|}{$\begin{array}{c}\text { XRA } \\
\left(\mathrm{g} / \mathrm{cm}^{3}\right)\end{array}$} \\
\hline $\begin{array}{c}\text { Mud } \\
\text { (mass \%) }\end{array}$ & Kaolin & $\begin{array}{l}\text { Kaolin/ } \\
\text { Bentonite }\end{array}$ & MR & Kaolin & $\begin{array}{l}\text { Kaolin/ } \\
\text { Bentonite }\end{array}$ & MR \\
\hline 0 & 1.93 & 1.93 & 1.93 & 1.91 & 1.91 & 1.91 \\
\hline 1 & 1.97 & 1.99 & 1.97 & 1.85 & 1.76 & 1.75 \\
\hline 2 & 2.00 & 2.02 & 1.96 & 1.82 & 1.78 & 1.74 \\
\hline 3 & 2.02 & 2.03 & 2.01 & 1.84 & 1.77 & 1.81 \\
\hline 4 & 2.03 & 2.04 & 2.02 & 1.83 & 1.82 & 1.80 \\
\hline 5 & 2.06 & 2.04 & 2.03 & 1.82 & 1.85 & 1.86 \\
\hline 8 & 2.05 & 2.04 & 2.08 & 1.84 & 1.86 & 1.84 \\
\hline 11 & 2.05 & 2.09 & 2.05 & 1.88 & 1.88 & 1.91 \\
\hline 15 & 2.04 & 2.06 & 2.05 & 1.89 & 1.89 & 1.91 \\
\hline 21 & 1.96 & 1.97 & 1.97 & 1.86 & 1.88 & 1.90 \\
\hline 29 & 1.86 & 1.84 & 1.87 & 1.80 & 1.76 & 1.84 \\
\hline 40 & 1.74 & 1.71 & 1.78 & 1.68 & 1.69 & 1.75 \\
\hline 60 & 1.57 & 1.57 & 1.62 & 1.53 & 1.51 & 1.60 \\
\hline 80 & 1.47 & 1.46 & 1.51 & 1.44 & 1.43 & 1.50 \\
\hline 100 & 1.39 & 1.38 & 1.43 & 1.38 & 1.33 & 1.43 \\
\hline
\end{tabular}


Figure 9. Plots showing bulk density versus mud content for each core. Blue, red, and black lines indicate cores made with kaolinite (K), kaolinite-bentonite (KB), and MR muds, respectively. Curves with solid lines depict density values calculated by wetdry analysis. Curves with dashed lines represent density values obtained from XRA.

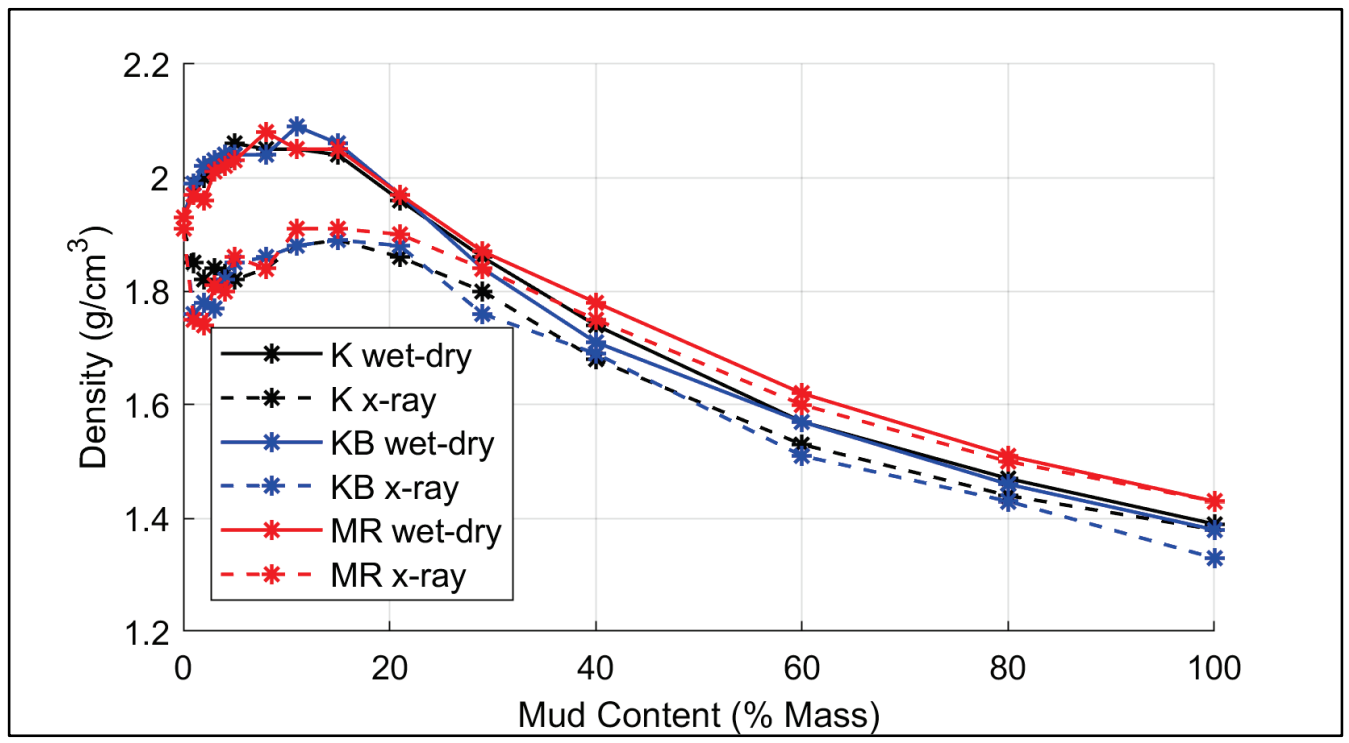

As previously described, the mixing process for samples with mud contents $\leq \mathbf{2 1} \%$ involved repeated folding and shearing of the sediment. These folding and shearing actions could have resulted in the addition of air into the mixture. The wet-dry method assumes a completely saturated sample and therefore does not account for any void space within the sediment occupied by gasses. In the event that significant amounts of gas were present, the total sample volume would be underestimated by the wet-dry method. Therefore, the mass measured from the water and sediment would be attributed to a partial volume of the total sample, and thus produce an elevated density. Cores which were exposed to limited folding and shearing mixing action (cores with $>21 \%$ mud content and the 100\% sand cores) had similar density values for both wet-dry and XRA methods. This observation supports the idea that the mixing process utilized with mud content $\leq 21 \%$ may have impacted the bulk density results by introducing air into the sediment matrix.

Analysis of the mean density data revealed maximum densities occurred when mud contents were between $10 \%$ to $20 \%$ by mass. This pattern was consistent for all three mud varieties and both methods of bulk density calculation, as seen in Figure 9. The higher mean densities of the mixtures with a $10 \%-20 \%$ mud content may reflect the filling of the sand pore spaces with mud. 


\subsubsection{Grain size}

Grain size distribution analyses were performed on the samples collected during the erosion testing of each core. Results of each sample were averaged to produce a mean grain size distribution for each core. Table 5 presents the sand, silt, and clay content, along with the $\mathrm{D}_{10}, \mathrm{D}_{50}$, and $\mathrm{D}_{90}$ of each kaolinite-bentonite mixture. Additional tables and figures presenting these results along with mean grain size distributions of all the sediment mixtures are found in Appendix A.

Mean LDPSA measured mud (silt \% + clay \%) content of each test core was plotted against the mass percentage of mud used in compositing the core material to evaluate the correlation between the two mud contents (Figure 10). While the majority of data in Figure 10 plotted below the 1:1 line, indicating that LDPSA commonly reported a lower mud content than the mass percentage, a strong correlation $\left(\mathrm{r}^{2}=0.94\right)$ was observed between the two mud contents. However, note that $100 \%$ mud was assumed for the kaolin, bentonite, and MR muds during the compositing process. Laser diffraction analysis reported these materials to have lower mud contents of 94\%, 95\%, and 97\%, respectively (Table 1). This fact helps explain the lower mud content commonly observed in the laser diffraction results. Additionally, winnowing of the fines during the erosion process and the formation of aggregates could also have contributed to a bias towards coarser materials in the diffraction data.

Notes taken during erosion testing periodically described "clouds" of sediment coming off the core surface when little bed erosion was observed. These clouds were likely composed of fine silts and clays and allowed for finer sediment to be removed from the bed while coarser sand material remained. Since grain size distribution samples were collected after completion of a series of erosion tests, it is possible that the sampled core surface had been partially winnowed of fine material. Additionally, aggregate particles were visually observed during erosion testing in cores with mud content as low as $2 \%-3 \%$ by mass. These aggregates were observed to erode by being plucked from the sediment surface as opposed to the transport of individual sand grains. As mud content increased, aggregates of mud were more commonly observed and became the dominant form of particle erosion. Although sediment samples were immersed in deflocculant and sonified prior to grain size analysis, it is possible that some sediments were not completely disaggregated prior to testing. Therefore, any aggregated particles that may have passed to the 
laser diffraction instrument could potentially skew the results towards coarser size distributions.

Table 5. Kaolinite-bentonite mud laser diffraction data.

\begin{tabular}{|c|c|c|c|c|c|c|}
\hline Sample & \% Sand & \% Silt & \% Clay & $\begin{array}{c}\mathrm{D}_{10} \\
(\mu \mathrm{m})\end{array}$ & $\begin{array}{c}\mathrm{D}_{50} \\
(\mu \mathrm{m})\end{array}$ & $\begin{array}{c}\mathrm{D} 90 \\
(\mu \mathrm{m})\end{array}$ \\
\hline KB001 & 99.9 & 0.1 & 0 & 100.5 & 162.0 & 261.4 \\
\hline KB002 & 99.9 & 0.1 & 0 & 99.4 & 162.2 & 265.2 \\
\hline KB003 & 99.9 & 0.1 & 0 & 98.0 & 159.9 & 260.4 \\
\hline KB004 & 99.7 & 0.2 & 0.2 & 96.2 & 160.1 & 265.6 \\
\hline KB005 & 98.7 & 1.0 & 0.3 & 93.4 & 157.2 & 260.8 \\
\hline KB005R & 94.8 & 3.6 & 1.6 & 91.3 & 157.1 & 250.2 \\
\hline KB008 & 94.8 & 3.6 & 1.6 & 91.2 & 157.1 & 250.6 \\
\hline KB008R & 90.1 & 6.9 & 3.1 & 63.5 & 153.7 & 258.5 \\
\hline KB011 & 93.5 & 4.5 & 2.0 & 88.7 & 158.4 & 254.5 \\
\hline KB011R & 92.1 & 5.4 & 2.5 & 81.3 & 155.9 & 252.7 \\
\hline KB015 & 90.7 & 6.3 & 3.0 & 72.9 & 153.6 & 249.0 \\
\hline KB021 & 92.9 & 4.8 & 2.3 & 86.2 & 160.0 & 260.1 \\
\hline KB021R & 77.5 & 16.1 & 6.4 & 6.3 & 132.4 & 244.8 \\
\hline KB029 & 81.4 & 13.3 & 5.3 & 8.0 & 138.7 & 244.8 \\
\hline KB040 & 81.8 & 13.0 & 5.3 & 8.2 & 147.6 & 261.6 \\
\hline KB060 & 57.0 & 31.4 & 11.5 & 3.6 & 94.5 & 248.0 \\
\hline KB080 & 42.6 & 41.8 & 15.6 & 3.0 & 23.7 & 234.9 \\
\hline KB080R & 19.8 & 58.7 & 21.5 & 2.5 & 10.8 & 144.0 \\
\hline KB100 & 4.6 & 70.9 & 24.5 & 2.4 & 8.3 & 37.8 \\
\hline
\end{tabular}


Figure 10. Plot of mean mud content measured by laser diffraction against mud content by mass of each test core. Dashed blue line indicates least squares regression while the solid black line shows 1:1 correlation.

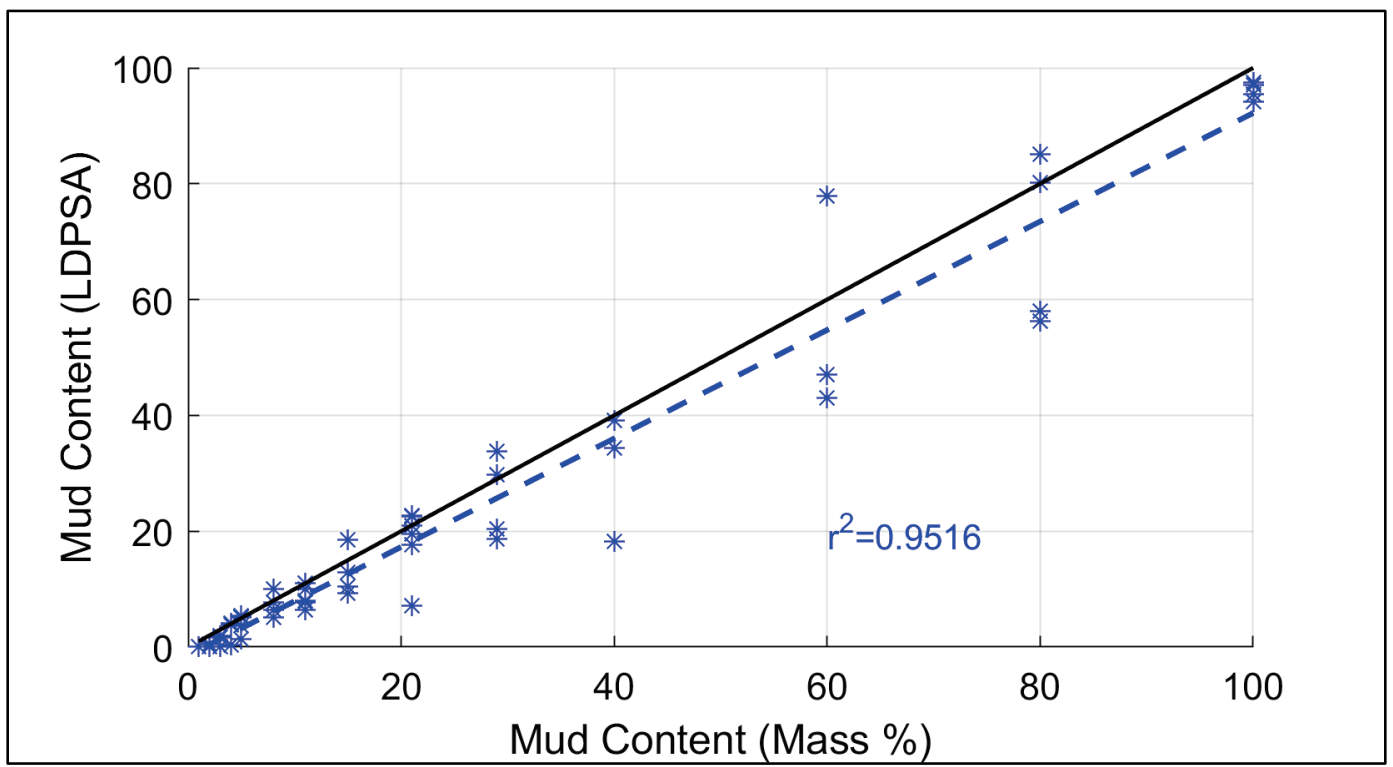

\subsection{Erosion tests}

\subsubsection{Erosion parameterization}

Cohesive sediment erosion is sensitive to changes in grain size, bed density, mineralogy, gas content, organic content, and a host of other factors. These factors can change significantly at relatively small scales. Consequently, measured cohesive sediment erosion rates are notoriously variable. Multiple steps were taken to reduce these sources of variability in this study. As previously described, sediments in this study were prepared and placed in core tubes in an effort to ensure as much homogeneity throughout the core as possible. Additionally, results of the $\mathrm{x}$-ray scans were utilized to ensure that erosion experiments were conducted within regions of the core that had constant density. Last, the erosion experiments were conducted in a manner to produce a large sample from which to derive statistically representative relationships for various numerical erosion algorithms. To ensure high quality in the data analysis, data and associated experimental notes were evaluated to identify outliers in the dataset. Outliers were rejected based on comparisons between adjacent data points and experiment log notes.

Erosion velocities showed consistency with shear stresses and did not indicate the presence of layers or heterogeneity within the cores. An example of the data collected during erosion experiments is presented in 
Figure 11, which shows erosion rate data plotted against shear stress for the 21\% kaolinite-bentonite mud mixtures on log-log scale (plots for each core can be found in Tables C- 1 through C- 4 and Figures $\mathrm{C}-1$ through C- 43 in Appendix C). The circles indicate the mean erosion rate for each unique shear stress that was evaluated during the erosion testing. The error bars on each circle indicate the $95 \%$ confidence interval around those means. A multivariate least square fit was applied to the data providing the algorithm for parameterization of the erosion process in the form:

$$
\begin{gathered}
E=0 ;\left(\tau<\tau_{c}\right) \\
E=A \tau^{n} ;\left(\tau_{c}<\tau\right)
\end{gathered}
$$

where $E$ represents erosion rate $(\mathrm{cm} / \mathrm{s})$ from the bed, $\tau$ is bed shear stress, $\tau_{c}$ is critical stress for erosion, $A$ is an empirical constant, and $n$ is an empirical exponent. For this study, an erosion rate of $1.0 \mathrm{E}-04 \mathrm{~cm} / \mathrm{s}$ was utilized to solve for $\tau_{c}$. Tables $6-9$ provide the erosion parameters $\tau_{c}, A$, and $n$ for each core. Additionally, these tables provide a low and high range for $\tau_{c}$ that was obtained from the 95\% confidence intervals of the least square fit.

Figure 11. Plot of mean erosion rate against shear stress for cores composed of $21 \%$ kaolinite-bentonite mud. Regression lines fit to the data were used to determine $T_{c}$ at an erosion rate of $1.0 \mathrm{E}-04 \mathrm{~cm} / \mathrm{s}$.

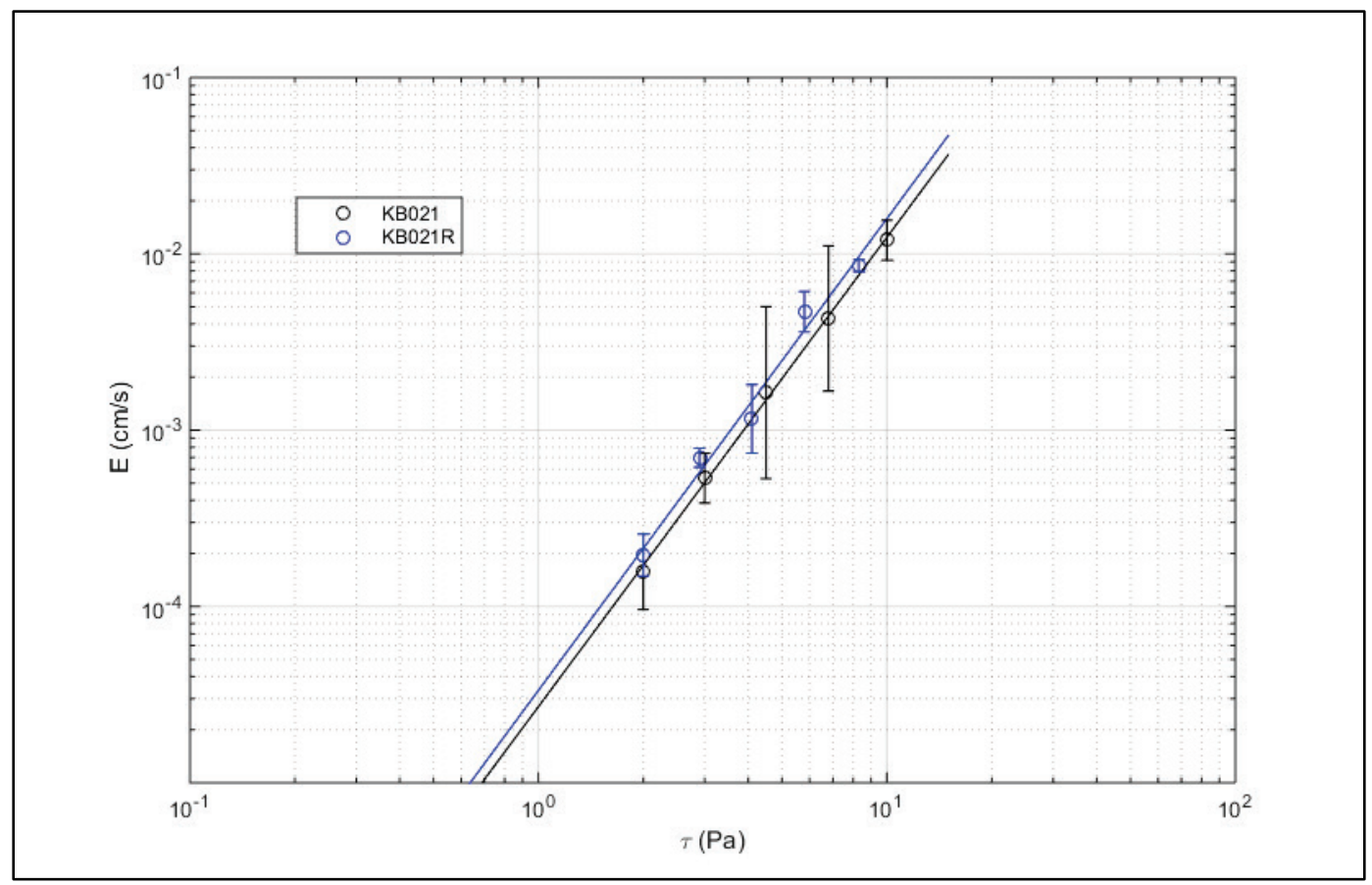


Table 6. Erosion parameters for sand cores.

\begin{tabular}{|c|c|c|c|c|c|}
\hline $\begin{array}{c}\text { Mud } \\
\text { (\% mass) }\end{array}$ & $T_{c}$ & $\begin{array}{c}T_{c} \\
\text { (low) }\end{array}$ & $\begin{array}{c}T_{c} \\
\text { (high) }\end{array}$ & $\boldsymbol{A}$ & $n$ \\
\hline 0 & 0.17 & 0.15 & 0.19 & $1.64 \mathrm{E}-01$ & 4.14 \\
\hline OR & 0.16 & 0.15 & 0.18 & $2.89 \mathrm{E}-02$ & 3.11 \\
\hline
\end{tabular}

Table 7. Erosion parameters for kaolinite mud cores.

\begin{tabular}{|c|c|c|c|c|c|}
\hline $\begin{array}{c}\text { Mud } \\
\text { (\% mass) }\end{array}$ & $T_{c}$ & $\begin{array}{c}T_{c} \\
\text { (low) }\end{array}$ & $\begin{array}{c}T_{c} \\
\text { (high) }\end{array}$ & $A$ & $n$ \\
\hline 1 & 0.17 & 0.14 & 0.18 & $1.12 \mathrm{E}-01$ & 3.93 \\
\hline $1 \mathrm{R}$ & 0.15 & 0.14 & 0.17 & $2.14 \mathrm{E}-02$ & 2.84 \\
\hline 2 & 0.20 & 0.19 & 0.22 & $4.03 \mathrm{E}-02$ & 3.76 \\
\hline 3 & 0.15 & 0.16 & 0.18 & $7.56 \mathrm{E}-03$ & 2.31 \\
\hline $3 \mathrm{R}$ & 0.20 & 0.19 & 0.21 & $6.57 \mathrm{E}-03$ & 2.58 \\
\hline 4 & 0.19 & 0.19 & 0.20 & $8.90 \mathrm{E}-03$ & 2.73 \\
\hline 5 & 0.30 & 0.28 & 0.32 & $4.79 \mathrm{E}-03$ & 3.20 \\
\hline $5 \mathrm{R}$ & 0.28 & 0.26 & 0.29 & $2.48 \mathrm{E}-03$ & 2.50 \\
\hline 8 & 0.29 & 0.27 & 0.32 & $1.37 \mathrm{E}-03$ & 2.13 \\
\hline 11 & 0.34 & 0.31 & 0.36 & $7.83 \mathrm{E}-04$ & 1.92 \\
\hline 15 & 0.47 & 0.44 & 0.51 & $5.05 \mathrm{E}-04$ & 2.17 \\
\hline $15 \mathrm{R}$ & 0.90 & 0.82 & 0.97 & $1.30 \mathrm{E}-04$ & 2.40 \\
\hline 21 & 0.36 & 0.32 & 0.39 & $6.38 \mathrm{E}-04$ & 1.83 \\
\hline $21 \mathrm{R}$ & 0.83 & 0.74 & 0.92 & $1.55 \mathrm{E}-04$ & 2.28 \\
\hline 29 & 0.88 & 0.72 & 1.07 & $1.40 \mathrm{E}-04$ & 2.67 \\
\hline 40 & 0.76 & 0.64 & 0.91 & $1.91 \mathrm{E}-04$ & 2.36 \\
\hline 60 & 0.50 & 0.37 & 0.54 & $4.28 \mathrm{E}-04$ & 2.08 \\
\hline 80 & 0.54 & 0.49 & 0.60 & $4.44 \mathrm{E}-04$ & 2.44 \\
\hline 100 & 0.33 & 0.31 & 0.39 & $1.37 \mathrm{E}-03$ & 2.35 \\
\hline
\end{tabular}


Table 8. Erosion parameters for kaolinite-bentonite mud cores.

\begin{tabular}{|c|c|c|c|c|c|}
\hline $\begin{array}{c}\text { Mud } \\
\text { (\% mass) }\end{array}$ & $T_{c}$ & $\begin{array}{c}T_{c} \\
\text { (low) }\end{array}$ & $\begin{array}{c}T_{c} \\
\text { (high) }\end{array}$ & $\boldsymbol{A}$ & $n$ \\
\hline 1 & 0.17 & 0.18 & 0.21 & $1.81 \mathrm{E}-02$ & 3.13 \\
\hline 2 & 0.19 & 0.18 & 0.20 & $7.90 \mathrm{E}-03$ & 2.62 \\
\hline 3 & 0.29 & 0.27 & 0.31 & $5.49 \mathrm{E}-03$ & 3.20 \\
\hline 4 & 0.30 & 0.29 & 0.31 & $2.38 \mathrm{E}-03$ & 2.64 \\
\hline 5 & 0.49 & 0.47 & 0.52 & $1.21 \mathrm{E}-03$ & 3.52 \\
\hline $5 \mathrm{R}$ & 0.56 & 0.53 & 0.61 & $5.63 \mathrm{E}-04$ & 3.02 \\
\hline 8 & 0.34 & 0.31 & 0.38 & $6.67 \mathrm{E}-04$ & 1.78 \\
\hline $8 \mathrm{R}$ & 0.64 & 0.60 & 0.67 & $3.62 \mathrm{E}-04$ & 2.83 \\
\hline 11 & 0.78 & 0.60 & 0.94 & $1.52 \mathrm{E}-04$ & 1.69 \\
\hline $11 \mathrm{R}$ & 0.90 & 0.82 & 0.97 & $1.30 \mathrm{E}-04$ & 2.40 \\
\hline 15 & 1.30 & 0.98 & 1.73 & $5.68 \mathrm{E}-05$ & 2.16 \\
\hline 21 & 1.63 & 1.29 & 2.07 & $2.70 \mathrm{E}-05$ & 2.66 \\
\hline $21 \mathrm{R}$ & 1.51 & 1.32 & 1.71 & $3.34 \mathrm{E}-05$ & 2.68 \\
\hline 29 & 1.80 & 1.52 & 2.12 & $1.76 \mathrm{E}-05$ & 2.96 \\
\hline 40 & 1.56 & 1.20 & 2.01 & $2.34 \mathrm{E}-05$ & 3.27 \\
\hline 60 & 1.52 & 1.28 & 1.83 & $2.25 \mathrm{E}-05$ & 3.54 \\
\hline 80 & 1.17 & 0.98 & 1.39 & $5.76 \mathrm{E}-05$ & 3.57 \\
\hline $80 \mathrm{R}$ & 1.13 & 1.00 & 1.27 & $6.13 \mathrm{E}-05$ & 4.12 \\
\hline 100 & 1.40 & 1.14 & 1.72 & $2.80 \mathrm{E}-05$ & 3.75 \\
\hline
\end{tabular}


Table 9. Erosion parameters for MR mud cores.

\begin{tabular}{|c|c|c|c|c|c|}
\hline $\begin{array}{c}\text { Mud } \\
\text { (\% mass) }\end{array}$ & $T_{c}$ & $\begin{array}{c}T_{c} \\
\text { (low) }\end{array}$ & $\begin{array}{c}T_{c} \\
\text { (high) }\end{array}$ & $A$ & $n$ \\
\hline 1 & 0.18 & 0.17 & 0.20 & $1.55 \mathrm{E}-02$ & 3.00 \\
\hline 2 & 0.22 & 0.21 & 0.24 & $8.58 \mathrm{E}-03$ & 2.96 \\
\hline 3 & 0.22 & 0.21 & 0.23 & $6.49 \mathrm{E}-03$ & 2.78 \\
\hline $3 \mathrm{R}$ & 0.25 & 0.23 & 0.26 & $4.17 \mathrm{E}-03$ & 2.67 \\
\hline 4 & 0.26 & 0.25 & 0.28 & $5.75 \mathrm{E}-03$ & 3.03 \\
\hline 5 & 0.25 & 0.23 & 0.27 & $4.73 \mathrm{E}-03$ & 2.80 \\
\hline 8 & 0.54 & 0.49 & 0.58 & $6.52 \mathrm{E}-04$ & 3.00 \\
\hline 11 & 0.31 & 0.23 & 0.37 & $9.54 \mathrm{E}-04$ & 1.91 \\
\hline $11 \mathrm{R}$ & 0.77 & 0.68 & 0.86 & $1.93 \mathrm{E}-04$ & 2.56 \\
\hline 15 & 0.55 & 0.51 & 0.58 & $4.27 \mathrm{E}-04$ & 2.41 \\
\hline 21 & 1.05 & 0.84 & 1.31 & $9.03 \mathrm{E}-05$ & 2.14 \\
\hline $21 \mathrm{R}$ & 1.47 & 1.23 & 1.76 & $3.45 \mathrm{E}-05$ & 2.75 \\
\hline 29 & 0.99 & 0.85 & 1.14 & $1.01 \mathrm{E}-04$ & 2.31 \\
\hline $29 \mathrm{R}$ & 1.43 & 1.05 & 1.93 & $3.73 \mathrm{E}-05$ & 2.77 \\
\hline 40 & 2.02 & 1.78 & 2.29 & $9.58 \mathrm{E}-06$ & 3.34 \\
\hline 60 & 1.98 & 1.73 & 2.26 & $1.05 \mathrm{E}-05$ & 3.31 \\
\hline 80 & 1.84 & 1.46 & 2.51 & $1.50 \mathrm{E}-05$ & 3.12 \\
\hline 100 & 1.94 & 1.60 & 2.36 & $5.44 \mathrm{E}-06$ & 4.40 \\
\hline $100 \mathrm{R}$ & 1.36 & 1.18 & 1.56 & $3.55 \mathrm{E}-05$ & 3.37 \\
\hline
\end{tabular}


Data from the erosion testing revealed that the $\tau_{c}$ of the sand bed could be expected to range between 0.15 to $0.19 \mathrm{~Pa}$. Using the $\mathrm{D}_{50}(159 \mu \mathrm{m})$ of the test sand, the Shields curve (Shields 1936) estimates a $\tau_{c}$ of $\sim 0.14 \mathrm{~Pa}$, a value in close agreement with the ranges observed in this test. In general, it was observed that $\tau_{c}$ values tended to increase slightly as small amounts of mud were added to the sand bed. A two- to threefold increase in critical shear stress was observed by $8 \%$ mud content with $\tau_{c}$ values ranging from 0.27 to $0.32 \mathrm{~Pa}, 0.3$ to $0.67 \mathrm{~Pa}$, and 0.49 to $0.58 \mathrm{~Pa}$ for the kaolin, kaolinbentonite, and MR mud mixtures, respectively. Some previous studies (Torfs et al. 2000; Barry et al. 2006) observed a reduction of critical shear stress associated with the addition of small amounts of mud to sand and attributed these reductions to a lubrication effect on the sand grains. Note that such a trend was not observed in any of the mud mixtures tested in this study.

The results from the erosion experiments also demonstrated that $\tau_{c}$ values tended to approach a maximum when mud content reached $30 \%-40 \%$ by mass (Figure 12). In both the kaolinite-bentonite and MR mud mixtures, this maximum value was approximately an order of magnitude greater than the $\tau_{c}$ of sand alone (1.8 $\mathrm{Pa}$ and $2.02 \mathrm{~Pa}$, respectively) and remained fairly constant as mud content increased to $100 \%$. By comparison, the kaolinite mud cores showed an approximate fivefold increase in $\tau_{c}(0.88$ $\mathrm{Pa}$ ). However, unlike the kaolinite-bentonite and MR muds, the kaolinite cores showed a decrease in $\tau_{c}$ after the maximum value was reached at $30 \%$ mud content (Figure 12).

These differences may be largely due to the mineralogical composition and properties of the muds. Swelling clays were present in both the kaolinitebentonite and MR mud mixtures. These mixtures were found to have higher PI values than the kaolinite (a non-swelling clay) mixtures at equal mud contents. As indicated in other research (Jacobs et al. 2011), higher PI values may suggest a more cohesive and erosion resistant sediment matrix. The greater cohesion due to the presence of the swelling clays would not only offer an explanation for the larger observed $\tau_{c}$ values but could also offer insight into the drop in $\tau_{c}$ in the non-swelling kaolin mixtures after a maximum was reached. As pore space within the sand bed was filled with mud and bridged the gaps in intergranular contact, the mud-sand mixtures may have reached a maximum $\tau_{c}$ that relied on both intergranular interaction and the cohesiveness of the mud. However, as the mud content increased, the $\tau_{c}$ of the sediment matrix may have become less dependent 
upon intergranular interaction and more dependent on the cohesiveness of the mud. The more cohesive swelling clays with higher PI values may have allowed for the sediment matrix to maintain their same level of critical shear stress. Conversely, the less cohesive kaolin mud may have depended on intergranular interaction to reach the maximum $\tau_{c}$. Therefore, as mud content increased beyond 30\% $-40 \%$ and reduced the intergranular contact the $\tau_{c}$ of the sediment matrix began to fall, as seen in Figure 12. Similar observations relating erosion resistance and $\tau_{c}$ of sand-mud mixtures to the fraction of the particle matrix filled with mud have been reported in numerous other studies (e.g., Mitchener and Torfs 1996; van Ledden et al. 2004; Jacobs et al. 2011; Dickhudt et al. 2011; Wu et al. 2018).

Figure 12. Critical shear stress ( $T_{c}$ ) plotted against mud content. Blue, red, and black lines indicate cores made with kaolinite (K), kaolinite-bentonite (KB), and MR muds,

respectively. Dashed lines represent the 95\% confidence interval of $T_{c}$. The $T_{c}$ obtained from replicate cores are plotted with triangles with error bars indicating the $95 \%$ confidence.

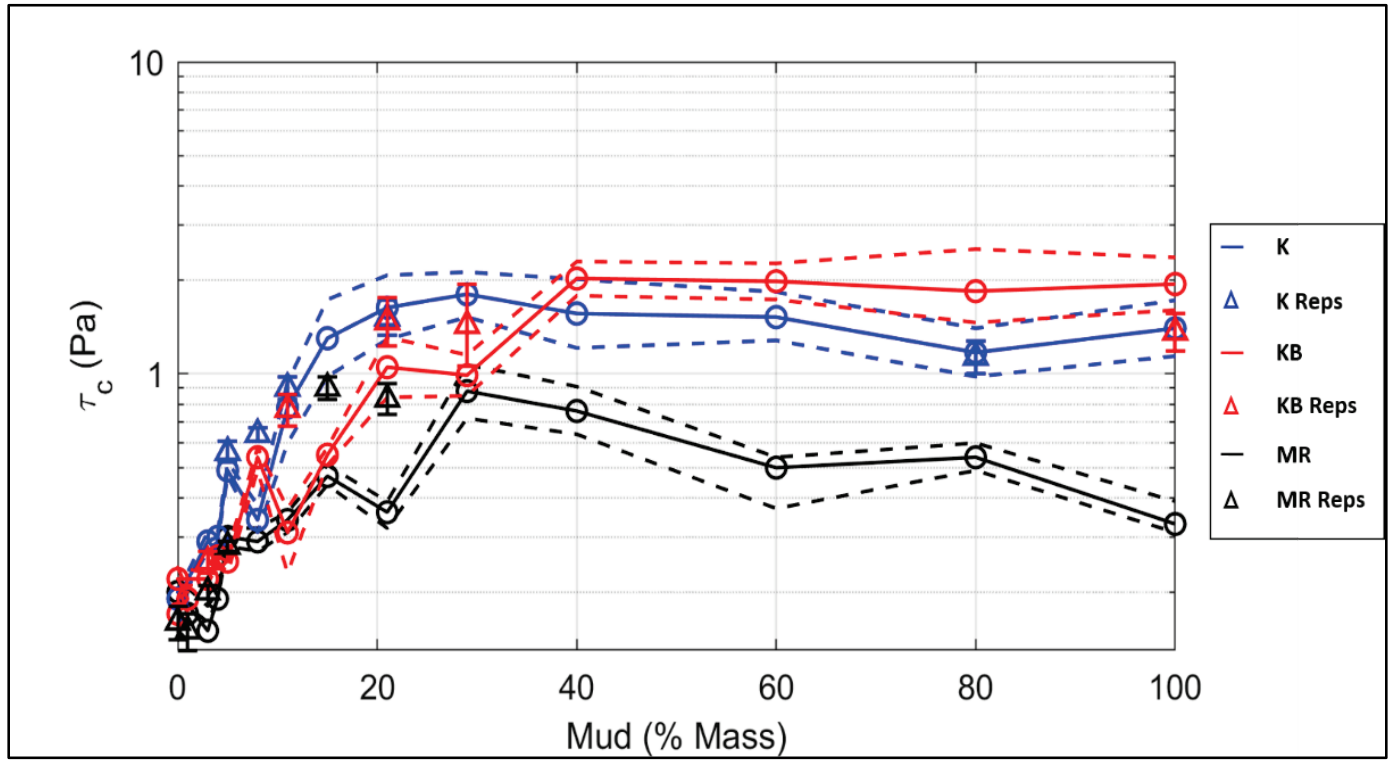

Cohesion also appeared to impact the variability in the erosion data collected. As seen in Figure 12, the variability observed in $\tau_{c}$ was often lower in sediment mixtures with mud contents $\leq 5 \%$. Observations made during erosion testing tended to describe discrete particle erosion, typical of sandy, non-cohesive sediment. However, as mud content and cohesiveness of the sediment increased, the variability in the calculated $\tau_{c}$ often became larger. It was also observed that the dominant mechanism of erosion transitioned from discrete particles to aggregates of varying size. This resulted in increased variability in the bed roughness. Increased bed 
roughness would often produce localized scour and thus impact the erosion rates being calculated. As multiple erosion cycles were made for each core, results from each cycle and shear stress would often be dependent upon the bed roughness at the start of each cycle. Non-cohesive beds that displayed uniform bed roughness and erosion in the form of discrete particles produced more consistent results for each cycle. The more cohesive beds that displayed changes in bed roughness produced results that were more variable.

\subsubsection{Sediment erosion rates}

While results showed slight increases in $\tau_{c}$ for mixtures with small amounts of mud ( $1 \%-5 \%)$, a larger impact was observed in the erosion rates of these sediments. The plots in Figures 13-15 show the change in erosion rate at various shear stresses as mud content increased in the cores. Solid lines indicate the resulting erosion rate from utilizing the erosion parameters obtained from the best fit line through the data presented in Appendix C. The dashed lines indicate the 95\% confidence interval of those erosion rates. When available, mean erosion rate data were plotted (circles) for each shear stress. Replicate data were plotted as triangles with error bars indicating the 95\% confidence interval of the mean erosion rate. For all three varieties of mud, erosion rates reduced rapidly with the addition of small amounts of mud. As mud concentrations approached $5 \%$, erosion rates diminished on the scale of 1 to 2 orders of magnitude for all three mud types tested in this study (Figure 13-15). Mirroring the trends in critical shear stress (Figure 12), erosion rates were also minimized when mud content approaches $30 \%-40 \%$ for all mud types. This information may prove useful for engineering purposes.

Recent changes in policy (via the Federal Standard; 33 CFR 335) have sought to increase the beneficial use of dredged materials and reduce disposal in Confined Disposal Facilities or Offshore Dredge Material Disposal Sites (ODMDSs) (EPA 2007). Therefore, the level of erosion rate reduction potentially realized using limited amounts of mud mixed with sand could have meaningful implications for planning and design of civil and environmental engineering projects where sediment stabilization is desired. Some examples include environmental capping of contaminated sediments, wetland and habitat restoration, and shoreline construction. The use of locally sourced sediment with adequate sandmud content to curtail erosion may provide a cost-effective solution for these types of projects. Alternatively, dredged sediments may also be 
engineered for specific projects using amendments such as clays or claypolymer composites (e.g., AquaBlok ${ }^{\mathrm{TM}}$ ) to enhance erosion resistance. Therefore, the results and insights gained from quantifying and predicting erosion rates will improve forecasts of project performance and life-cycle analysis, in addition to better predicting the erosion, transport, and fate of sediment mixtures.

Figure 13. Erosion rate plotted against kaolinite mud content. The colored solid lines depict the calculated erosion rates at various shear stresses, with dashed lines indicating 95\% confidence. Mean erosion rate data are plotted with circles. Triangles represent replicate mean erosion rates with error bars indicating the $95 \%$ confidence.

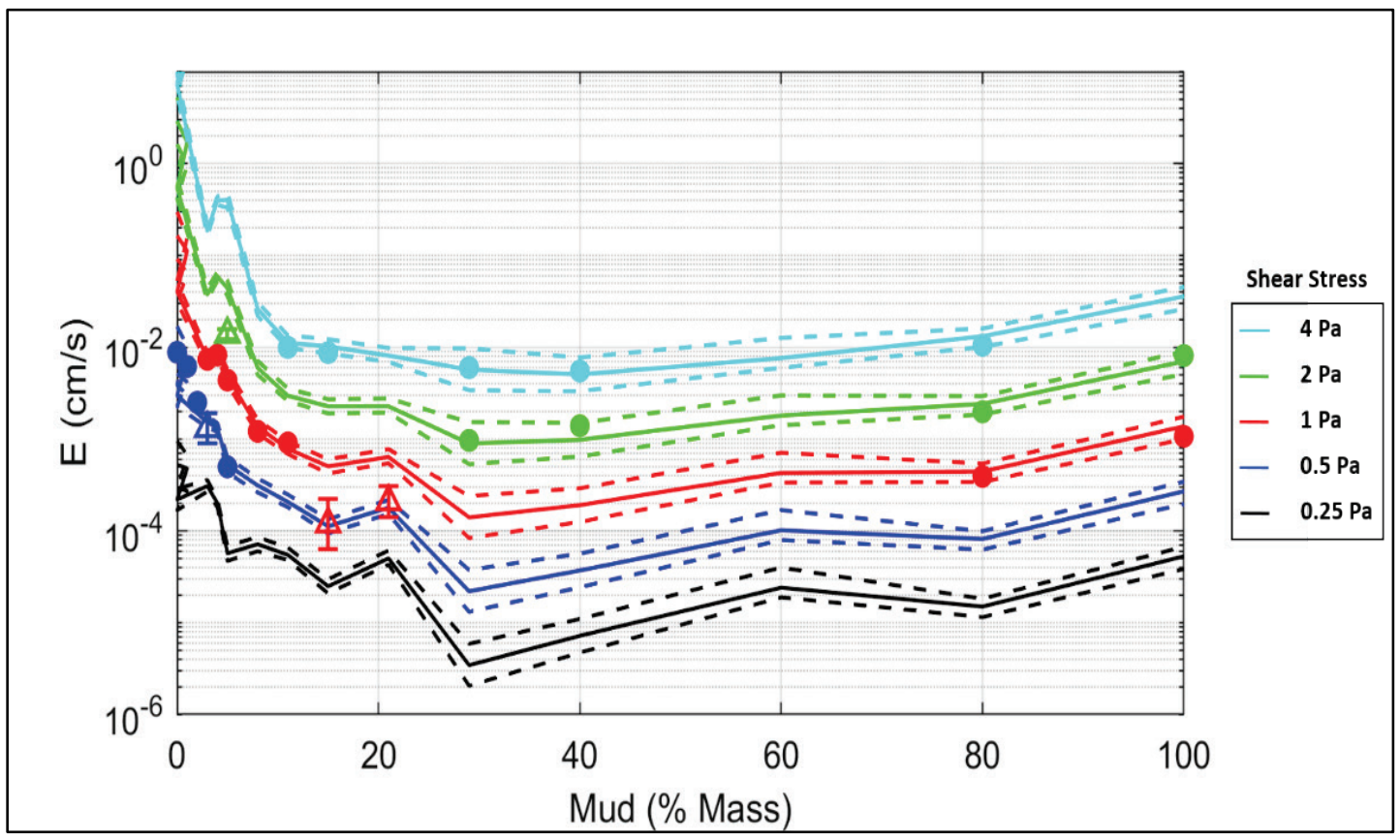


Figure 14. Erosion rate plotted against kaolinite-bentonite mud content. The colored solid lines depict the calculated erosion rates at various shear stresses, with dashed lines indicating $95 \%$ confidence. Mean erosion rate data are plotted with circles. Triangles represent replicate mean erosion rates with error bars indicating the $95 \%$ confidence.

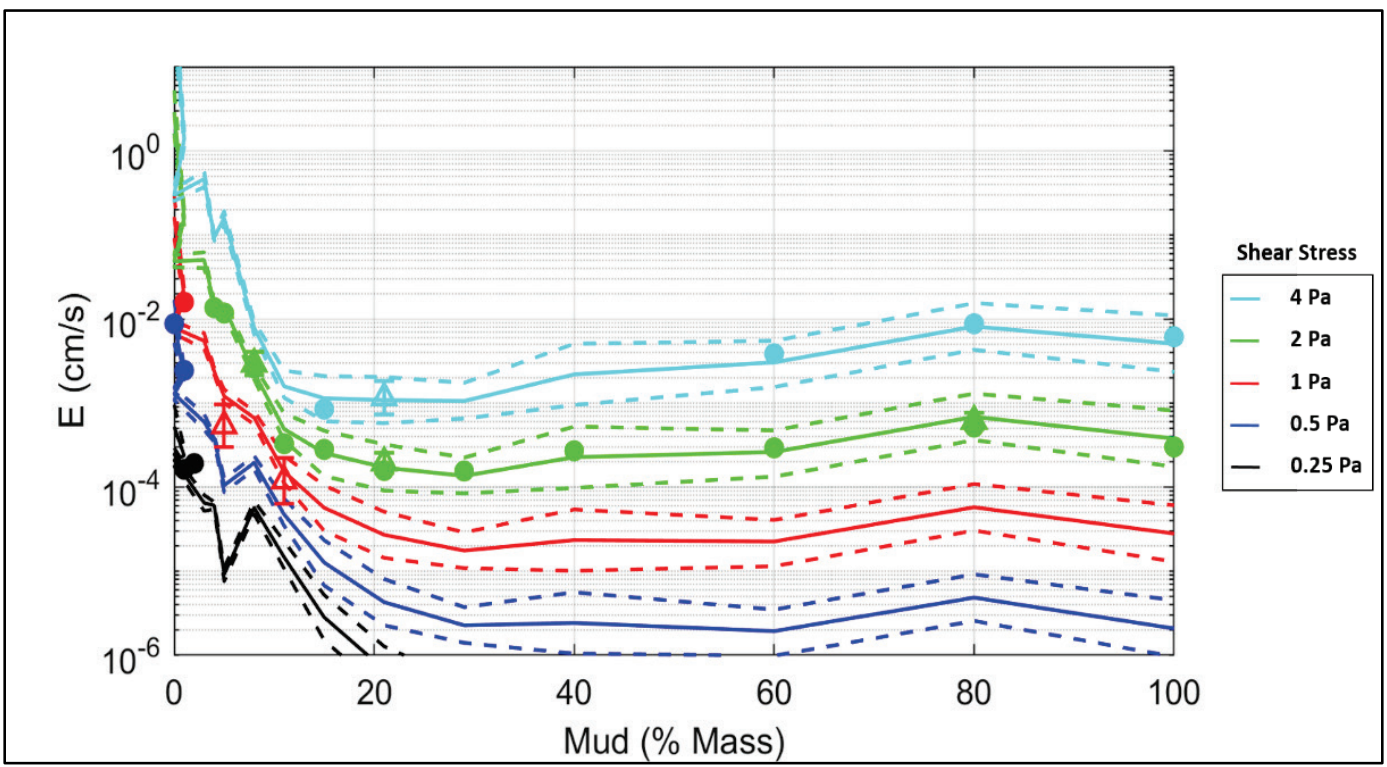

Figure 15. Erosion rate plotted against MR mud content. The colored solid lines depict the calculated erosion rates at various shear stresses, with dashed lines indicating 95\% confidence. Mean erosion rate data are plotted with circles. Triangles represent replicate mean erosion rates with error bars indicating the $95 \%$ confidence.

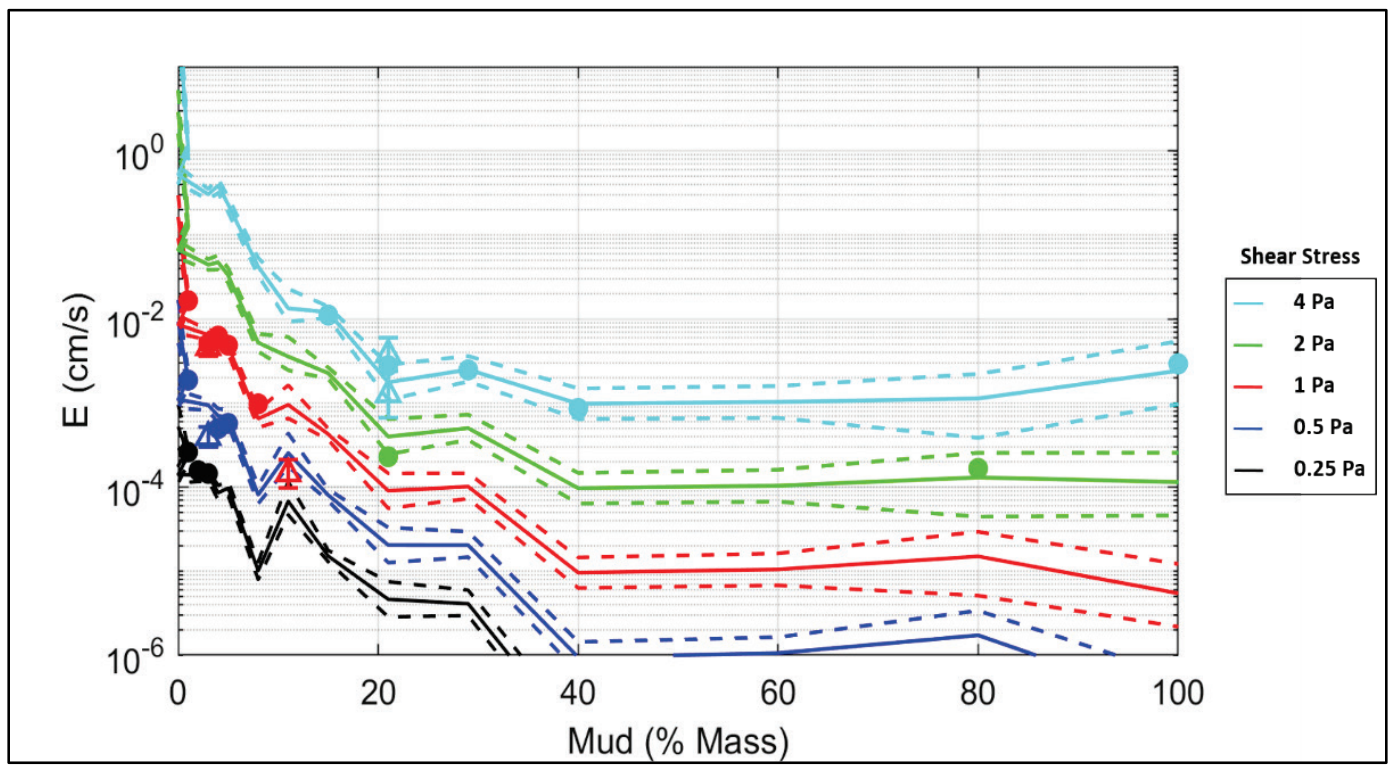




\section{Summary and Conclusions}

To gain insight into the relationship between mud content, critical shear stress, and erosion rate, erosion experiments were conducted on sandmud mixtures with varying mud content utilizing three different muds: (1) a non-swelling clay (kaolinite), (2) an 8o/20 mixture of kaolinite with a swelling clay (sodium bentonite), (3) a natural mud containing swelling and non-swelling clays from the MR. Mixed sediments were prepared in the laboratory by mixing varying fractions of mud with fine quartz sand and placing the material in $10 \mathrm{~cm}$ diameter cores.

Erosion experiments were conducted with Sedflume (McNeil et al. 1996). Results of the testing performed on the non-cohesive (100\% sand) cores yielded $\tau_{c}$ values that agreed closely with values predicted by the shields curve. As small amounts of mud were introduced to the sand, $\tau_{c}$ values increased. This trend was constant for all three mud varieties. Typically, a two- to threefold increase in critical shear stress was observed when mud content reached 8\%. A maximum critical shear stress was obtained when mud content reached $30 \%-40 \%$. In instances where the mud contained swelling clays (bentonite-kaolinite and MR), the maximum $\tau_{c}$ was approximately an order of magnitude greater than that of fine sand. By comparison, maximum $\tau_{c}$ values in the kaolinite clay were approximately five times greater than $\tau_{c}$ of fine sand.

Atterberg limit tests showed that the kaolinite-bentonite and MR mud mixtures had higher PI values than kaolinite mixtures with equivalent mud content. The direct correlation observed between PI and $\tau_{c}$ supports previous research, indicating that PI values can be used as an indication of the cohesiveness of a material (Jacobs et al. 2011). Data in these tests also showed that as cohesion of the test material increased, variability in the erosion data also increased. This increase in variability was attributed to bed aggregate erosion that was observed in more cohesive sediments. This mechanism of erosion resulted in variable bed roughness throughout a test sequence. As bed roughness increased, local scour was often observed, which impacted erosion rates.

While $\tau_{c}$ was shown to increase slightly as small amounts of mud (1\% $5 \%$ ) were added to sand, a larger impact was observed in the erosion rates of these mixtures. Compared to the erosion rate of fine sand, a ten- to one hundredfold fold decrease in erosion rate was observed as mud content 
approached 5\%, and minimized as mud content approached $30 \%-40 \%$, for each of the mud varieties tested in this study. These data suggest that dredged sand-mud mixtures may be a viable, cost-effective solution for use to erosion abatement and capping projects in ports, harbors, and waterways across the country. 


\section{Future Work}

While three varieties of clay materials were evaluated in this study, the sand matrix with which those clays were mixed was a constant, well-sorted, fine sand. Previous works evaluating the impact of clay content on the erodibility of sediment mixtures (e.g., Barry et al. 2006) utilized coarser grained sands. To allow for a more direct comparison of results with previous work such as Barry et al. (2006) and to assess sediment mixtures that may be more representative of materials commonly observed in natural systems, future experiments should utilize a more poorly sorted (well-graded) sand that would include coarser grained material. Additional research should focus on the swelling properties of various clay types at the sediment-water interface and its effect on erosion resistance.

Additional research is being conducted in which the results of the present work could be relevant, which include the production and durability of mud aggregates*, the erosion resistance of the AquaBlok commercial product $^{\dagger}$, and the separation and fate of fine sediment during the dredging and placement process (Smith et al. 2019).

First, observations made during erosion testing suggest that as clay content increased, the occurrence of aggregate erosion became more prevalent. These eroded aggregates were noted to range in size and frequency throughout the course of erosion experiments. Ongoing research is being performed that will evaluate the size, density, and settling velocity of the aggregates that were eroded during testing. This research hopes to provide insight into the clay content at which these aggregates form and if their size and concentration change with varying clay content and shear stress. This information can then be utilized in conjunction with the erosion rate data to help characterize how the mechanical process of erosion may vary with clay content.

\footnotetext{
${ }^{*}$ Perkey, D. W., K. A. Fall, and S. J. Smith. In review. Physical Factors That Influence Muddy Bed Aggregate Production, Size, and Durability. ERDC Technical Report. Vicksburg, MS: U.S. Army Engineer Research and Development Center.

† Priestas, A. M., C. F. Mackenzie, J. H. Hull, R. Ellis, and J. Z. Gailani. In review. Laboratory Evaluation of Aquablok ${ }^{\circledR}$ Erosion Resistance: Implications for Geotechnical Applications. ERDC Special Report. Vicksburg, MS: U.S. Army Engineer Research and Development Center.
} 
Erosion testing of AquaBlok is being performed to assess its performance under non-compacted and compacted states. These results of these tests can inform how AquaBlok may perform as an amendment to dredged material.

Finally, sediments dredged using hopper dredges with induced overflow tend to coarsen their load. This research attempts to predict the subsequent change in the fine sediment content of the hopper load. The results of the present study can be used to inform sediment transport models to determine the ultimate fate of these materials eroded from ODMDSs or other placement sites. 


\section{References}

ASTM D2216-19. 2019. Standard Test Methods for Laboratory Determination of Water (Moisture) Content of Soil and Rock by Mass. West Conshohocken, PA: ASTM International.

ASTM D4318-05, 2015. Standard Test Methods for Liquid Limit, Plastic Limit and Plasticity Index of Soils. West Conshohocken, PA: ASTM International.

Barry, K. M., R. J. Thieke, and A. J. Mehta. 2006. "Quasi-Hydrodynamic Lubrication Effect of Clay Particles on Sand Grain Erosion.” Estuarine, Coastal and Shelf Science 67(1): 161-169.

Buurman, P., T. Pape, J. A. Reijneveld, F. De Jong, and E. Van Gelder. 2001. "LaserDiffraction and Pipette-Method Grain Sizing of Dutch Sediments: Correlations for Fine Fractions of Marine, Fluvial, and Loess Samples." Geologie en Mijnbouw 80(2): $49-58$.

Dickhudt, Patrick J., Carl T. Friedrichs, and Lawrence P. Sanford. 2011. "Mud Matrix Solids Fraction and Bed Erodibility in the York River Estuary, USA, and Other Muddy Environments." Continental Shelf Research 31(10): S3-S13.

EPA/USACE (Environmental Protection Agency, U.S. Army Corps of Engineers). 2007. The Role of the Federal Standard in the Beneficial Use of Dredged Material from U.S. Army Corps of Engineers New and Maintenance Navigation Projects. EPA842-B-07-002. Washington, DC: U.S. Environmental Protection Agency/U.S. Army Corps of Engineers.

Eshel, G., G. J. Levy, U. Mingelgrin, and M. J. Singer. 2004. "Critical Evaluation of the Use of Laser Diffraction for Particle-Size Distribution Analysis.” Soil Science Society of America Journal 68(3): 736-743.

Gailani, J. Z., L. Jin, J. McNeil, and W. Lick. 2001. Effects of Bentonite Clay on Sediment Erosion Rates. ERDC-TN-DOER-N9. Vicksburg MS: U.S. Army Engineer Research and Development Center.

Garcia, Marcelo, ed. 2008. "Sedimentation Engineering: Processes, Measurements, Modeling, and Practice." American Society of Civil Engineers.

Gaudette, H. E., J. L. Eades, and R. E. Grim. 1966. "The Nature of Illite.” Clays and Clay Minerals 13: 33-48

Goossens, Dirk. 2008. “Techniques to Measure Grain-Size Distributions of Loamy Sediments: A Comparative Study of Ten Instruments for Wet Analysis." Sedimentology 55(1): 65-96.

Graf, Walter Hans. 1984. Hydraulics of Sediment Transport. Water Resources Publication. Littleton, CO.

Jackson, M. L., and P. Barak. 2005. Soil Chemical Analysis: Advanced Course. UWMadison Libraries Parallel Press.

Jacobs, W., P. Le Hir, W. Van Kesteren, and P. Cann. 2011. "Erosion Threshold of SandMud Mixtures." Cont. Shelf Res. 31(10): (S14-S25).

doi:10.1016/j.csr.2010.05.012 
Jepsen, R., J. Roberts, and W. Lick. 1997. "Effects of Bulk Density on Sediment Erosion Rates.” In The Interactions between Sediments and Water. The Netherlands: Springer.

Jepsen, R., J. Roberts, and J. Gailani. 2010. "Effects of Bed Load and Suspended Load on Separation of Sands and Fines in Mixed Sediment." J. Waterw. Port, Coast. Ocean Eng. 136(6): 319-326. https://doi.org/10.1061/(ASCE)WW.1943-5460.0000054

Konert, M., and J. E. F. Vandenberghe. 1997. "Comparison of Laser Grain Size Analysis with Pipette and Sieve Analysis: A Solution for the Underestimation of the Clay Fraction." Sedimentology 44(3): 523-535.

Lemos, L. J. L., and P. R. Vaughan. 2000. “Clay-Interface Shear Resistance.” Géotechnique 50(1): 55-64.

McNeil, Joe, Catherine Taylor, and Wilbert Lick. 1996. "Measurements of Erosion of Undisturbed Bottom Sediments with Depth." Journal of Hydraulic Engineering 122(6): 316-324.

Mehta, Ashish J. 2013. An Introduction to Hydraulics of Fine Sediment Transport. Vol. 38. World Scientific Publishing Company.

Mehta, A. J., E. J. Hayter, W. R. Parker, R. B. Krone, and A. M. Teeter. 1989. "Cohesive Sediment Transport. I: Process Description.” J. Hydraulic Eng. 115(8): 1076-1093.

Mehta, Ashish J., and William H. McAnally. 2008. "Fine Grained Sediment Transport." In Sedimentation Engineering: Processes, Measurements, Modeling, and Practice. Reston, VA: American Society of Civil Engineers.

Mitchener, H., and H. Torfs. 1996. "Erosion of Mud/Sand Mixtures." Coast. Eng. 29: 125 .

Moore, D. M., and R. C. Reynolds. 1989. X-Ray Diffraction and the Identification and Analysis of Clay Minerals. Oxford University Press.

Sasanian, S., and T. A. Newson. 2014. "Basic Parameters Governing the Behaviour of Cement-Treated Clays. Soils and Foundations 54(2): 209-224.

Seed, H. B., R. J. Woodward, and R. Lundgren. 1964. "Clay Mineralogical Aspects of the Atterberg Limits.” Journal of the Soil Mechanics and Foundations Division 90(4): 107-134.

Shields, A. 1936. Application of Similarity Principles and Turbulence Research to BedLoad Movement. Soil Conservation Service.

Smith, S. J., Anthony M. Priestas, Duncan B. Bryant, Katherine E. Brutsché, and Kelsey A. Fall. 2019. Sediment Sorting by Hopper Dredging and Pumpout Operations. Sterling (VA): U.S. Department of the Interior, Bureau of Ocean Energy Management. OCS Study BOEM 2019-010.

Torfs, H., J. Jiang, and A. J. Mehta. 2000. "Assessment of the Erodibility of Fine/Coarse Sediment Mixtures.” In Proceedings in Marine Science, vol. 3. Elsevier.

Van Ledden, M., W. G. M. Van Kesteren, and J. C. Winterwerp. 2004. "A Conceptual Framework for the Erosion Behaviour of Sand-Mud Mixtures." Cont. Shelf Res. 24(1): 1-11. https://doi.org/10.1016/j.csr.2003.09.002 
White, W. A. 1949. “Atterberg Plastic Limits of Clay Minerals.” Report of Investigations No. 144.

Winterwerp, J. C., and W. G. M. Van Kesteren. 2004. Introduction to the Physics of Cohesive Sediment in the Marine Environment. Amsterdam, Netherlands: Elsevier.

Wu, Weiming, Chamil Perera, Jarrell Smith, and Alejandro Sanchez. 2018. "Critical Shear Stress for Erosion of Sand and Mud Mixtures." Journal of Hydraulic Research 56(1): 96-110. 


\section{Appendix A: Grain Size Data}

Table A-1. Sand laser diffraction data.

\begin{tabular}{|c|c|c|c|c|c|c|}
\hline Sample & \% Sand & \% Silt & \% Clay & $\begin{array}{c}\mathrm{D}_{10} \\
(\mu \mathrm{m})\end{array}$ & $\begin{array}{c}\mathrm{D}_{50} \\
(\mu \mathrm{m})\end{array}$ & $\begin{array}{c}\mathrm{D}_{90} \\
(\mu \mathrm{m})\end{array}$ \\
\hline Sand & 100.0 & 0.0 & 0 & 100.3 & 160.3 & 256.8 \\
\hline SandR & 99.9 & 0.1 & 0 & 96.6 & 157.5 & 258.2 \\
\hline
\end{tabular}

Figure A-1. Cumulative grain size distributions for sand.

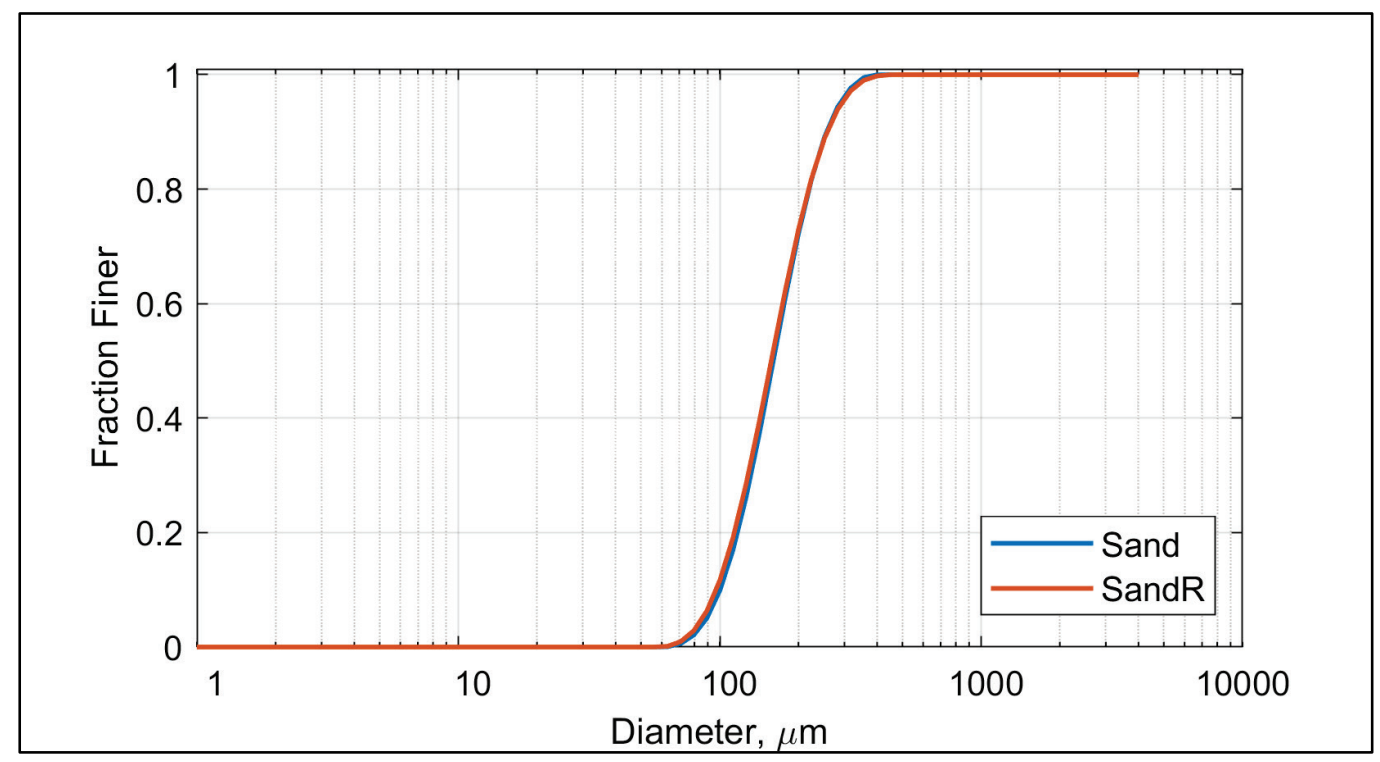

Figure A-2. Grain size distributions for sand.

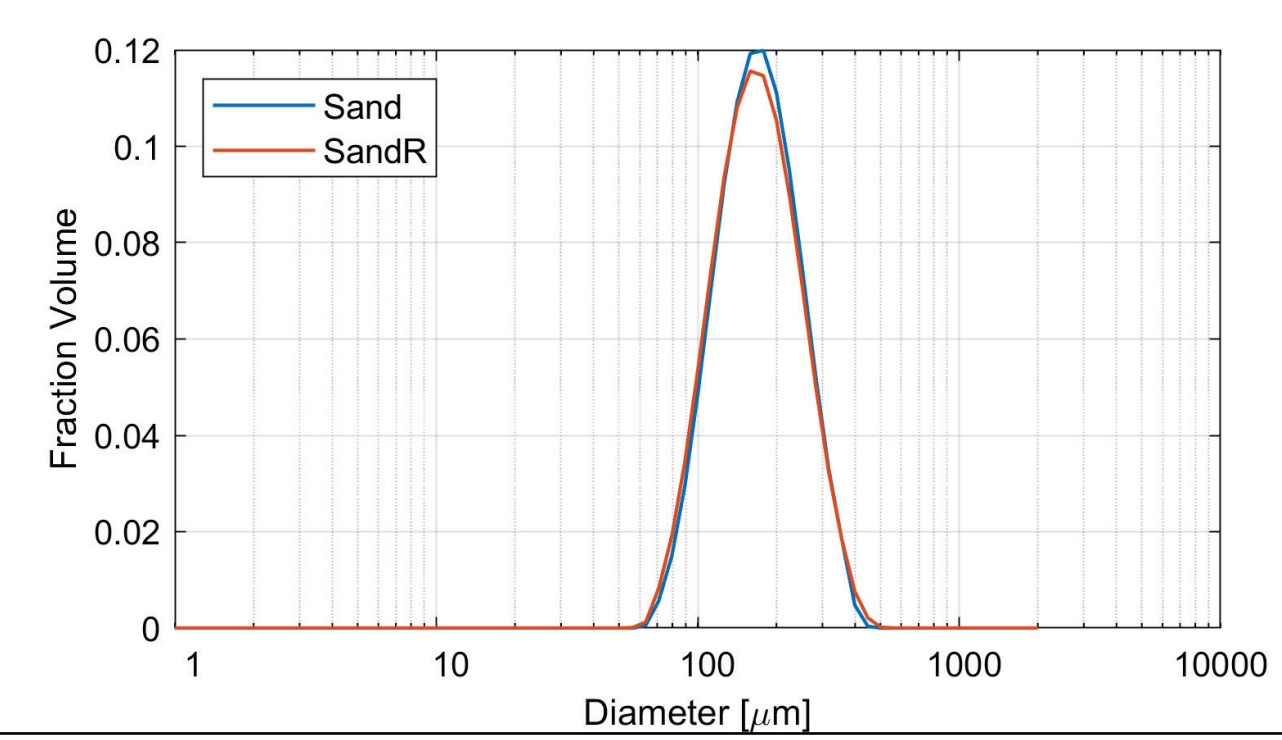


Table A-2. Kaolinite mud laser diffraction data.

\begin{tabular}{|c|c|c|c|c|c|c|}
\hline Sample & $\%$ Sand & $\%$ Silt & $\%$ Clay & $\begin{array}{c}\mathrm{D}_{10} \\
(\mu \mathrm{m})\end{array}$ & $\begin{array}{c}\mathrm{D}_{50} \\
(\mu \mathrm{m})\end{array}$ & $\begin{array}{c}\mathrm{D}_{90} \\
(\mu \mathrm{m})\end{array}$ \\
\hline $\mathrm{K} 001$ & 99.9 & 0.1 & 0 & 98.5 & 160.0 & 259.4 \\
\hline $\mathrm{K} 001 \mathrm{R}$ & 99.9 & 0.1 & 0 & 99.8 & 162.5 & 264.3 \\
\hline $\mathrm{K} 002$ & 99.6 & 0.2 & 0.2 & 95.5 & 160.5 & 268.8 \\
\hline $\mathrm{K} 003$ & 98.1 & 1.1 & 0.8 & 95.3 & 158.3 & 258.5 \\
\hline $\mathrm{K} 003 \mathrm{R}$ & 98.3 & 0.8 & 0.9 & 100.3 & 165.5 & 269.4 \\
\hline $\mathrm{K} 004$ & 96.2 & 2.8 & 1.1 & 93.6 & 157.1 & 250.0 \\
\hline $\mathrm{K} 005$ & 94.6 & 3.8 & 1.6 & 90.4 & 156.4 & 249.9 \\
\hline $\mathrm{K} 005 \mathrm{R}$ & 94.8 & 3.5 & 1.7 & 92.2 & 161.4 & 261.5 \\
\hline $\mathrm{K} 008$ & 92.3 & 5.3 & 2.5 & 82.0 & 154.2 & 248.6 \\
\hline $\mathrm{K} 011$ & 92.2 & 5.3 & 2.5 & 80.8 & 153.0 & 248.0 \\
\hline $\mathrm{K} 015$ & 89.5 & 7.2 & 3.3 & 23.1 & 150.0 & 253.0 \\
\hline $\mathrm{K} 015 \mathrm{R}$ & 81.5 & 12.8 & 5.7 & 7.6 & 138.9 & 248.0 \\
\hline $\mathrm{K} 021$ & 82.3 & 12.2 & 5.4 & 8.2 & 138.0 & 242.5 \\
\hline $\mathrm{K} 021 \mathrm{R}$ & 79.0 & 14.4 & 6.5 & 6.3 & 134.5 & 241.8 \\
\hline $\mathrm{K} 029$ & 79.7 & 14.6 & 5.8 & 7.1 & 138.9 & 248.0 \\
\hline $\mathrm{K} 040$ & 65.7 & 24.6 & 9.7 & 4.1 & 111.4 & 242.0 \\
\hline $\mathrm{K} 060$ & 53.0 & 33.8 & 13.2 & 3.3 & 78.2 & 229.0 \\
\hline $\mathrm{K} 080$ & 40.1 & 43.2 & 16.7 & 2.9 & 20.0 & 232.1 \\
\hline $\mathrm{K} 100$ & 5.6 & 72.7 & 21.7 & 2.5 & 10.2 & 46.1 \\
\hline
\end{tabular}


Figure A-3. Cumulative grain size distributions for kaolinite cores with mud contents ranging from $1 \%$ to $5 \%$.

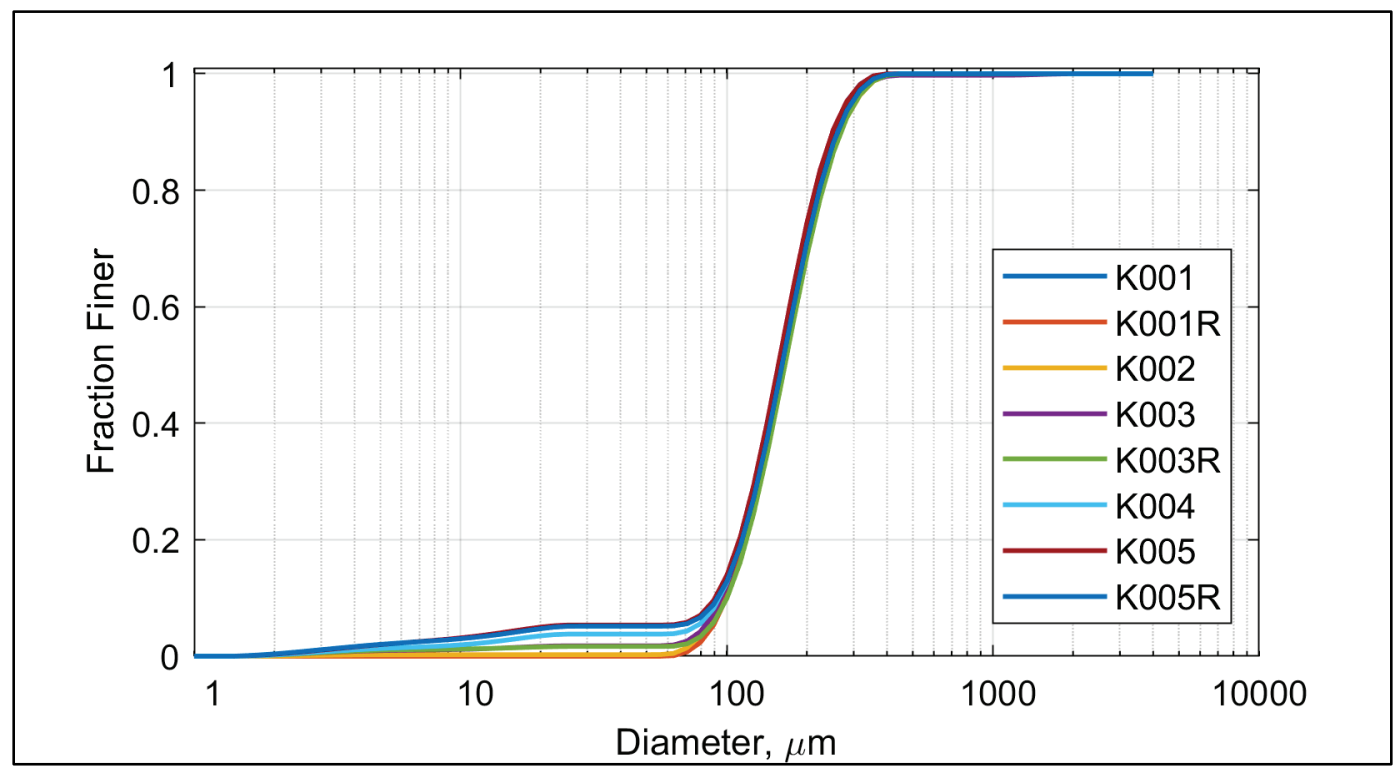

Figure A-4. Cumulative grain size distributions for kaolinite cores with mud contents ranging from $8 \%$ to $21 \%$.

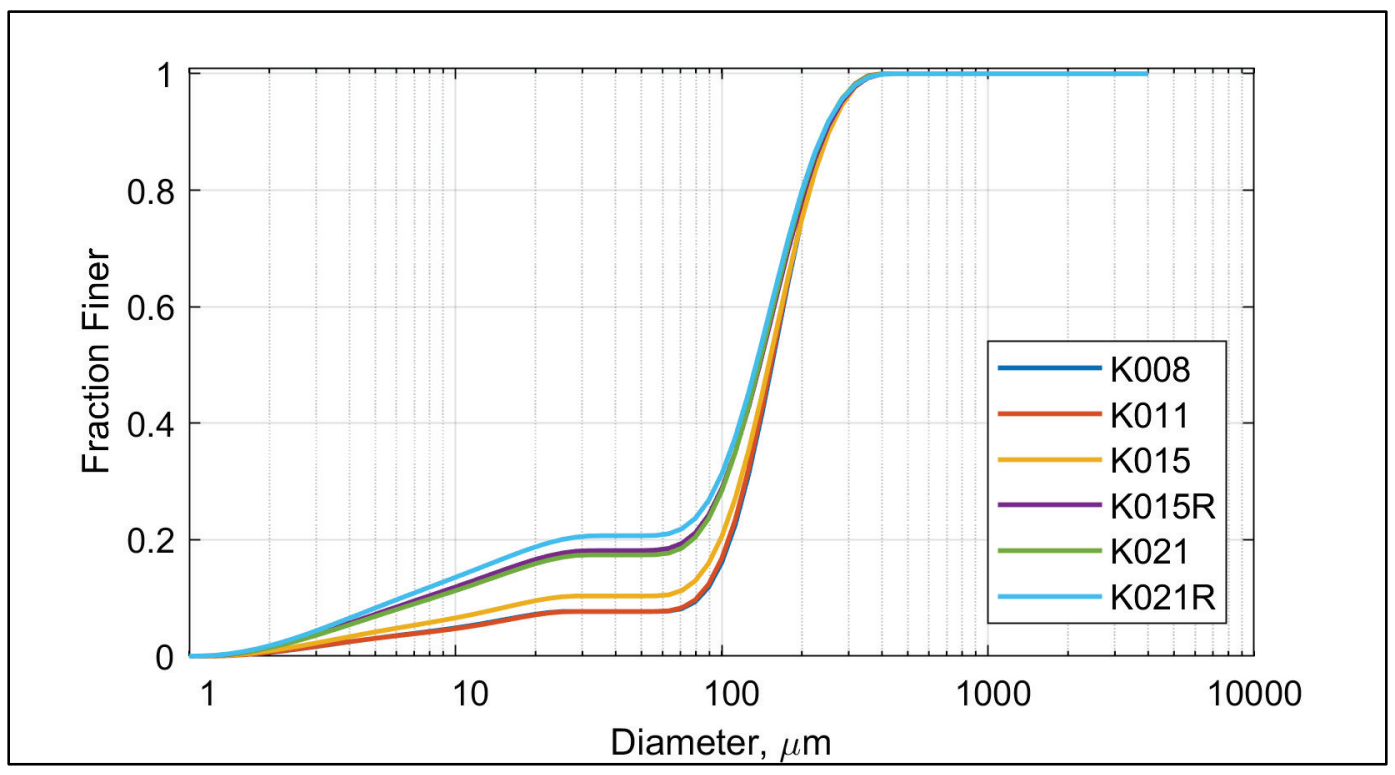


Figure A-5. Cumulative grain size distributions for kaolinite cores with mud contents ranging from $29 \%$ to $100 \%$.

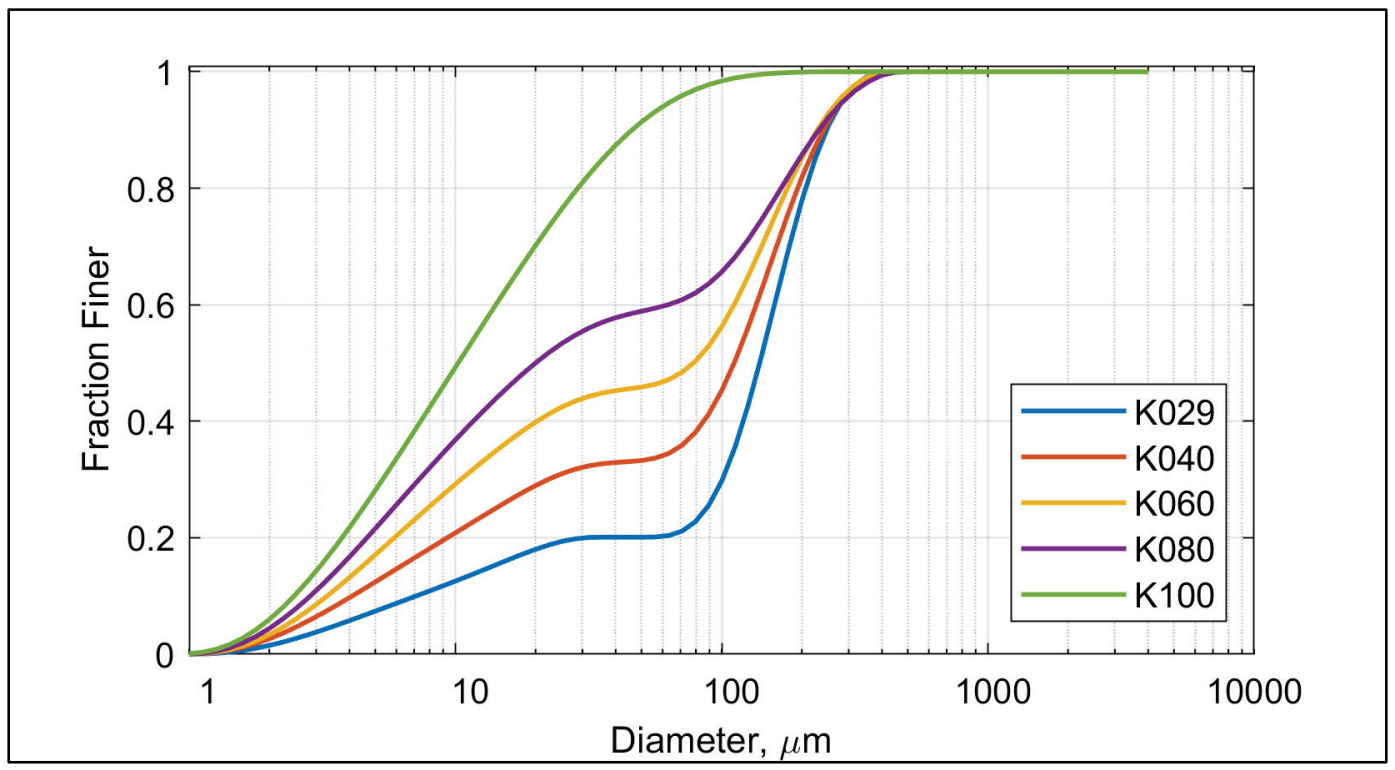

Figure A-6. Grain size distributions for kaolinite cores with mud contents ranging from $1 \%$ to $5 \%$.

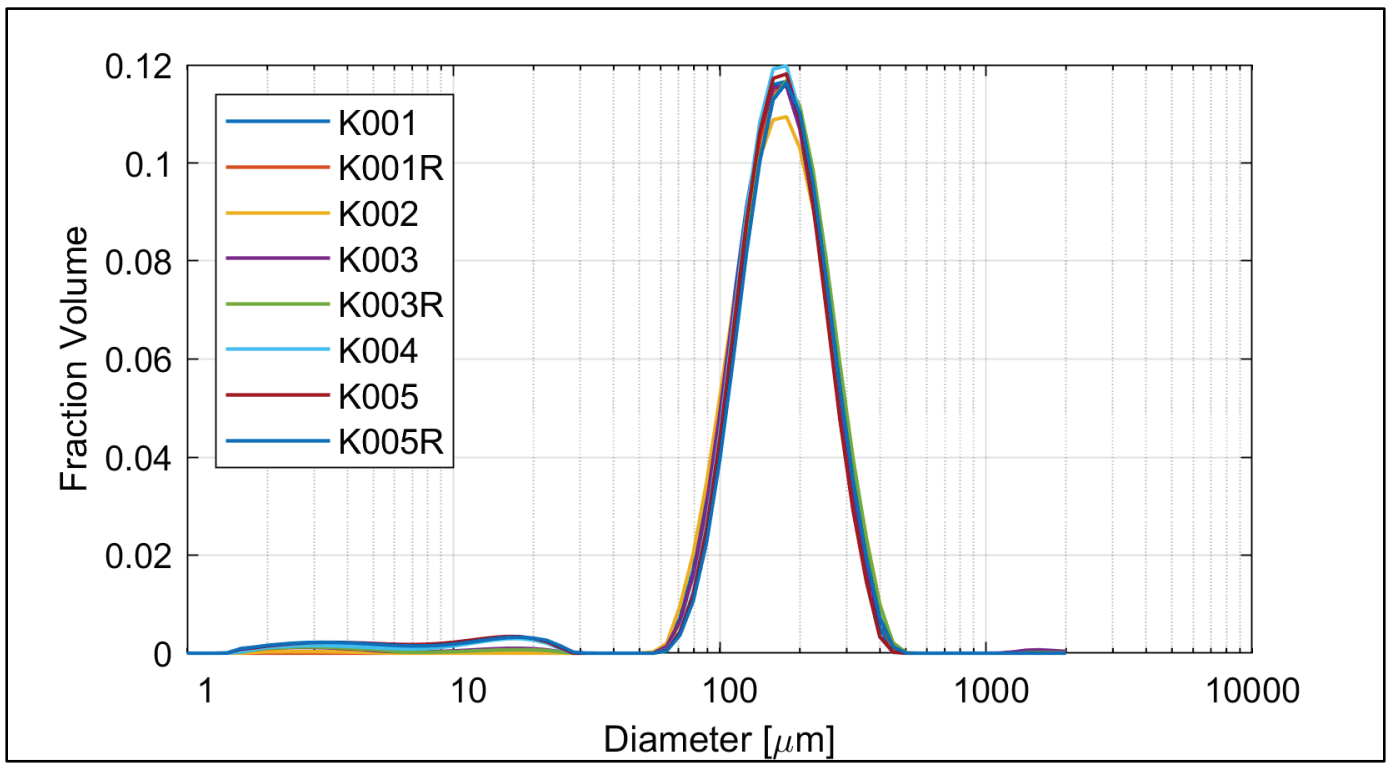


Figure A-7. Grain size distributions for kaolinite cores with mud contents ranging from $8 \%$ to $21 \%$.

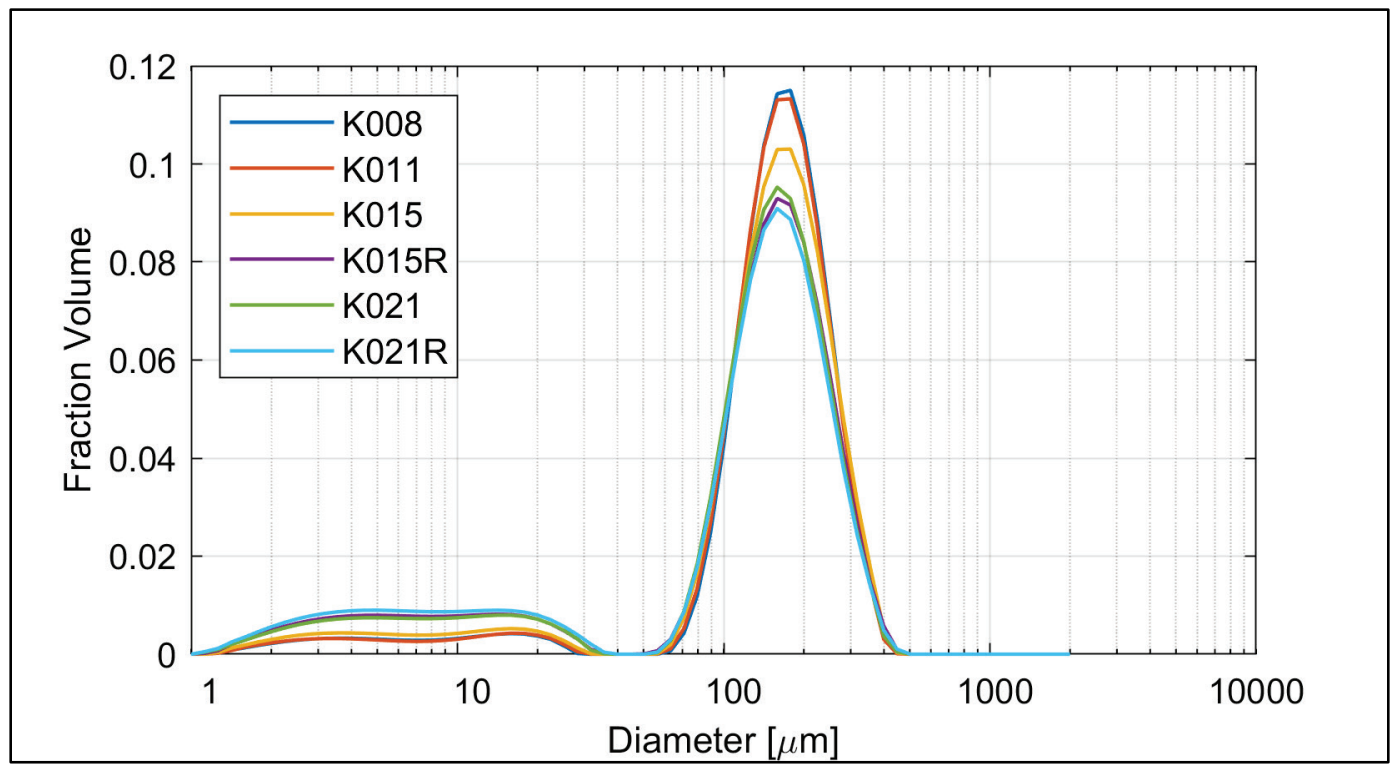

Figure A-8. Grain size distributions for kaolinite cores with mud contents ranging from $29 \%$ to $100 \%$.

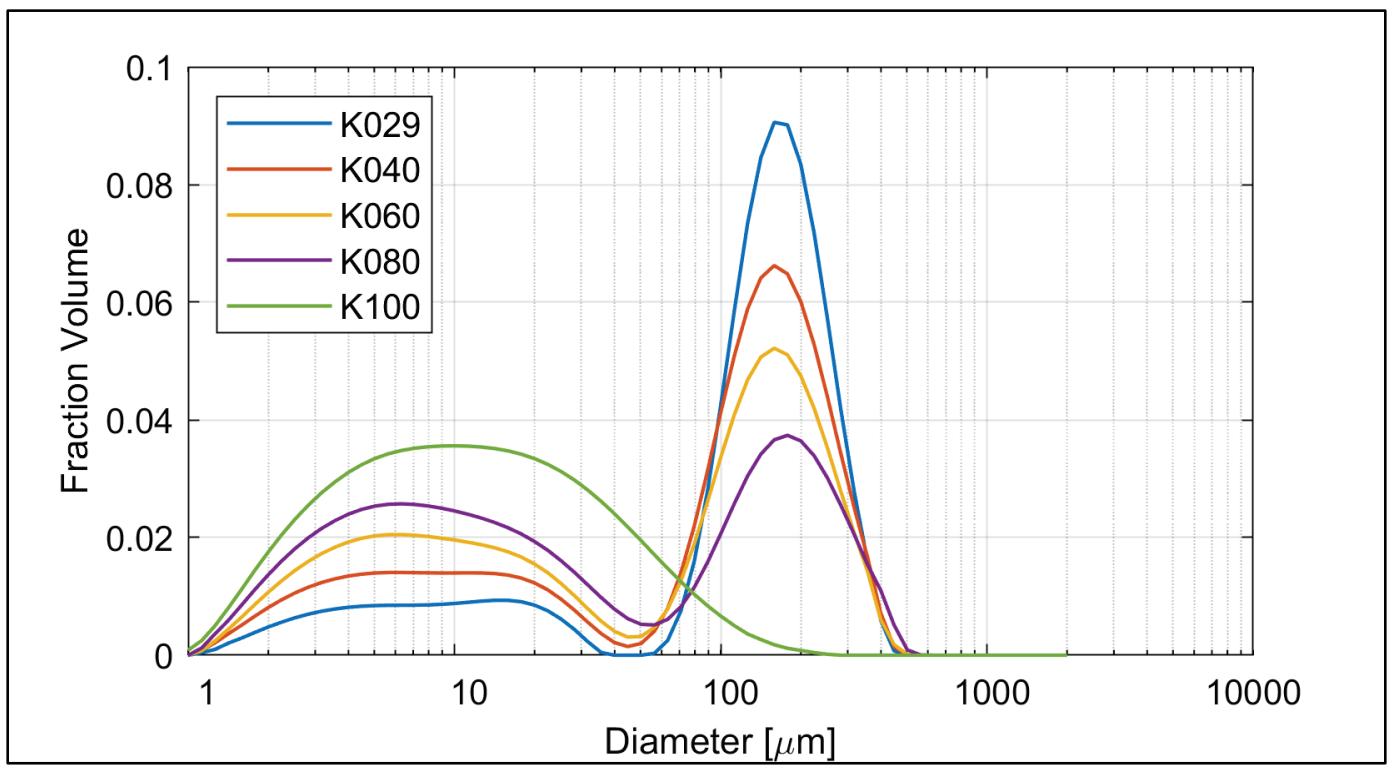


Table A-3. Kaolinite-bentonite mud laser diffraction data.

\begin{tabular}{|c|c|c|c|c|c|c|}
\hline Sample & $\%$ Sand & $\%$ Silt & $\%$ Clay & $\begin{array}{c}\mathrm{D}_{10} \\
(\mu \mathrm{m})\end{array}$ & $\begin{array}{c}\mathrm{D}_{50} \\
(\mu \mathrm{m})\end{array}$ & $\begin{array}{c}\mathrm{D}_{90} \\
(\mu \mathrm{m})\end{array}$ \\
\hline KB001 & 99.9 & 0.1 & 0 & 100.5 & 162.0 & 261.4 \\
\hline KB002 & 99.9 & 0.1 & 0 & 99.4 & 162.2 & 265.2 \\
\hline KB003 & 99.9 & 0.1 & 0 & 98.0 & 159.9 & 260.4 \\
\hline KB004 & 99.7 & 0.2 & 0.2 & 96.2 & 160.1 & 265.6 \\
\hline KB005 & 98.7 & 1.0 & 0.3 & 93.4 & 157.2 & 260.8 \\
\hline KB005R & 94.8 & 3.6 & 1.6 & 91.3 & 157.1 & 250.2 \\
\hline KB008 & 94.8 & 3.6 & 1.6 & 91.2 & 157.1 & 250.6 \\
\hline KB008R & 90.1 & 6.9 & 3.1 & 63.5 & 153.7 & 258.5 \\
\hline KB011 & 93.5 & 4.5 & 2.0 & 88.7 & 158.4 & 254.5 \\
\hline KB011R & 92.1 & 5.4 & 2.5 & 81.3 & 155.9 & 252.7 \\
\hline KB015 & 90.7 & 6.3 & 3.0 & 72.9 & 153.6 & 249.0 \\
\hline KB021 & 92.9 & 4.8 & 2.3 & 86.2 & 160.0 & 260.1 \\
\hline KB021R & 77.5 & 16.1 & 6.4 & 6.3 & 132.4 & 244.8 \\
\hline KB029 & 81.4 & 13.3 & 5.3 & 8.0 & 138.7 & 244.8 \\
\hline KB040 & 81.8 & 13.0 & 5.3 & 8.2 & 147.6 & 261.6 \\
\hline KB060 & 57.0 & 31.4 & 11.5 & 3.6 & 94.5 & 248.0 \\
\hline KB080 & 42.6 & 41.8 & 15.6 & 3.0 & 23.7 & 234.9 \\
\hline KB080R & 19.8 & 58.7 & 21.5 & 2.5 & 10.8 & 144.0 \\
\hline
\end{tabular}


Figure A-9. Cumulative grain size distributions for kaolinite-bentonite cores with mud contents ranging from $1 \%$ to $5 \%$.

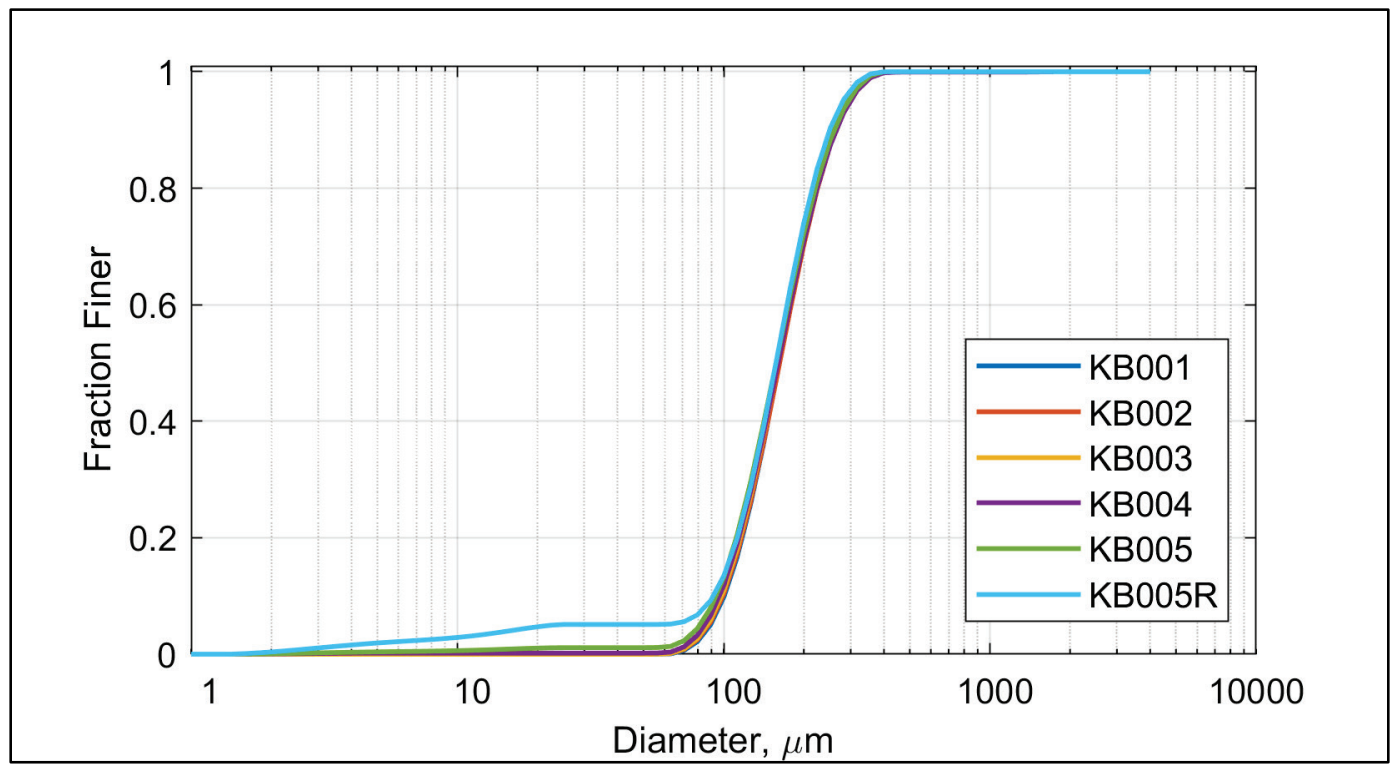

Figure A-10. Cumulative grain size distributions for kaolinite-bentonite cores with mud contents ranging from $8 \%$ to $21 \%$.

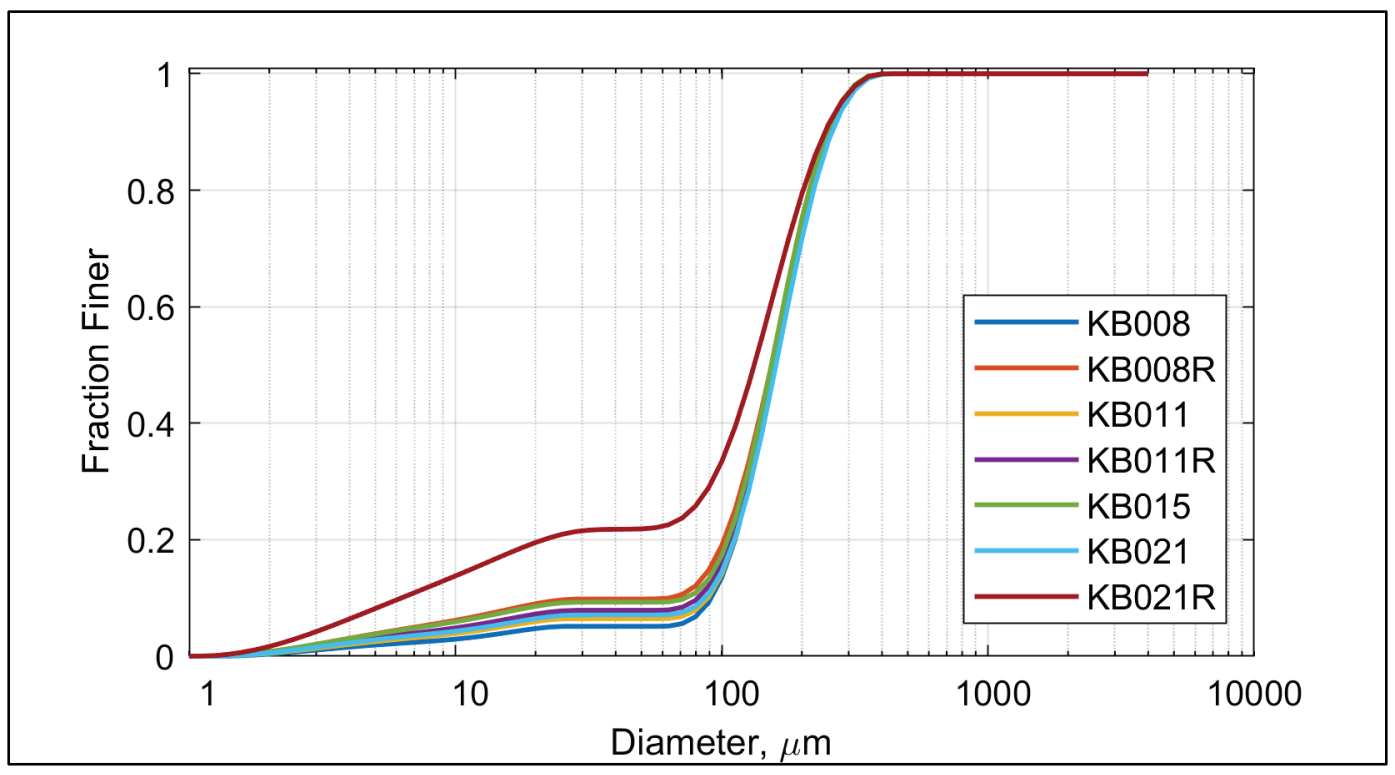


Figure A-11. Cumulative grain size distributions for kaolinite-bentonite cores with mud contents ranging from $29 \%$ to $100 \%$.

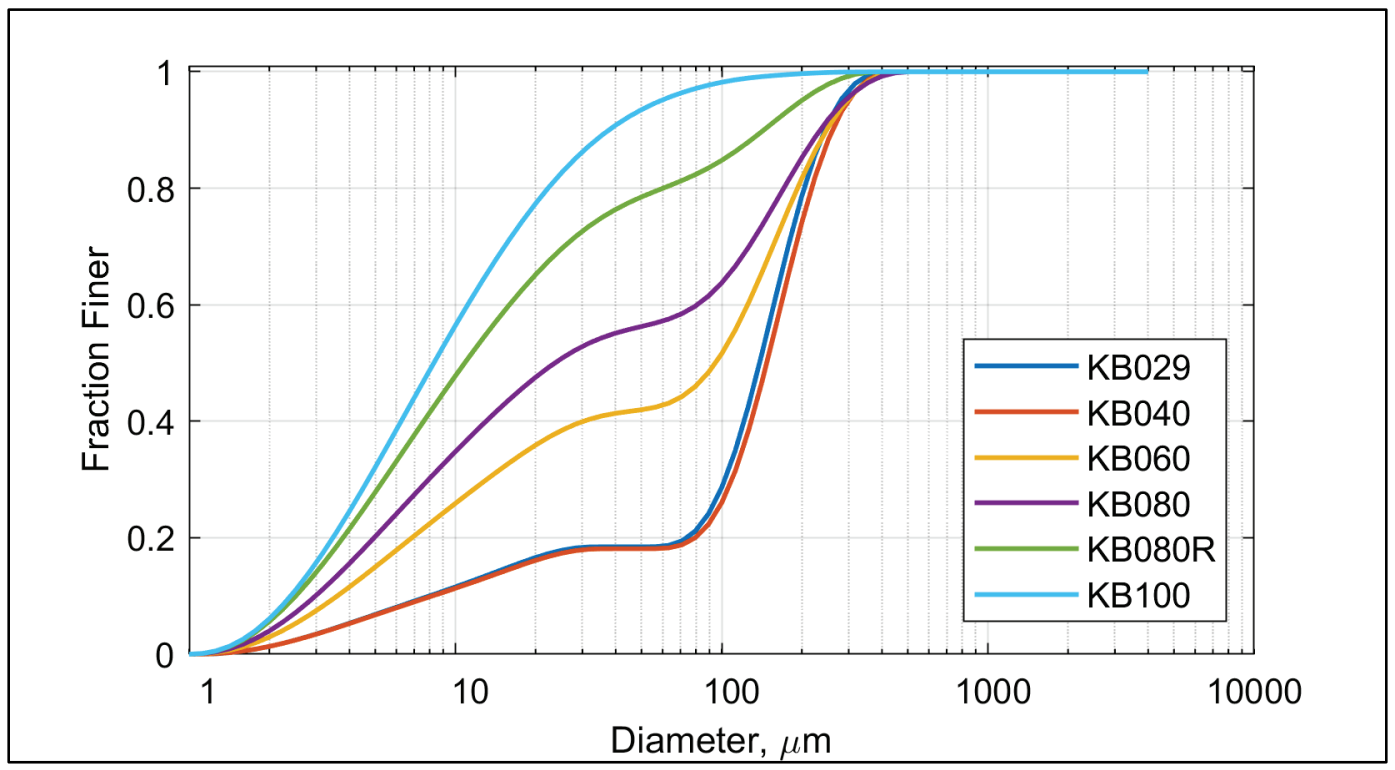

Figure A-12. Grain size distributions for kaolinite-bentonite cores with mud contents ranging from $1 \%$ to $5 \%$.

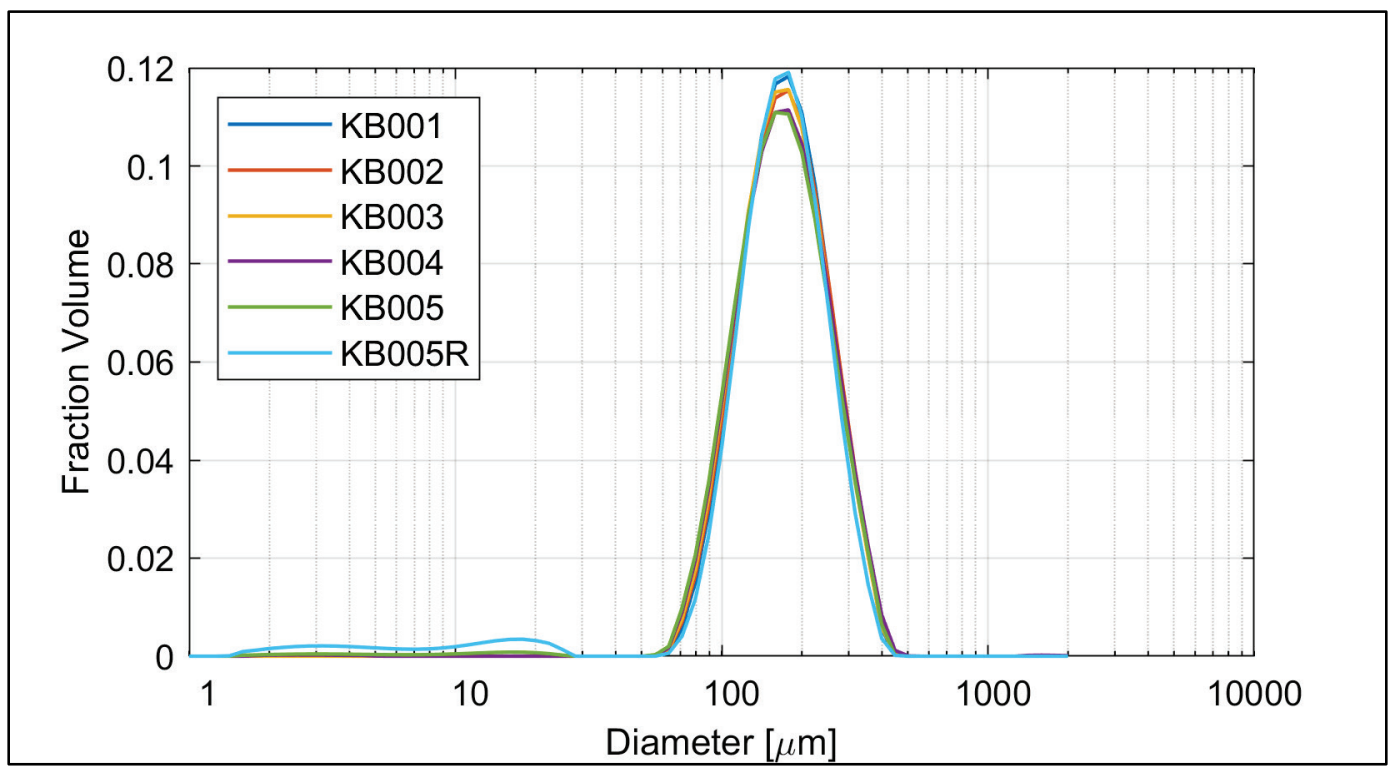


Figure A-13. Grain size distributions for kaolinite-bentonite cores with mud contents ranging from $8 \%$ to $21 \%$.

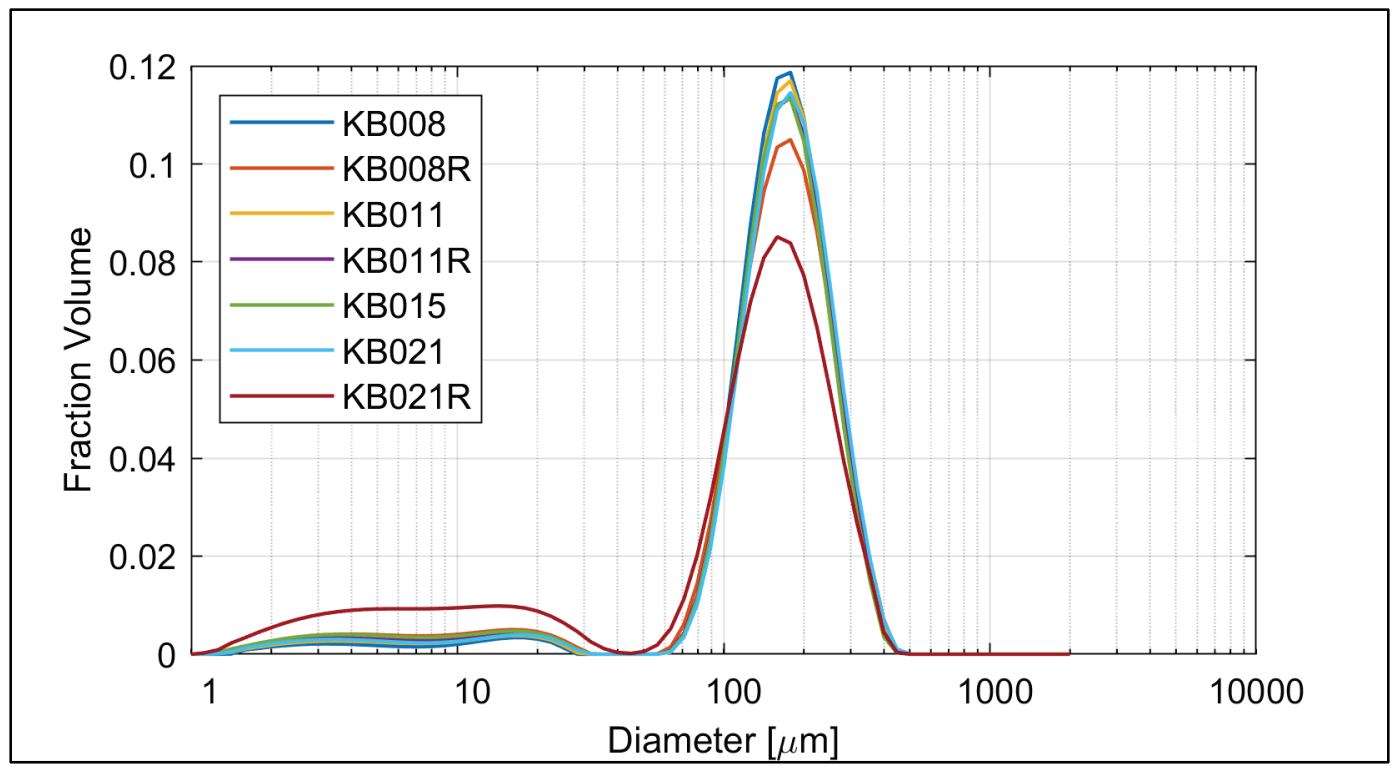

Figure A-14. Grain size distributions for kaolinite-bentonite cores with mud contents ranging from $29 \%$ to $100 \%$.

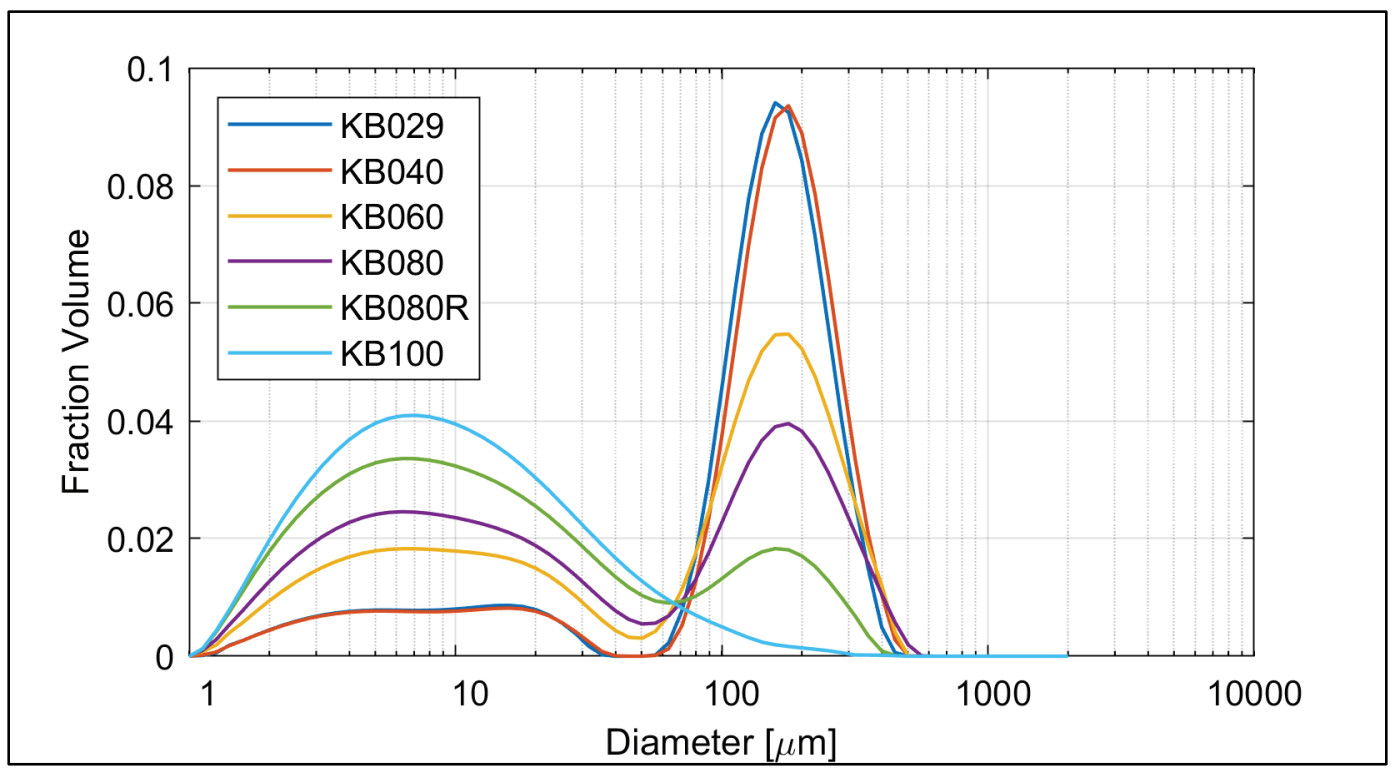


Table A-4. MR mud laser diffraction data.

\begin{tabular}{|c|c|c|c|c|c|c|}
\hline Sample & $\%$ Sand & \% Silt & \% Clay & $\begin{array}{c}D_{10} \\
(\mu \mathrm{m})\end{array}$ & $\begin{array}{l}D_{50} \\
(\mu \mathrm{m})\end{array}$ & $\begin{array}{c}D_{90} \\
(\mu \mathrm{m})\end{array}$ \\
\hline MR001 & 99.9 & 0.1 & 0 & 98.9 & 158.9 & 254.5 \\
\hline MR002 & 99.9 & 0.1 & 0 & 99.3 & 161.4 & 262.3 \\
\hline MR003 & 99.9 & 0.1 & 0 & 100.4 & 164.5 & 269.4 \\
\hline MR003R & 98.0 & 1.6 & 0.4 & 95.3 & 159.3 & 259.2 \\
\hline MR004 & 95.9 & 3.1 & 0.9 & 96.4 & 163.7 & 262.2 \\
\hline MR005 & 96.3 & 2.8 & 0.9 & 95.9 & 162.5 & 261.0 \\
\hline MR008 & 93.6 & 4.7 & 1.7 & 92.8 & 164.8 & 262.8 \\
\hline MR011 & 88.9 & 8.6 & 2.5 & 20.9 & 150.3 & 246.5 \\
\hline MR011R & 90.0 & 8.0 & 2.0 & 62.0 & 153.1 & 251.5 \\
\hline MR015 & 87.2 & 10.1 & 2.7 & 16.8 & 155.1 & 260.6 \\
\hline MR021 & 80.5 & 15.9 & 3.6 & 10.2 & 140.7 & 248.0 \\
\hline MR021R & 77.3 & 18.5 & 4.2 & 8.8 & 137.6 & 248.4 \\
\hline MR029 & 66.3 & 28.0 & 5.7 & 6.1 & 118.5 & 246.1 \\
\hline MR029R & 70.2 & 24.5 & 5.2 & 6.6 & 127.8 & 253.7 \\
\hline MR040 & 60.9 & 32.7 & 6.3 & 5.6 & 104.9 & 247.7 \\
\hline MR060 & 22.1 & 65.4 & 12.4 & 3.5 & 14.7 & 172.9 \\
\hline MR080 & 14.9 & 70.6 & 14.5 & 3.2 & 12.9 & 117.9 \\
\hline MR100 & 3.0 & 80.9 & 16.1 & 3.1 & 10.9 & 35.5 \\
\hline MR100R & 2.6 & 82.6 & 14.8 & 3.2 & 11.2 & 34.5 \\
\hline
\end{tabular}


Figure A-15. Cumulative grain size distributions for MR cores with mud contents ranging from $1 \%$ to $5 \%$.

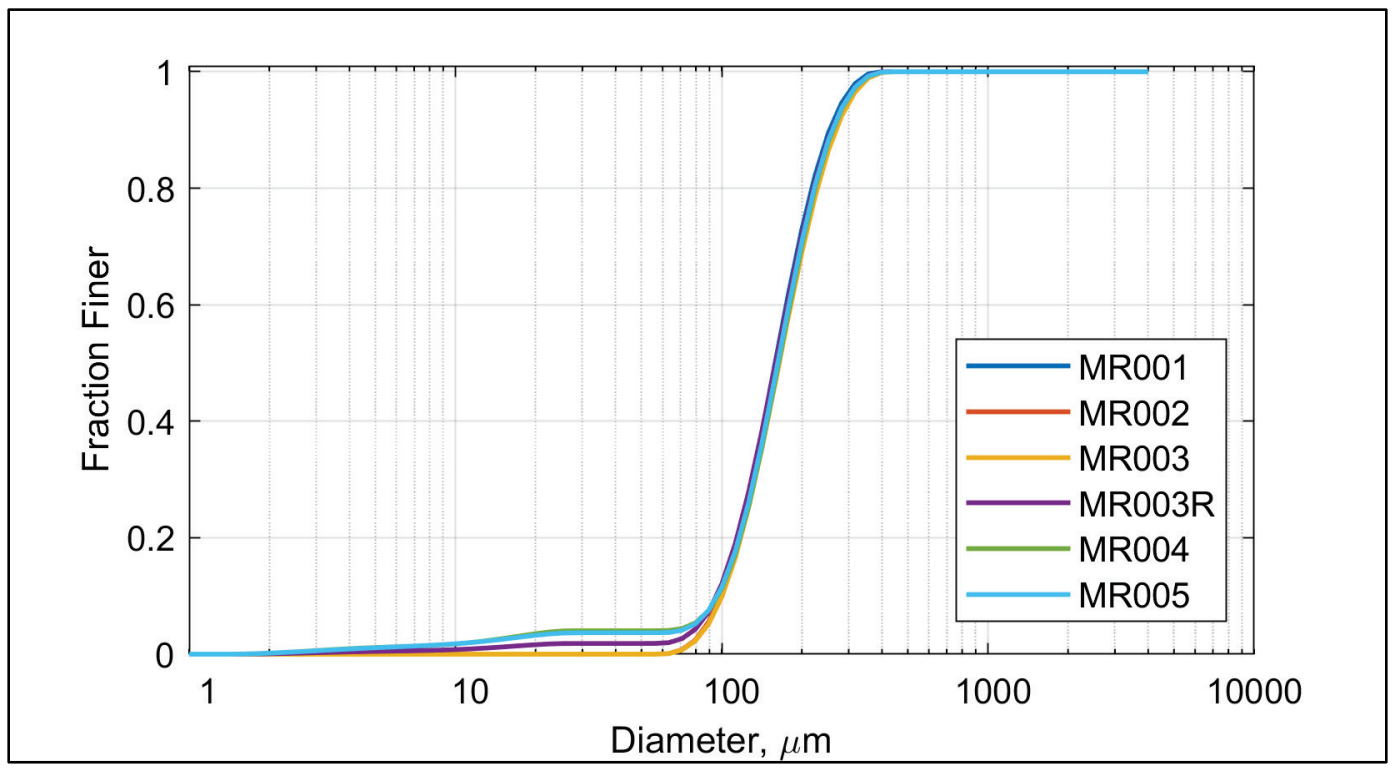

Figure A-16. Cumulative grain size distributions for MR cores with mud contents ranging from $8 \%$ to $21 \%$.

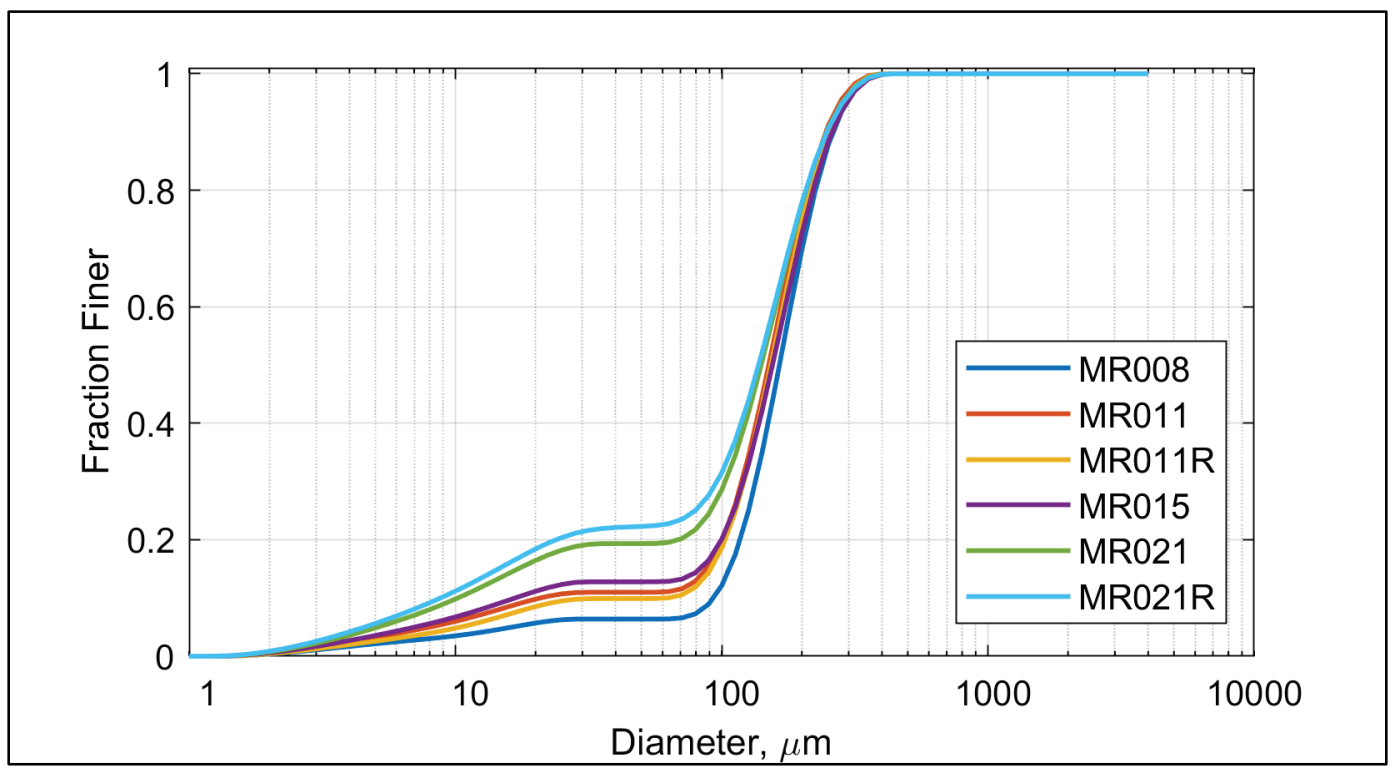


Figure A-17. Cumulative grain size distributions for MR cores with mud contents ranging from $29 \%$ to $100 \%$.

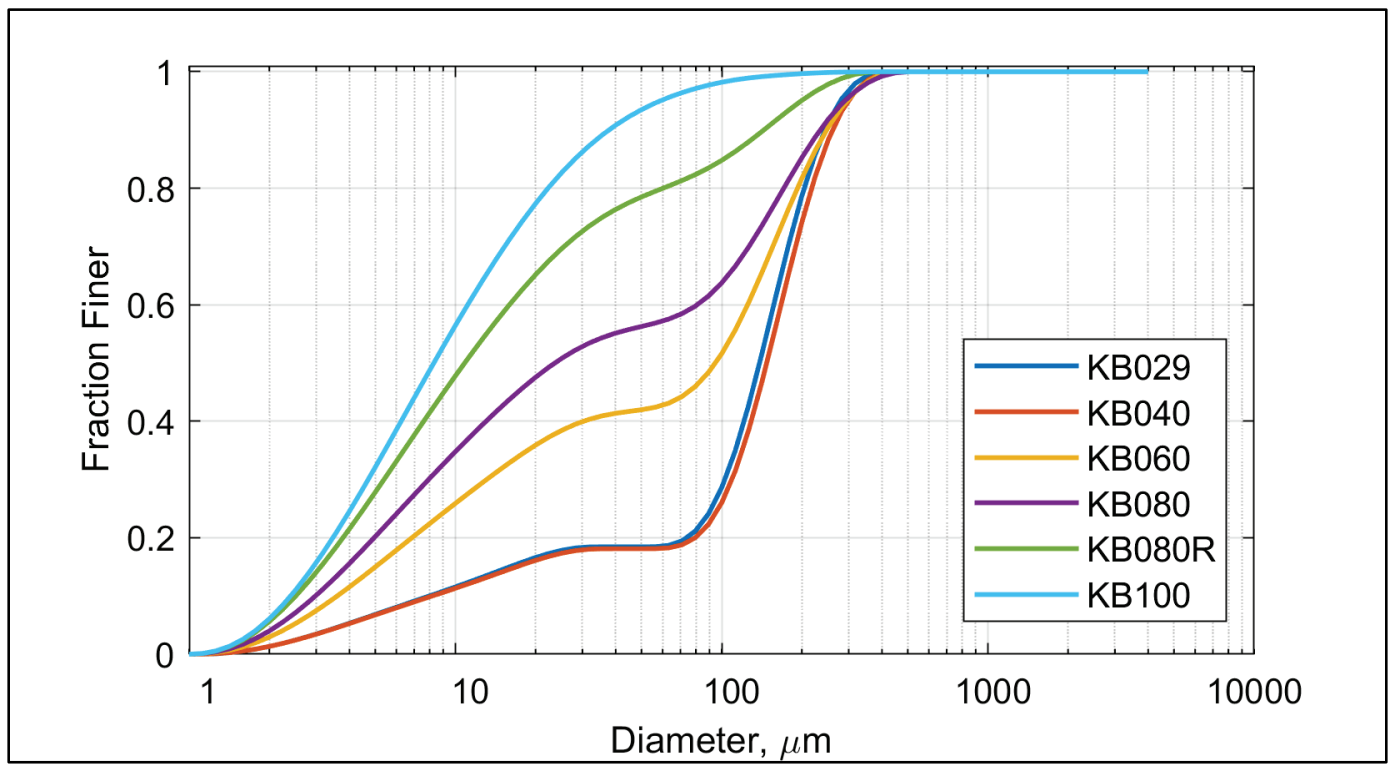

Figure A-18. Grain size distributions for MR cores with mud contents ranging from $1 \%$ to $5 \%$.

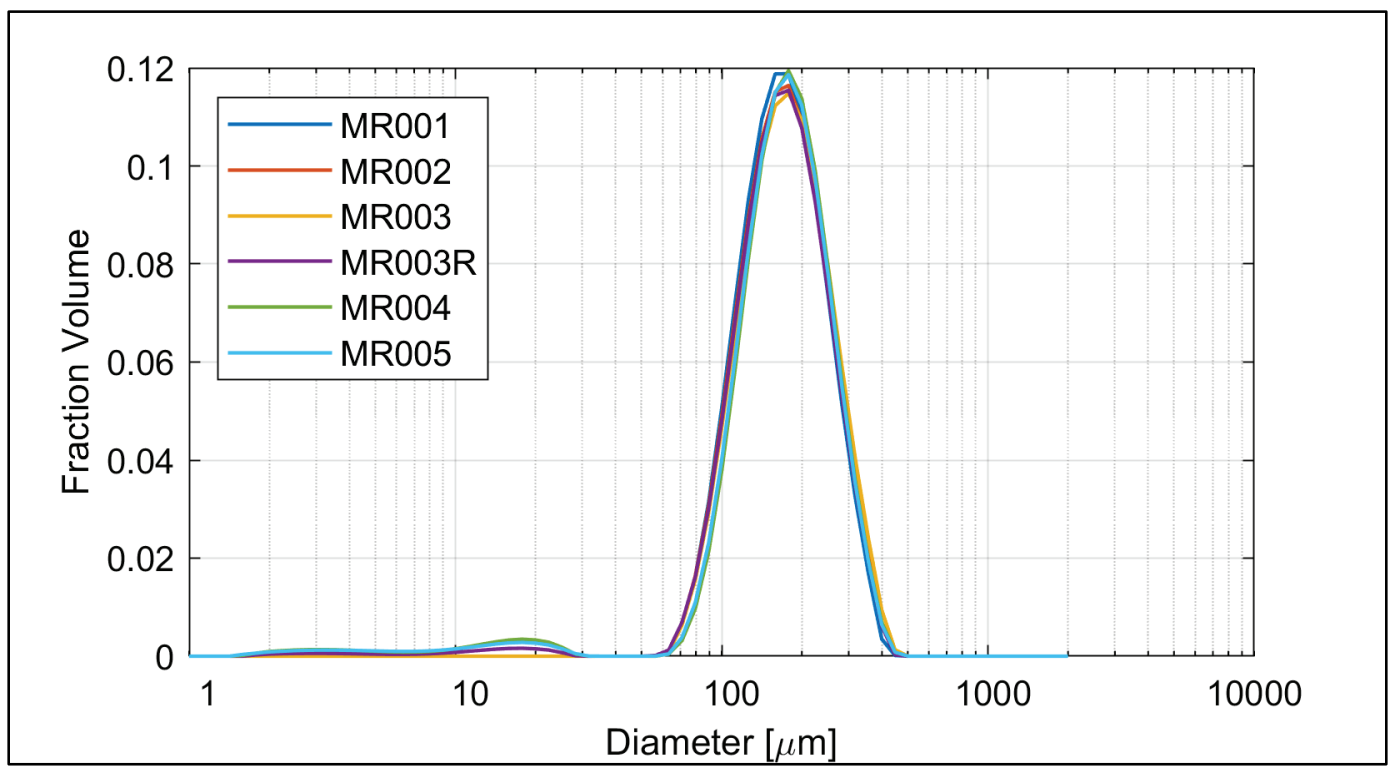


Figure A-19. Grain size distributions for MR cores with mud contents ranging from $8 \%$ to $21 \%$.

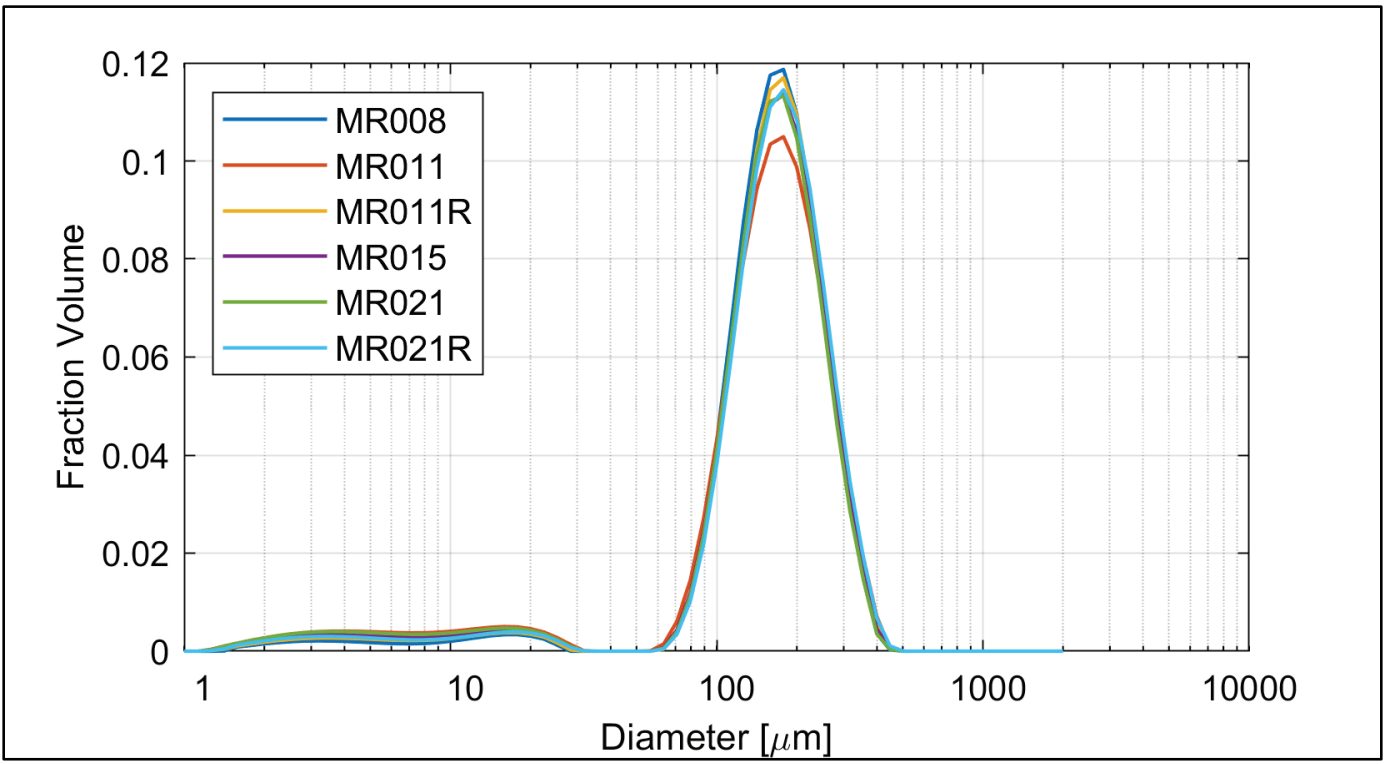

Figure A-20. Grain size distributions for MR cores with mud contents ranging from $29 \%$ to $100 \%$.

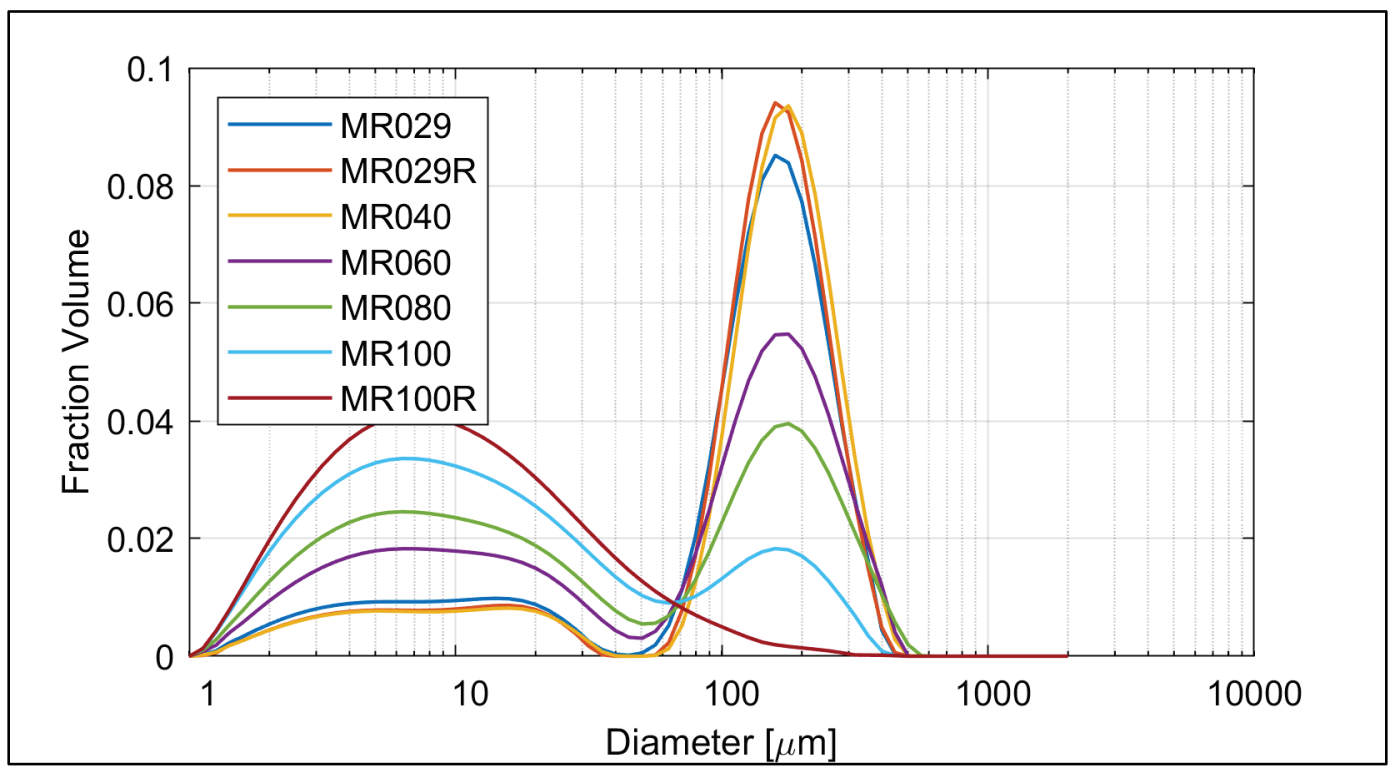




\section{Appendix B: X-Ray Attenuation Bulk Density Plots}

Figure B-1. Bulk densities obtained through x-ray attenuation are shown for sand cores.

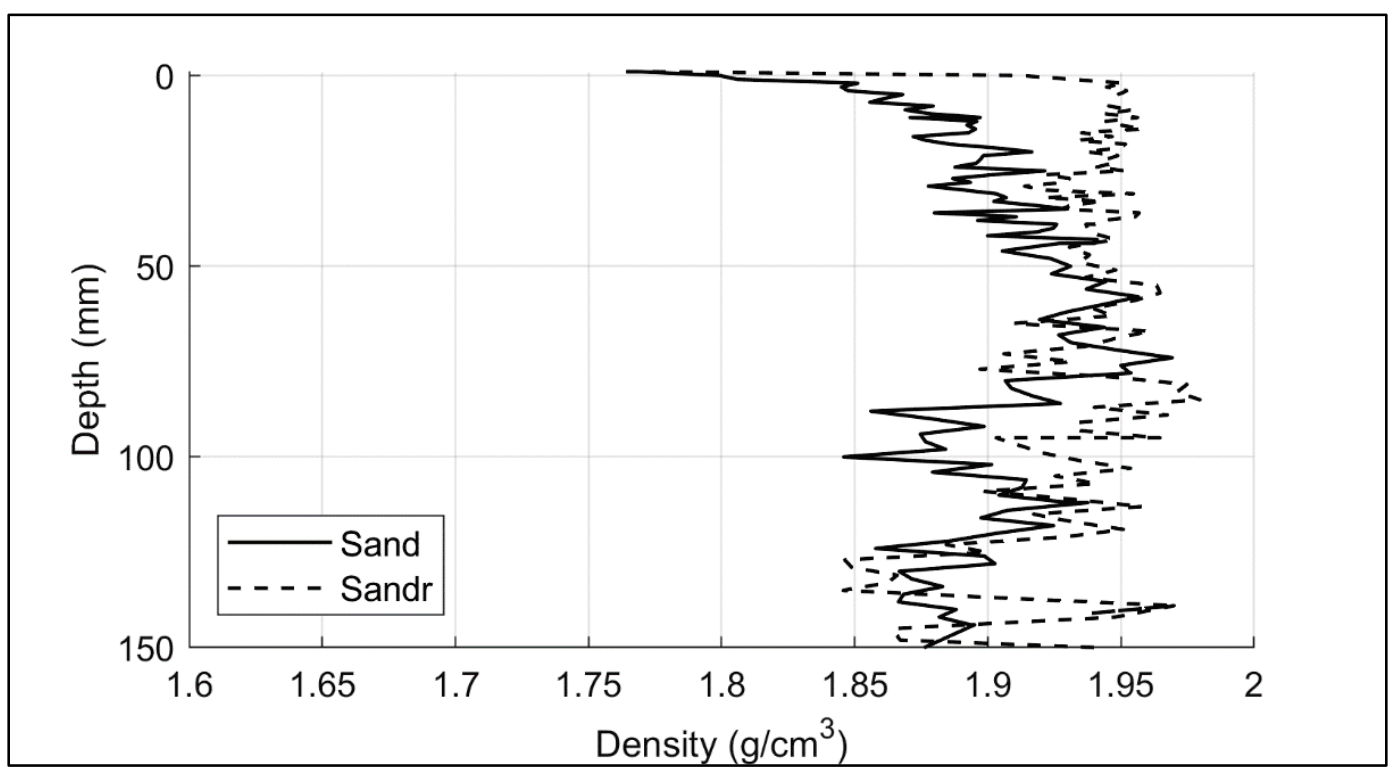

Figure B-2. Bulk densities obtained through x-ray attenuation are shown for kaolinite cores with mud contents ranging from $1 \%$ to $5 \%$.

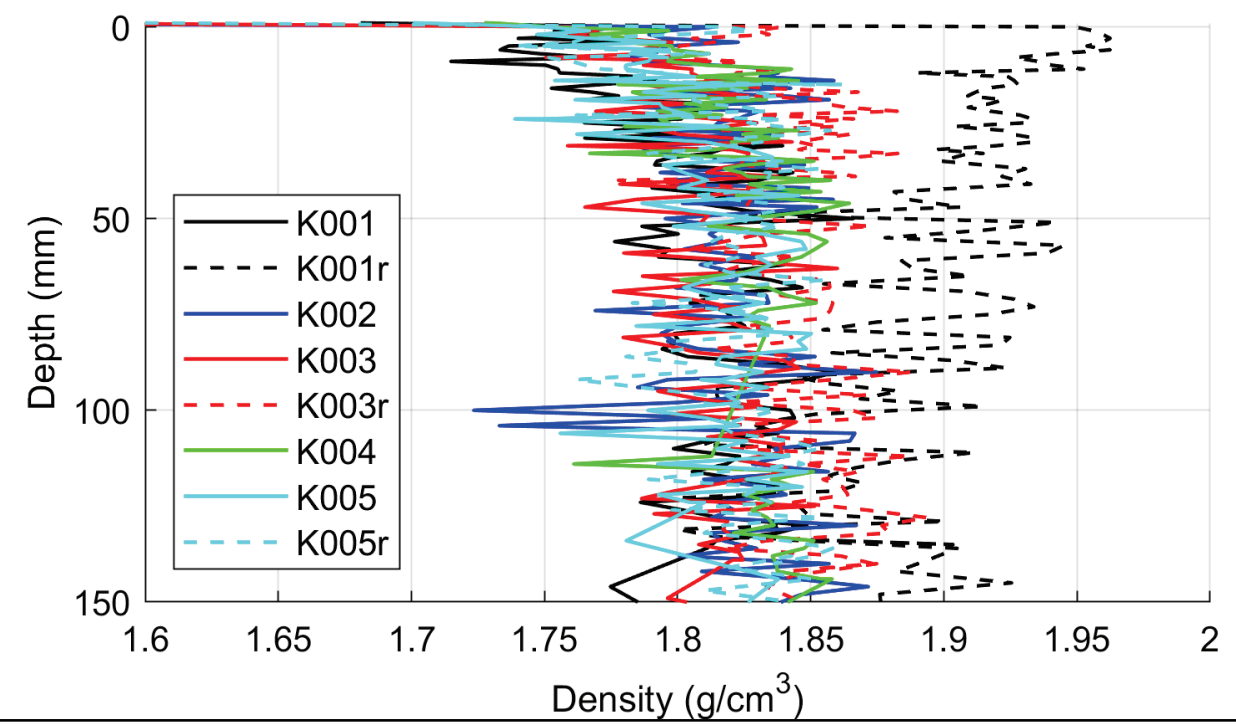


Figure B-3. Bulk densities obtained through x-ray attenuation are shown for kaolinite cores with mud contents ranging from $8 \%$ to $21 \%$.

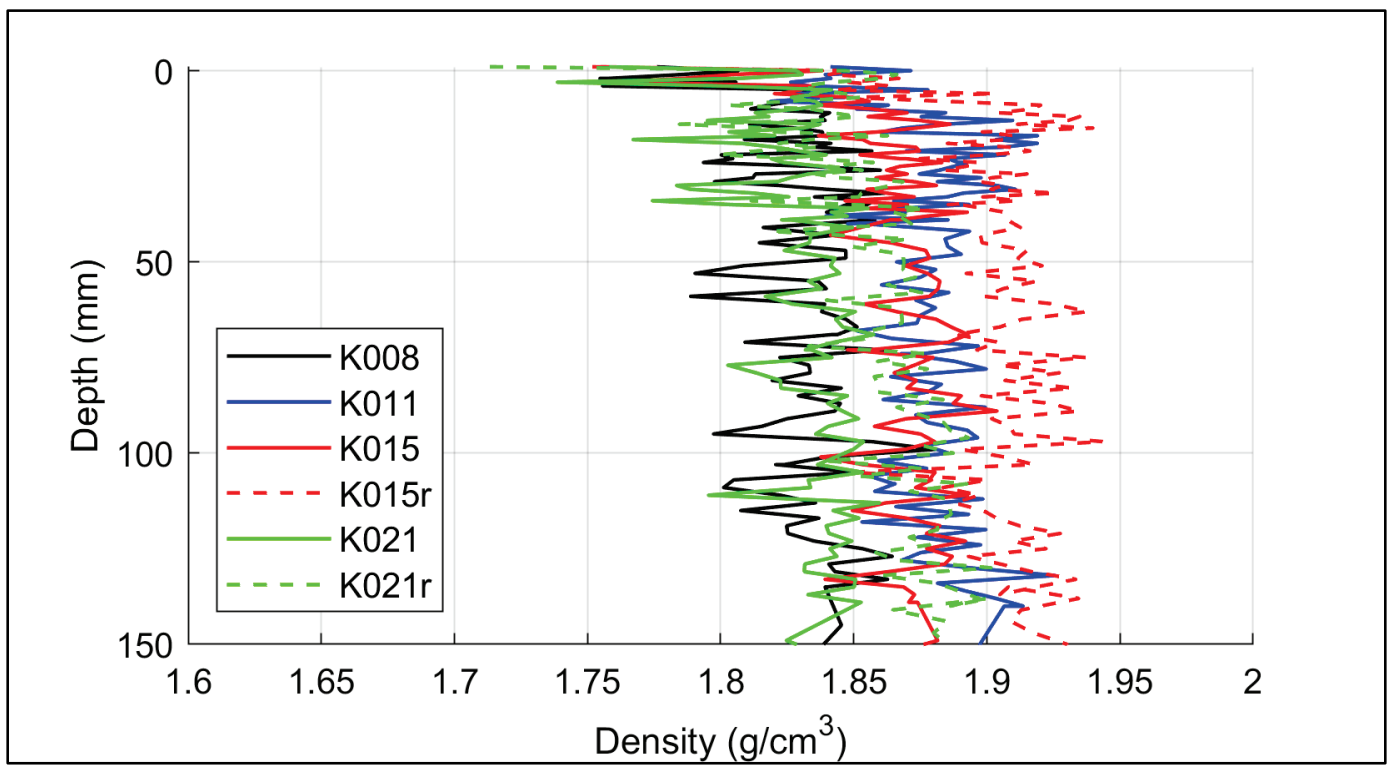

Figure B-4. Bulk densities obtained through x-ray attenuation are shown for kaolinite cores with mud contents ranging from $29 \%$ to $100 \%$.

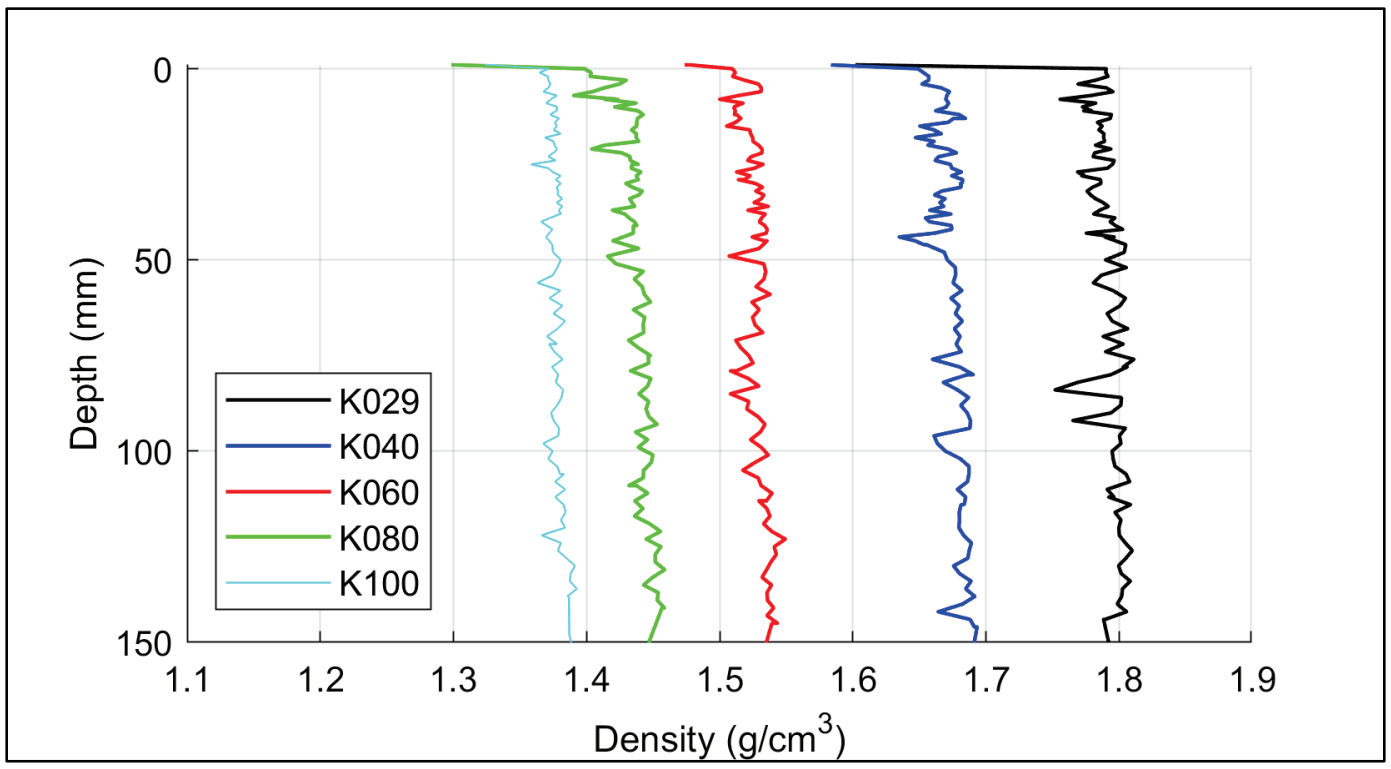


Figure B-5. Bulk densities obtained through x-ray attenuation are shown for kaolinitebentonite cores with mud contents ranging from $1 \%$ to $5 \%$.

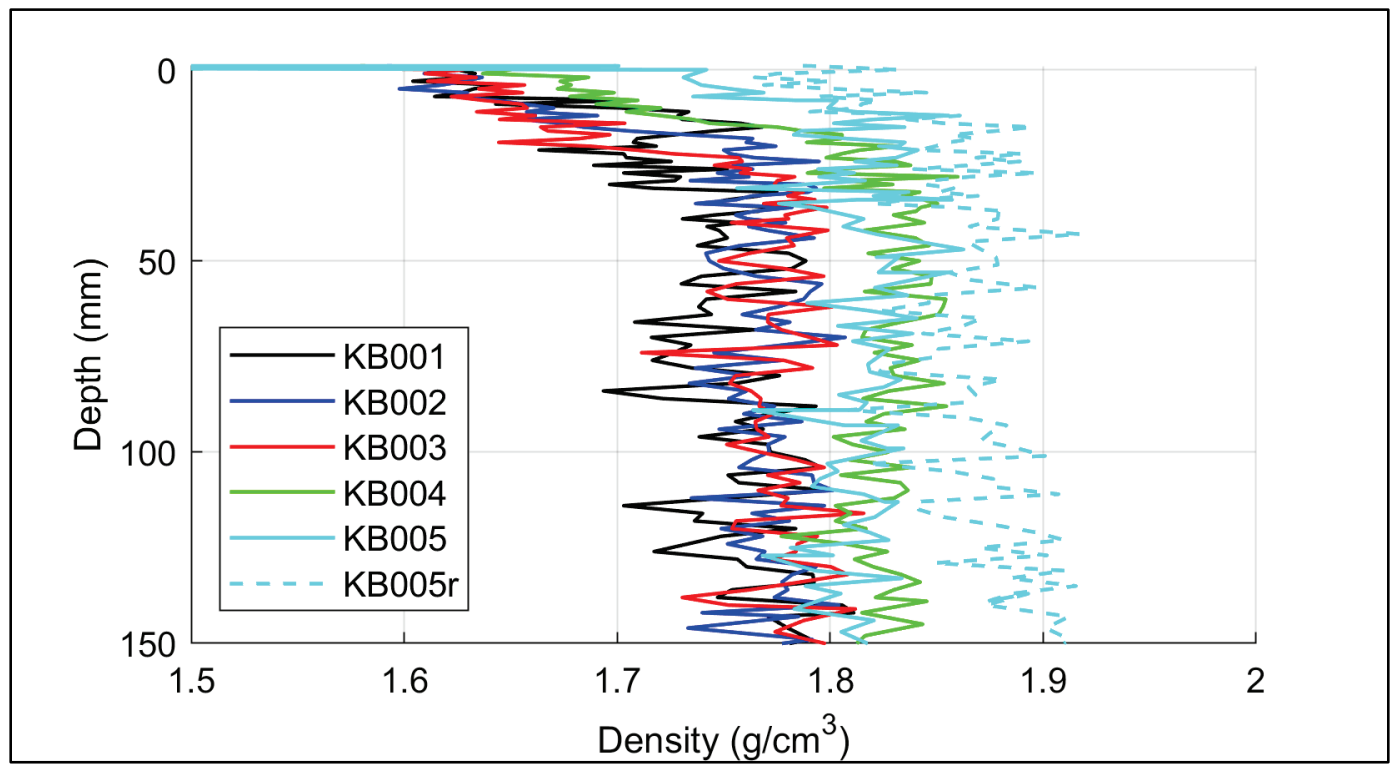

Figure B-6. Bulk densities obtained through x-ray attenuation are shown for kaolinitebentonite cores with mud contents ranging from $8 \%$ to $21 \%$.

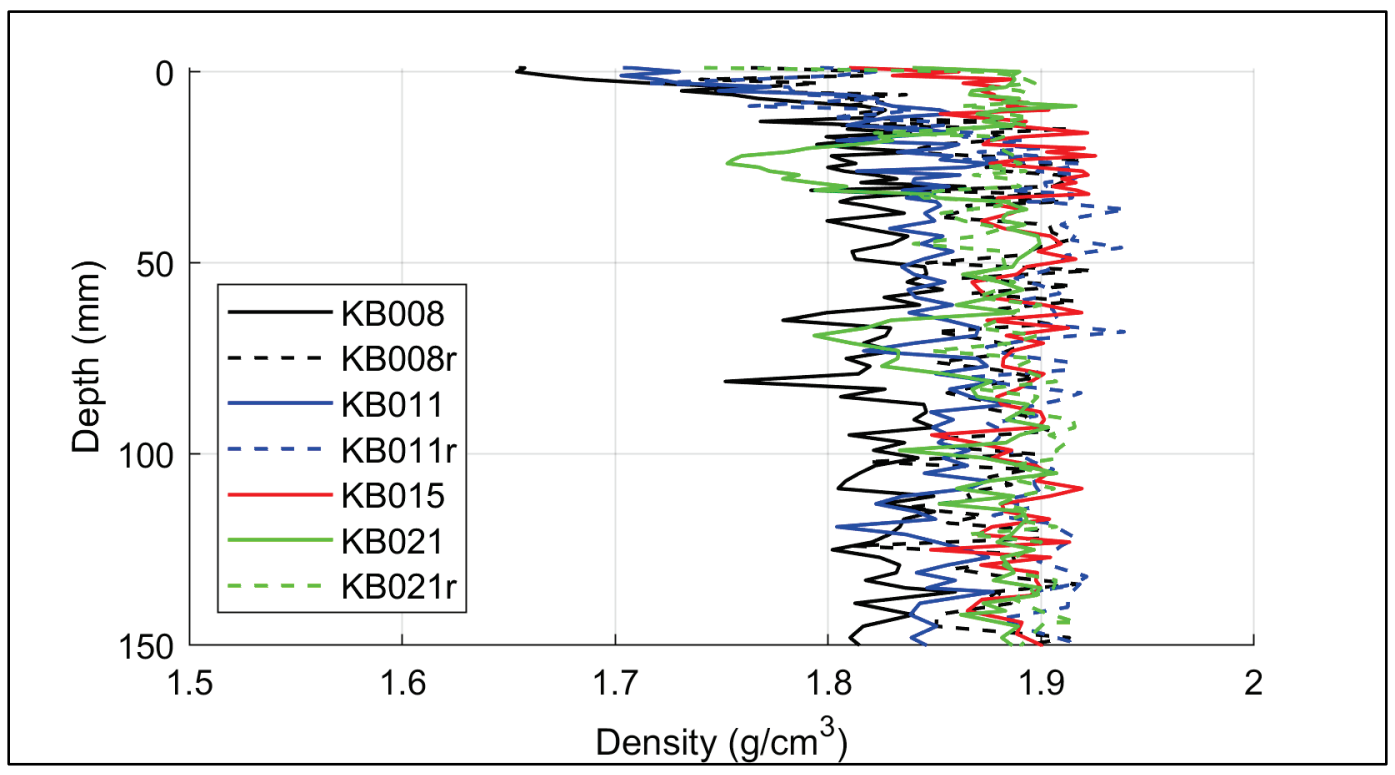


Figure B-7. Bulk densities obtained through x-ray attenuation are shown for kaolinitebentonite cores with mud contents ranging from $29 \%$ to $100 \%$.

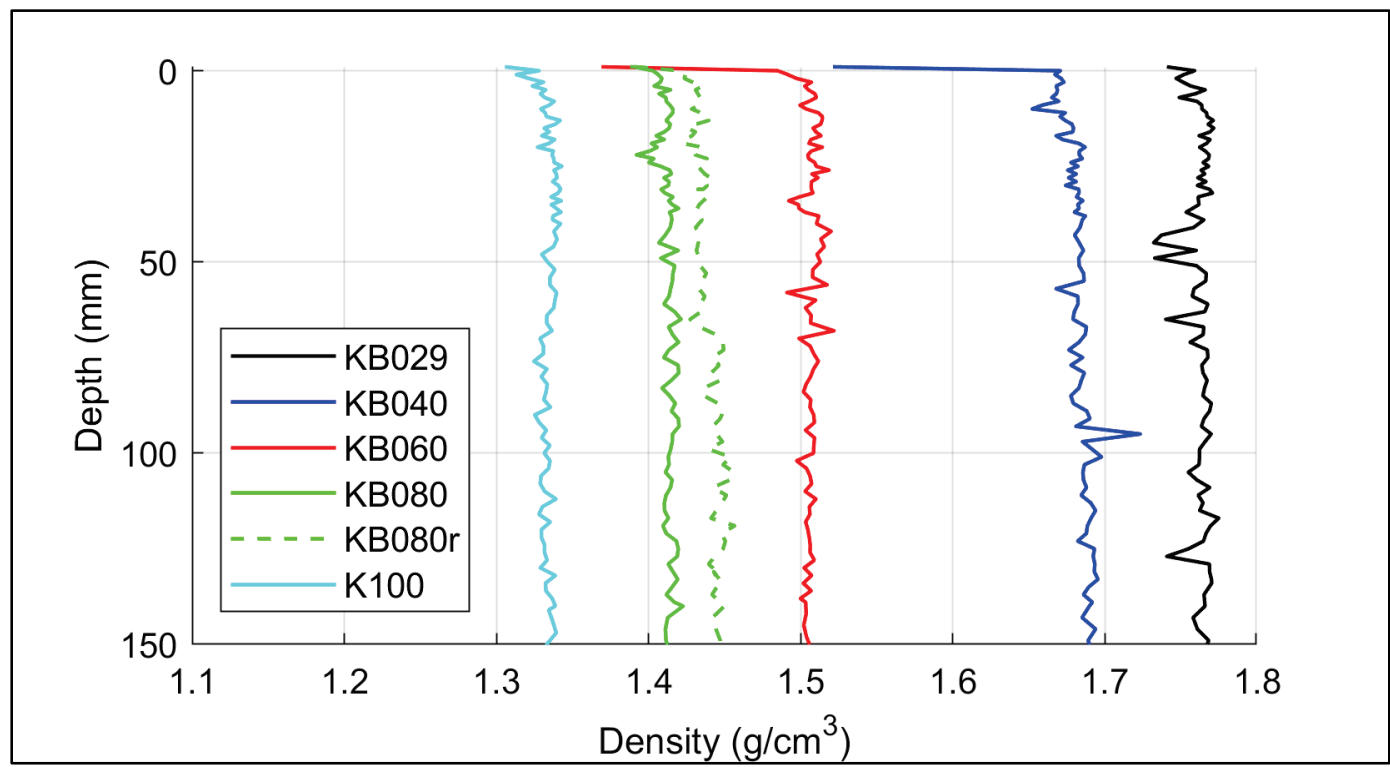

Figure B-8. Bulk densities obtained through x-ray attenuation are shown for MR cores with mud contents ranging from $1 \%$ to $5 \%$.

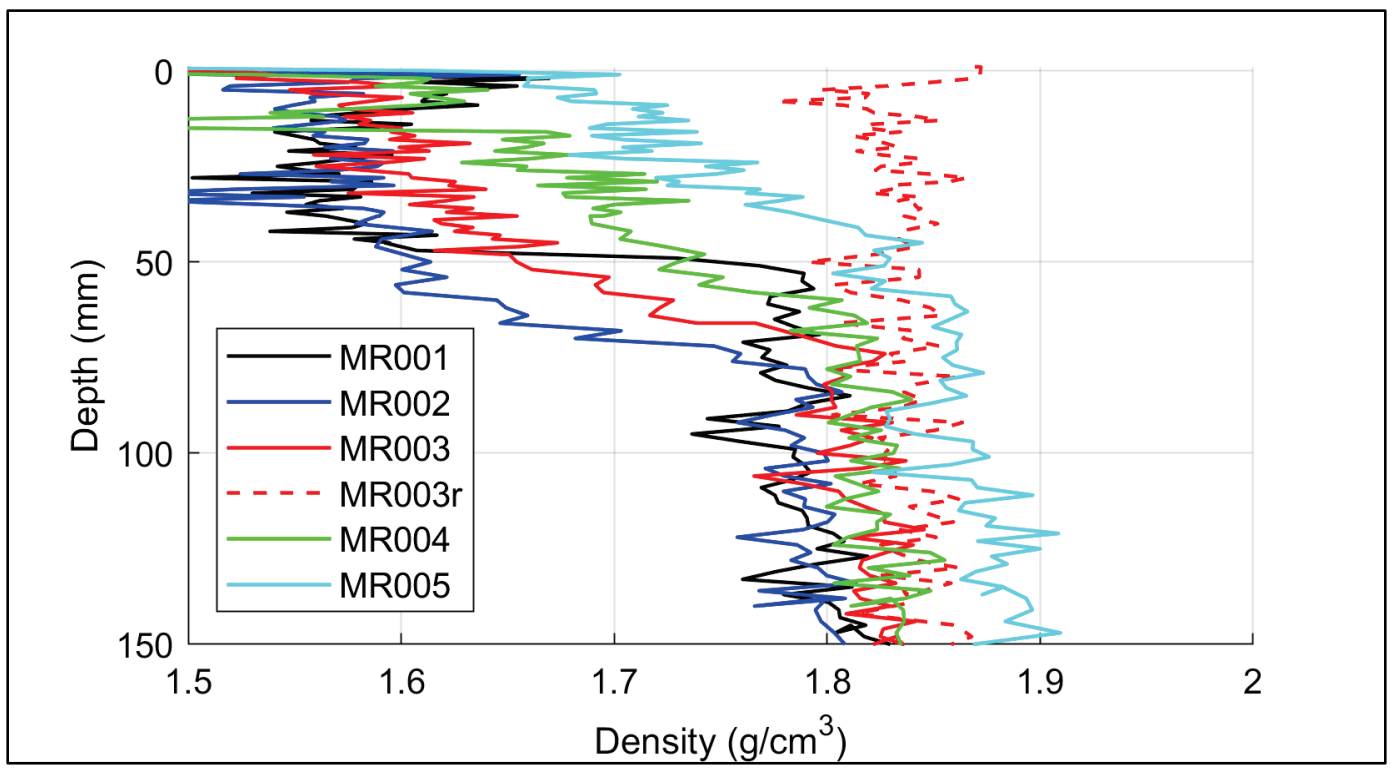


Figure B-9. Bulk densities obtained through x-ray attenuation are shown for MR cores with mud contents ranging from $8 \%$ to $21 \%$.

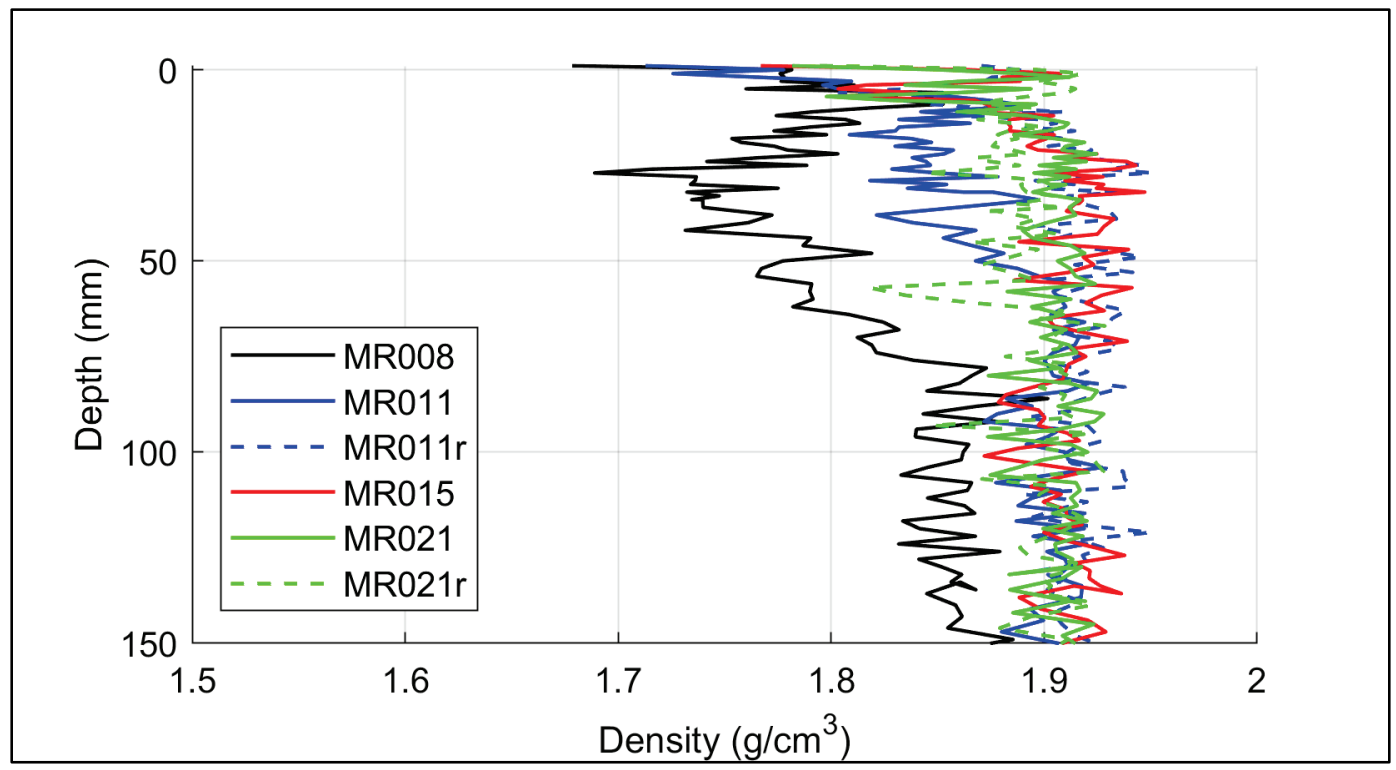

Figure B-10. Bulk densities obtained through x-ray attenuation are shown for MR cores with mud contents ranging from $29 \%$ to $100 \%$.

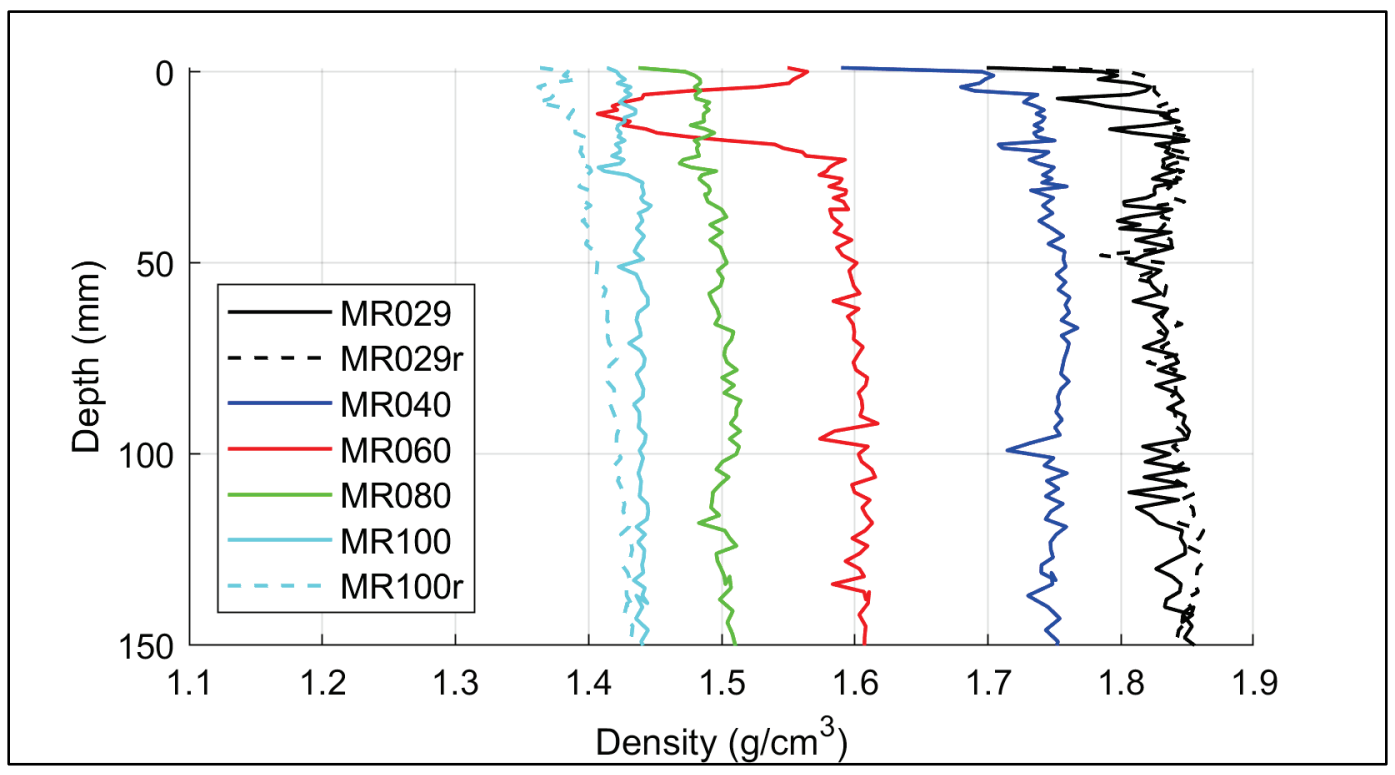




\section{Appendix C: Erosion Data}

Table C-1. Sand erosion parameters.

\begin{tabular}{|c|c|c|c|c|c|}
\hline $\begin{array}{c}\text { Mud } \\
\text { (\% mass) }\end{array}$ & $T_{c}$ & $\begin{array}{c}T_{c} \\
\text { (low) }\end{array}$ & $\begin{array}{c}T_{c} \\
\text { (high) }\end{array}$ & $\boldsymbol{A}$ & $n$ \\
\hline 0 & 0.17 & 0.15 & 0.19 & $1.64 \mathrm{E}-01$ & 4.14 \\
\hline OR & 0.16 & 0.15 & 0.18 & $2.89 \mathrm{E}-02$ & 3.11 \\
\hline
\end{tabular}

Figure C-1. Plot of mean erosion rate data against shear stress for cores composed of $100 \%$ sand. Regression lines fit to the data were used to determine TC at an erosion rate of 1.0E-04.

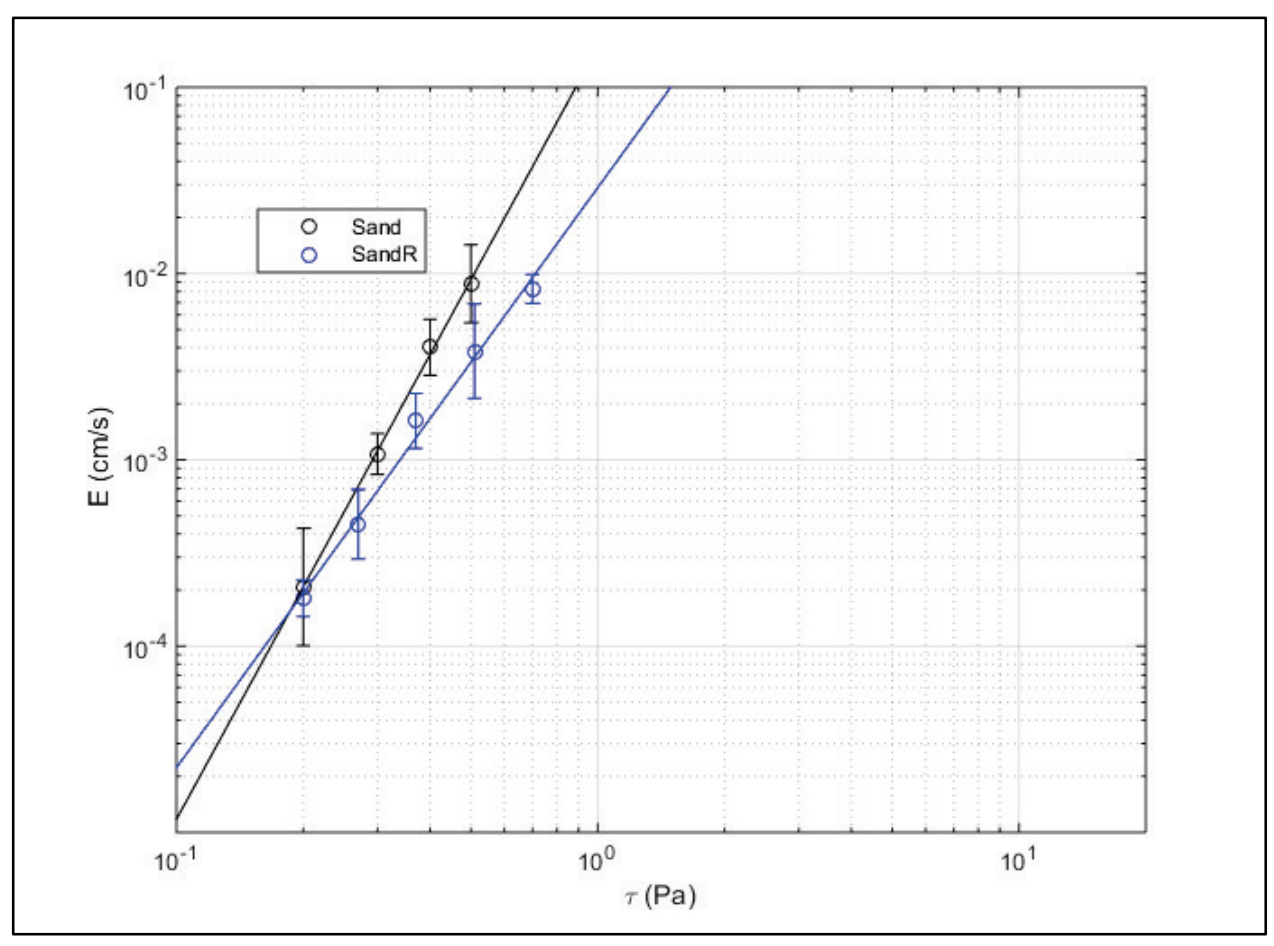


Table C-2. Kaolinite mud erosion parameters.

\begin{tabular}{|c|c|c|c|c|c|}
\hline $\begin{array}{c}\text { Mud } \\
\text { (\% mass) }\end{array}$ & $T_{c}$ & $\begin{array}{c}T_{c} \\
\text { (low) }\end{array}$ & $\begin{array}{c}T_{c} \\
\text { (high) }\end{array}$ & $A$ & $n$ \\
\hline 1 & 0.17 & 0.14 & 0.18 & 1.12E-01 & 3.93 \\
\hline $1 R$ & 0.15 & 0.14 & 0.17 & 2.14E-02 & 2.84 \\
\hline 2 & 0.20 & 0.19 & 0.22 & 4.03E-02 & 3.76 \\
\hline 3 & 0.15 & 0.16 & 0.18 & 7.56E-03 & 2.31 \\
\hline $3 R$ & 0.20 & 0.19 & 0.21 & 6.57E-03 & 2.58 \\
\hline 4 & 0.19 & 0.19 & 0.20 & 8.90E-03 & 2.73 \\
\hline 5 & 0.30 & 0.28 & 0.32 & 4.79E-03 & 3.20 \\
\hline $5 R$ & 0.28 & 0.26 & 0.29 & $2.48 \mathrm{E}-03$ & 2.50 \\
\hline 8 & 0.29 & 0.27 & 0.32 & 1.37E-03 & 2.13 \\
\hline 11 & 0.34 & 0.31 & 0.36 & 7.83E-04 & 1.92 \\
\hline 15 & 0.47 & 0.44 & 0.51 & 5.05E-04 & 2.17 \\
\hline $15 R$ & 0.90 & 0.82 & 0.97 & 1.30E-04 & 2.40 \\
\hline 21 & 0.36 & 0.32 & 0.39 & 6.38E-04 & 1.83 \\
\hline $21 R$ & 0.83 & 0.74 & 0.92 & $1.55 \mathrm{E}-04$ & 2.28 \\
\hline 29 & 0.88 & 0.72 & 1.07 & $1.40 \mathrm{E}-04$ & 2.67 \\
\hline 40 & 0.76 & 0.64 & 0.91 & 1.91E-04 & 2.36 \\
\hline 60 & 0.50 & 0.37 & 0.54 & 4.28E-04 & 2.08 \\
\hline 80 & 0.54 & 0.49 & 0.60 & 4.44E-04 & 2.44 \\
\hline 100 & 0.33 & 0.31 & 0.39 & 1.37E-03 & 2.35 \\
\hline
\end{tabular}


Figure C-2. Plot of mean erosion rate data against shear stress for cores composed of $1 \%$ kaolinite mud. Regression lines fit to the data were used to determine $\mathrm{Tc}$ at an erosion rate of $1.0 \mathrm{E}-04$.

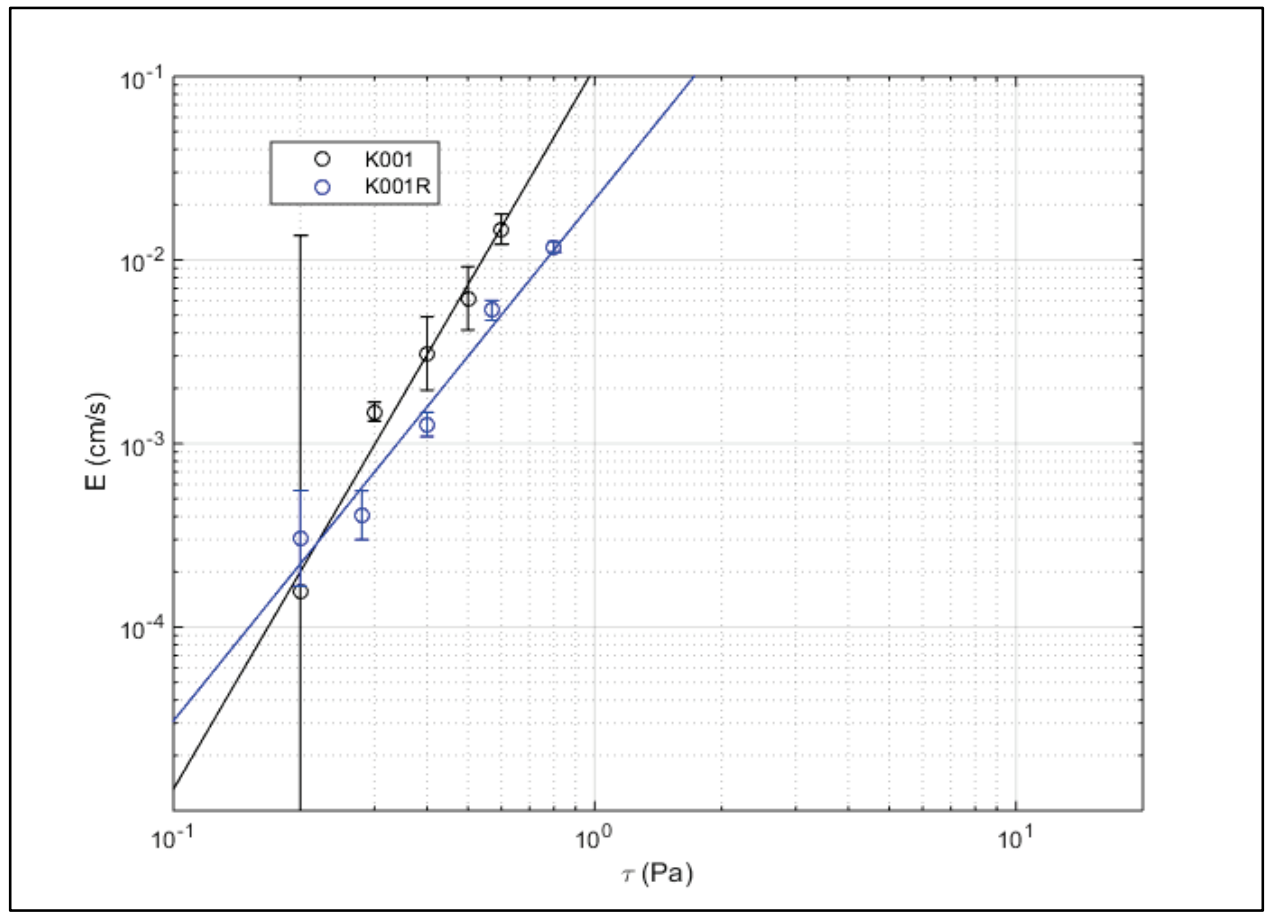

Figure C-3. Plot of mean erosion rate data against shear stress for cores composed of $2 \%$ kaolinite mud. Regression lines fit to the data were used to determine Tc at an erosion rate of $1.0 \mathrm{E}-04$.

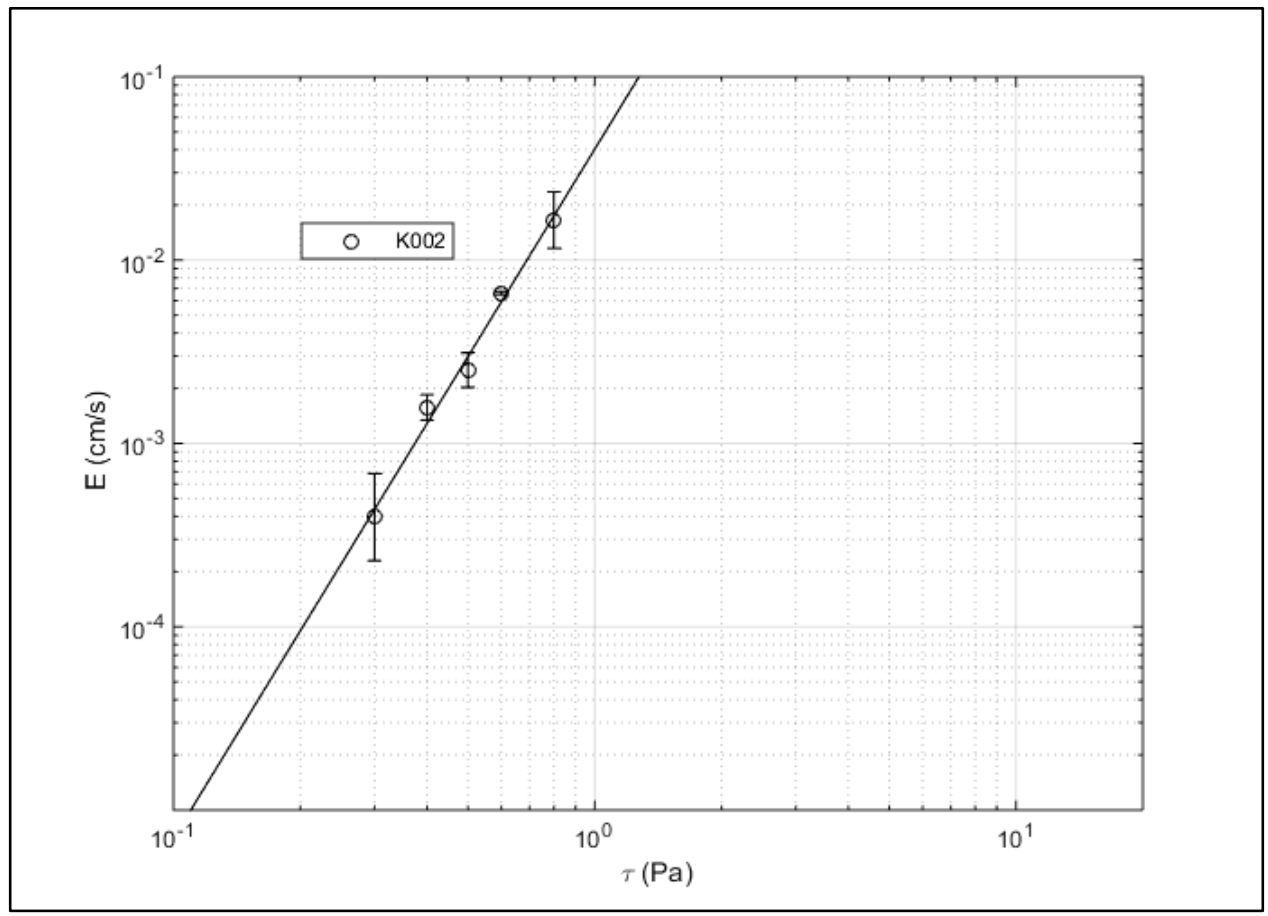


Figure C-4. Plot of mean erosion rate data against shear stress for cores composed of $3 \%$ kaolinite mud. Regression lines fit to the data were used to determine Tc at an erosion rate of $1.0 \mathrm{E}-04$.

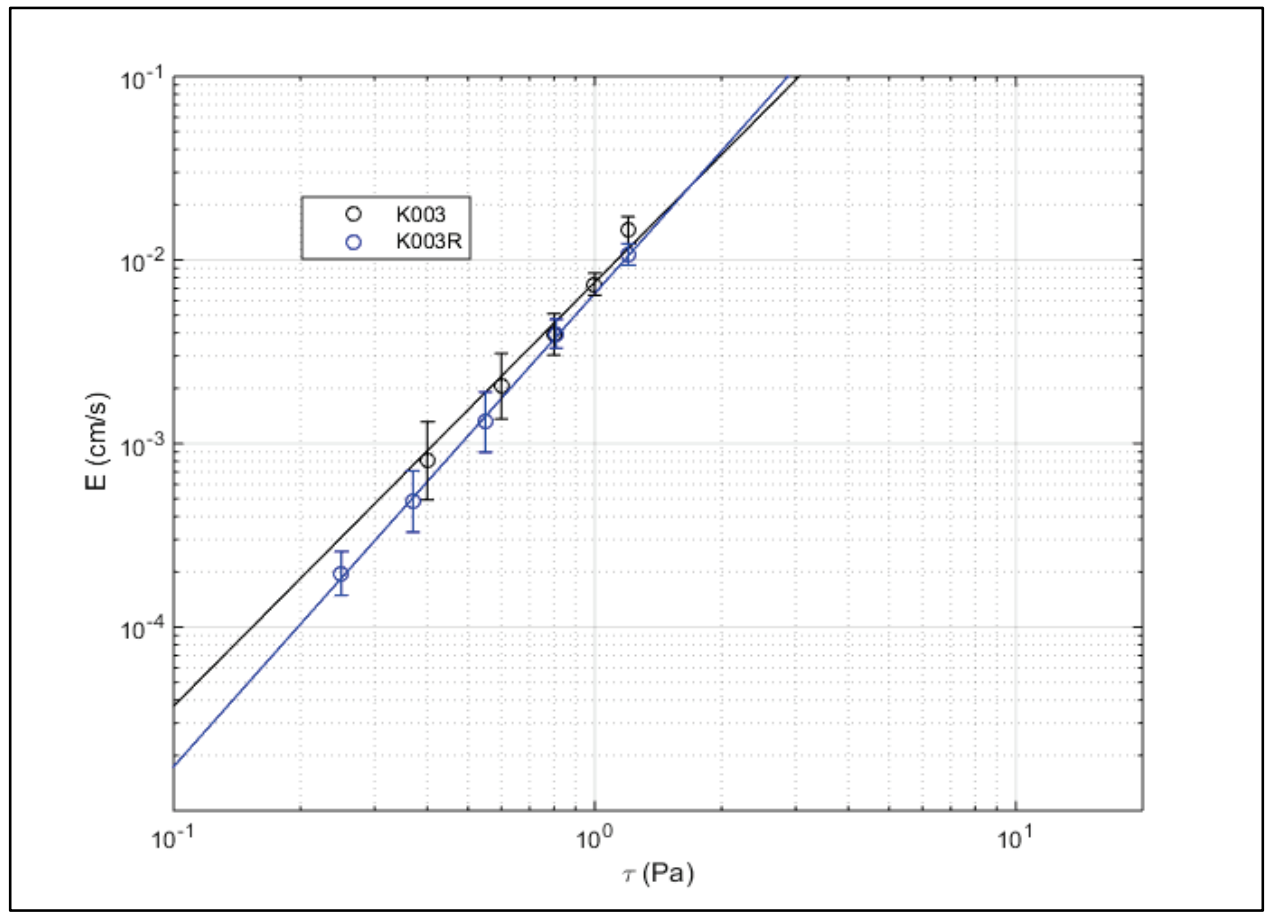

Figure C-5. Plot of mean erosion rate data against shear stress for cores composed of $4 \%$ kaolinite mud. Regression lines fit to the data were used to determine Tc at an erosion rate of $1.0 \mathrm{E}-04$.

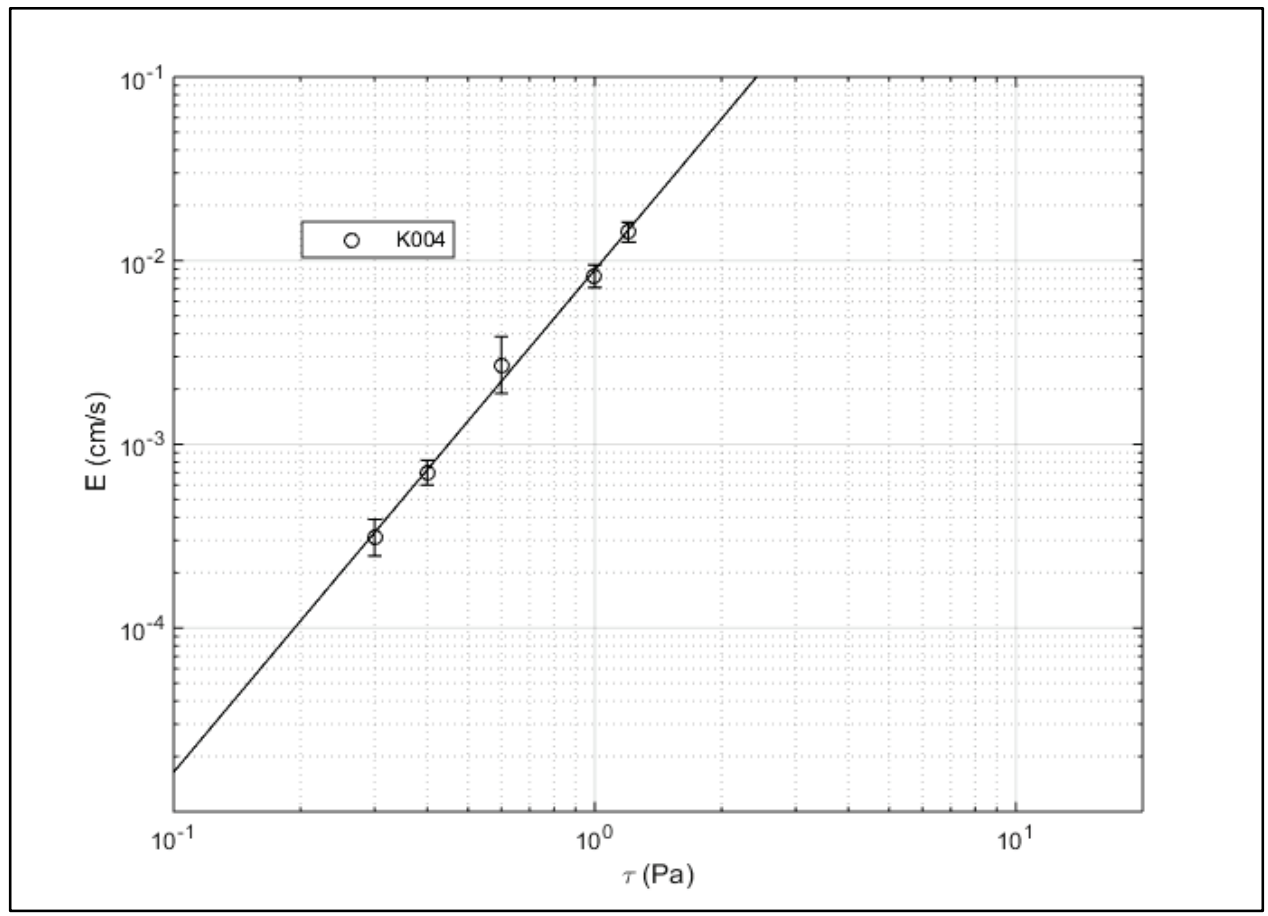


Figure C-6. Plot of mean erosion rate data against shear stress for cores composed of $5 \%$ kaolinite mud. Regression lines fit to the data were used to determine $T_{c}$ at an erosion rate of $1.0 \mathrm{E}-04$.

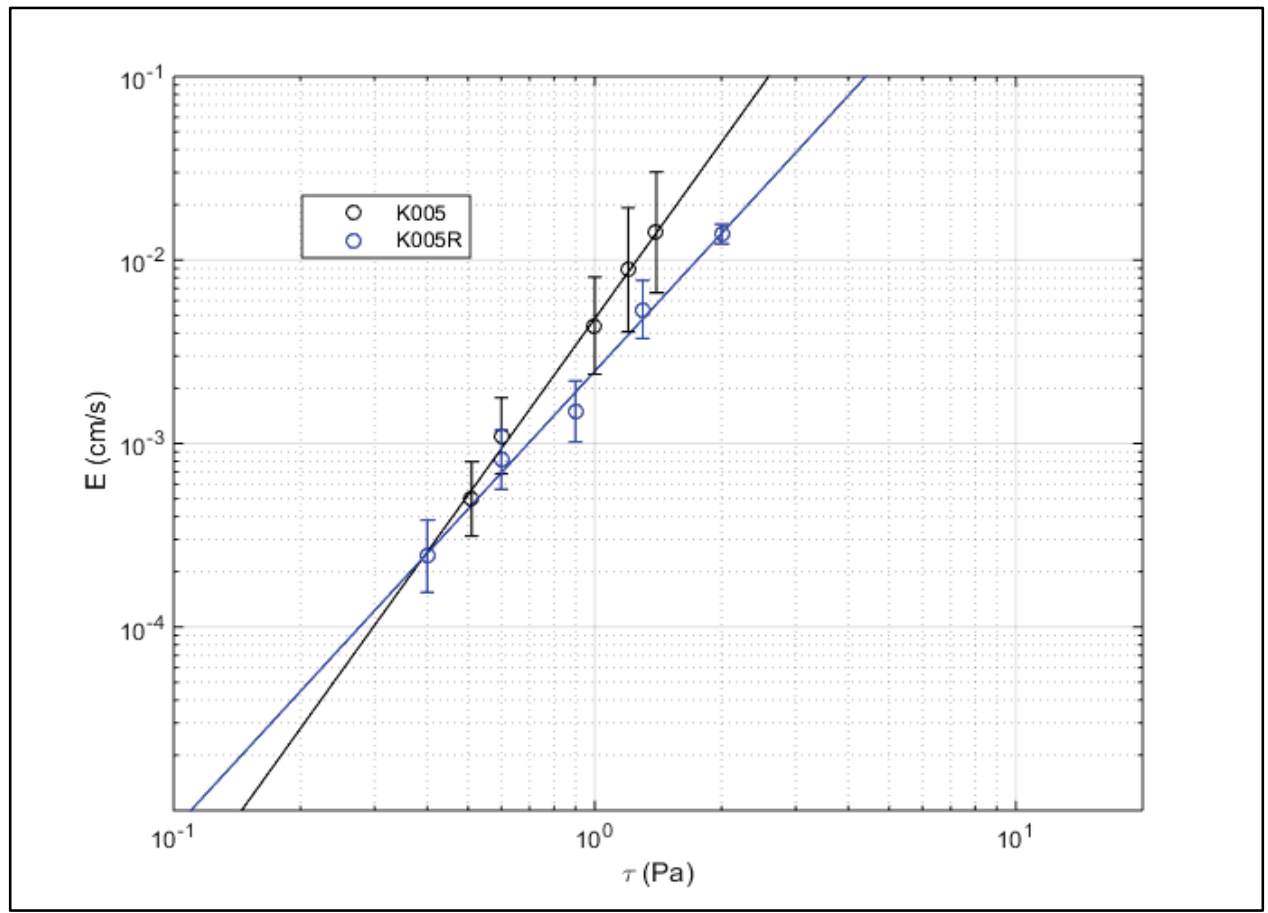

Figure C-7. Plot of mean erosion rate data against shear stress for cores composed of $8 \%$ kaolinite mud. Regression lines fit to the data were used to determine $T_{c}$ at an erosion rate of $1.0 \mathrm{E}-04$.

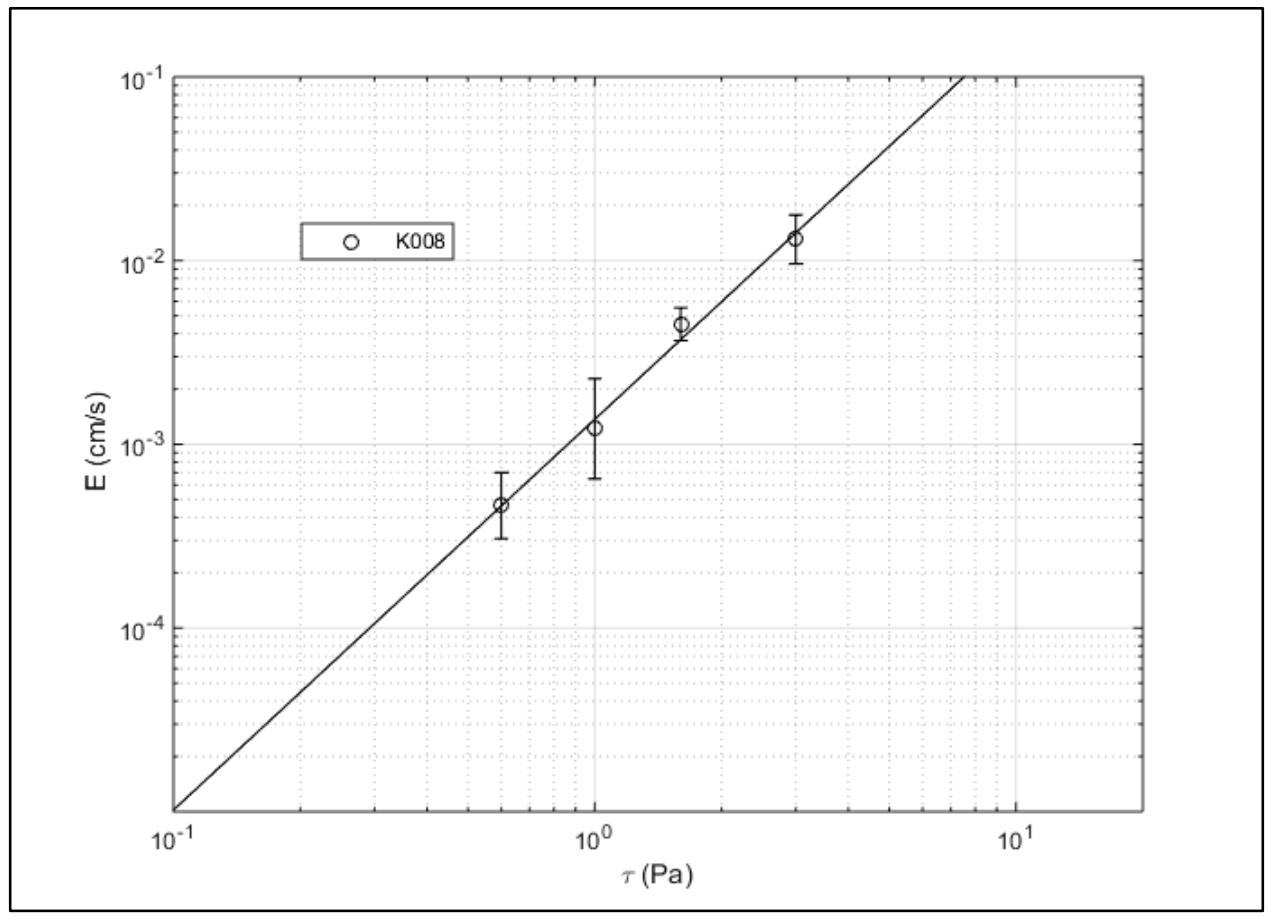


Figure C-8. Plot of mean erosion rate data against shear stress for cores composed of $11 \%$ kaolinite mud. Regression lines fit to the data were used to determine $T_{c}$ at an erosion rate of $1.0 \mathrm{E}-04$.

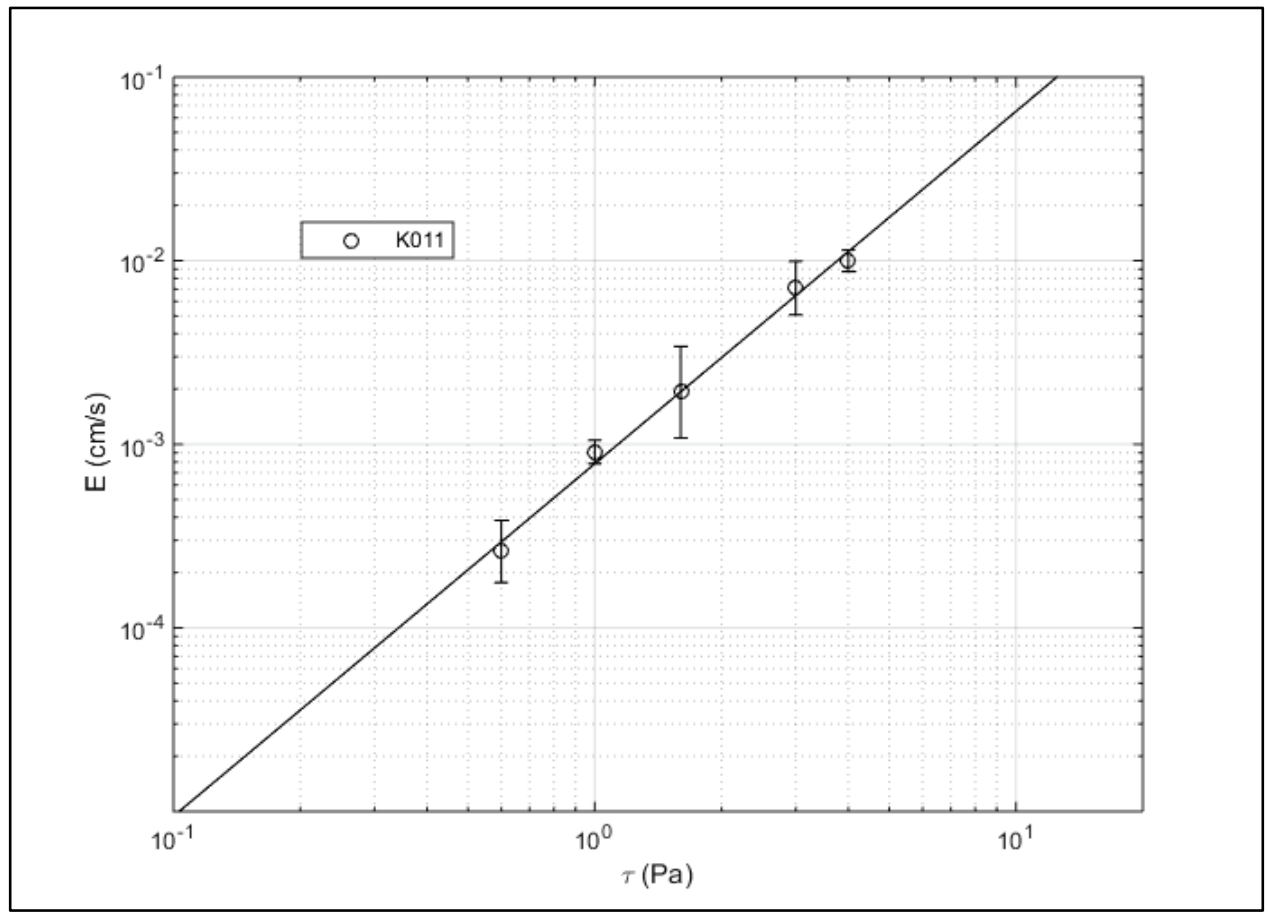

Figure C-9. Plot of mean erosion rate data against shear stress for cores composed of $15 \%$ kaolinite mud. Regression lines fit to the data were used to determine $\tau_{c}$ at an erosion rate of $1.0 \mathrm{E}-04$.

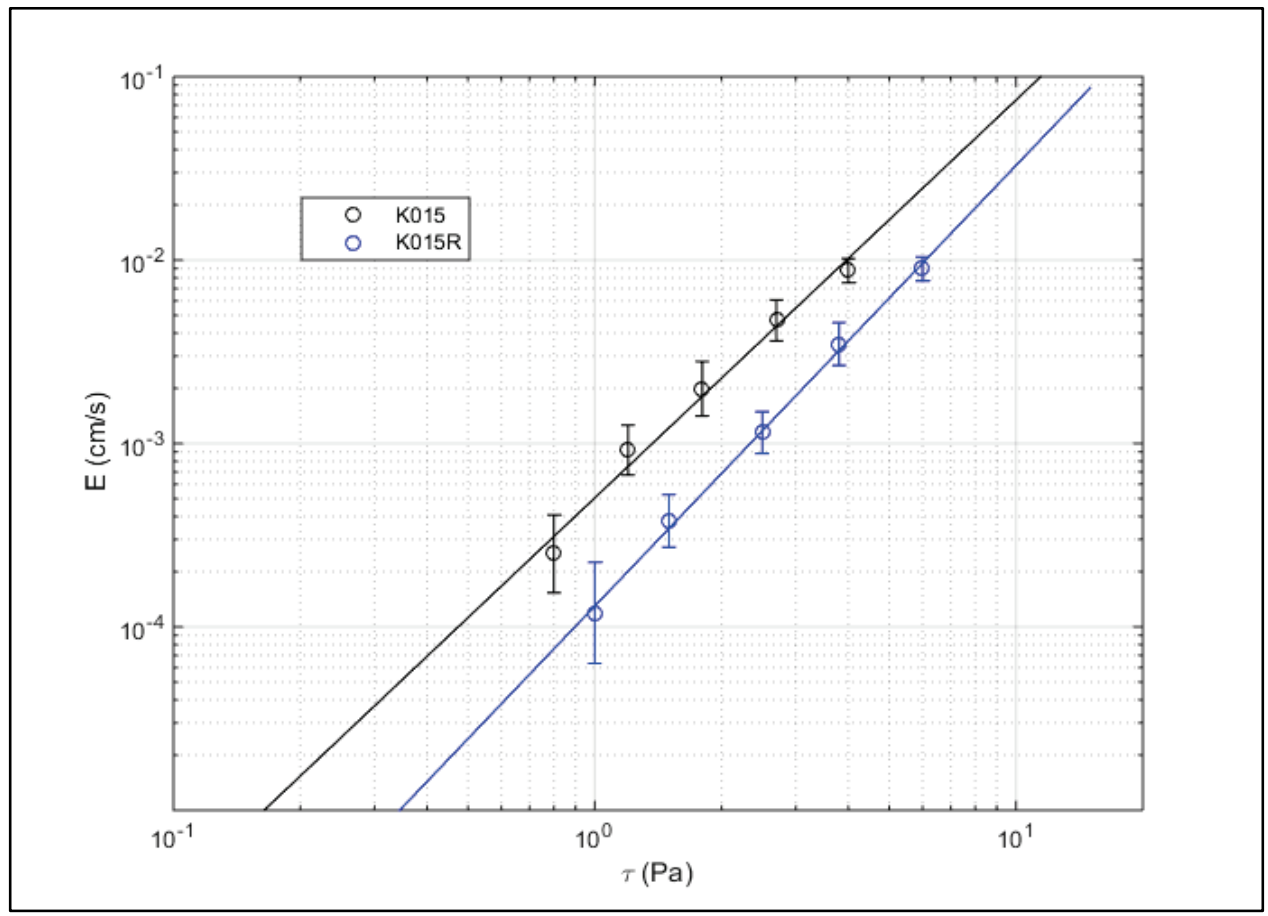


Figure C-10. Plot of mean erosion rate data against shear stress for cores composed of $21 \%$ kaolinite mud. Regression lines fit to the data were used to determine $T_{c}$ at an erosion rate of 1.0E-04.

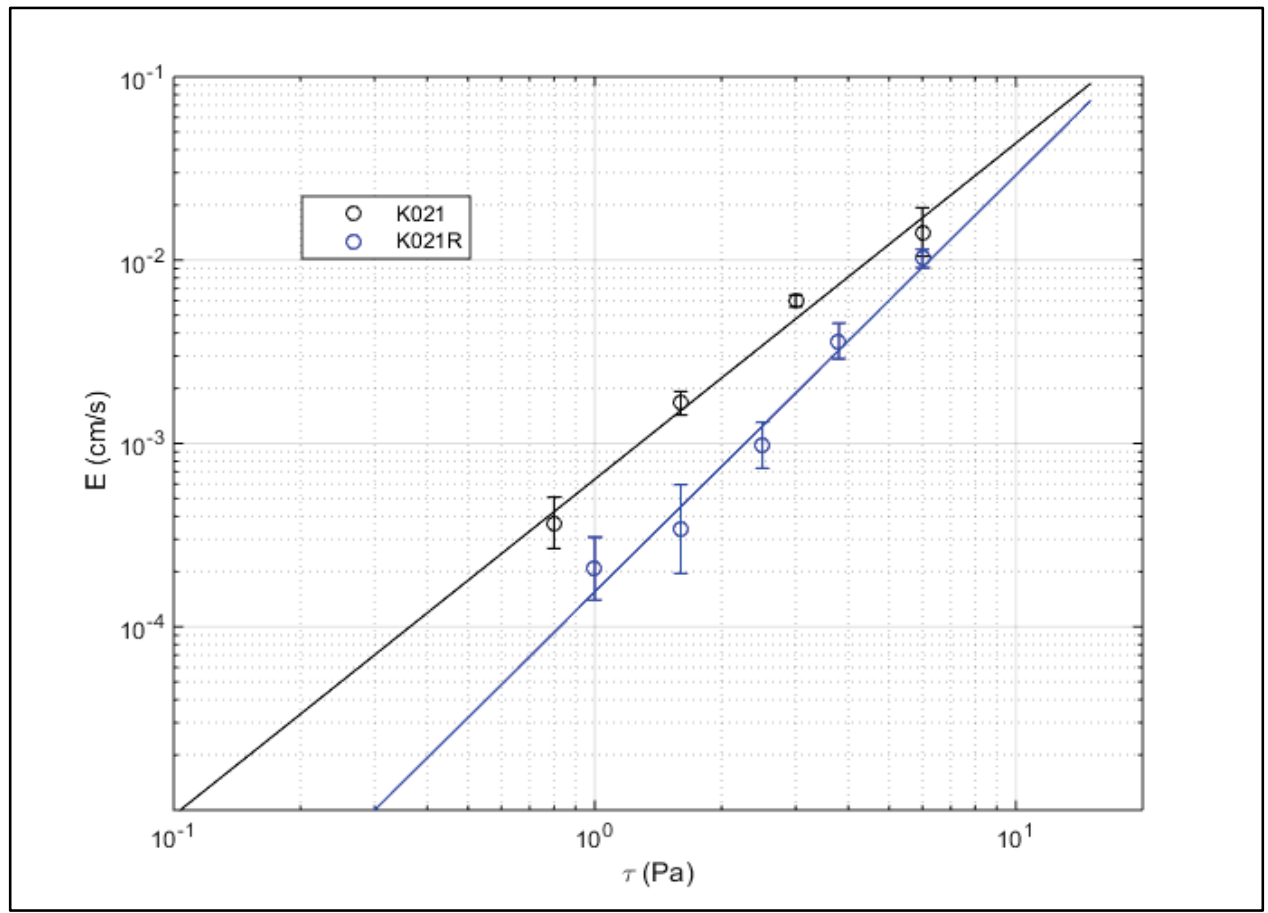

Figure $\mathrm{C}-11$. Plot of mean erosion rate data against shear stress for cores composed of $29 \%$ kaolinite mud. Regression lines fit to the data were used to determine $\tau_{c}$ at an erosion rate of 1.0E-04.

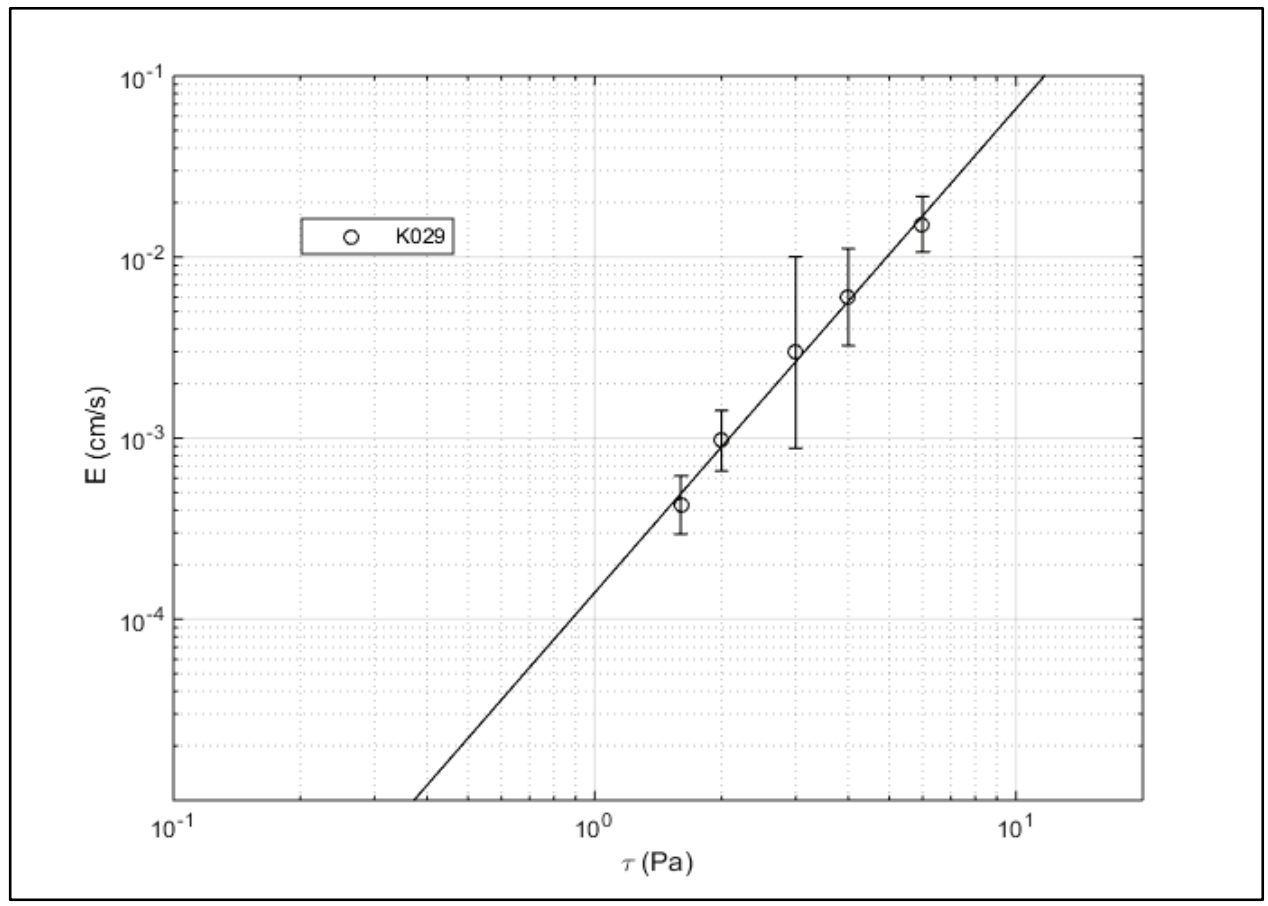


Figure $\mathrm{C}-12$. Plot of mean erosion rate data against shear stress for cores composed of $40 \%$ kaolinite mud. Regression lines fit to the data were used to determine $\tau_{c}$ at an erosion rate of 1.0E-04.

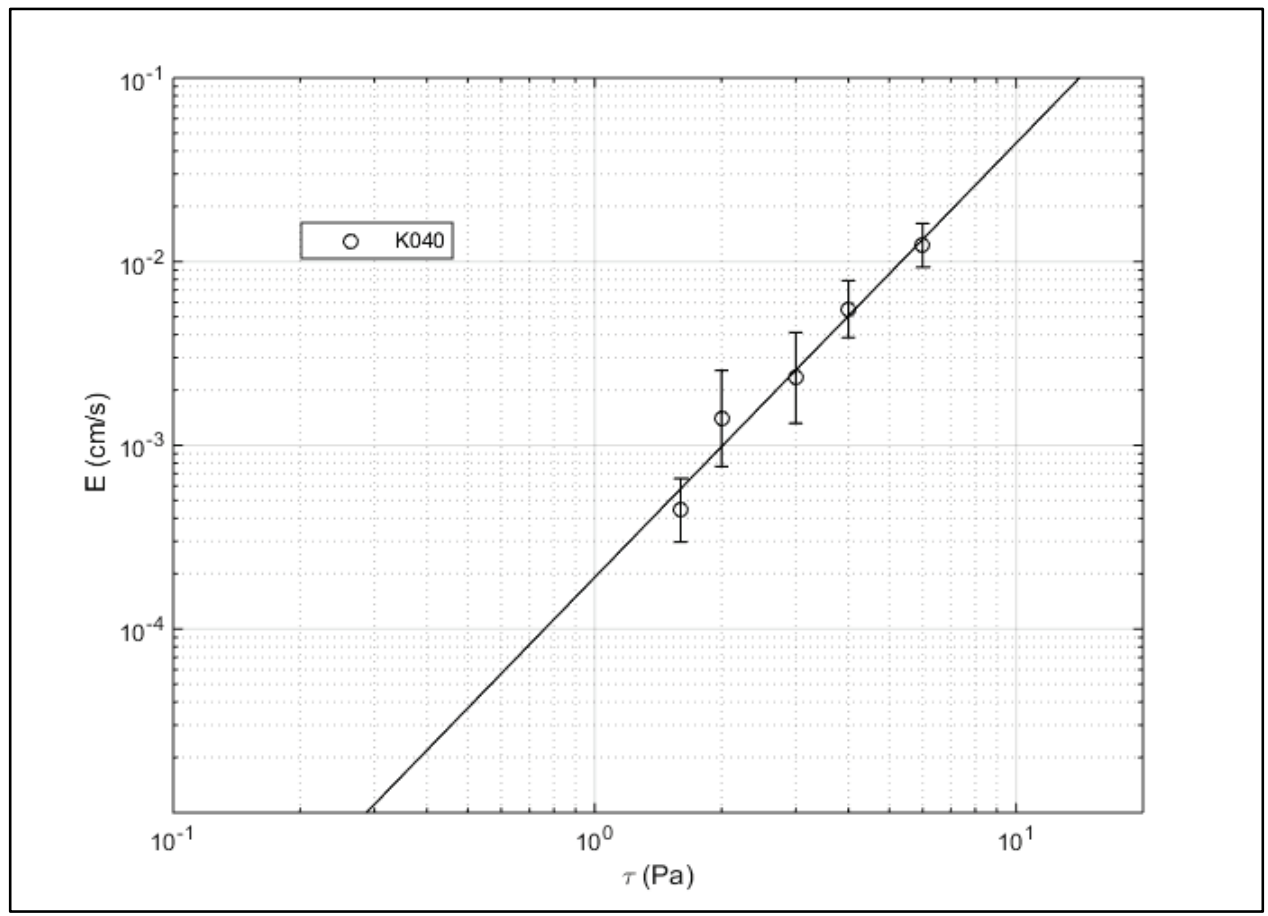

Figure $\mathrm{C}-13$. Plot of mean erosion rate data against shear stress for cores composed of $60 \%$ kaolinite mud. Regression lines fit to the data were used to determine $\tau_{c}$ at an erosion rate of 1.0E-04.

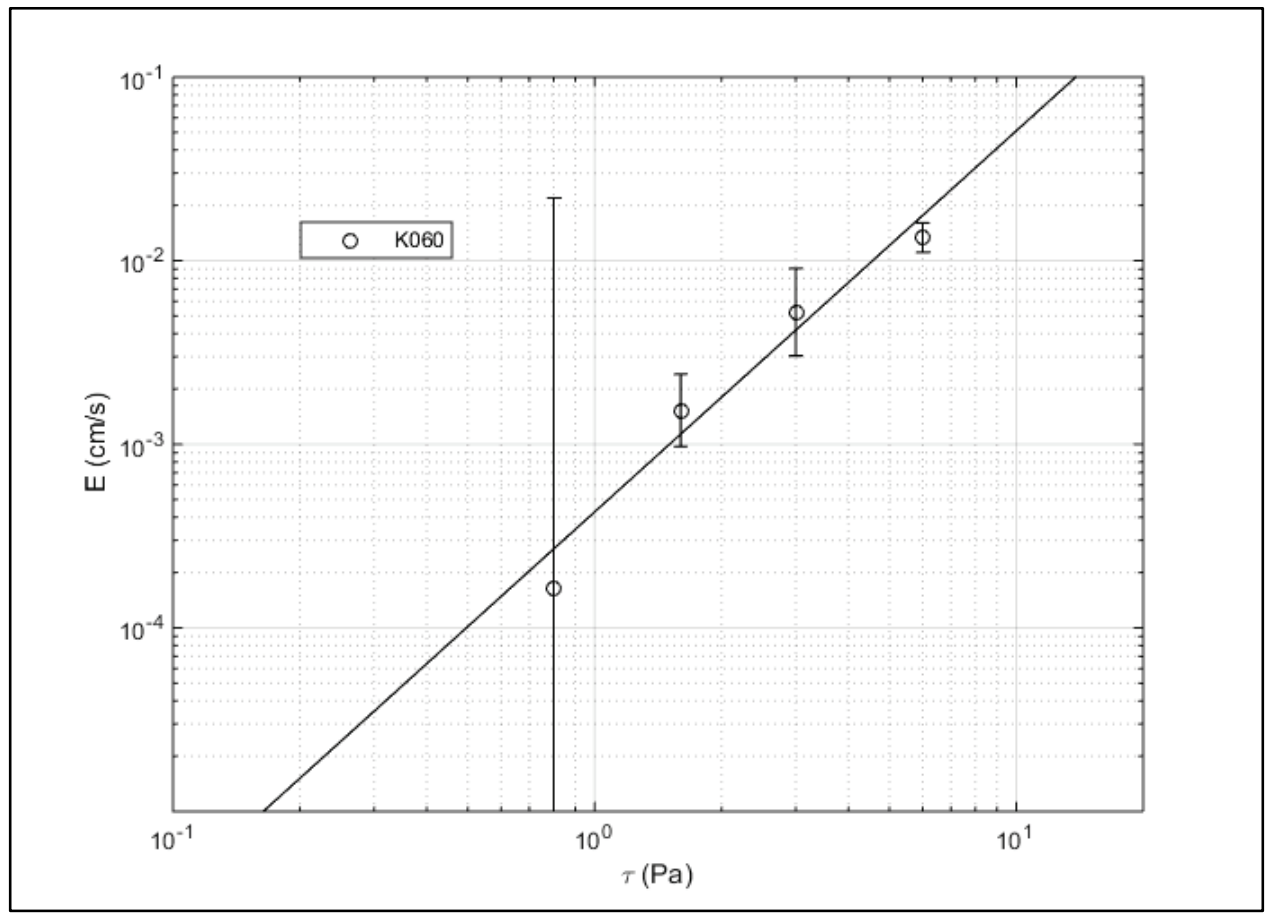


Figure C-14. Plot of mean erosion rate data against shear stress for cores composed of $80 \%$ kaolinite mud. Regression lines fit to the data were used to determine $\tau_{c}$ at an erosion rate of 1.0E-04.

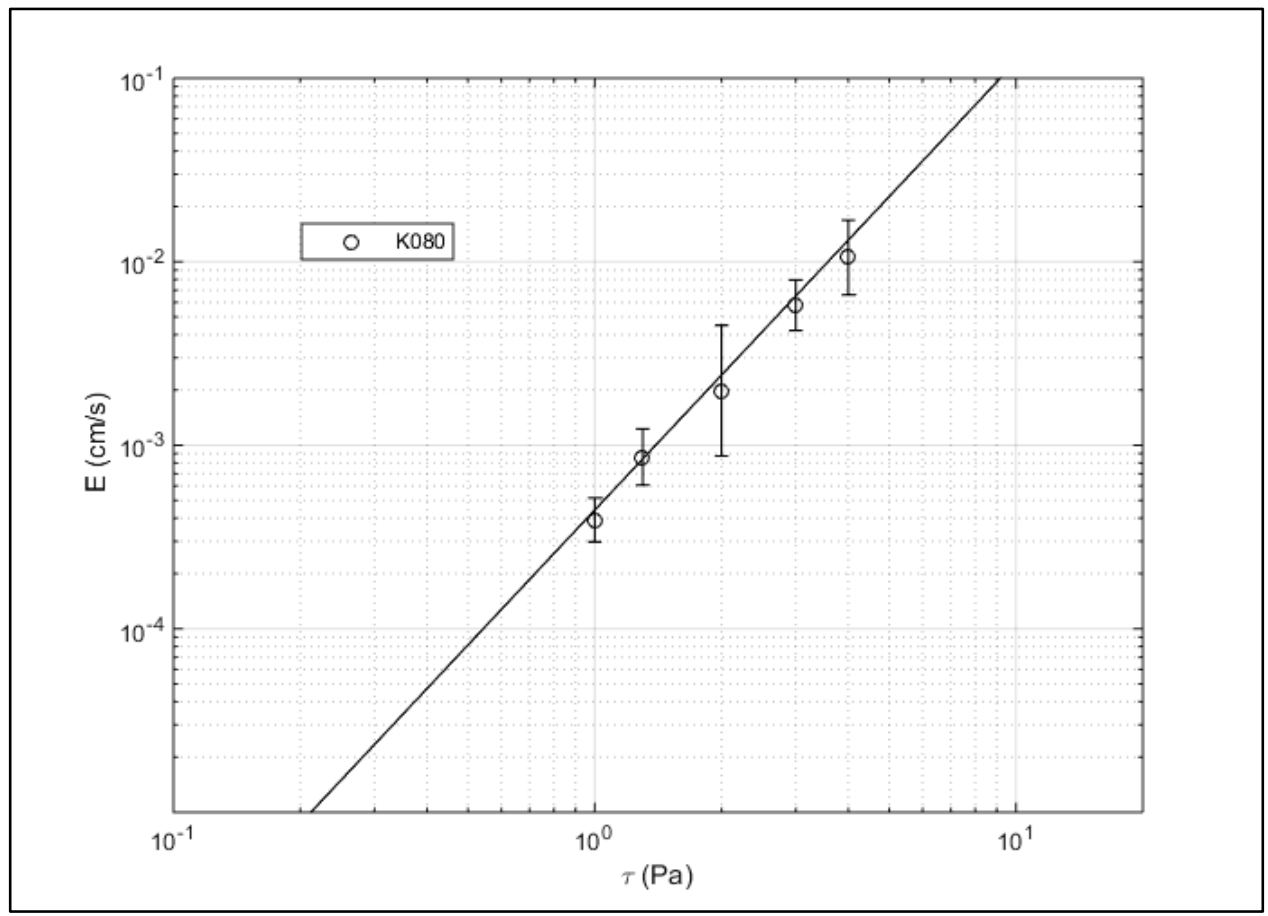

Figure $\mathrm{C}-15$. Plot of mean erosion rate data against shear stress for cores composed of $100 \%$ kaolinite mud. Regression lines fit to the data were used to determine $\tau_{c}$ at an erosion rate of $1.0 \mathrm{E}-04$.

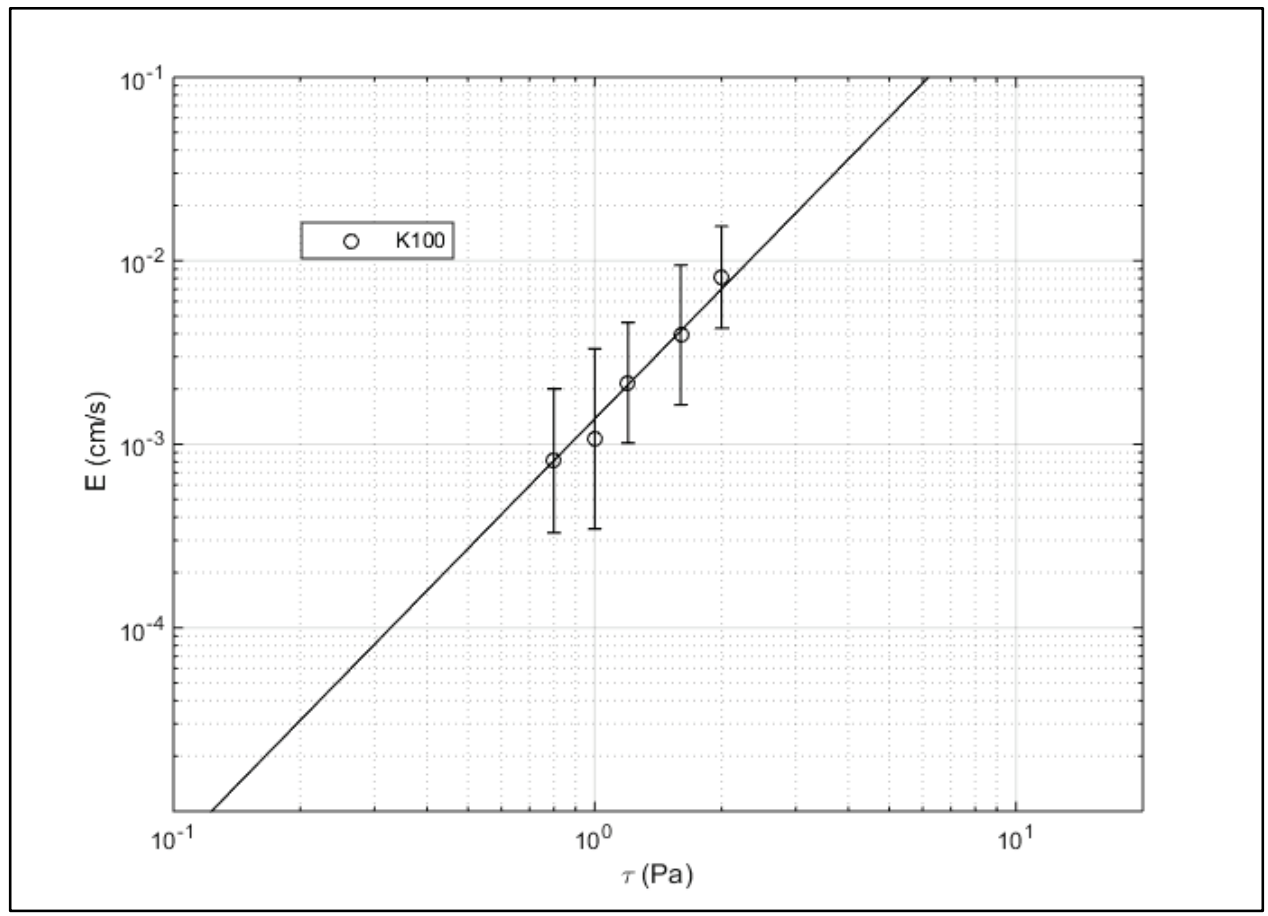


Table C-3. Kaolinite-bentonite mud erosion parameters.

\begin{tabular}{|c|c|c|c|c|c|}
\hline $\begin{array}{c}\text { Mud } \\
\text { (\% mass) }\end{array}$ & $T_{c}$ & $\begin{array}{c}T_{c} \\
\text { (low) }\end{array}$ & $\begin{array}{c}T_{c} \\
\text { (high) }\end{array}$ & $A$ & $n$ \\
\hline 1 & 0.17 & 0.18 & 0.21 & 1.81E-02 & 3.13 \\
\hline 2 & 0.19 & 0.18 & 0.20 & 7.90E-03 & 2.62 \\
\hline 3 & 0.29 & 0.27 & 0.31 & 5.49E-03 & 3.20 \\
\hline 4 & 0.30 & 0.29 & 0.31 & $2.38 \mathrm{E}-03$ & 2.64 \\
\hline 5 & 0.49 & 0.47 & 0.52 & $1.21 \mathrm{E}-03$ & 3.52 \\
\hline $5 R$ & 0.56 & 0.53 & 0.61 & 5.63E-04 & 3.02 \\
\hline 8 & 0.34 & 0.31 & 0.38 & 6.67E-04 & 1.78 \\
\hline $8 \mathrm{R}$ & 0.64 & 0.60 & 0.67 & 3.62E-04 & 2.83 \\
\hline 11 & 0.78 & 0.60 & 0.94 & $1.52 \mathrm{E}-04$ & 1.69 \\
\hline $11 R$ & 0.90 & 0.82 & 0.97 & 1.30E-04 & 2.40 \\
\hline 15 & 1.30 & 0.98 & 1.73 & 5.68E-05 & 2.16 \\
\hline 21 & 1.63 & 1.29 & 2.07 & 2.70E-05 & 2.66 \\
\hline $21 R$ & 1.51 & 1.32 & 1.71 & 3.34E-05 & 2.68 \\
\hline 29 & 1.80 & 1.52 & 2.12 & 1.76E-05 & 2.96 \\
\hline 40 & 1.56 & 1.20 & 2.01 & 2.34E-05 & 3.27 \\
\hline 60 & 1.52 & 1.28 & 1.83 & $2.25 \mathrm{E}-05$ & 3.54 \\
\hline 80 & 1.17 & 0.98 & 1.39 & 5.76E-05 & 3.57 \\
\hline $80 R$ & 1.13 & 1.00 & 1.27 & 6.13E-05 & 4.12 \\
\hline 100 & 1.40 & 1.14 & 1.72 & 2.80E-05 & 3.75 \\
\hline
\end{tabular}


Figure C-16. Plot of mean erosion rate data against shear stress for cores composed of $1 \%$ kaolinite-bentonite mud. Regression lines fit to the data were used to determine $\tau_{c}$ at an erosion rate of 1.0E-04.

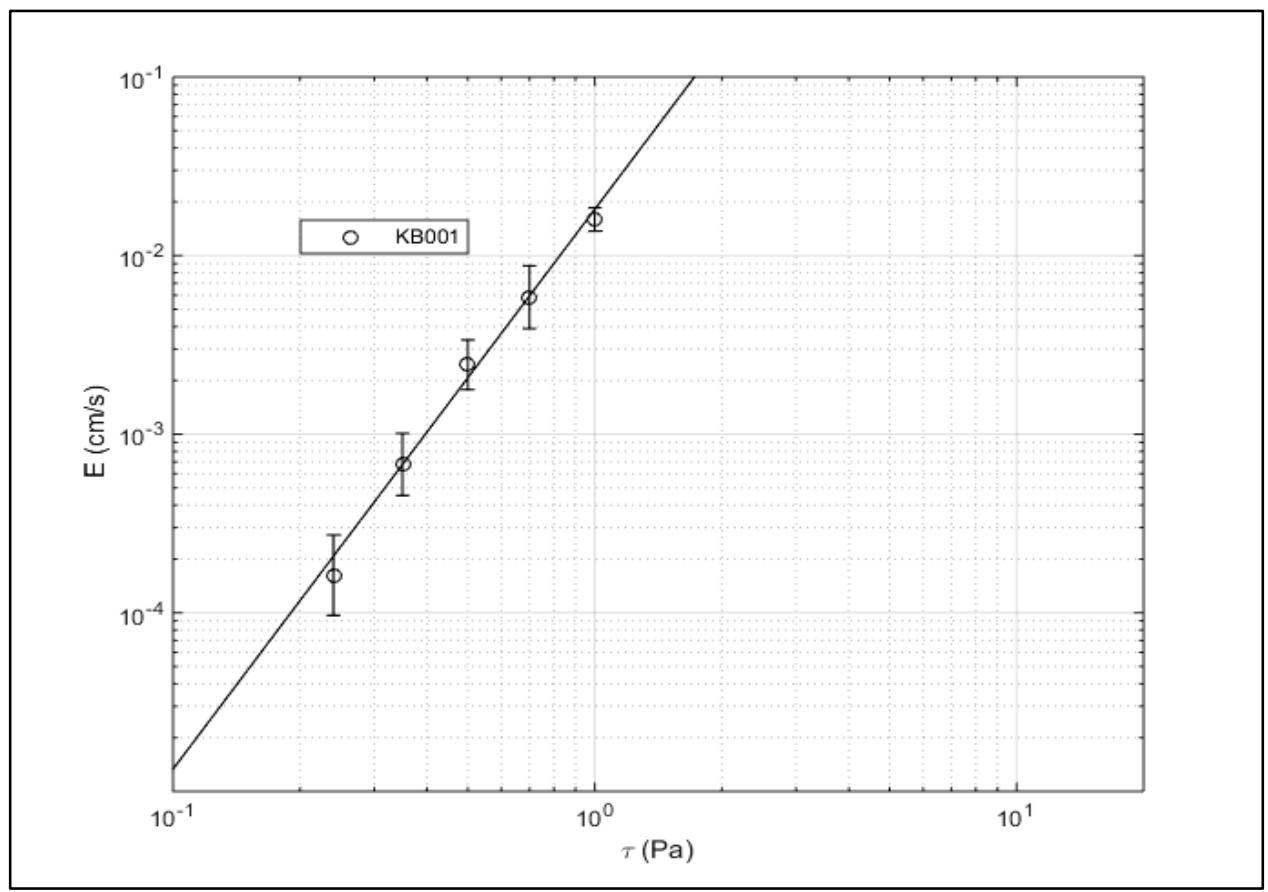

Figure C-17. Plot of mean erosion rate data against shear stress for cores composed of $2 \%$ kaolinite-bentonite mud. Regression lines fit to the data were used to determine $T_{c}$ at an erosion rate of 1.0E-04.

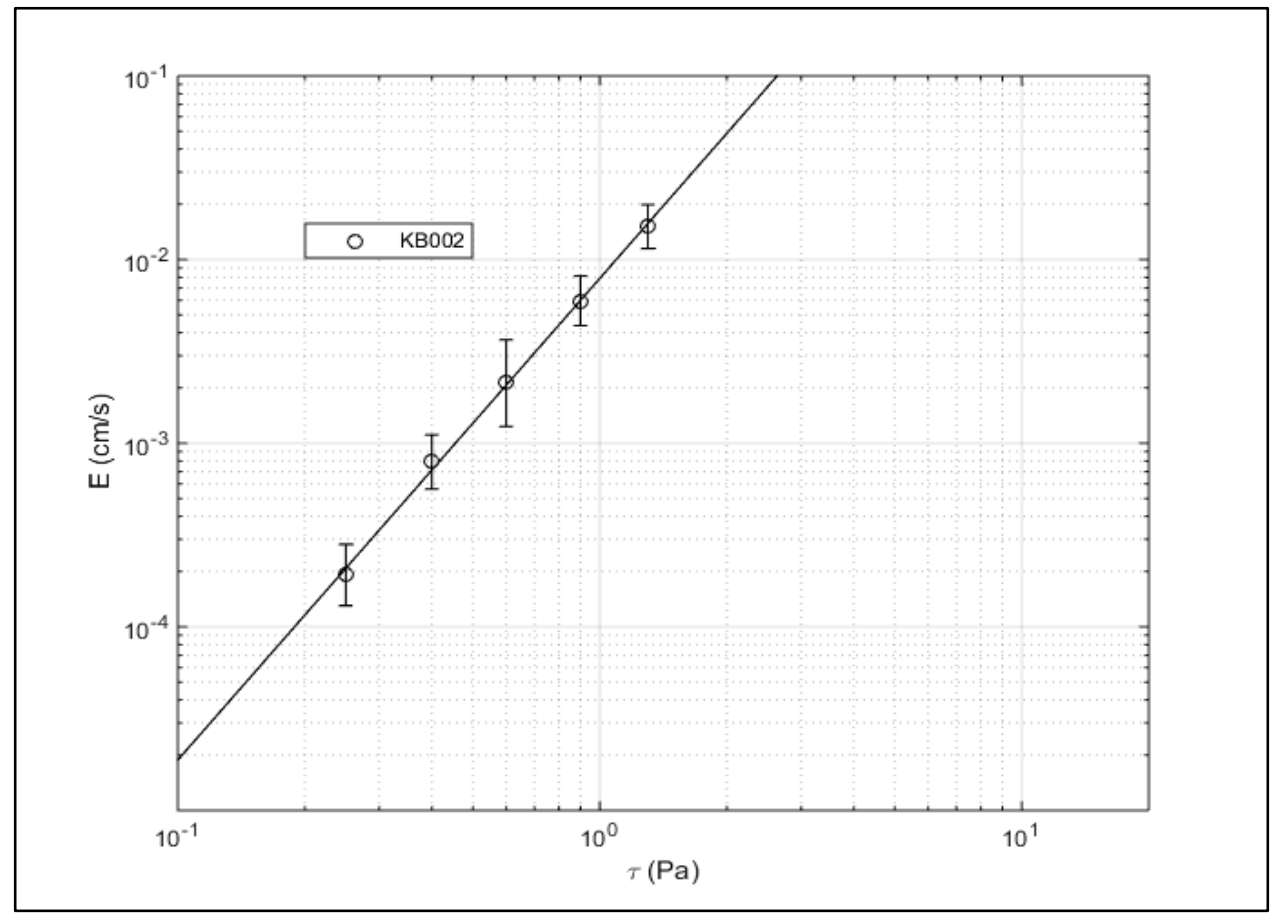


Figure C-18. Plot of mean erosion rate data against shear stress for cores composed of $3 \%$ kaolinite-bentonite mud. Regression lines fit to the data were used to determine $T_{c}$ at an erosion rate of 1.0E-04.

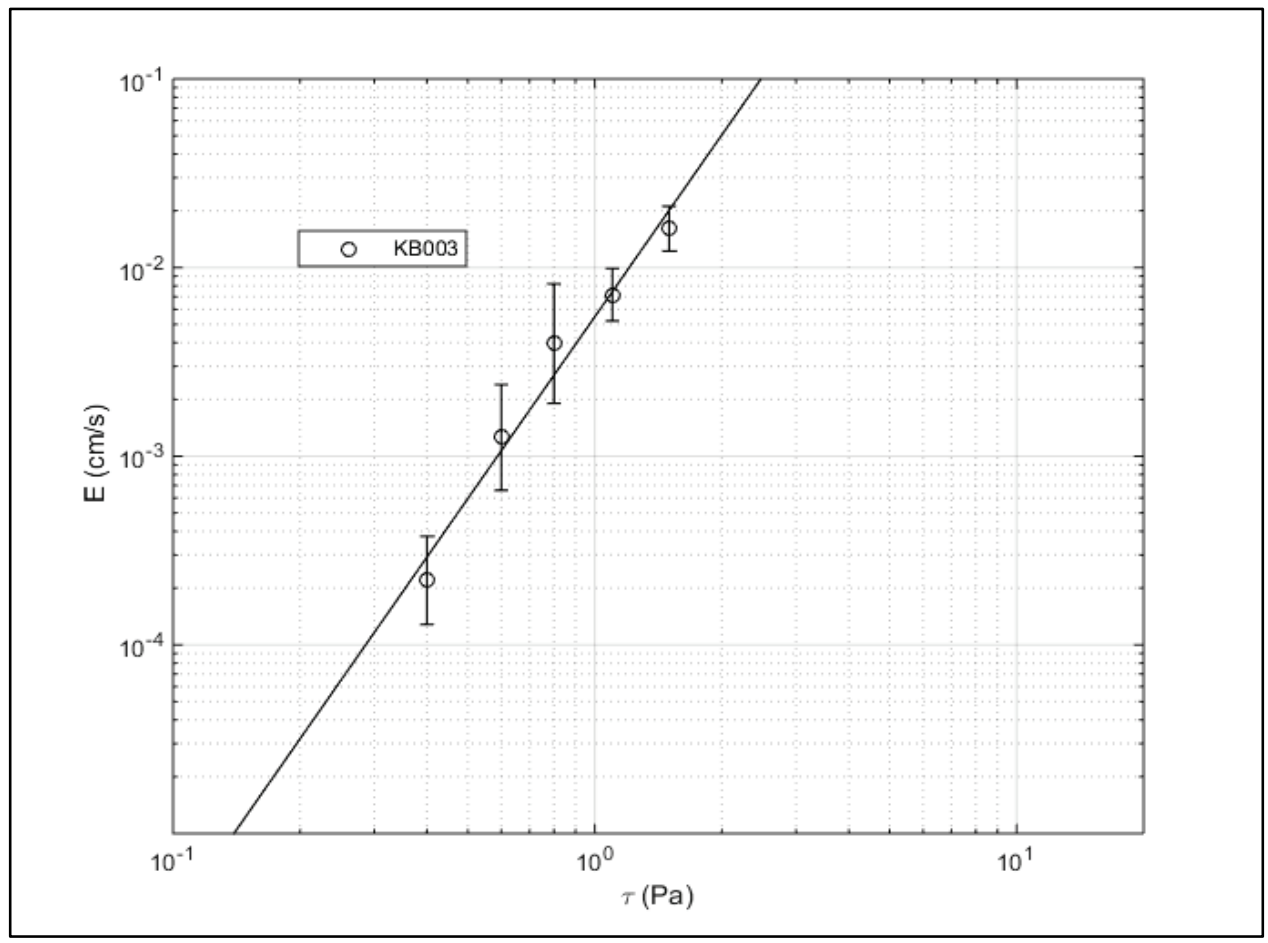

Figure C-19. Plot of mean erosion rate data against shear stress for cores composed of $4 \%$ kaolinite-bentonite mud. Regression lines fit to the data were used to determine $T_{c}$ at an erosion rate of 1.0E-04.

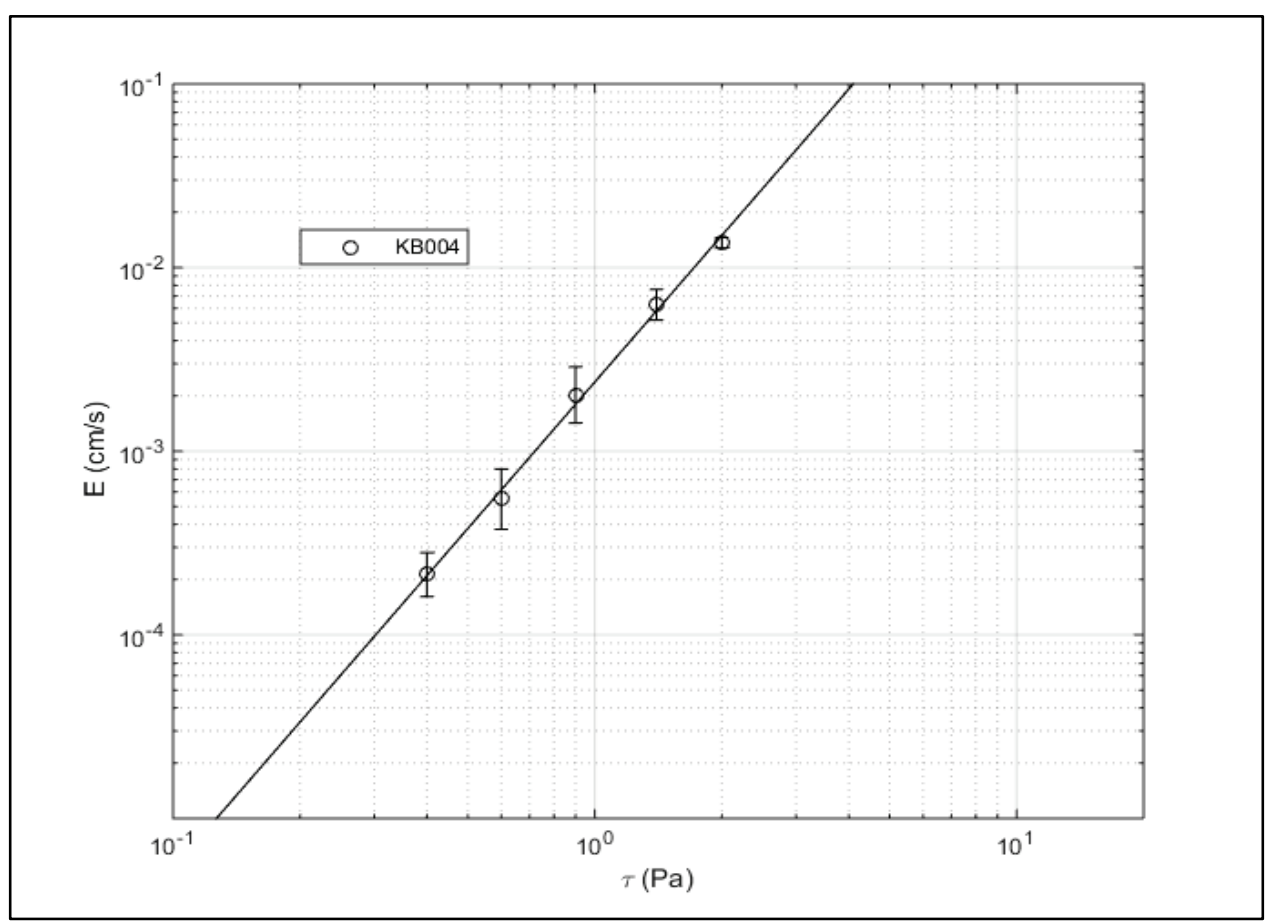


Figure C-20. Plot of mean erosion rate data against shear stress for cores composed of $5 \%$ kaolinite-bentonite mud. Regression lines fit to the data were used to determine $\tau_{c}$ at an erosion rate of 1.0E-04.

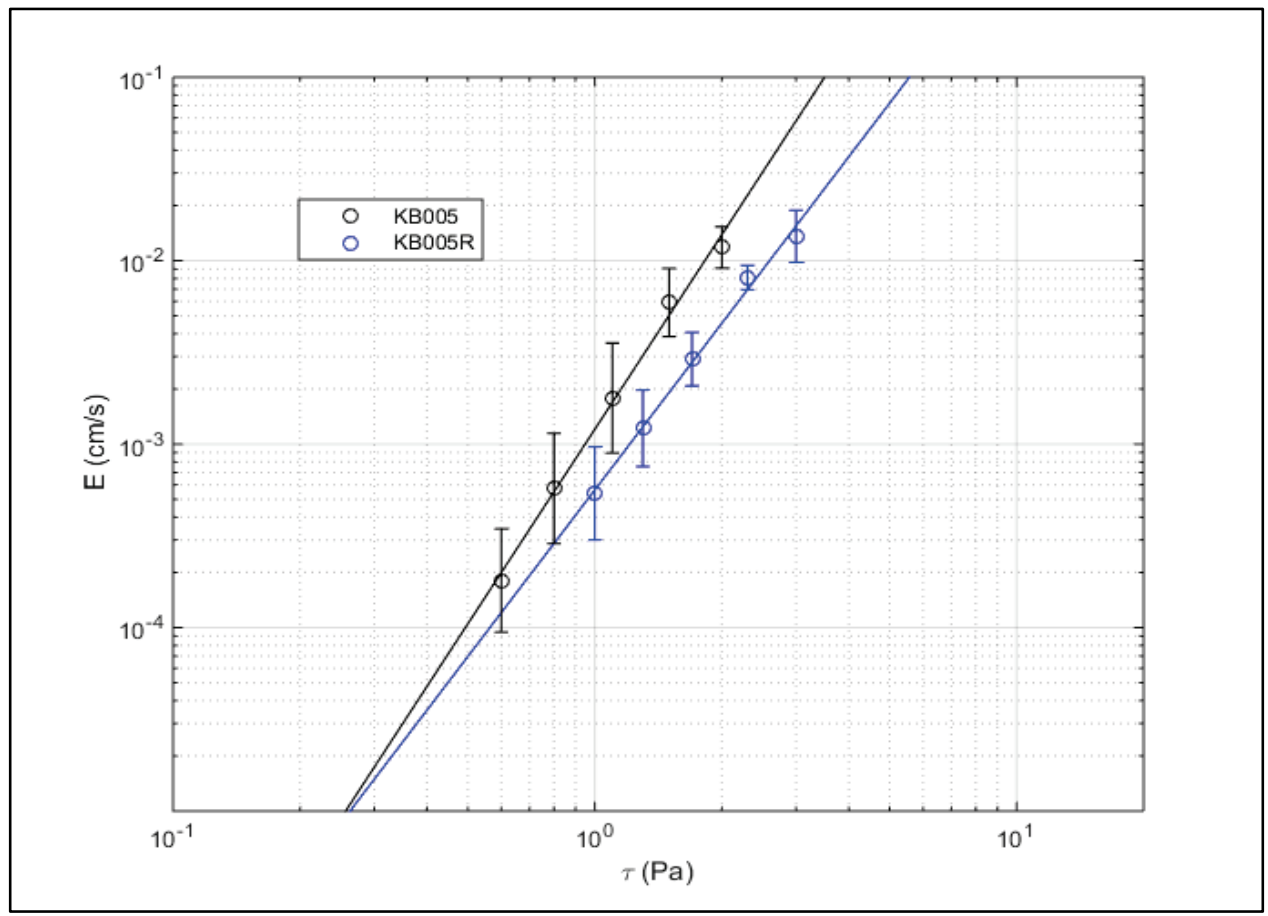

Figure C-21. Plot of mean erosion rate data against shear stress for cores composed of $8 \%$ kaolinite-bentonite mud. Regression lines fit to the data were used to determine $T_{c}$ at an erosion rate of 1.0E-04.

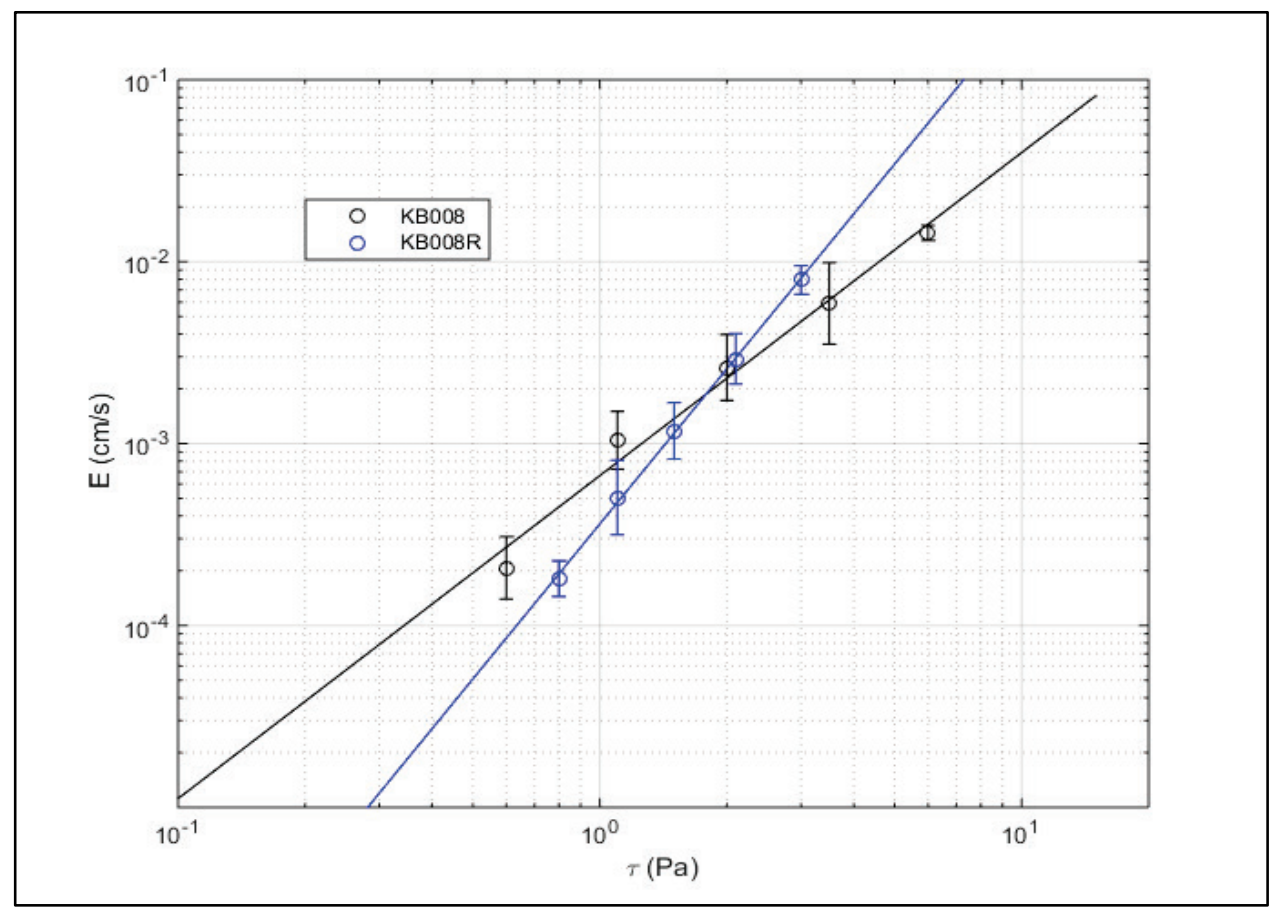


Figure C-22. Plot of mean erosion rate data against shear stress for cores composed of $11 \%$ kaolinite-bentonite mud. Regression lines fit to the data were used to determine $T_{c}$ at an erosion rate of 1.0E-04.

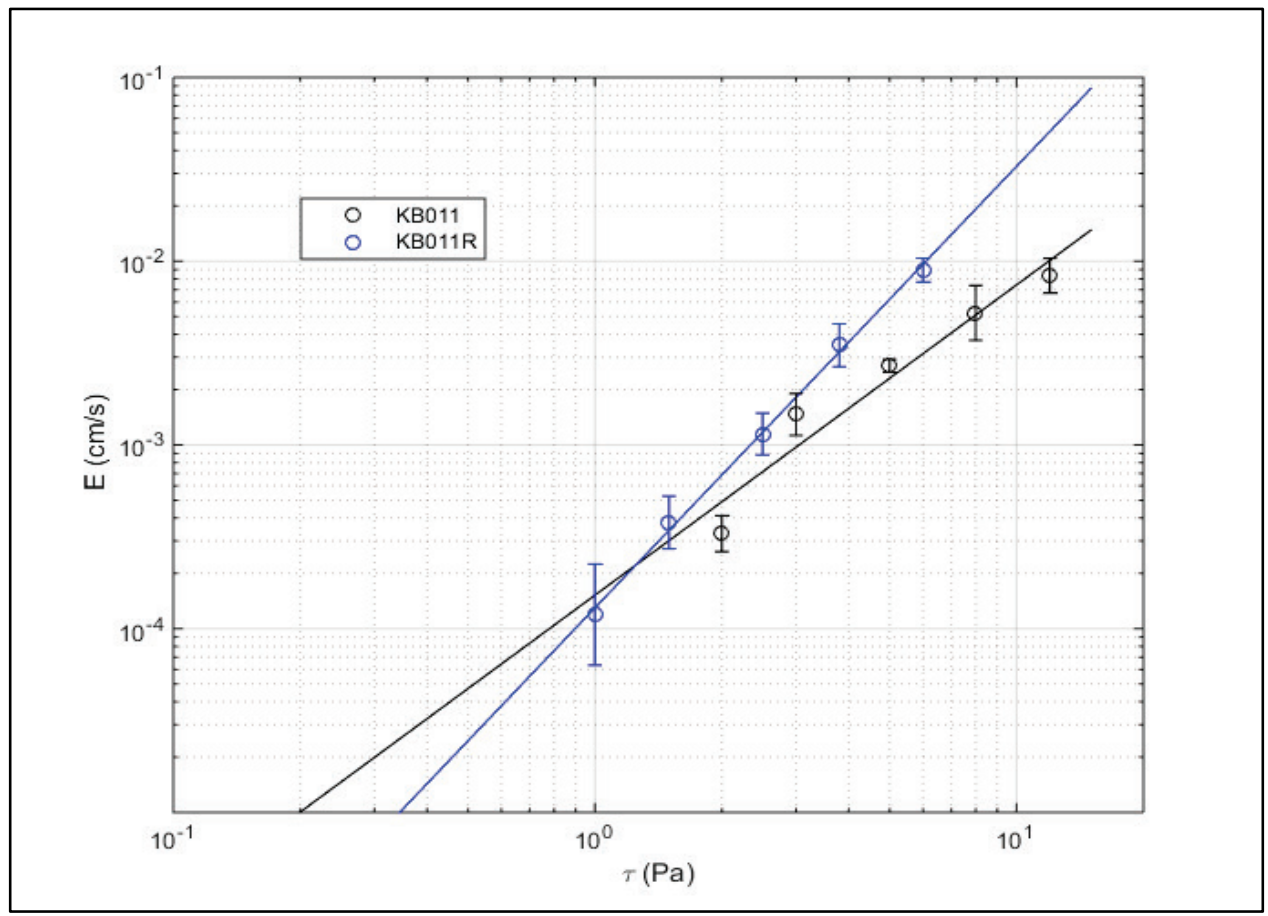

Figure C-23. Plot of mean erosion rate data against shear stress for cores composed of $15 \%$ kaolinite-bentonite mud. Regression lines fit to the data were used to determine $T_{c}$ at an erosion rate of 1.0E-04.

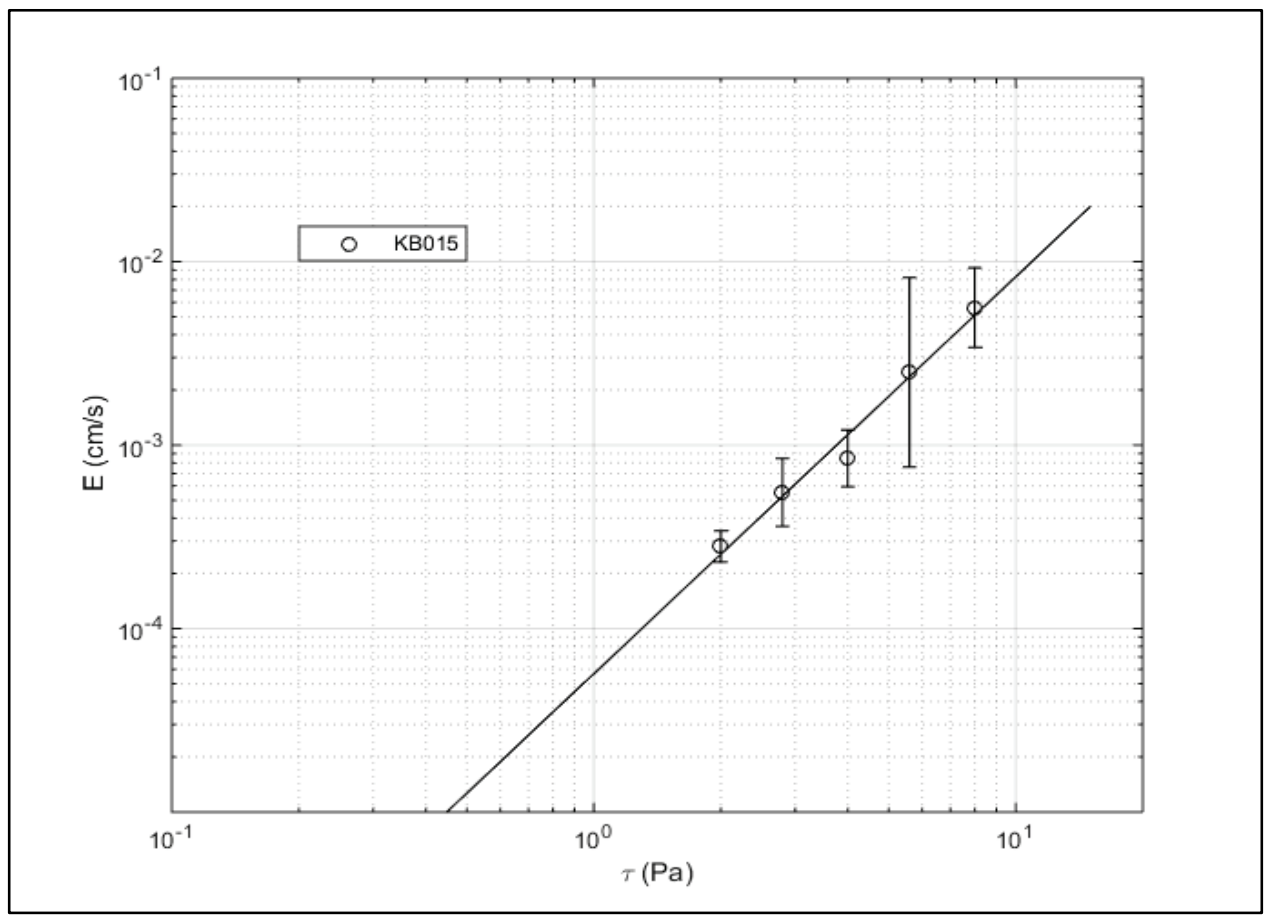


Figure C-24. Plot of mean erosion rate data against shear stress for cores composed of $21 \%$ kaolinite-bentonite mud. Regression lines fit to the data were used to determine $T_{c}$ at an erosion rate of 1.0E-04.

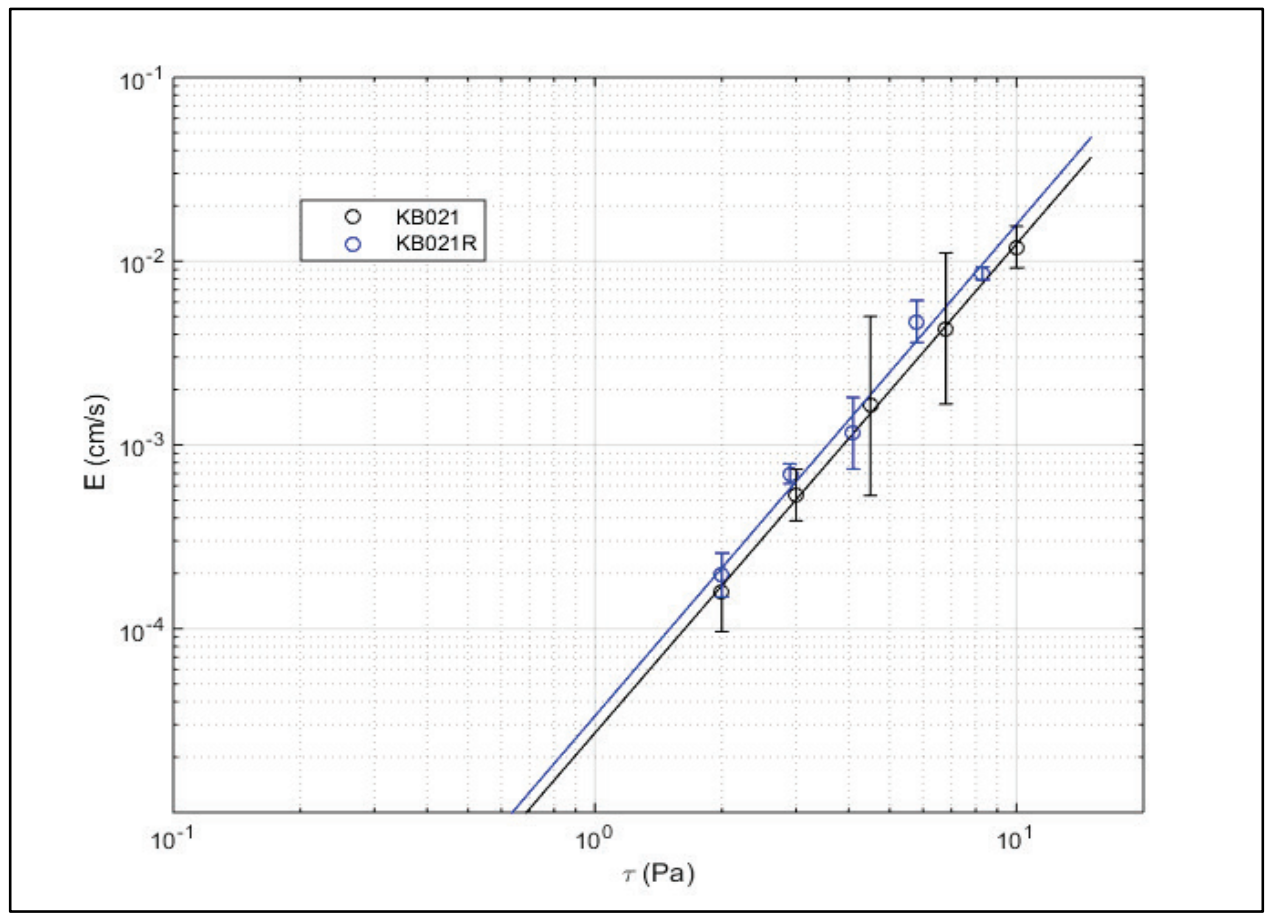

Figure C-25. Plot of mean erosion rate data against shear stress for cores composed of $29 \%$ kaolinite-bentonite mud. Regression lines fit to the data were used to determine $T_{c}$ at an erosion rate of 1.0E-04.

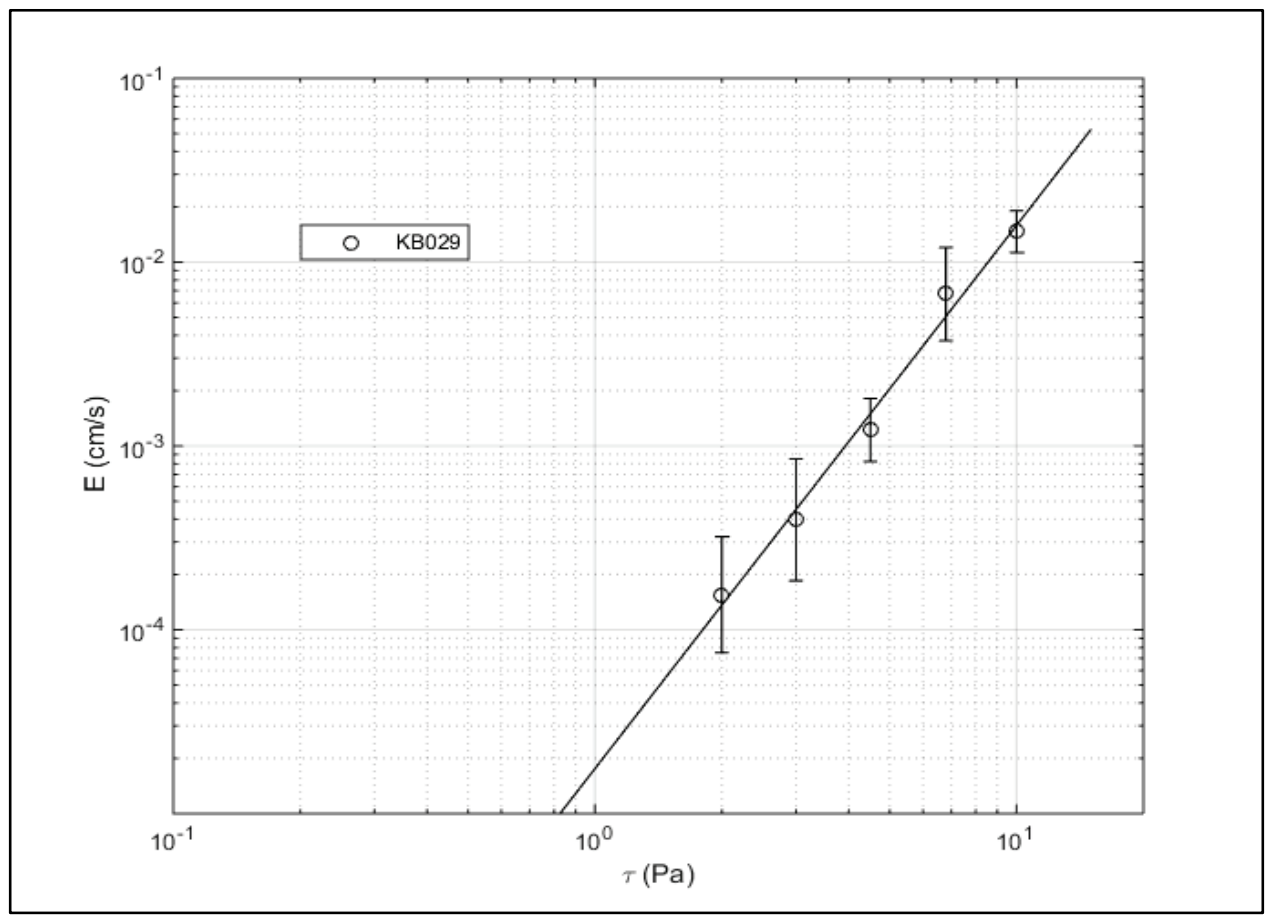


Figure C-26. Plot of mean erosion rate data against shear stress for cores composed of $40 \%$ kaolinite-bentonite mud. Regression lines fit to the data were used to determine $\tau_{c}$ at an erosion rate of 1.0E-04.

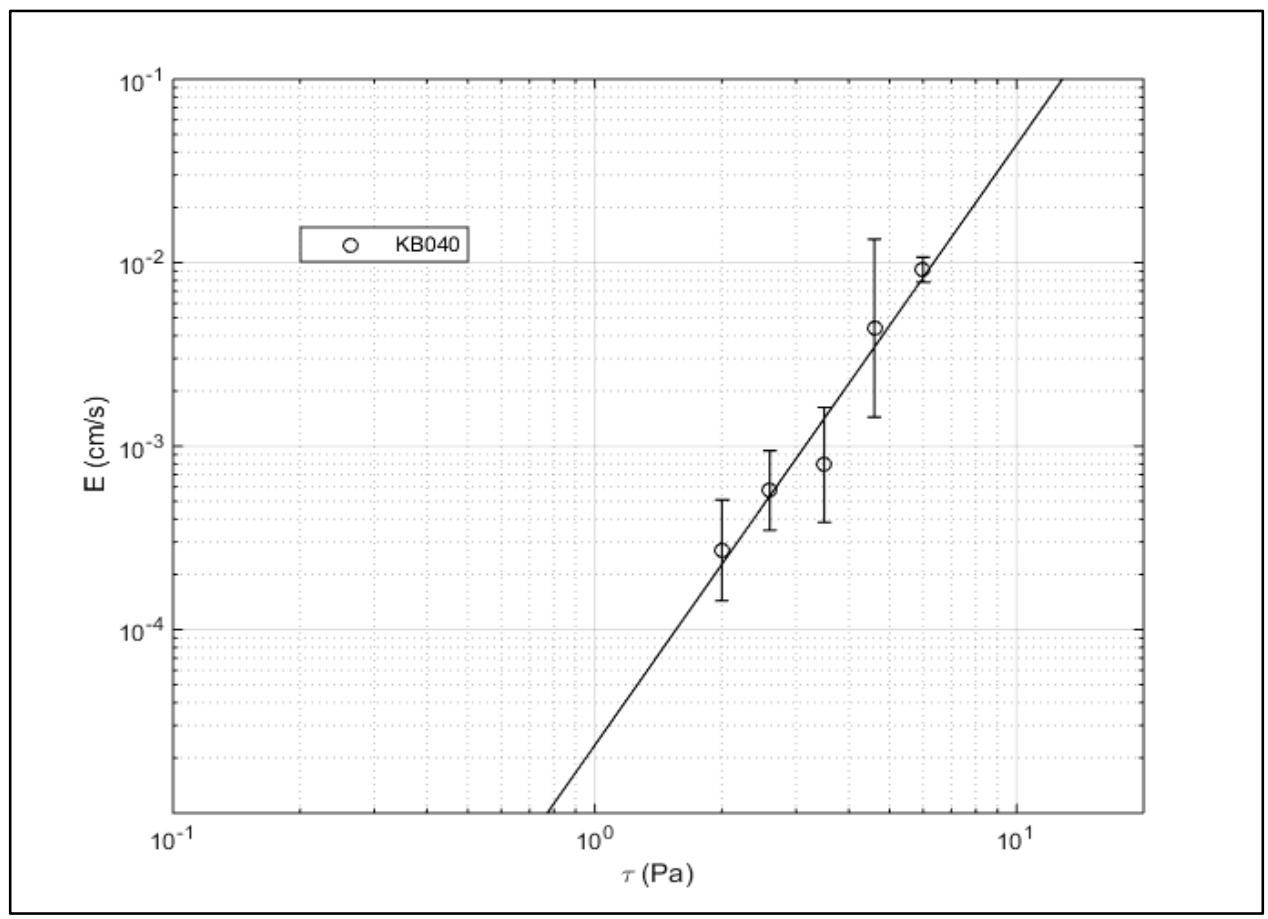

Figure C-27. Plot of mean erosion rate data against shear stress for cores composed of $60 \%$ kaolinite-bentonite mud. Regression lines fit to the data were used to determine $T_{c}$ at an erosion rate of 1.0E-04.

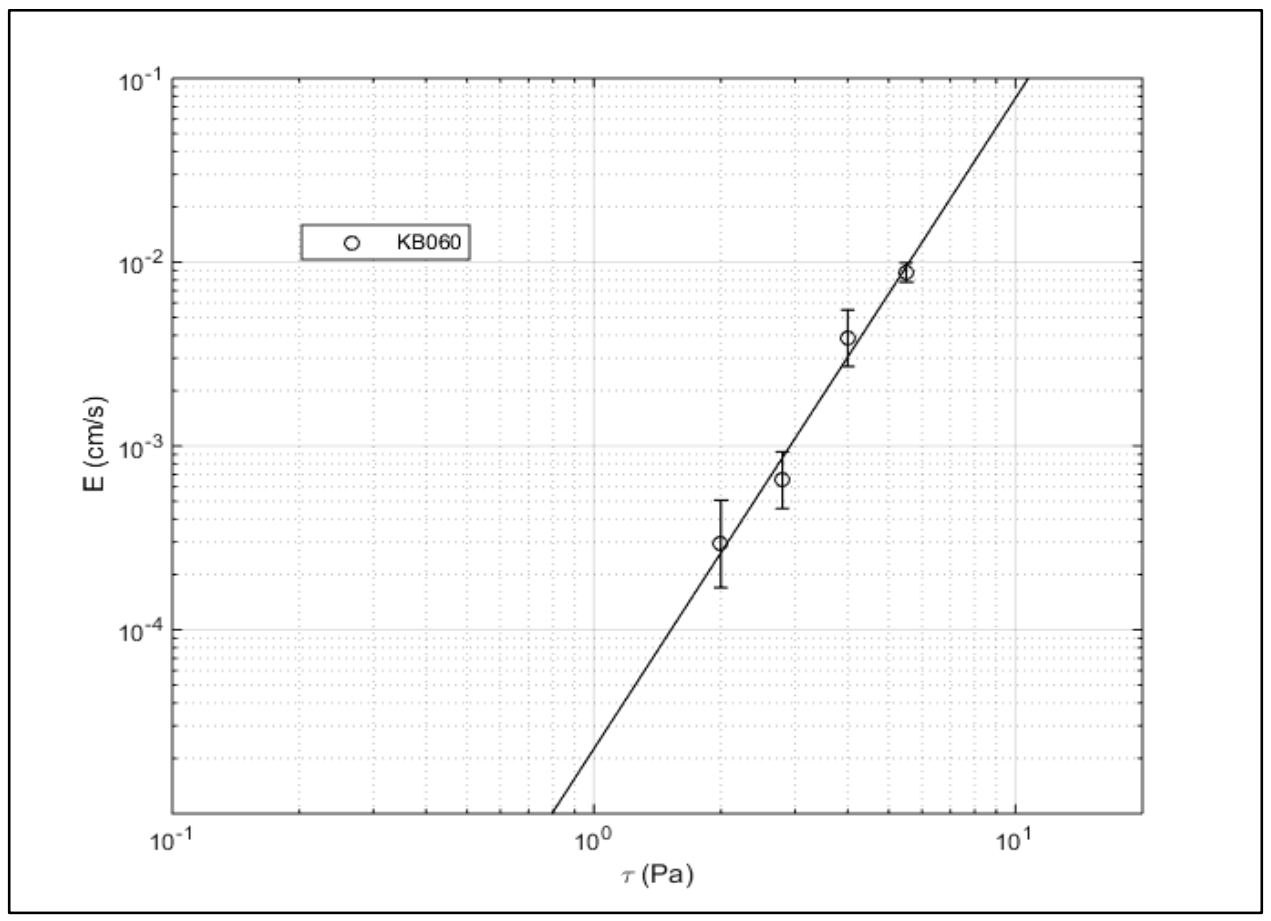


Figure C-28. Plot of mean erosion rate data against shear stress for cores composed of $80 \%$ kaolinite-bentonite mud. Regression lines fit to the data were used to determine $\tau_{c}$ at an erosion rate of 1.0E-04.

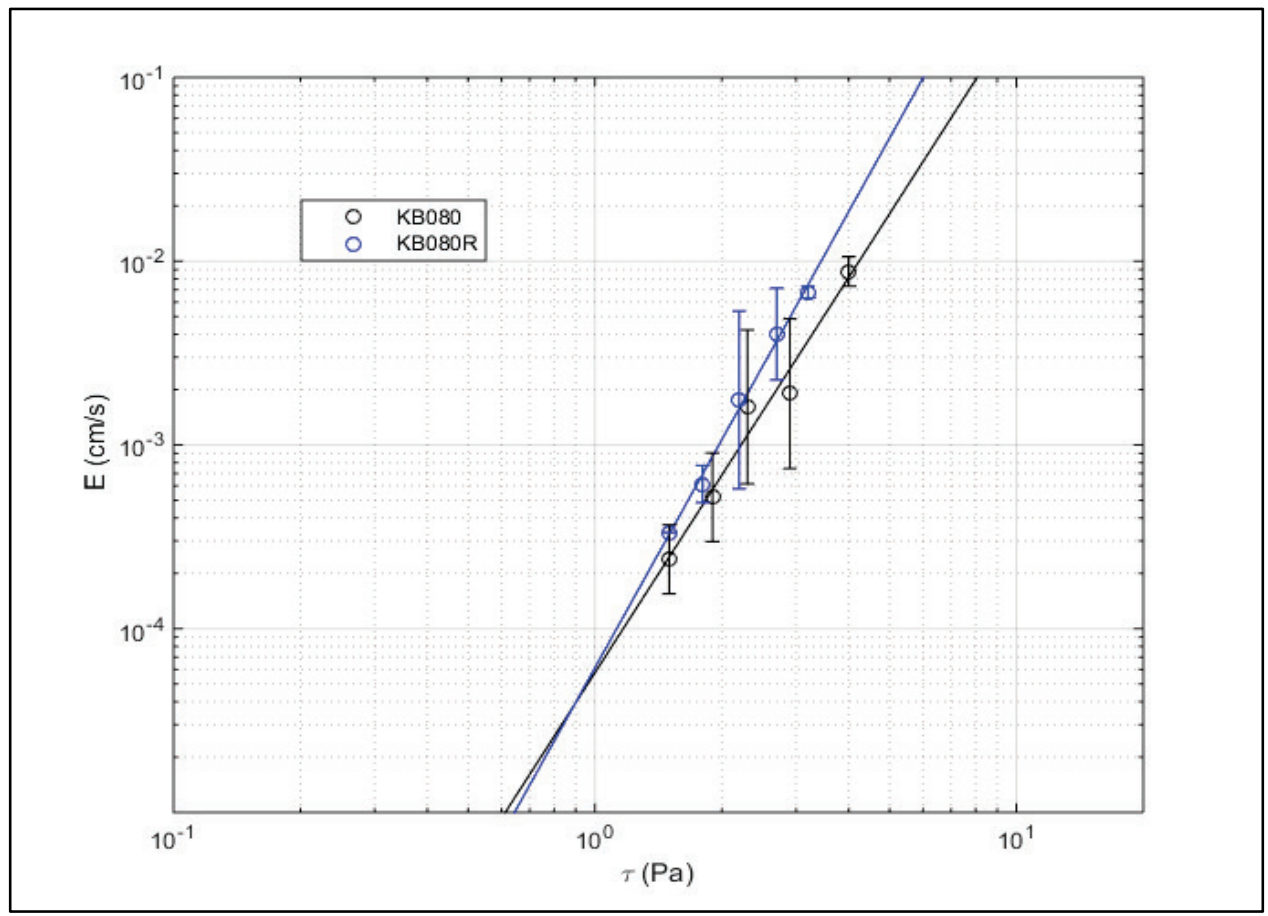

Figure C-29. Plot of mean erosion rate data against shear stress for cores composed of $100 \%$ kaolinite-bentonite mud. Regression lines fit to the data were used to determine $T_{c}$ at an erosion rate of 1.0E-04.

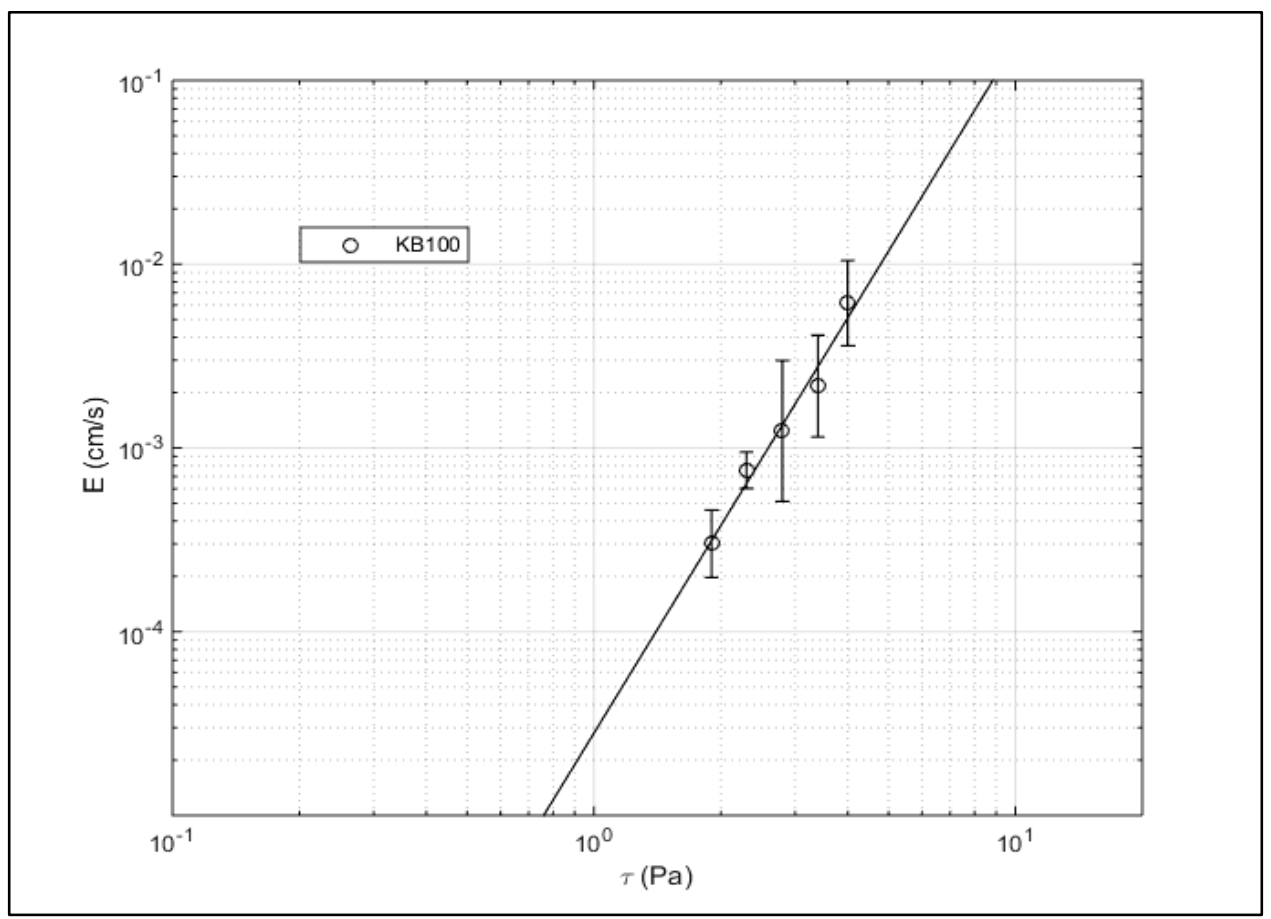


Table C-4. MR mud erosion parameters.

\begin{tabular}{|c|c|c|c|c|c|}
\hline $\begin{array}{c}\text { Mud } \\
\text { (\% mass) }\end{array}$ & $T_{c}$ & $\begin{array}{c}T_{c} \\
\text { (low) }\end{array}$ & $\begin{array}{c}T_{c} \\
\text { (high) }\end{array}$ & $A$ & $n$ \\
\hline 1 & 0.18 & 0.17 & 0.20 & 1.55E-02 & 3.00 \\
\hline 2 & 0.22 & 0.21 & 0.24 & 8.58E-03 & 2.96 \\
\hline 3 & 0.22 & 0.21 & 0.23 & 6.49E-03 & 2.78 \\
\hline $3 R$ & 0.25 & 0.23 & 0.26 & 4.17E-03 & 2.67 \\
\hline 4 & 0.26 & 0.25 & 0.28 & 5.75E-03 & 3.03 \\
\hline 5 & 0.25 & 0.23 & 0.27 & 4.73E-03 & 2.80 \\
\hline 8 & 0.54 & 0.49 & 0.58 & 6.52E-04 & 3.00 \\
\hline 11 & 0.31 & 0.23 & 0.37 & 9.54E-04 & 1.91 \\
\hline $11 R$ & 0.77 & 0.68 & 0.86 & 1.93E-04 & 2.56 \\
\hline 15 & 0.55 & 0.51 & 0.58 & 4.27E-04 & 2.41 \\
\hline 21 & 1.05 & 0.84 & 1.31 & 9.03E-05 & 2.14 \\
\hline $21 R$ & 1.47 & 1.23 & 1.76 & 3.45E-05 & 2.75 \\
\hline 29 & 0.99 & 0.85 & 1.14 & 1.01E-04 & 2.31 \\
\hline $29 R$ & 1.43 & 1.05 & 1.93 & 3.73E-05 & 2.77 \\
\hline 40 & 2.02 & 1.78 & 2.29 & 9.58E-06 & 3.34 \\
\hline 60 & 1.98 & 1.73 & 2.26 & 1.05E-05 & 3.31 \\
\hline 80 & 1.84 & 1.46 & 2.51 & 1.50E-05 & 3.12 \\
\hline 100 & 1.94 & 1.60 & 2.36 & 5.44E-06 & 4.40 \\
\hline $100 R$ & 1.36 & 1.18 & 1.56 & 3.55E-05 & 3.37 \\
\hline
\end{tabular}


Figure C-30. Plot of mean erosion rate data against shear stress for cores composed of $1 \%$ MR mud. Regression lines fit to the data were used to determine $\tau_{c}$ at an erosion rate of $1.0 \mathrm{E}-04$.

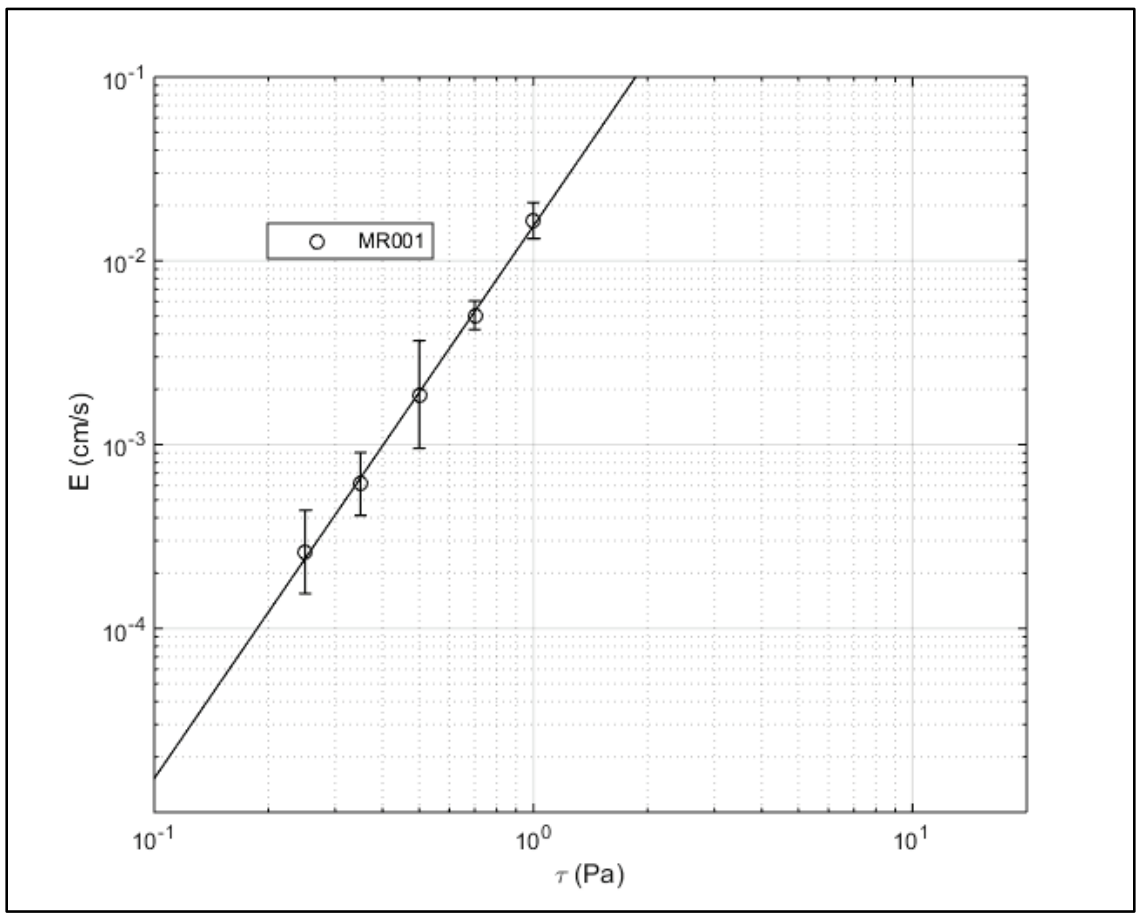

Figure C-31. Plot of mean erosion rate data against shear stress for cores composed of $2 \%$ MR mud. Regression lines fit to the data were used to determine $\tau_{c}$ at an erosion rate of $1.0 \mathrm{E}-04$.

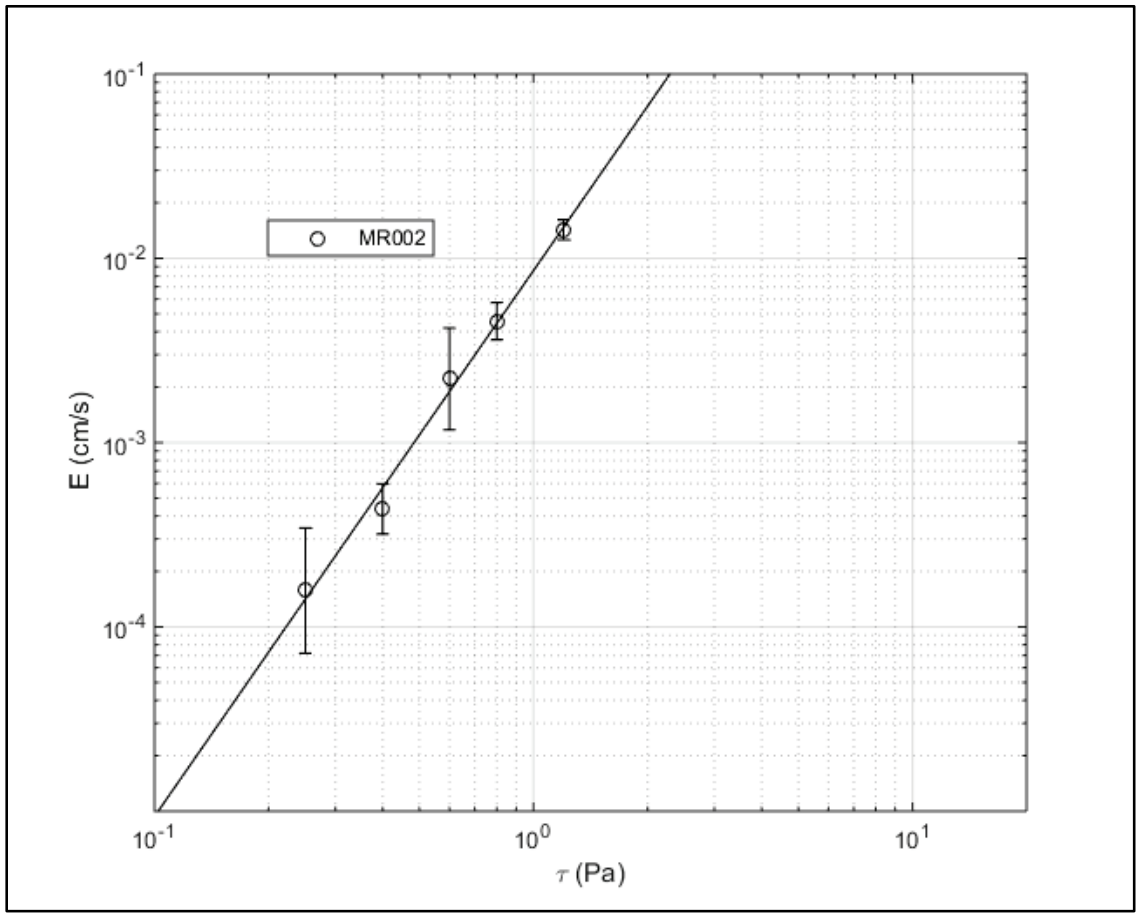


Figure C-32. Plot of mean erosion rate data against shear stress for cores composed of 3\% MR mud. Regression lines fit to the data were used to determine $\tau_{c}$ at an erosion rate of $1.0 \mathrm{E}-04$.

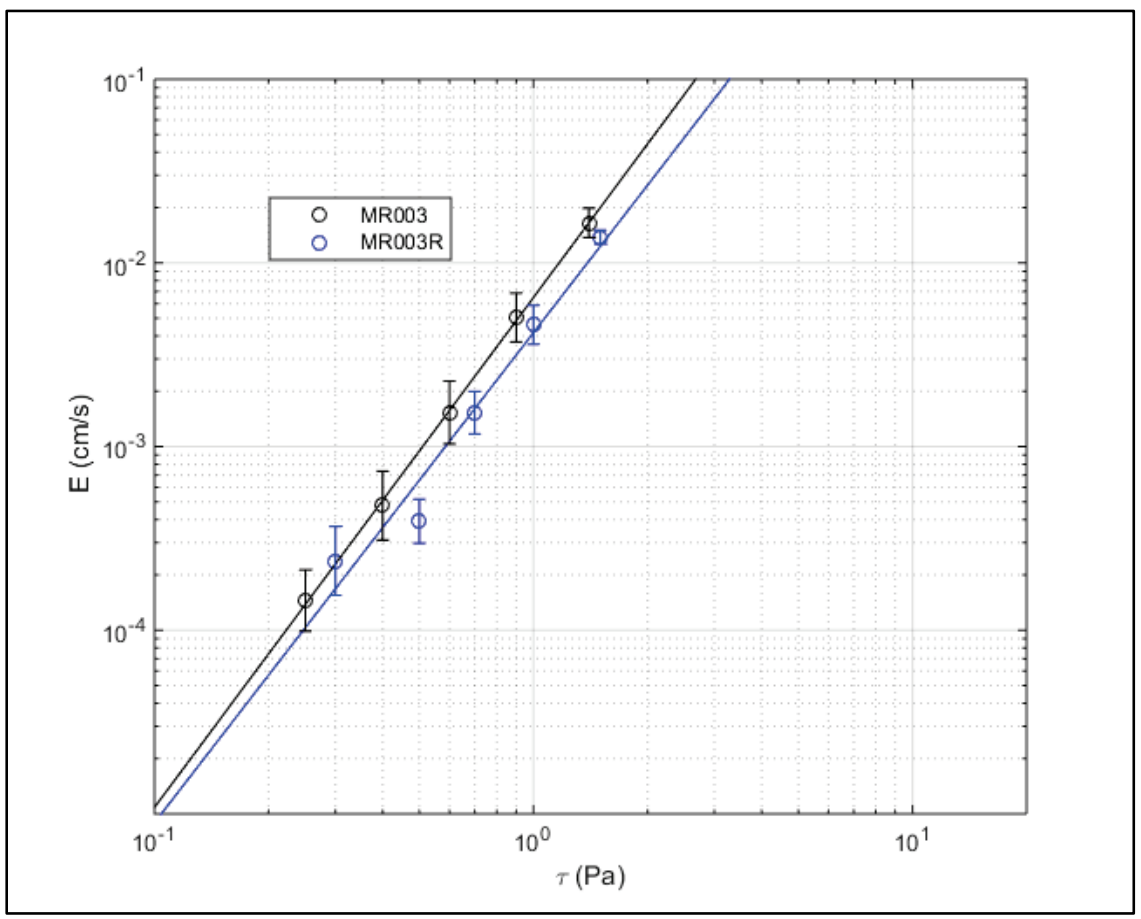

Figure 33. Plot of mean erosion rate data against shear stress for cores composed of 4\% MR mud. Regression lines fit to the data were used to determine $T_{c}$ at an erosion rate of 1.0E-04.

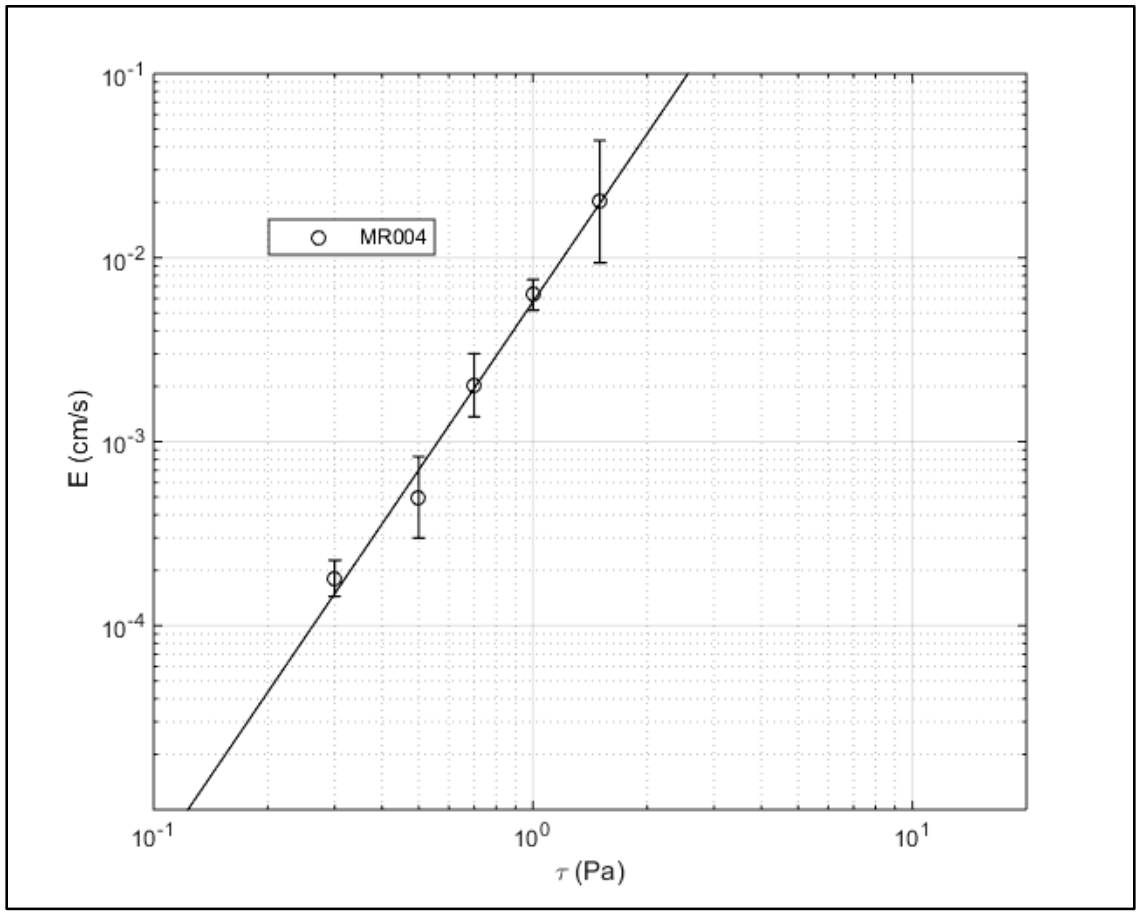


Figure C-34. Plot of mean erosion rate data against shear stress for cores composed of $5 \%$ MR mud. Regression lines fit to the data were used to determine $T_{c}$ at an erosion rate of $1.0 \mathrm{E}-04$.

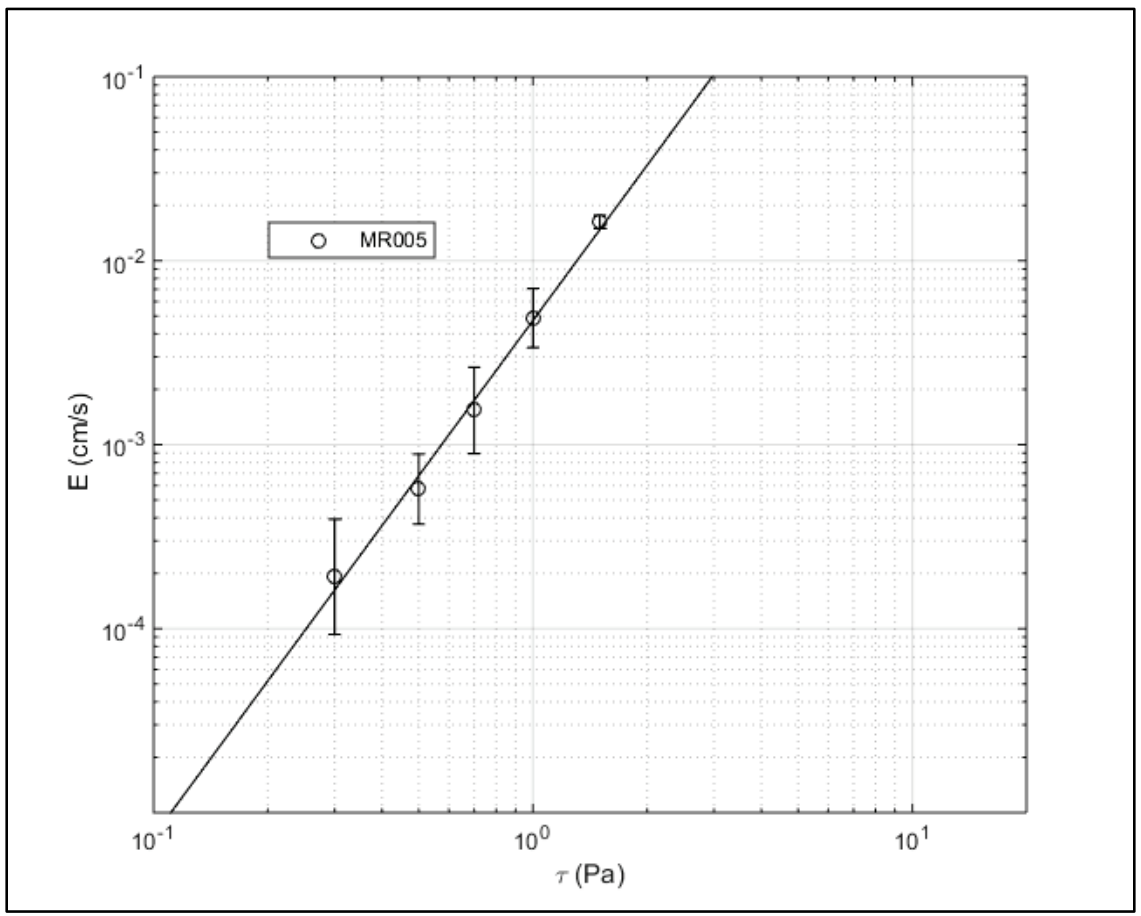

Figure C-35. Plot of mean erosion rate data against shear stress for cores composed of $8 \%$ MR mud. Regression lines fit to the data were used to determine $\tau_{c}$ at an erosion rate of $1.0 \mathrm{E}-04$.

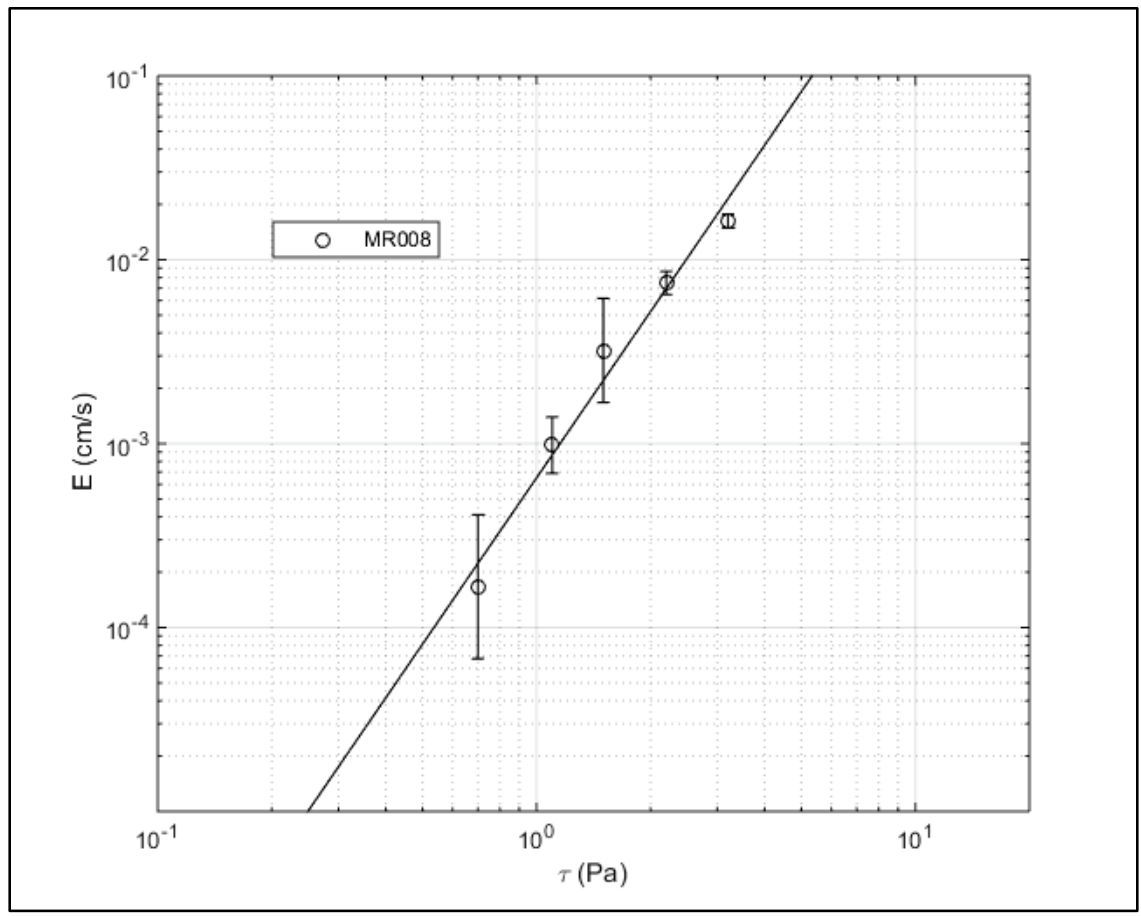


Figure C-36. Plot of mean erosion rate data against shear stress for cores composed of $11 \%$ MR mud. Regression lines fit to the data were used to determine $\tau_{c}$ at an erosion rate of 1.0E-04.

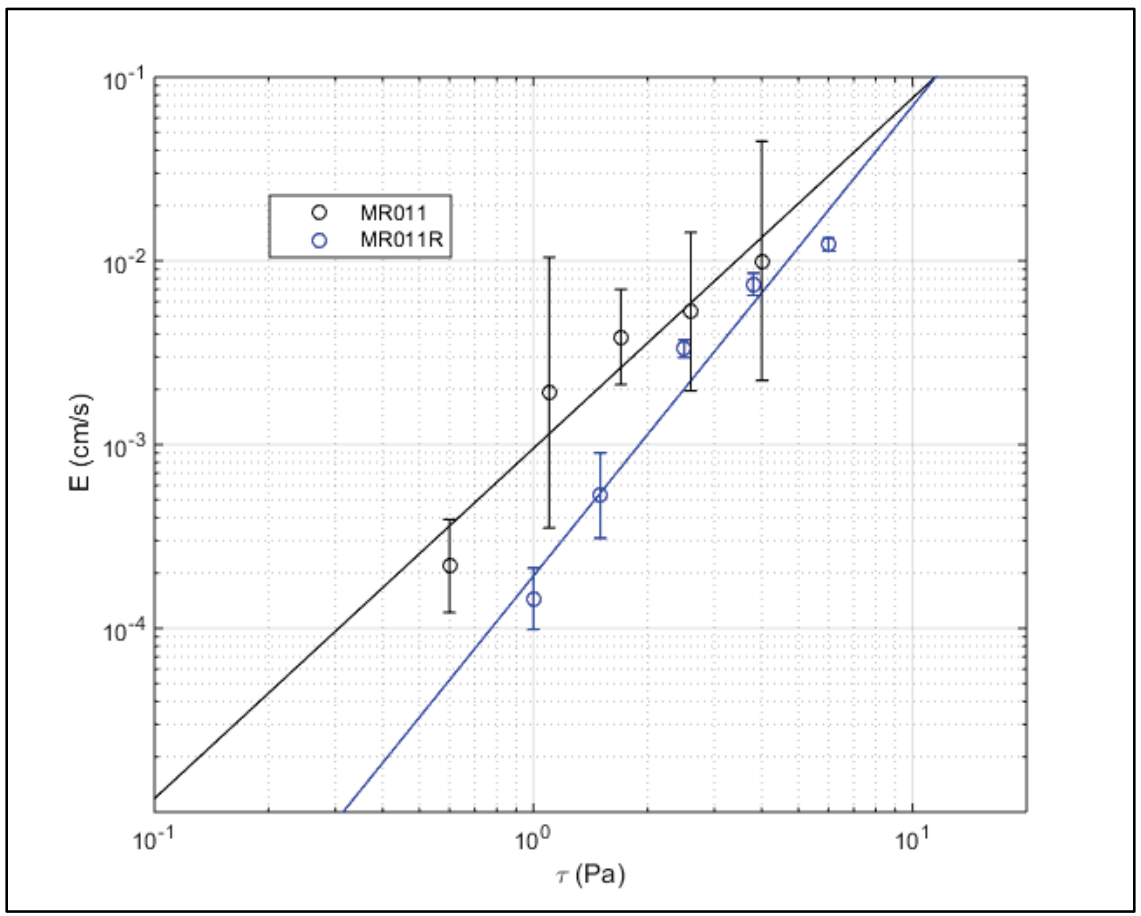

Figure C-37. Plot of mean erosion rate data against shear stress for cores composed of $15 \%$ MR mud. Regression lines fit to the data were used to determine $\tau_{c}$ at an erosion rate of $1.0 \mathrm{E}-04$.

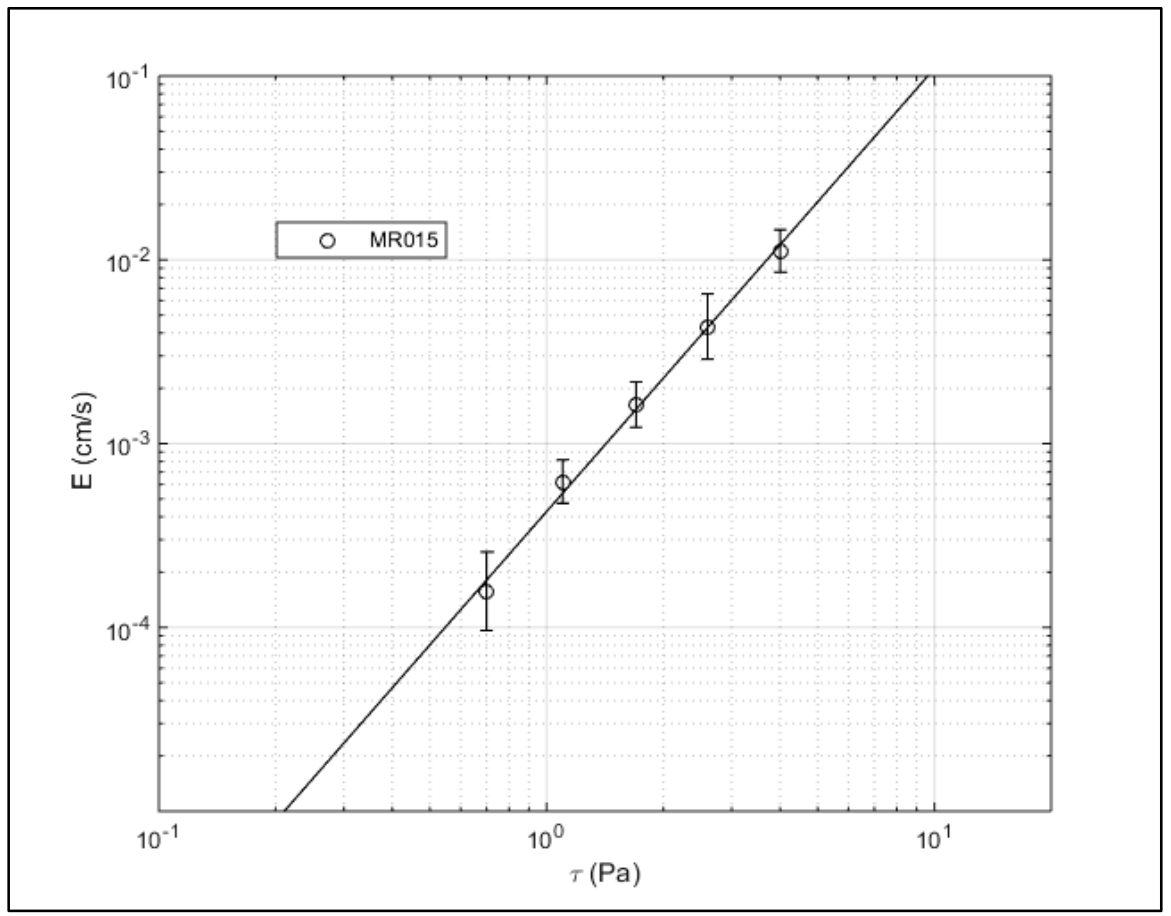


Figure C-38. Plot of mean erosion rate data against shear stress for cores composed of $21 \%$ MR mud. Regression lines fit to the data were used to determine $T_{c}$ at an erosion rate of 1.0E-04.

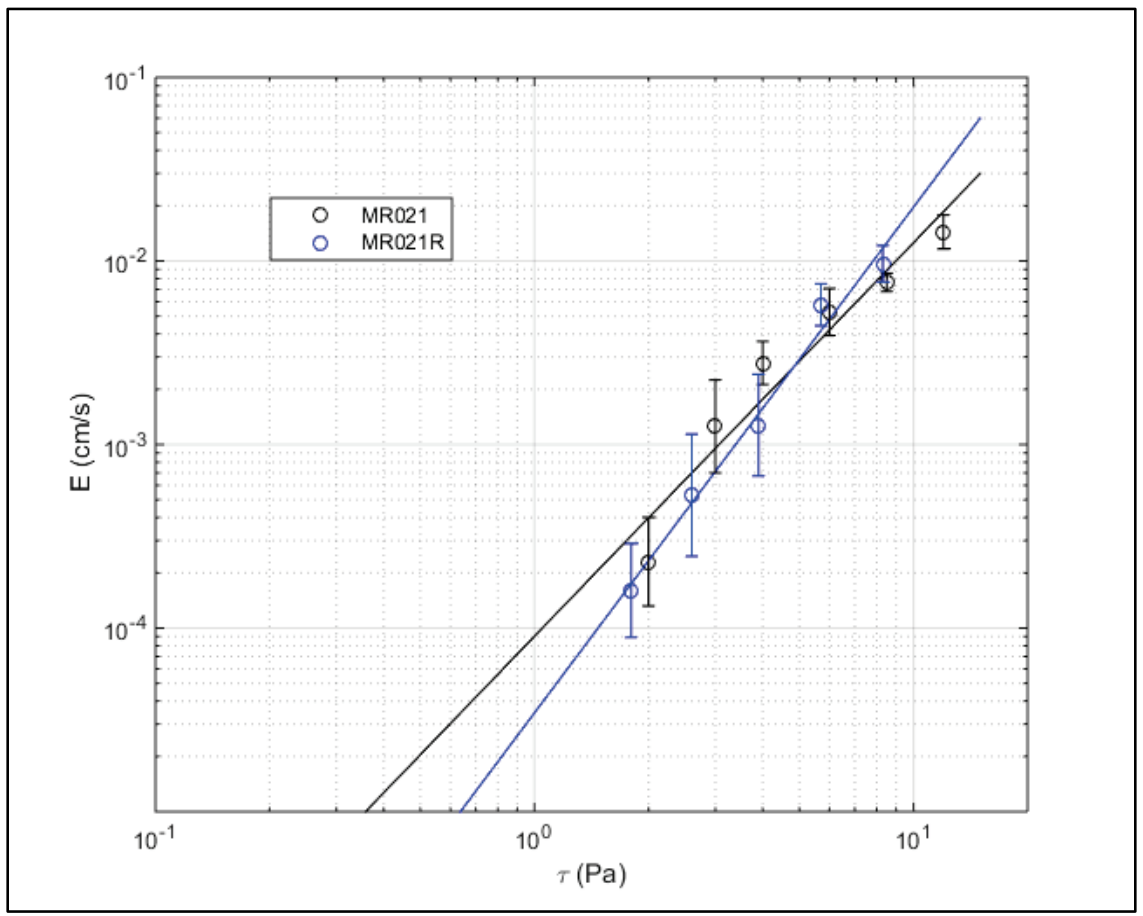

Figure C-39. Plot of mean erosion rate data against shear stress for cores composed of $29 \%$ MR mud. Regression lines fit to the data were used to determine $\tau_{c}$ at an erosion rate of $1.0 \mathrm{E}-04$.

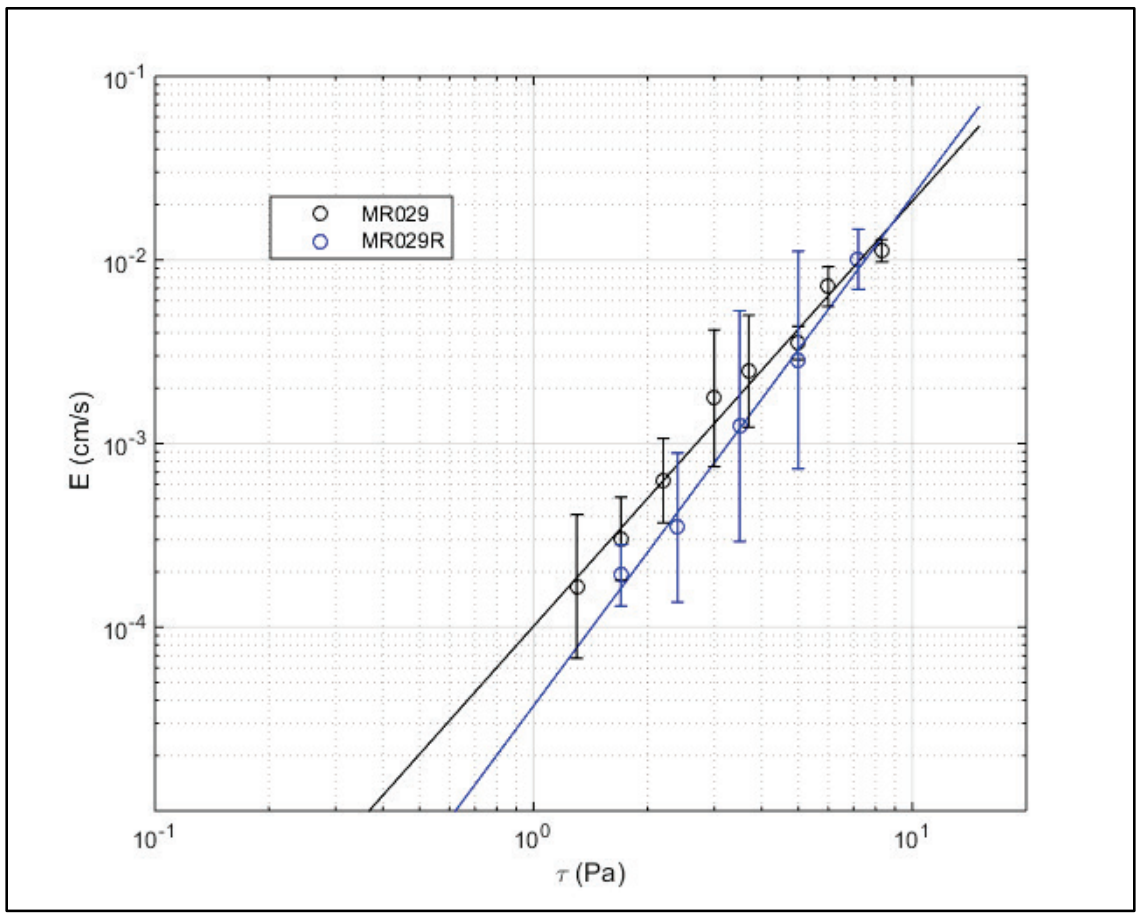


Figure C-40. Plot of mean erosion rate data against shear stress for cores composed of $40 \%$ MR mud. Regression lines fit to the data were used to determine $\tau_{c}$ at an erosion rate of $1.0 \mathrm{E}-04$.

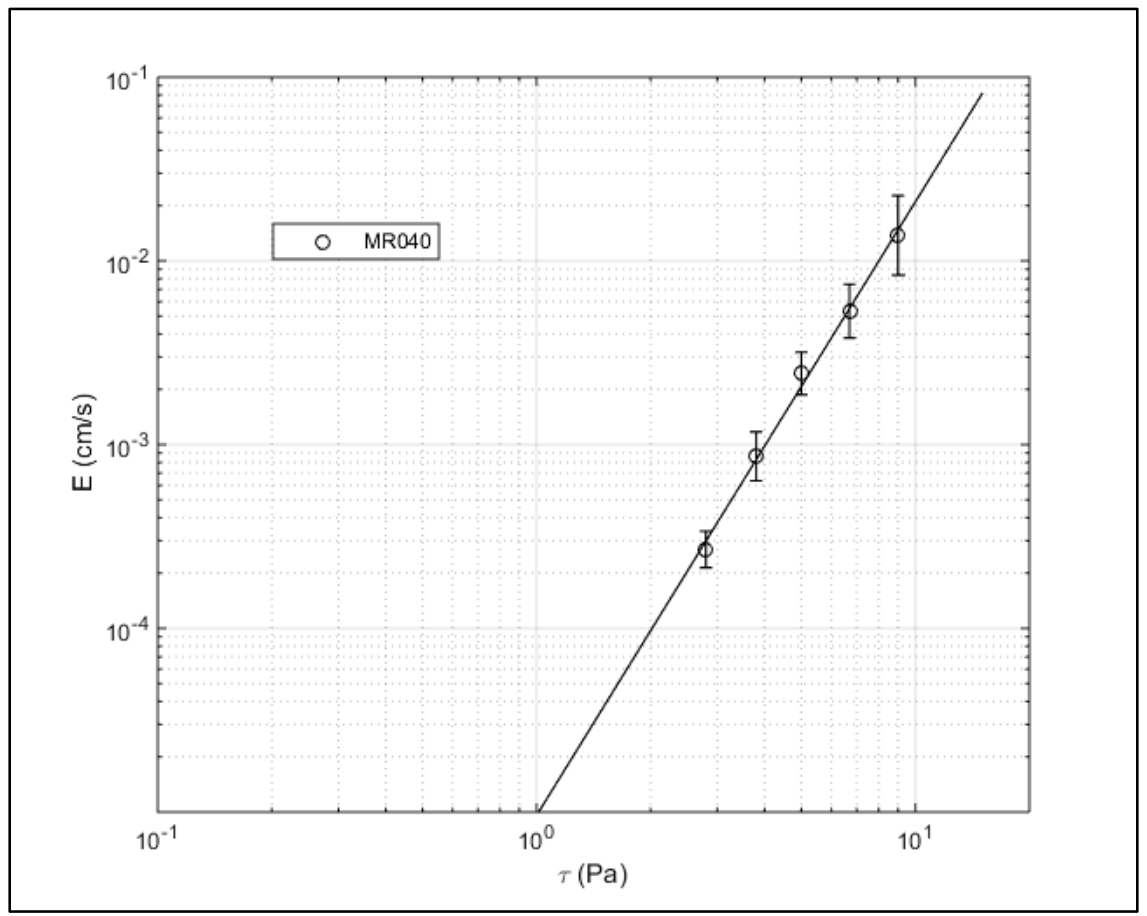

Figure C-41. Plot of mean erosion rate data against shear stress for cores composed of $60 \%$ MR mud. Regression lines fit to the data were used to determine $\tau_{c}$ at an erosion rate of $1.0 \mathrm{E}-04$.

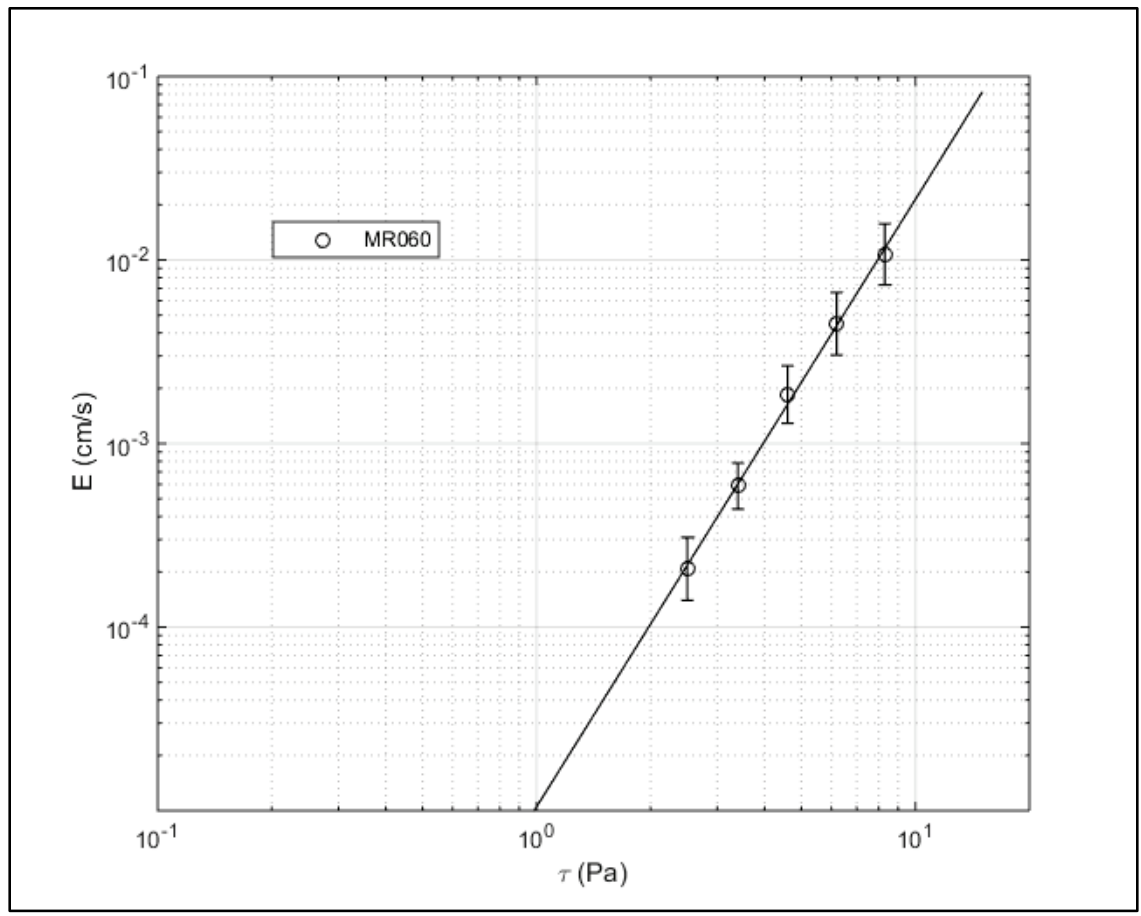


Figure C-42. Plot of mean erosion rate data against shear stress for cores composed of $80 \%$ MR mud. Regression lines fit to the data were used to determine $\tau_{c}$ at an erosion rate of $1.0 \mathrm{E}-04$.

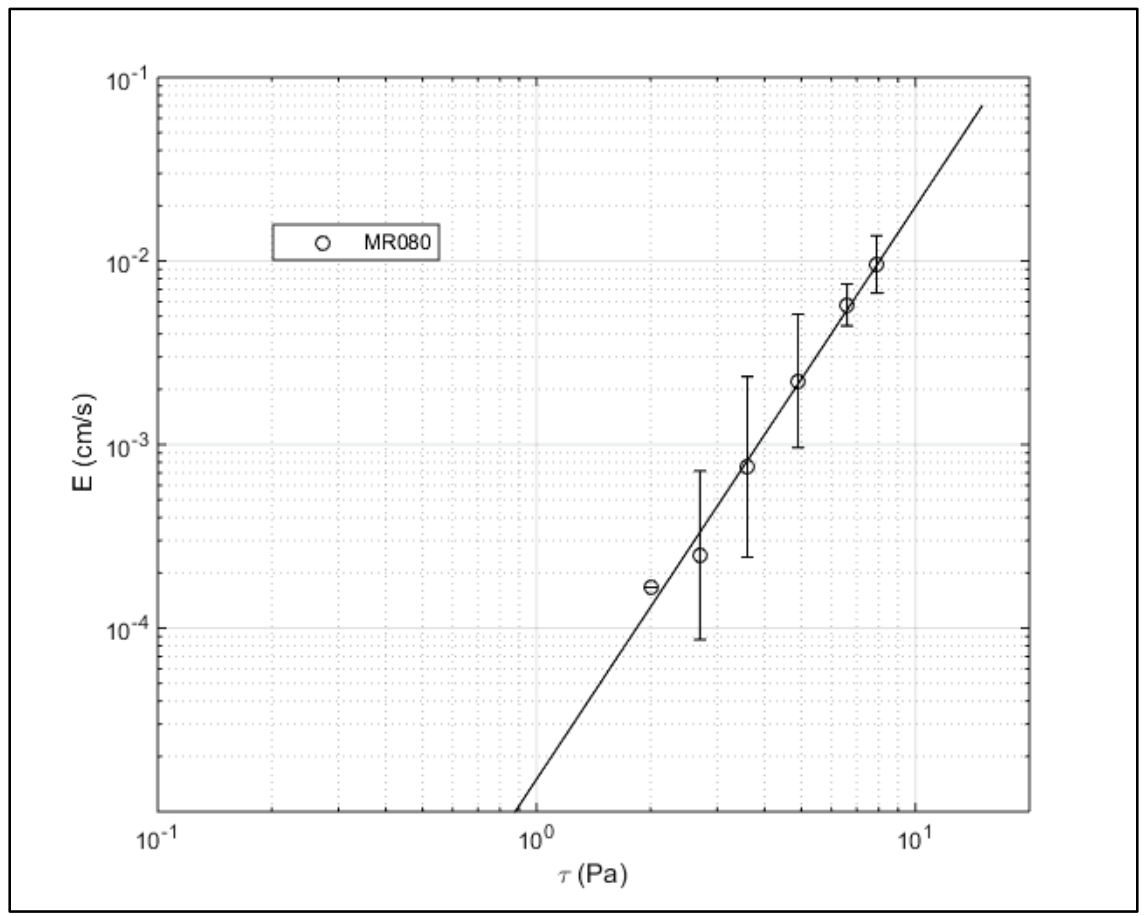

Figure C-43. Plot of mean erosion rate data against shear stress for cores composed of $100 \%$ MR mud. Regression lines fit to the data were used to determine $T_{c}$ at an erosion rate of $1.0 \mathrm{E}-04$.

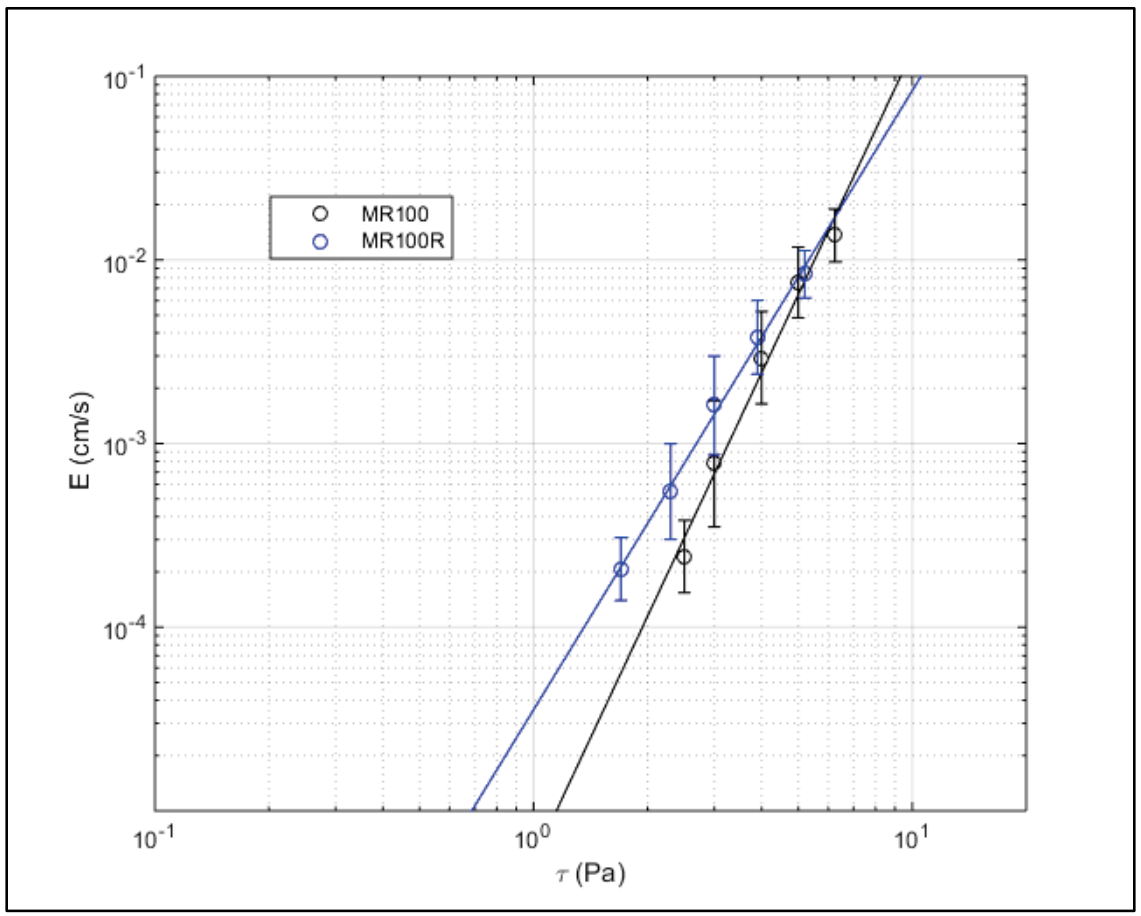




\section{Acronyms and Abbreviations}

$\begin{array}{ll}\text { EPK } & \text { Edgar Plastic Kaolin } \\ \text { LDPSA } & \text { Laser Diffraction Particle Size Analysis } \\ \text { LL } & \text { liquid limit } \\ \text { MR } & \text { Mississippi River } \\ \text { ODMDS } & \text { Offshore Dredge Material Disposal Site } \\ \text { PI } & \text { plasticity index } \\ \text { PL } & \text { plastic limit } \\ \text { SED } & \text { Sediment Erosion with Depth } \\ \text { USACE } & \text { U.S. Army Corps of Engineers } \\ \text { XRA } & \text { X-Ray Attenuation }\end{array}$




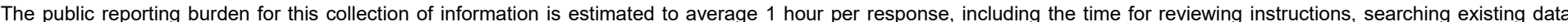

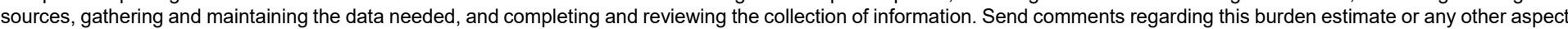

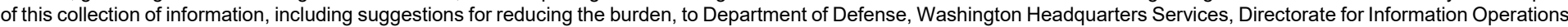

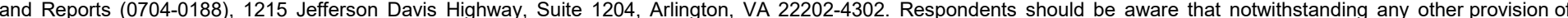
law, no person shall be subject to any penalty for failing to comply with a collection of information if it does not display a currently valid OMB control number. PLEASE DO NOT RETURN YOUR FORM TO THE ABOVE ADDRESS.

\begin{tabular}{l|l|l}
$\begin{array}{l}\text { 1. REPORT DATE } \\
\text { July } 2020\end{array}$ & $\begin{array}{l}\text { 2. REPORT TYPE } \\
\text { Final Report }\end{array}$ & 3. DATES COVERED (FrOm - To)
\end{tabular}

\section{TITLE AND SUBTITLE}

Erosion Thresholds and Rates for Sand-Mud Mixtures 5a. CONTRACT NUMBER

5b. GRANT NUMBER

5c. PROGRAM ELEMENT NUMBER

5d. PROJECT NUMBER

485304

5e. TASK NUMBER

5f. WORK UNIT NUMBER

8. PERFORMING ORGANIZATION REPORT NUMBER

ERDC/CHL TR-20-13

U.S. Army Engineer Research and Development Center

3909 Halls Ferry Road

Vicksburg, MS 39180-6199

9. SPONSORING/MONITORING AGENCY NAME(S) AND ADDRESS(ES)

Dredging Operations and Environmental Research Program

10. SPONSOR/MONITOR'S ACRONYM(S)

DOER

11. SPONSOR/MONITOR'S REPORT NUMBER(S)

\section{DISTRIBUTION/AVAILABILITY STATEMENT}

Approved for public release; distribution is unlimited.

\section{SUPPLEMENTARY NOTES}

\section{ABSTRACT}

Differences in erosion behavior of non-cohesive and cohesive sediments are widely recognized. In many natural environments, sand and mud are not completely separated and occur as mixtures. Significantly less research has been conducted on the erosion behavior of sandmud mixtures compared to the separate treatment of sand and mud erosion. Sedflume erosion experiments were conducted on sand-mud mixtures with varying mud content to define the relationships between mud content, critical stress for erosion ( $\square \mathrm{c}$ ), and erosion rate. Sand-mud mixtures were prepared with three mud sources: (1) non-swelling clay (kaolinite), (2) swelling clay (kaolinite/bentonite), and (3) a swelling, natural mud from the Mississippi River.

Test results showed that critical shear stresses of the mixed sediments departed from that of pure sand with mud fractions on the order of $2 \%$ to $10 \%$. Peak $\tau \mathrm{c}$ was observed between $30 \%$ to $40 \%$ mud content, with swelling muds achieving a ten-fold increase in $\tau \mathrm{c}$ while a five fold increase in $\tau \mathrm{c}$ was measured for kaolinite. Additionally, this study demonstrated that the introduction of small amounts ( $\leq 5 \%)$ of mud to sand reduced erosion rates by a factor of 10 to 100 . This observed abatement of erosion rate has implications for the use of dredged materials in civil and environmental engineering projects.

\section{SUBJECT TERMS}

Dredging, Dredging spoil, Erosion, Mud, Sand

\section{SECURITY CLASSIFICATION OF:}

\begin{tabular}{|l|c|c|}
\hline a. REPORT & b. ABSTRACT & c. THIS PAGE \\
Unclassified & Unclassified & Unclassified \\
\hline
\end{tabular}

17. LIMITATION OF ABSTRACT

SAR
18. NUMBER 19a. NAME OF RESPONSIBLE PERSON

OF PAGES

95 David Perkey

19b. TELEPHONE NUMBER (Include area code) 601-634-2736 
